Florida International University FIU Digital Commons

$10-27-2017$

\title{
ID3, Estrogenic Chemicals, and the Pathogenesis of Tumor-Like Proliferative Vascular Lesions
}

Vincent E. Avecilla

Florida International University, vavec001@fiu.edu

DOI: 10.25148 /etd.FIDC004046

Follow this and additional works at: https://digitalcommons.fiu.edu/etd

Part of the Bioinformatics Commons, Cardiovascular Diseases Commons, Cell Biology Commons, Environmental Public Health Commons, and the Epidemiology Commons

\section{Recommended Citation}

Avecilla, Vincent E., "ID3, Estrogenic Chemicals, and the Pathogenesis of Tumor-Like Proliferative Vascular Lesions" (2017). FIU Electronic Theses and Dissertations. 3519.

https://digitalcommons.fiu.edu/etd/3519 


\title{
FLORIDA INTERNATIONAL UNIVERSITY
}

\author{
Miami, Florida
}

ID3, ESTROGENIC CHEMICALS, AND THE PATHOGENESIS OF TUMOR LIKE PROLIFERATIVE VASCULAR LESIONS

A dissertation submitted in partial fulfillment of

\author{
the requirements for the degree of \\ DOCTOR OF PHILOSOPHY \\ in
}

PUBLIC HEALTH

by

Vincent E. Avecilla

2017 
To: Dean Tomás R. Guilarte

Robert Stempel College of Public Health \& Social Work

This dissertation, written by Vincent E. Avecilla, entitled ID3, Estrogenic Chemicals, and the Pathogenesis of Tumor-Like Proliferative Vascular Lesions, having been approved in respect to style and intellectual content, is referred to you for judgment.

We have read the dissertation and recommend that it be approved.

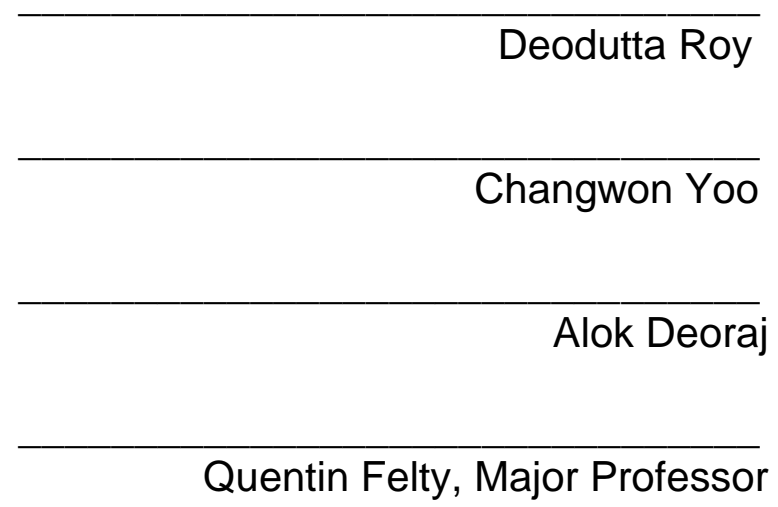

Date of Defense: October 27, 2017

The dissertation of Vincent $\mathrm{E}$. Avecilla is approved.

Dean Tomás R. Guilarte

Robert Stempel College of Public Health \& Social Work

Andres G. Gil

Vice President for Research and Economic Development and Dean of the University Graduate School

Florida International University, 2017 


\section{DEDICATION}

To whomever has a dream or goal in life. If you believe it, you can achieve it. I recall during my 1 st year as a doctoral candidate I came across a PhD candidate's memoir about his experience from Massachusetts Institute of Technology (MIT). What this student had written in his memoir but particularly in his epilogue had an everlasting impression on me and was one of many sources of motivation through the ups \& downs of graduate school. "So why would anyone spend six or more years doing a PhD when they aren't going to become professors? Everyone has different motivations but one possible answer is that a $\mathrm{PhD}$ program provides a safe environment for types of people to push themselves far beyond their mental limits and then emerge stronger as a result. For example, my six years of PhD training have made me wiser, savvier, grittier and more steely, focused, creative, eloquent, perceptive, and professionally effective than I was as a fresh college graduate." - Philip J. Guo 


\section{ACKNOWLEDGMENTS:}

I wanted to take this opportunity to first thank my major professor \& research mentor Dr. Quentin Felty for the opportunity to work with him in addition to his knowledge, guidance, motivation, flexibility, and patience through this entire process not only academically/professionally but personally as well. Words cannot describe the gratitude I have towards your mentoring for the past 6.5 years $(\mathrm{MPH} / \mathrm{PhD})$. I would also like to give many thanks to my committee members Dr. Deodutta Roy, Dr. Changwon Yoo, and Dr. Alok Deoraj for their assistance in guiding my research in the right direction, great amounts of patience, and aid in my development of knowledge/background in their respected fields. Additionally this would have also not been possible without my family, friends, co-workers, the Statistical Machine Learning Group (SMLG), and fellow students in our Environmental Health Science graduate school cohort past \& present. Thank you so much for your constant encouragement, camaraderie, \& support. I would additionally like to thank Dr. Jayanta Das for all his kind words of wisdom \& reassurance throughout the years dating back to when we both began in the $\mathrm{EOH}$ department in 2011. Thank you for your guidance \& expertise during my MPH especially with your assistance, knowledge, \& expertise in learning how to run \& perform SDS gels, cell culture, \& western blots. This would have not been possible without the financial support of my 529 educational savings plan; Dr. Aaron Welch and the FIU Chaplin School of Hospitality \& Tourism Management; and the companies; past \& present that I have had the pleasure of working for. First thank you to the tutoring companies for their guidance allowing me to become a better 
teacher/mentor to the younger generation of students. Also thank you to Banco De Exito Ventures for the funding opportunity \& flexibility so that I was able to complete my dissertation in a timely manner \& be part of the wonderful, stressful, and complicated world of venture capitalism \& entrepreneurship. Truly blessed to have been part of a hardworking, driven, \& sincerely ambitious team. The guidance and invaluable skills you have instilled in me will be constantly everlasting and has taught me that if an idea will solve a problem, add value to society, \& service other people it can be achievable no matter how great the obstacle \& setback. Lastly an incredible thank you to both my aunt Dr. Divina Grossman who used to be part of the FIU faculty in the College of Nursing \& Health Sciences and Office of Engagement and to Dr. Deodutta Roy, professor and founding chair of the Environmental \& Occupational Health Department. Without her initial guidance when deciding to come to FIU for graduate school meeting Dr. Deodutta Roy who introduced me to Dr. Quentin Felty would not have been possible. 


\title{
ABSTRACT OF DISSERTATION
}

\section{ID3, ESTROGENIC CHEMICALS, AND THE PATHOGENESIS OF TUMOR - LIKE PROLIFERATIVE VASCULAR LESIONS}

\author{
Vincent E. Avecilla \\ Florida International University, 2017 \\ Miami, Florida \\ Professor Quentin Felty, Major Professor
}

Tumor-like proliferative vascular lesions manifest in several diseases such as peripheral arterial disease (PAD) and atherosclerosis (AS) after arterial injury. The cause of the vascular cell dysfunction in PAD patients is not known. Our recent novel discovery shows that inhibitor of differentiation 3 (ID3) is highly expressed in intimal lesions of clinical vascular disease samples. The central hypothesis of our study is: estrogenic chemical induced dysregulation of ID3 target genes is involved in the development of vascular disease. NHANES data analysis demonstrated higher geometric levels of all 6 PCB congeners in both PAD diagnosed participants and defined AS participants when compared to the rest of the population. Adjusted models showed association between higher exposure of PCBs, phthalates, BPA, and increased risk of PAD. Furthermore PCB153 was shown to have the highest geometric mean amongst all PCB congeners in both participants diagnosed with PAD and at risk of AS. Gene expression of ID3 \& ID3 candidate targets in blood \& tissue studies identified ID3 \& ID3 candidate target genes as a driver of vascular 
disease. Overlapping ID3 \& ID3 candidate target genes included: ABCB6, ACP1, BYSL, CAD, CDH15, DCBLD2, DHRS3, DNMT1, ID3, MCM4, and NDUFA7. The ID3 target genes involved in the: focal adhesion pathway were ACTN1, COL1A2, COL3A1, COL6A1, CTNNB1, IBSP, ID3, ITGA8, and MYL2; ECM-receptor interaction were COL1A2, COL3A1, COL6A1, IBSP, ID3, and ITGA8; oxidative phosphorylation pathway ATP5D, ATP5H, ATP6V0B, ATP6V0D1, ATP6V1B2, COX5A, COX7C, COX8A, CYC1, ID3, NDUFA1, NDUFA7, NDUFS4, NDUFV1, NDUFV2; and cell cycle pathway ANAPC10, ATM, CDKN2B, E2F5, MCM3, and MCM4. In summary our results showed an association between exposure to PCBs, phthalates, BPA, and increased risk of PAD and AS, and possible molecular mechanisms of interaction of ID3 target genes and estrogenic chemicals involved in PAD and AS. 


\section{TABLE OF CONTENTS}

CHAPTER

PAGE

CHAPTER I

INTRODUCTION

1

References

1

HYPOTHESIS

7

SPECIFIC AIMS

CHAPTER II

REVIEW OF LITERATURE

MANUSCRIPT 1

Contribution of Inhibitor of DNA-binding/Differentiation-3 and endocrine disrupting chemicals to pathophysiological aspects of chronic disease

Abstract

Introduction

Inhibitor of DNA binding/Differentiation-3 (ID3)

Structure and Function

ID3 and Metabolic Syndrome (MetS)

ID3 \& Endocrine Disrupting Chemicals Influence Metabolic

Perturbation

ID3 \& Disease Outcomes

Vascular Diseases

Neurological Disorders

Kidney disease

32

Cancer

Bone Disease

Autoimmune Diseases

Conclusion

References

Association of PCB exposure in Peripheral Arterial Disease

(PAD) Among the U.S. Population: NHANES 1999 - 2004

52

Abstract

Introduction

Methods

Statistical Analysis

60

Results

61

Discussion

79

Conclusion

References 
MANUSCRIPT 3

Association of Endocrine Disrupting Chemical (EDCs) Exposure in Peripheral Arterial Disease (PAD) Among the U.S. Population:

NHANES 1999 - 2004

Abstract

Introduction $\quad 87$

Methods $\quad 88$

Statistical Analysis $\quad 92$

Results 93

Discussion 99

Conclusion 101

References 102

$\begin{array}{ll}\text { CHAPTER V } & 105\end{array}$

MANUSCRIPT 4

Genome-wide gene expression profiling of Inhibitor of

DNA-binding/Differentiation-3 (ID3) Candidate Targets in

Vascular-Intimal Lesions $\quad 105$

Abstract 106

Introduction 107

Methods \& Materials $\quad 110$

Identification of microarray datasets \& analysis $\quad 110$

Computational identification of ID3 and ID3 candidate

target genes

118

Bayesian analysis \& network $\quad 119$

Genie $\quad 120$

Gene Ontology \& Pathway Analysis $\quad 120$

Comparative Toxicogenomic Analysis (CTD) 120

Results

Gene expression of ID3 \& ID3 candidate targets in blood

\& tissue studies

Gene expression of ID3 \& ID3 candidate targets in blood versus tissue studies

Gene expression of ID3 \& ID3 candidate target genes in specific vascular diseases

ID3 \& ID3 gene-associated biological processes

ID3 and ID3 candidate target genes in blood

ID3 and ID3 candidate target genes in tissue

ID3 \& ID3 gene-associated signaling pathways

135

ID3 and ID3 candidate target genes in blood

ID3 and ID3 candidate target genes in tissue

ID3 \& ID3 candidate target genes \& EDC-associated genes 
Discussion $\quad 180$

Conclusion $\quad 186$

$\begin{array}{lr}\text { References } & 187\end{array}$

$\begin{array}{ll}\text { CHAPTER VI } & 191\end{array}$

OVERALL CONCLUSIONS 191

Limitations 196

$\begin{array}{lr}\text { Future Studies } & 196\end{array}$

$\begin{array}{ll}\text { VITA } & 197\end{array}$ 


\section{LIST OF TABLES}

TABLE

PAGE

\section{LITERATURE REVIEW}

\section{MANUSCRIPT 1}

$1 \quad$ ID3 and Endocrine Disrupting Chemicals (EDCs)

MANUSCRIPT 2

2.1 $\mathrm{ABI}$ (Ankle-Brachial Index)

58

2.2 Descriptive statistics for PAD \& selected covariates among Participants $\geq 40$ years of age, NHANES $1999-2004$

2.3 Geometric mean PCB levels (ng/g) above the LOD by PAD status among participants $\geq 40$ years of age, NHANES $1999-2004$

2.4 Geometric mean PCB levels $(\mathrm{ng} / \mathrm{g}$ ) by peripheral arterial disease status by age groups, NHANES 1999 - 2004

2.5 Age standardized geometric mean PCB levels (ng/g) above the LOD by race/ethnicity among participants $\geq 40$ years old PAD by age groups, NHANES 1999 - 2004

2.6 Serum levels of dioxin-like PCBs $(\mathrm{ng} / \mathrm{g})$ in the study population, participants $\geq 40$ years of age, NHANES $1999-200470$

2.7 Serum levels of non-dioxin like PCBs ( $\mathrm{ng} / \mathrm{g})$ in the study population, participants $\geq 40$ years of age, NHANES $1999-200471$

2.8 Geometric mean PCB levels ( $\mathrm{ng} / \mathrm{g}$ ) by PAD status among participants $\geq 40$ years of age, NHANES $1999-2004$

2.9 Geometric mean PCB levels ( $\mathrm{ng} / \mathrm{g}$ ) by PAD status among participants $\geq 40$ years of age, NHANES $1999-2004$

2.10 Serum levels of non-dioxin like PCBs (ng/g) in the study population, participants $\geq 40$ years of age, NHANES $1999-200475$

2.11 Estimated ORs \& 95\% Cl of PAD status by concentration of PCB levels among participants $\geq 40$ years of age, 
NHANES $1999-2004$

2.12 Estimated ORs \& 95\% $\mathrm{Cl}$ of PAD status by concentration of $\mathrm{PCB}$ levels among participants $\geq 40$ years of age, NHANES $1999-2004$

2.13 Estimated ORs (95\% Cls) of PAD status by concentration of dioxin-like \& non-dioxin like PCB levels among participants $\geq 40$ years of age, NHANES $1999-2004$

MANUSCRIPT 3

3.1 Descriptive statistics for PAD \& selected covariates among participants $\geq 40$ years of age, NHANES $1999-2004$

3.2 Descriptive statistics for PAD \& selected covariates among participants $\geq 40$ years of age with bisphenol A (BPA) measurements NHANES $2003-2004$

3.3 Geometric mean of urinary phthalate metabolites and BPA levels above the LOD by PAD status among participants $\geq 40$ years of age, NHANES 1999 - 2004

3.4 Estimated ORs (95\% Cls) of PAD status by concentration of creatinine adjusted urinary phthalate metabolites \& BPA among participants $\geq 40$ years of age, NHANES $1999-2004$ \& $2003-2004$

\section{MANUSCRIPT 4}

4.1 NCBI GEO datasets represented in study

4.2.1 Characteristics of peripheral arterial disease dataset

4.2.2 Characteristics of infantile hemangioma dataset

4.2.3 Characteristics of atherosclerosis dataset

4.2.4 Characteristics of atherosclerosis dataset

4.2.5 Characteristics of atherosclerosis dataset

4.2.6 Characteristics of infantile hemangioma dataset 
4.2.8 Characteristics of idiopathic pulmonary arterial hypertension

4.3 ID3 and ID3 candidate target genes in blood studies

4.4 Top 10 most significant ID3 candidate target genes in blood

4.5 ID3 and ID3 candidate target genes in tissue studies 129

4.6 Top 10 most significant ID3 candidate target genes in tissue

4.7 ID3 and common candidate target genes between blood and tissue studies

4.8 Demonstration of biological processes that ID3 \& ID3 target genes are involved with in blood

4.9 Biological processes that ID3 \& ID3 candidate target genes in tissue

4.10 Demonstrated pathways of ID3 and ID3 candidate target genes in blood

4.11 Biological processes represented through STRING database of ID3 \& ID3-candidate targets proteins in blood

4.12 Demonstrated pathways of ID3 \& ID3 candidate target proteins in tissue

4.13 Biological processes of ID3 and ID3 candidate target genes in tissue

4.14.1 ID3 candidate target genes in blood associated with polychlorinated biphenyls (PCBs)

4.14.2 ID3 candidate target genes in tissue associated with polychlorinated biphenyls (PCBs)

4.14.3 Overlapping ID3 candidate target genes in blood-tissue associated with polychlorinated biphenyls (PCBs)

4.14.4 ID3 candidate target genes in blood associated with polychlorinated biphenyl 153 (PCB153)

4.14.5 ID3 target genes in tissue associated with 
polychlorinated biphenyl 153 (PCB153)

4.14.6 ID3 target genes in blood-tissue associated with polychlorinated biphenyl 153 (PCB153).

4.14.7 ID3 candidate target genes in blood associated with polychlorinated biphenyl 180 (PCB180)

4.14.8 ID3 candidate target genes in tissue associated with polychlorinated biphenyl 180 (PCB180)

4.14.9 ID3 candidate target genes in blood-tissue associated with polychlorinated biphenyl 180 (PCB180).

4.15.1 ID3 candidate target genes in blood associated with BPA 


\section{LIST OF FIGURES}

FIGURE

\section{REVIEW OF LITERATURE}

\section{MANUSCRIPT 1}

1.1 ID3 transcriptional regulation

1.2 ID3 molecular mechanism \& vascular diseases

$\begin{array}{lll}1.3 & \text { ID3 involvement in arteriovenous malformation } & 27\end{array}$

1.4 Epigenetic mechanism of ID3 in neurological disorders 29

1.5 ID3 signaling pathway proposed in development of Autism Spectrum Disorder

1.6 ID3 involvement in kidney disease 34

1.7 ID3 involvement in various types of cancer 35

$\begin{array}{lll}1.8 & \text { ID3 and brain cancer mechanisms } & 36\end{array}$

1.9 ID3 involvement in brittle bone disease pathogenesis 39

\section{MANUSCRUPT 2}

2.1 Geometric mean PCB levels (ng/g) by PAD status for participants $\geq 40$ years of age, NHANES 1999-2004

2.2.1 Geometric mean PCB levels (ng/g) by PAD status for participants $\geq 40-59$ years of age, NHANES 1999-2004

2.2.2 Geometric mean PCB levels ( $\mathrm{ng} / \mathrm{g}$ ) by PAD status for participants 60-74 years of age, NHANES 1999-2004

2.2.3 Geometric mean PCB levels (ng/g) by PAD status for participants $\geq 75$ years of age, NHANES 1999-2004 


\section{MANUSCRIPT 4}

4.1 Flow chart summarizing the steps in this study

4.2 Venn diagram illustration summarizes ID3 \& ID3 candidate target genes

4.3 Representation of ID3 and overlapping ID3-candidate target genes in both blood and tissue samples

4.4.1 Best fit model based on Genie Modeler with overlapping ID3 \& ID3candidate target genes

4.4.2 Representation of ID3 \& ID3-candidate targets in vascular state

4.4.3 Figure 4.4.3 Representation of ID3 \& ID3-candidate targets in location of vascular disease

4.4.4 Representation of models based on expression of ID3

4.5.1 Venn diagram illustration summarizes ID3 \& ID3 candidate target genes in vascular diseases in blood studies

4.5.2 Venn diagram summarizes ID3 \& ID3 candidate target genes in specific diseases in tissue studies.

4.6.1 Network demonstrated from STRING database of ID3-involved pathway in Extra Cellular Matrix Receptor (ECM) interaction

4.6.2 Network demonstrated from STRING database of ID3-involved pathway in focal adhesion

4.7.1 Network demonstrated from STRING database of ID3 candidate targets involved in the oxidative phosphorylation pathway

4.7.2 Network demonstrated from STRING database of ID3 candidate targets involved in the cell cycle pathway

4.8.1 Venn diagram illustrating ID3 candidate target genes in blood with PCBs

4.8.2 Venn diagram illustrating ID3 candidate target genes in tissue with PCBs 
4.8.3 Venn diagram summarizing overlapping ID3 candidate target genes in blood-tissue with PCBs.

4.8.4 Venn diagram summarizing ID3 candidate target genes in blood with PCB153

4.8.5 Venn diagram summarizing ID3 candidate target genes in tissue with PCB153

4.8.6 Venn diagram summarizing ID3 candidate target genes in blood-tissue with PCB153

4.8.7 Venn diagram summarizing ID3 target genes in blood with PCB180

4.8.8 Venn diagram summarizing ID3 candidate target genes in tissue with PCB180

4.8.9 Venn diagram summarizing overlapping ID3 candidate target genes in blood-tissue with PCB180

4.9.1 Venn diagram summarizing ID3 candidate target genes in blood with BPA

4.9.2 Venn diagram summarizing ID3 candidate target genes in tissue with BPA 


\section{ABBREVIATIONS AND ACRYONYMS}

$\begin{array}{ll}\text { AVM } & \text { Arteriovenous malformation } \\ \text { AS } & \text { Atherosclerosis } \\ \text { BPA } & \text { Bisphenol A } \\ \text { CDC } & \text { Center for Disease Control \& Prevention } \\ \text { CI } & \text { Confidence Interval } \\ \text { E2 } & \text { Estradiol } \\ \text { ECM } & \text { Extracellular Matrix } \\ \text { EDC } & \text { Endocrine Disrupting Chemical } \\ \text { GEO } & \text { Gene Expression Omnibus } \\ \text { GM } & \text { Geometric Mean } \\ \text { IL } & \text { Interleukin } \\ \text { GSE } & \text { Geometric Standard Error } \\ \text { HLH } & \text { Inhibitor of Differentiation-3 } \\ \text { ID1 } & \text { Inhibitor of Differentiation-1 } \\ \text { ID2 } & \text { Intoop-helix } \\ \text { ID } & \end{array}$




\begin{tabular}{ll} 
IPAH & Idiopathic pulmonary arterial hypertension \\
LDL & Low density lipoprotein \\
MetS & Metabolic Syndrome \\
NHANES & National Health and Nutrition Examination Survey \\
LAM & Lymphangioleiomyomatosis \\
OR & Odds Ratio \\
PAD & Peripheral Arterial Disease \\
PDR & Proliferative Diabetic Retinopathy \\
PCB & Polychlorinated Biphenyl \\
SNP & Single Nucleotide Polymorphism \\
TNF & Tumor Neurosis Factor \\
VEGF & Vascular Endothelial Growth Factor \\
VEGFR & Vascular Endothelial Growth Factor Receptor \\
VSMC & Vascular Smooth Muscle Cells \\
\hline
\end{tabular}




\section{CHAPTER I}

\section{INTRODUCTION}

Systematic \& pulmonary vascular biologists have inclined to position their particular research in different ways. This distinction is readily implicit in light of their predominantly different interests. Those that are engaged in research on pulmonary circulation have often centered their attention on pulmonary arterial hypertension, a life threatening condition that affect your arteries which go from your heart to your lungs. Oppositely systematic circulation have traditionally focused on the pathogenesis of atherosclerosis, a common disease that affects large arteries and in which the lipid metabolism features chiefly have been explored in mechanisms in restenosis after angioplasty. These divergent pathways intersect at obliterative and proliferative vascular diseases which commonly disrupt the blood vessel. These two types of vascular diseases certainly have similar elements such as interactions between the vessel wall and various components of blood. Others involve interactions between the smooth muscle of the media \& endothelial lining but while exasperating and preserving mechanisms have been established in both, the unique perturbations that initiates these processes remains uncertain.

A class of proteins that have been seen to be involved with these types of vascular diseases are ID proteins (ID1, ID2, ID3, and ID4). Their names relate to their ability to regulate the programming of cell fate determination and differentiation in various types of cells through normal development and adult life 
(Lasorella et al., 2014). The ID3 gene was first identified as a serum-inducible immediate early gene in an established murine fibroblastic cell line (Christy et al., 1991). Previous studies have demonstrated its involvement in various biological processes, including: tumor-induced angiogenesis, embryonic neurogenesis, osteogenesis, vascular smooth muscle cell proliferation, T \& B cell development, and skeletal muscle differentiation (Atherton et al., 1996; Deed et al., 1996; Melnikova \& Christy, 1996; Pan et al., 1999, Lyden et al., 1999; Rivera et al., 2000; Forrest et al., 2004; Maeda et al., 2004). ID3 has been shown to be involved in various types of vascular diseases such as adult kidney injury (AKI) which is involved in loss of capillary function and vascular remodeling in the luteum (CL), a temporary endocrine organ that is involved in the production of high levels of progesterone and moderate levels of estradiol, atherosclerotic disease, and pulmonary hypertension (Lee et al., 2014; Yang et al., 2013; Nio-Kobayashi et al., 2012; Doran et al., 2010). Expression and function of the protein is under several multifaceted layers of regulation and therefore can provide beneficial targets for therapeutic interventions.

Vascular diseases can manifest from a combination of both environmental \& molecular determinants. Progression in machine/deep learning and genomic technologies have facilitated investigators to generate hypotheses regarding the integration \& contribution of genetic factors at a rapid pace. However, the assessment of specific and numerous environmental pollutants and their interactions with the genome has not. There still lacks methodologies to comprehensively analyze and interpret several multifaceted environmental \& 
cellular constitutes to disease and human health. One environmental determinant that has been demonstrated to show association with ID3 are chemicals commonly known as estrogenic or endocrine disrupting chemicals (EDCs). These chemicals are synthetic and natural that have the ability to disrupt metabolic pathways by either mimicking or blocking endogenous hormones and modifying hormone function (Roy et al. 1997). Many EDCs are considered highly carcinogenic and include an assortment of chemicals such as industrial compounds, by-products of industrial procedures, chemicals that are used in the manufacturing of plastics, and pesticides. Of specific concern to public health professionals are agents that are persistent in the environment that are hormonally active, greatly lipophilic, amplify within the food chain, and are readily bio-accumulative (Lyche et al., 2009; Meeker et al., 2009).

Since many of these chemicals are used in numerous amounts of consumer products, exposure to EDCs through the general population is prevalent. Human exposure to EDCs may result in different ways such as absorption through the skin, ingestion of contaminated food \& water, and airborne inhalation (Balabanic et al., 2001). During the last decade multiple EDC exposure such as polychlorinated biphenyls (PCBs), bisphenol A (BPA), and phthalates have been detected in $>90 \%$ urine \& blood samples collected from the general population of the United States (Silva et al., 2004; Calafat et al., 2008; Woodruff et al., 2011). EDCs that are persistent today in the environment have shown properties of endocrine disruption. PCBs have demonstrated to have estrogenic and antiestrogenic properties contingent on the congener. Previously PCB exposure has 
been shown to be associated with cardiovascular disease (Perkins et al. 2016). Higher exposure of urinary phthalates furthermore have been demonstrated to be associated with hypertension in childhood (Trasande et al. 2013). Exposure to BPA has demonstrated to result in atherosclerosis, altered cardiac remodeling, and changes in blood pressure in rodents (Gao \& Wang, 2014). Although there are vast amount of EDCs in the environment the most extensively studied EDCs include polychlorinated biphenyls, phthalates, and bisphenol A.

The existing disciplines of studying environmental pollutants \& molecular determinants of health include epidemiology, molecular/genetic biology, \& toxicology which function on population, bioinformatics, and molecular scales, respectively. This dissertation proposes methodology in all of these disciplines emphasizing the framework of environmental - and genomic - wide association studies through the utilization of public databases such as the National Health and Nutrition Examination Survey (NHANES) and NCBI Gene Omnibus Expression (GEO). The overachieving goals of this research was to first determine the association between exposure to these endocrine disrupting chemicals in a U.S. population diagnosed with vascular disease and secondly; determine the role of ID3 in vascular-intimal lesion formation and investigate its activity via regulation of cell adhesion, extracellular matrix proteolysis, and cell growth. Documenting both exposure to EDCs among the U.S. population \& associations with vascular disease and the role of ID3 in vascular-intimal lesions will help guide our understanding of the complexity of environmental molecular determinants in vascular disease. 


\section{References:}

1. Christy BA, Sanders LK, Lau LF, Copeland NG, Jenkins NA, Nathans D. An Idrelated helix-loop-helix protein encoded by a growth factor-inducible gene. Proceedings of the National Academy of Science of the United States of America. 1991; 88: 1815-9.

2. Pan L, Sato S, Frederick JP, Sun XH, Zhuang Y. Impaired immune responses and B-cell proliferation in mice lacking the Id3 gene. Molecular and Cellular Biology. 1999; 19: 5969-80.

3. Rivera RR, Johns CP, Quan J, Johnson RS, Murre C. Thymocyte selection is regulated by the helix-loop-helix inhibitor protein, Id3. Immunity. 2000; 12: 17-26.

4. Lyden D, Young AZ, Zagzag D, Yan W, Gerald W, O'Reilly R, et al. Id1 and Id3 are required for neurogenesis, angiogenesis and vascularization of tumour xenografts. Nature. 1999; 401: 670-7.

5. Atherton GT, Travers H, Deed R, Norton JD. Regulation of cell differentiation in C2C12 myoblasts by the Id3 helix-loop-helix protein. Cell Growth \& Differentiation. 1996; 7: 1059-66.

6. Melnikova IN, Christy BA. Muscle cell differentiation is inhibited by the helixloop-helix protein Id3. Cell Growth \& Differentiation. 1996; 7: 1067-79.

7. Forrest ST, Barringhaus KG, Perlegas D, Hammarskjold ML, McNamara CA. Intron retention generates a novel Id3 isoform that inhibits vascular lesion formation. Journal of Biological Chemistry. 2004; 279: 32897-903.

8. Deed RW, Jasiok M, Norton JD. Attenuated function of a variant form of the helix-loop-helix protein, Id-3, generated by an alternative splicing mechanism. FEBS Letters. 1996; 393: 113-6.

9. Maeda Y, Tsuji K, Nifuji A, Noda M. Inhibitory helix-loop-helix transcription factors Id1/ld3 promote bone formation in vivo. Journal of Cellular Biochemistry. 2004; 93: 337-44.

10. Lyche JL, Gutleb AC, Bergman A, Eriksen GS, Murk AJ, et al. Reproductive and developmental toxicity of phthalates. Journal of Toxicology and Environmental Health. 2009; 12:225-249.

11. Meeker JD, Sathyanarayana S, Swan SH. Phthalates and other additives in plastics: human health exposure and associated health outcomes. Philosophical Transactions of the Royal Society B. 2009; 364:2097-2113.

12. Calafat AM, Xiaoyun X, Wong LY, Reidy JA, Needham LL. Exposure of the U.S. Population to Bisphenol A and 4-tertiary-Octylphenol: 2003-2204. Environmental Health Perspectives. 2008; 116(1): 39-44. 
13. Woodruff TJ, Zota AR, Schwartz JM. Environmental Chemicals in Pregnant Women in the United States: NHANES 2003-2004. Environmental Health Perspectives. 2011; 119 (6): 878-885.

14. Silva MJ, Barr DB, Reidy, JA, Malek NA, Hodge CC, Caudill AP, Brock JW, Needham LL, Calafat AM. Urinary levels of seven phthalate metabolites in the U.S. population from the National Health and Nutrition Examination Survey (NHANES) 1999-2000. Environmental Health Perspectives. 2000; 112:331-338

15. Gao X, Wang H-S. Impact of Bisphenol A on the Cardiovascular System Epidemiological and Experimental Evidence and Molecular Mechanisms. International Journal of Environmental Research and Public Health. 2014; 11(8):8399-8413.

16. Fishman AP, Fishman MC, Freeman BA, Gimbrone MA, Rabinovitch M, Robinson D, Gail DB. Mechanisms of proliferative and obliterative vascular diseases. Insights from the pulmonary and systemic circulations. NHLBI Workshop summary. American Journal of Respiratory Critical Care Medicine. 1998; 158(2):670-4.

17. Trasande L, Sathyanarayana S, Spanier AJ, Trachtman H, Attina TM, Urbina EM. Urinary Phthalates Are Associated with Higher Blood Pressure in Childhood. Journal of Pediatrics. 2013; 163:747-53.

18. Roy D, Palangat M, Chen C, Thomas RD, Colerangle J, Atkinson A, Yan Z. Biochemical and molecular changes at the cellular level in response to exposure to environmental estrogen-like chemicals. Journal of Toxicology and Environmental Health. 1997; 50:1, 1-30. 


\section{HYPOTHESIS}

Estrogenic chemical induced dysregulation of ID3 target genes is involved in the development of vascular disease

\section{SPECIFIC AIMS}

Aim 1: Collect environmental exposure data from National Health and Nutrition Examination Survey (NHANES) database and gene expression data from the Gene Expression Omnibus (GEO) database

Aim 2: Investigate the association between exposure to estrogenic chemicals and vascular disease (peripheral arterial disease)

Aim 3: Identify ID3 regulated molecular gene networks 


\section{CHAPTER II}

\section{REVIEW OF LITERATURE}

\section{MANUSCRIPT 1}

Contribution of Inhibitor of DNA-binding/Differenatiation-3 (ID3) and endocrine disrupting chemicals to pathophysiological aspects of chronic disease 


\section{Abstract}

The overwhelming increase in the global incidence of obesity and its associated complications such as insulin resistance, atherosclerosis, pulmonary disease, and degenerative disorders including dementia constitutes a serious public health problem. The Inhibitor of DNA binding/Differentiation-3 (ID3), a member of the ID family of transcriptional regulators, has been shown to play a role in adipogensis and therefore ID3 may influence obesity and metabolic health in response to environmental factors. This review will highlight the current understanding of how ID3 may contribute to complex chronic diseases via metabolic perturbations. Based on the increasing number of reports that suggest chronic exposure to and accumulation of endocrine disrupting chemicals (EDCs) within the human body are associated with metabolic disorders, we will also consider the impact of these chemicals on ID3. Improved understanding of the ID3 pathways by which exposure to EDCs can potentiate complex chronic diseases in populations with metabolic disorders (obesity, metabolic syndrome, and glucose intolerance) will likely provide useful knowledge in the prevention and control of complex chronic diseases associated with exposure to environmental pollutants.

Keywords: endocrine disrupting chemicals, ID3, metabolic disorders, chronic disease 


\section{Introduction}

Inhibitor of DNA binding/Differentiation-3 is a member of the ID family of helix-loophelix proteins encoded by an immediate-early gene responsive to mitogenic signals and oxidative stress. ID3 functions as a transcriptional regulator known to prevent stem cell differentiation and promote cell cycle progression. An increasing body of evidence suggests that ID3 may be involved in metabolic perturbations characterized by insulin resistance, hyperglycemia, abdominal obesity, dyslipidemia, and hypertension. Interactions across multiple organ systems that contribute to metabolic perturbations presents a challenge to ongoing research attempting to elucidate biological mechanisms of chronic disease associated with metabolic health. For instance, insulin resistance and systemic low-grade inflammation result from complex interactions between the vasculature, metabolic tissue, and immune cells. With regard to these interactions, it is noteworthy that ID3 plays a significant role in vasculogenesis, energy metabolism, and in the development of the immune system. In the vasculature, ID3 is essential to embryonic vasculogenesis and endothelial cell activation (Sakurai et al. 2004; Felty and Porther. 2008; Eelen et al. 2015). Given that metabolic perturbations are observed in endothelial cells from diseased vasculature (He et al. 2014), ID3 may mediate endothelial dysfunction often found in individuals with metabolic syndrome. In addition to the vasculature, ID3 function spans to metabolic tissue and immune cells. In vivo studies have demonstrated that ID3 mediates high fat diet induced obesity and promotes obesity-induced inflammatory macrophage accumulation (Doran et al. 2008; Cutchins et al. 2012). Thus, we intend to discuss 
the current understanding of how ID3 may influence chronic diseases associated with metabolic perturbations. Since adipose tissue is an endocrine organ as well as a metabolic organ, exposure to endocrine disrupting chemicals (EDCs) may also contribute to metabolic perturbations associated with chronic disease. EDCs are mostly synthetic chemicals ubiquitously found in our environment that act by altering hormone action. Estrogenic EDCs such as diethylstilbestrol (DES), bisphenol A (BPA), estrogenic polychlorinated biphenyls (PCBs), and phthalates have been implicated to interfere with metabolic health during critical periods of development and into adulthood. Epidemiological studies have reported associations between exposures to EDCs and metabolic syndrome (Swedenborg et al. 2003; Hatch et al. 2010; Casals-Casas and Desvergne. 2011). Based on our recent findings that showed ID3 dependent endothelial cell activation by exposure to estrogenic PCB congener 153 (Felty. 2011; Das and Felty. 2014), we will also discuss how low dose EDC exposure from the environment may potentiate complex chronic disease in populations with metabolic disorders (obesity, metabolic syndrome, and glucose intolerance) via ID3. A better understanding of interactions between ID3 and EDC is critical in deepening our understanding of how environmental factors modify chronic disease risk and health outcomes. Further study in these areas may reveal novel or more effective therapeutic modalities as well as provide prevention and control strategies of complex chronic diseases associated with exposure to EDCs. 


\section{Inhibitor of DNA binding/Differentiation-3 (ID3)}

Structure and Function. The ID (Inhibitor of DNA binding/Differentiation) family of small proteins consists of four genes (ID1-ID4). The four members of the ID family share extensive amino acid sequence homology (69-78\%) within their helixloop-helix (HLH) domain (Lyden et al. 1999, Yang et al. 2014), but the remaining parts of the proteins are non-related. Experimental studies in genetically engineered mice have revealed the importance of ID3 in embryonic development and cell differentiation. ID3 gene knockout mice are viable, however, they have demonstrated defects in immune cell differentiation (Pan et al. 1999; Lasorella et al. 2014). In contrast, double ID1/ID3 knockout mice showed abnormal vascularization of the brain (Poulsen et al. 2001), neuronal differentiation, and cardiac defects (Fraidenraich et al. 2004) that were embryonically lethal. Resistance to tumor angiogenesis was reported in mice deficient in 1-3 alleles of ID1/ID3 gene knockout combination (Lyden et al. 1999). ID3 is highly expressed in embryonic tissue, but declines as cells differentiate (Lyden et al. 1999). In adult tissues, the expression of ID3 is context specific and tends to be highest in proliferating and undifferentiated cells. ID3 expression has been reported to be induced by diverse stimuli in many cell types (Lim and Wu. 2005).

The ID3 gene was initially identified as a serum-inducible immediate-early gene in mouse fibroblasts that peaks transcriptionally at $1 \mathrm{~h}$ (Lasorella et al. 2001; Lasorella et al. 2014). Subsequently, ID3 expression has been reported to be biphasic with maximal stimulation at $1 \mathrm{~h}$ following a second burst at $24 \mathrm{~h}$ as in the case of tissue regeneration after injury. We and others have shown that ID3 
expression is redox sensitive (Felty and Porther. 2008; Mueller et al. 2012) specifically, we have shown that vascular endothelial cells exposed to either $17 \beta$ estradiol (E2) or the estrogenic PCB congener 153 (PCB153) resulted in increased ID3 expression, protein phosphorylation, and endothelial neovascularization. Treatment with reactive oxygen species scavengers inhibited estrogenic chemical induced neovascularization (Das and Felty. 2014; Das and Felty. 2014). Proteasomes reportedly degrade ID3 by an ubiquitin dependent mechanism. The protein half-life of ID3 has been demonstrated to be approximately 20 min in HEK293 cells (Yang and Morrell. 2014). In mammals, ID protein-protein interactions occur via the HLH-motif in which ID proteins dimerize and block the DNA binding activity of basic HLH transcription factors, such as a group of $E$ proteins (E12/E47, E2-2, HEB) encoded by the TCF3, TCF4, and TCF12 gene, respectively. Among these E proteins, ID3 has been most often reported to interact with E12/E47 (Loveys et al. 1996). The E proteins are basic HLH transcription factors that bind to the E-box consensus sequence (CANNTG) in the promoter of target genes. ID3 plays an important role in cell proliferation via its interactions with E proteins. For example, E proteins have been shown to bind the E-box sequence in the promoter of the cyclin dependent kinase inhibitor $\mathrm{p} 21^{\mathrm{Cip} 1}$ and activate its transcription (Liu et al. 2004). The level of p21 ${ }^{\text {Cip1 }}$ is elevated in quiescent cells where it acts as a suppressor of cell proliferation (Sherr and Roberts. 1995). In the context of the cell cycle, ID3 promotes cell cycle progression by the inhibition of p21 ${ }^{\text {Cip1 }}$ expression (Forrest and McNamara. 2004). Specifically, ID3 protein-protein interactions with $\mathrm{E}$ proteins can disrupt their ability to bind gene promoters and 
thereby blocks transcriptional activation by these factors. ID3 has been shown to inhibit $\mathrm{E}$ proteins from activating the $\mathrm{p} 21^{\mathrm{Cip} 1}$ promoter in proliferating vascular cells (Taylor et al. 2006). Thus, ID3 has been frequently described as a dominant negative inhibitor of E proteins. Although ID proteins have been shown to function as dominant negative transcriptional regulators of $E$ proteins, there may be circumstances by which ID3 acts as a positive transcriptional regulator. ID3 has been shown to regulate the binding of Transcription Factor 3 (TCF3) to the E-box motif in target gene promoters (Langlands et al. 1997). TCF3 has been reported to repress the expression of pluripotency genes OCT4, SOX2, and NANOG that contribute to cell differentiation (Lasorella et al. 2014). Our research has shown that ectopic overexpression of ID3 increased OCT4 and SOX2 expression in endothelial cells as well as resulted in a population of cells that were positive for the molecular stemness signature CD133+ VEGFR3 ${ }^{+} \mathrm{CD}^{+} 4^{+}$(Felty et al. 2015). These endothelial stem cells were morphologically differentiated into smooth muscle cells and neuron cells. Based on these lines of evidence, ID3 maintains cells in an undifferentiated or non-committed state by preventing the repression of pluripotency factors by TCF3. Hence, it is also plausible for ID3 to function as a positive regulator of gene transcription. In lieu of a recent report that showed ID3 to modulate genes essential for maintaining genome integrity during cell division (Ji et al. 2011) a dual regulatory role of ID3 in both positive and negative gene transcription expands its influence as shown in Figure 1.1. ID3 protein-protein interactions are not exclusive to E-proteins as ID proteins have also been reported 
to bind to proteins that do not contain the HLH motif such as caveolin-1 (Zhang et al. 2007).

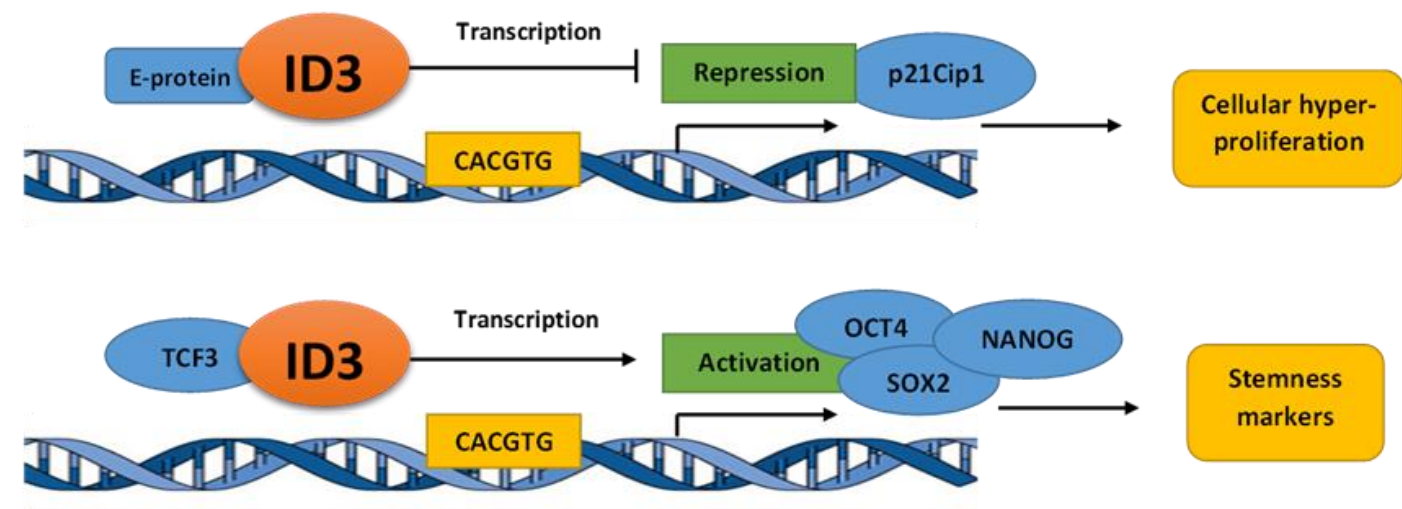

Figure 1.1 ID3 transcriptional regulation. Scheme illustrating how ID3 can repress expression of p21 gene (upper panel) or activate gene expression of embryonic transcription factors (lower panel).

\section{ID3 and Metabolic Syndrome (MetS)}

There has been increasing evidence that ID3 plays a role in adipogenesis. ID3 through adiponectin is considered to improve $\beta$-cell function, circulating lipids, and insulin sensitivity levels (Arita et al.1999; Steinberg and Kemp. 2009). ID3 inhibits transcriptional activity of E47 in undifferentiated pre-adipocytes (Doran et al. 2008). ID3 negatively inhibits the FAS (fatty acid synthase) promoter via SREP1c in adipose tissue. ID3 furthermore plays a role in blood glucose, which if dysregulated can lead to insulin resistance. In human islet cells ID1 and ID3 mRNA levels are increased with addition of glucose (Wice et al. 2001). The induction of ID1 and ID3 expression, insulin secretion, and gene transcription suggests that IDs may play a role in promoting $\beta$-cell function (Wice et al. 2001, Lee et al. 2011). 


\section{ID3 \& Endocrine Disrupting Chemicals Influence Metabolic Perturbation}

Metabolic Syndrome (MetS) and its associated complications such as insulin resistance, abdominal obesity, dyslipidemia, and hypertension contribute to chronic diseases including cardiovascular disease (CVD), type 2 diabetes, cancer, and chronic kidney disease (CKD). Some studies have shown the prevalence of MetS in the United States at approximately $34 \%$ of the adult population (Ford et al. 2002). MetS is an illness of energy consumption and storage which is a diagnosis of the co-occurrence of a minimum of three of the following medical conditions: abdominal obesity, high triglyceride levels, low HDL cholesterol levels, high fasting blood sugar, and high blood pressure. The molecular mechanisms of MetS are not fully understood. Most patients are older, sedentary, obese, and have a certain amount of insulin resistance. Important factors that are associated with MetS can include aging, diet, sedentary behavior, genetics, excessive alcohol use, or low physical activity (Poulsen et al. 2001; Pollex and Hegele. 2006; Malik et al. 2010; Edwardson et al. 2012). MetS appears to have three conceivable etiological groupings: obesity and disorders of adipose tissue; insulin resistance; and a collection of independent factors (ex: molecules of hepatic, vascular, and immunologic origin).

Inflammatory factors produced during obesity are a major pathway for developing metabolic perturbation which can lead to MetS. Experimental studies have demonstrated ID3 to be a key regulator of Monocyte chemoattractant protein-

1 (MCP-1) (Kapla et al. 2015). MCP-1 is a well-known chemokine impacted by MetS (Panee. 2012). ID3 has also been reported to regulate the production 
of interleukins IL-5, IL-6, IL-8, and IL-10 (Jin et al. 2011; Kuo et al. 2011; Perry et al. 2012).The induction of these chemokines have been observed in population studies of obesity and/or MetS. ID3 is also an oxidative stress regulated gene which may provide a positive feedback pathway in response to metabolic perturbations (Mueller et al. 2002; Felty and Porther. 2008). Taken together, these lines of evidence provide the basis for how ID3 can participate in metabolic perturbations via controlling the expression of inflammatory factors involved in obesity and/or MetS. A growing number of reports implicate endocrine-disrupting chemicals (EDCs) as an environmental factor that contributes to the occurrence of MetS. We performed a comprehensive search in the Comparative Toxicogenomic Database (CTD) to identify known ID3 and EDC interactions with results shown in Table 1 (Mattingly et al. 2004).

Table 1. ID3 and Endocrine Disrupting Chemicals (EDCs)

\begin{tabular}{|c|c|c|c|c|c|c|c|c|c|c|c|}
\hline Chemical name & $\begin{array}{l}\text { Chemical } \\
\text { ID }\end{array}$ & $\begin{array}{l}\text { CAS } \\
\text { RN }\end{array}$ & $\begin{array}{l}\text { Interaction } \\
\text { count }\end{array}$ & $\begin{array}{c}\text { Organism } \\
\text { count }\end{array}$ & Interaction & $\begin{array}{l}\text { PubMed } \\
\text { ID }\end{array}$ & Authors & Title & Year & Citation & Organism \\
\hline \multirow[t]{4}{*}{ Tetrachlorodibenzodioxin } & \multirow[t]{4}{*}{ D013749 } & \multirow[t]{4}{*}{$\begin{array}{l}1746- \\
01-6\end{array}$} & \multirow[t]{4}{*}{18} & \multirow[t]{4}{*}{3} & $\begin{array}{l}\text { Tetrachlorodibenzodioxin } \\
\text { affects the expression of ID3 } \\
\text { mRNA }\end{array}$ & 23238561 & Nault et al. & $\begin{array}{l}\text { Comparison of TCDD- } \\
\text { elicited genome-wide } \\
\text { hepatic gene expression in } \\
\text { Sprague-Dawley rats and } \\
\text { C57BL } / 6 \text { mice. }\end{array}$ & 2013 & $\begin{array}{l}\text { Toxicol Appl } \\
\text { Pharmacol. } \\
\text { 2013 Mar 1; } \\
\text { 267(2): 184-91. }\end{array}$ & $\begin{array}{c}\text { Rattus } \\
\text { norvegicus }\end{array}$ \\
\hline & & & & & $\begin{array}{l}\text { Tetrachlorodibenzodioxin } \\
\text { cotreated with TIPARP gene } \\
\text { mutant form results in } \\
\text { decreased expression of ID3 } \\
\text { mRNA }\end{array}$ & 21496263 & Dere et al. & $\begin{array}{c}\text { Differences in TCDD- } \\
\text { elicited gene expression } \\
\text { profiles in human HepG2, } \\
\text { mouse Hepa1c1c7, and rat } \\
\text { H4IIE hepatoma cells. }\end{array}$ & 2011 & $\begin{array}{c}\text { BMC } \\
\text { Genomics. } \\
\text { 2011;12: } 193 \text {. }\end{array}$ & $\begin{array}{c}\text { Rattus } \\
\text { norvegicus }\end{array}$ \\
\hline & & & & & $\begin{array}{l}\text { Tetrachlorodibenzodioxin } \\
\text { results in increased } \\
\text { expression of ID3 mRNA }\end{array}$ & 19684285 & Kim et al. & $\begin{array}{l}\text { Comparative analysis of } \\
\text { AhR-mediated TCDD- } \\
\text { elicited gene expression in } \\
\text { human liver adult stem } \\
\text { cells. }\end{array}$ & 2009 & $\begin{array}{l}\text { Toxicol Sci. } \\
\text { 2009 Nov; } \\
\text { 112(1): 229-44. }\end{array}$ & $\begin{array}{c}\text { Homo } \\
\text { sapiens }\end{array}$ \\
\hline & & & & & & 17942748 & $\begin{array}{l}\text { Boverhof et } \\
\text { al. }\end{array}$ & $\begin{array}{l}\text { Inhibition of estrogen- } \\
\text { mediated uterine gene } \\
\text { expression responses by } \\
\text { dioxin. }\end{array}$ & 2008 & $\begin{array}{c}\text { Mol } \\
\text { Pharmacol. } \\
\text { 2008 Jan; } 73(1): \\
\text { 82-93. }\end{array}$ & $\begin{array}{c}\text { Rattus } \\
\text { norvegicus }\end{array}$ \\
\hline
\end{tabular}


TABLE 1: Continued.

\begin{tabular}{|c|c|c|c|c|c|c|c|c|c|c|c|}
\hline Chemical name & $\begin{array}{l}\text { Chemical } \\
\text { ID }\end{array}$ & CAS RN & $\begin{array}{l}\text { Interaction } \\
\text { count }\end{array}$ & $\begin{array}{c}\text { Organism } \\
\text { count }\end{array}$ & Interaction & PubMed ID & Authors & Title & Year & Citation & Organism \\
\hline \multirow[t]{5}{*}{ Bisphenol A } & \multirow[t]{5}{*}{ C006780 } & \multirow[t]{5}{*}{$80-05-7$} & \multirow[t]{5}{*}{5} & \multirow[t]{5}{*}{3} & \multirow[t]{5}{*}{$\begin{array}{l}\text { Bisphenol A results in } \\
\text { increased expression of ID3 } \\
\text { mRNA }\end{array}$} & 26982218 & $\begin{array}{l}\text { Porreca et } \\
\text { al. }\end{array}$ & $\begin{array}{l}\text { "Stockpile" of slight } \\
\text { transcriptomic changes } \\
\text { determines the indirect } \\
\text { genotoxicity of low-dose } \\
\text { BPA in thyroid cells. } \\
\text { Fxposure to low-dose }\end{array}$ & 2016 & $\begin{array}{l}\text { PLoS One. 2016; } \\
\text { 11(3): e0151618. }\end{array}$ & $\begin{array}{c}\text { Rattus } \\
\text { norvegicus }\end{array}$ \\
\hline & & & & & & 25181051 & Ali et al. & $\begin{array}{l}\text { bisphenol A impairs meiosis } \\
\text { in the rat seminiferous } \\
\text { tubule culture model: a } \\
\text { physiotoxicogenomic } \\
\text { approach. }\end{array}$ & 2014 & $\begin{array}{l}\text { PLoS One. 2014; } \\
\text { 9(9): el06245. }\end{array}$ & $\begin{array}{c}\text { Rattus } \\
\text { norvegicus }\end{array}$ \\
\hline & & & & & & 25270620 & Schaap et al. & $\begin{array}{c}\text { A novel } \\
\text { toxicogenomics-based } \\
\text { approach to categorize } \\
\text { (non)genotoxic carcinogens. }\end{array}$ & 2014 & $\begin{array}{l}\text { Arch Toxicol. } 2014 \\
\text { Oct } 2 .\end{array}$ & $\begin{array}{c}\text { Mus } \\
\text { musculus }\end{array}$ \\
\hline & & & & & & 16474171 & $\begin{array}{l}\text { Buterin et } \\
\text { al. }\end{array}$ & $\begin{array}{l}\text { Convergent transcriptional } \\
\text { profiles induced by } \\
\text { endogenous estrogen and } \\
\text { distinct xenoestrogens in }\end{array}$ & 2006 & $\begin{array}{c}\text { Carcinogenesis. } \\
2006 \text { Aug; } 27(8) \text { : } \\
\text { 1567-78. }\end{array}$ & $\begin{array}{c}\text { Homo } \\
\text { sapiens }\end{array}$ \\
\hline & & & & & & 25912373 & Fic et al. & $\begin{array}{l}\text { Genome-wide gene } \\
\text { expression profiling of } \\
\text { low-dose, long-term } \\
\text { exposure of human } \\
\text { osteosarcoma cells to } \\
\text { bisphenol A and its analogs } \\
\text { bisphenols AF and S. }\end{array}$ & 2015 & $\begin{array}{l}\text { Toxicol In Vitro. } \\
\text { 2015 Aug; 29(5): } \\
\text { 1060-9. }\end{array}$ & $\begin{array}{c}\text { Homo } \\
\text { sapiens }\end{array}$ \\
\hline
\end{tabular}

TABle 1: Continued.

\begin{tabular}{|c|c|c|c|c|c|c|c|c|c|c|c|}
\hline Chemical name & $\begin{array}{l}\text { Chemical } \\
\text { ID }\end{array}$ & CAS RN & $\begin{array}{c}\text { Interaction } \\
\text { count }\end{array}$ & $\begin{array}{c}\text { Organism } \\
\text { count }\end{array}$ & Interaction & PubMed ID & Authors & Title & Year & Citation & Organism \\
\hline Ethinylestradiol & D004997 & $57-63-6$ & 5 & 2 & $\begin{array}{l}\text { Ethinylestradiol inhibits the } \\
\text { reaction [IL/B protein results } \\
\text { in increased expression of ID3 } \\
\text { mRNA] }\end{array}$ & 12072388 & Evans et al. & $\begin{array}{l}\text { Estrogen receptor alpha } \\
\text { inhibits IL-1beta induction } \\
\text { of gene expression in the } \\
\text { mouse liver. }\end{array}$ & 2002 & $\begin{array}{l}\text { Endocrinology. } \\
\text { 2002 Jul; 143(7): } \\
2559-70 .\end{array}$ & $\begin{array}{c}\text { Mus } \\
\text { musculus }\end{array}$ \\
\hline \multirow[t]{2}{*}{ Benzo(a)pyrene } & D001564 & $50-32-8$ & 4 & 2 & $\begin{array}{c}\text { Benzo(a)pyrene results in } \\
\text { increased expression of ID3 } \\
\text { mRNA }\end{array}$ & 22228805 & $\begin{array}{c}\text { Kerley- } \\
\text { Hamilton et } \\
\text { al. }\end{array}$ & $\begin{array}{c}\text { Inherent and } \\
\text { benzo[a]pyrene-induced } \\
\text { differential aryl hydrocarbon } \\
\text { receptor signaling greatly } \\
\text { affects life span, } \\
\text { atherosclerosis, cardiac gene } \\
\text { expression, and body and } \\
\text { heart growth in mice. }\end{array}$ & 2012 & $\begin{array}{l}\text { Toxicol Sci. 2012 } \\
\text { Apr; 126(2): } \\
\text { 391-404. }\end{array}$ & $\begin{array}{c}\text { Mus } \\
\text { musculus }\end{array}$ \\
\hline & & & & & & 20064835 & Sparfel et al. & $\begin{array}{l}\text { Transcriptional signature of } \\
\text { human macrophages } \\
\text { exposed to the } \\
\text { environmental contaminant } \\
\text { benzo(a)pyrene. }\end{array}$ & 2010 & $\begin{array}{c}\text { Toxicol Sci. } 2010 \\
\text { Apr; 114(2): 247-59. }\end{array}$ & $\begin{array}{l}\text { Homo } \\
\text { sapiens }\end{array}$ \\
\hline \multirow[t]{2}{*}{ Coumestrol } & D003375 & $479-13-0$ & 3 & 1 & $\begin{array}{l}\text { Coumestrol cotreated with } \\
2,3 \text {-bis }\left(3^{\prime} \text { - }\right. \\
\text { hydroxybenzyl)butyrolactone } \\
\text { results in decreased expression } \\
\text { of ID3 mRNA }\end{array}$ & & & & & & \\
\hline & & & & & $\begin{array}{l}\text { Coumestrol cotreated with } \\
\text { resveratrol results in decreased } \\
\text { expression of ID } 3 \mathrm{mRNA}\end{array}$ & 19167446 & Dip et al. & $\begin{array}{c}\text { Pleiotropic combinatorial } \\
\text { transcriptomes of human } \\
\text { breast cancer cells exposed } \\
\text { to mixtures of dietary } \\
\text { phytoestrogens. }\end{array}$ & 2009 & $\begin{array}{l}\text { Food Chem Toxicol. } \\
2009 \text { Apr; 47(4): } \\
\text { 787-95. }\end{array}$ & $\begin{array}{l}\text { Homo } \\
\text { sapiens }\end{array}$ \\
\hline
\end{tabular}




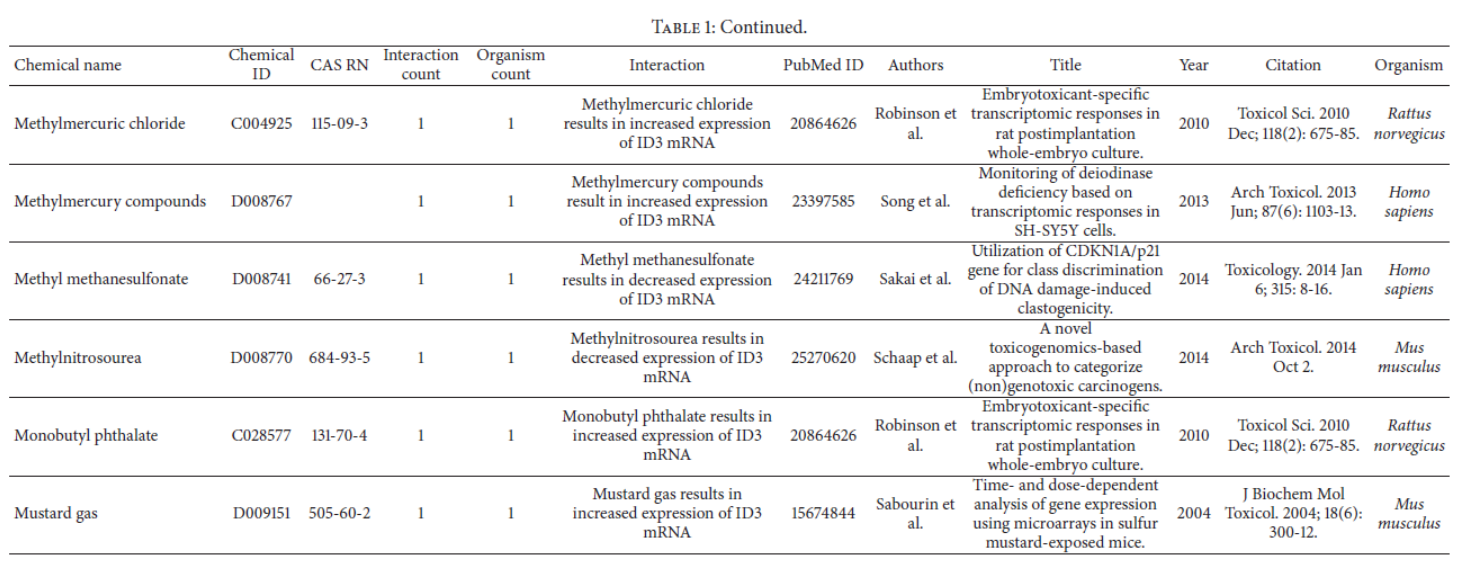

TABLE 1: Continued.

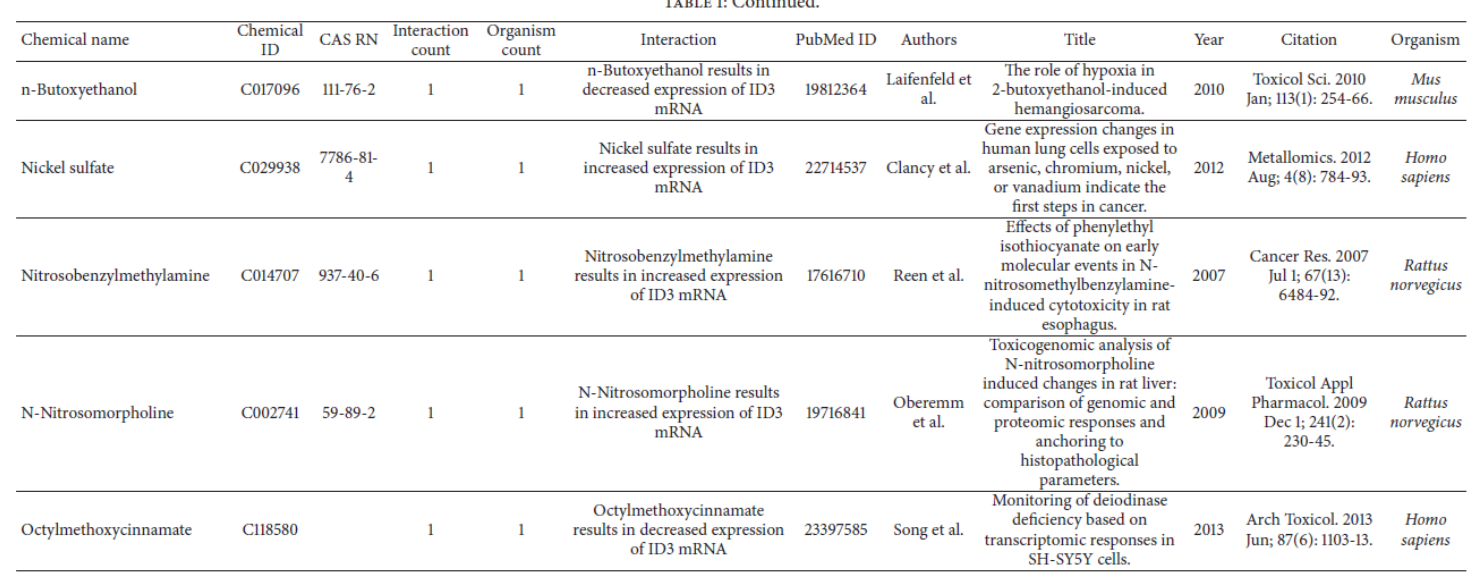

TABLE 1: Continued.

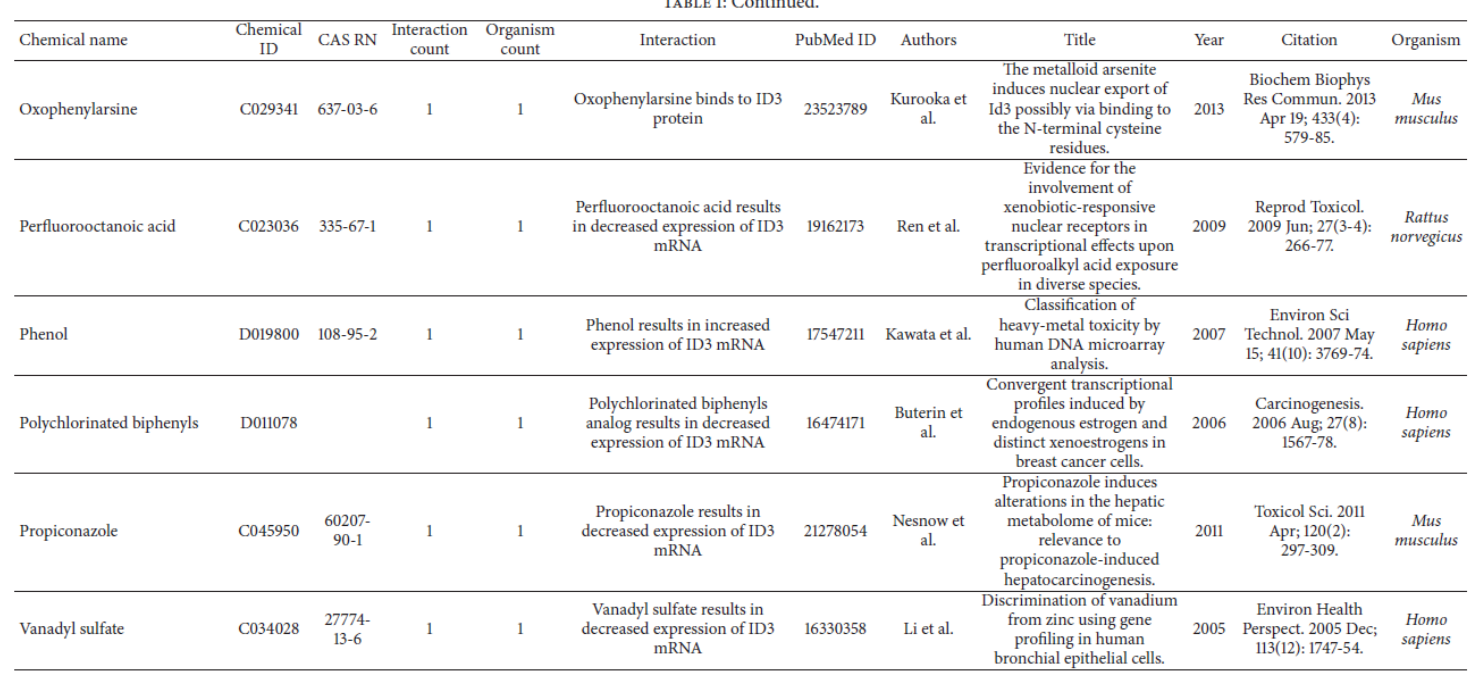


TABLE 1: Continued.

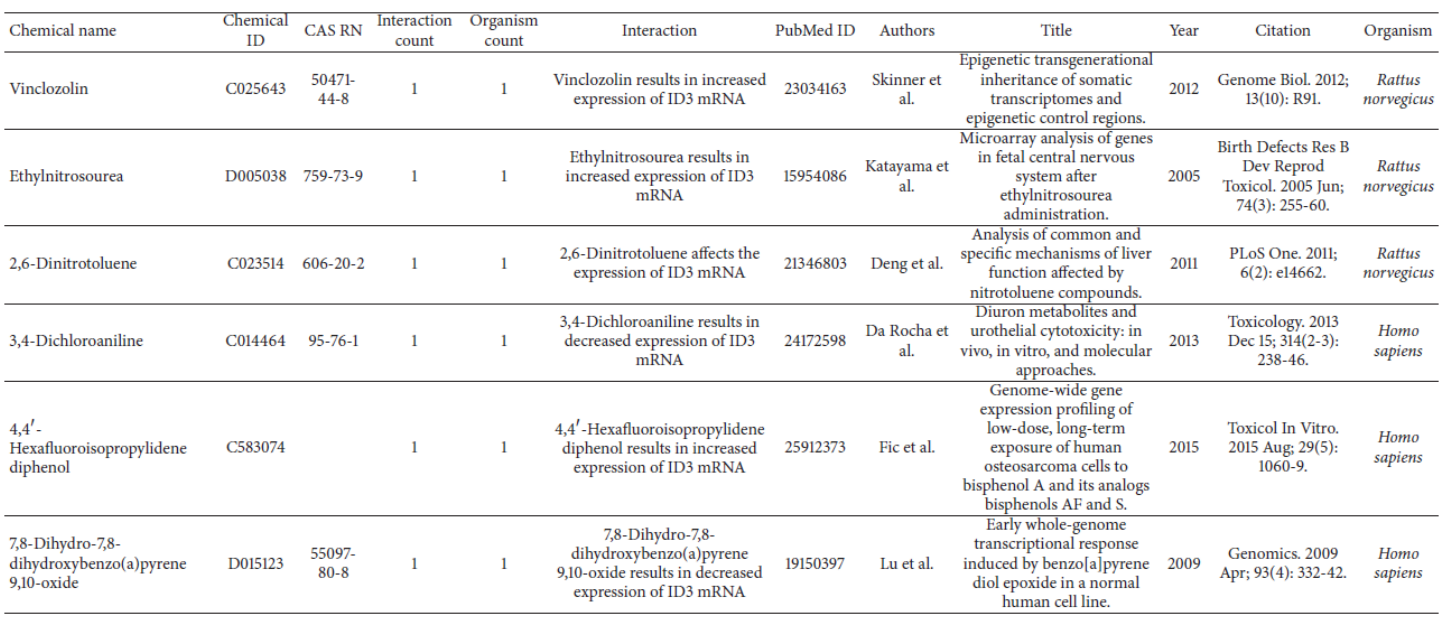

TABLE 1: Continued.

\begin{tabular}{|c|c|c|c|c|c|c|c|c|c|c|c|}
\hline Chemical name & $\begin{array}{l}\text { Chemical } \\
\text { ID }\end{array}$ & CAS RN & $\begin{array}{c}\text { Interaction } \\
\text { count }\end{array}$ & $\begin{array}{c}\text { Organism } \\
\text { count }\end{array}$ & Interaction & PubMed ID & Authors & Title & Year & Citation & Organism \\
\hline Bis(4-hydroxyphenyl)sulfone & C543008 & $80-09-1$ & 1 & 1 & $\begin{array}{l}\text { Bis(4-hydroxyphenyl)sulfone } \\
\text { results in increased expression } \\
\text { of ID3 mRNA }\end{array}$ & 25912373 & Fic et al. & $\begin{array}{l}\text { Genome-wide gene } \\
\text { expression profiling of } \\
\text { low-dose, long-term } \\
\text { exposure of human } \\
\text { osteosarcoma cells to } \\
\text { bisphenol A and its analogs } \\
\text { bisphenols AF and S. }\end{array}$ & 2015 & $\begin{array}{l}\text { Toxicol In Vitro. } \\
2015 \text { Aug; 29(5): } \\
\text { 1060-9. }\end{array}$ & $\begin{array}{c}\text { Homo } \\
\text { sapiens }\end{array}$ \\
\hline Bismuth tripotassium dicitrate & C002791 & $\begin{array}{c}57644- \\
54-9\end{array}$ & 1 & 1 & $\begin{array}{l}\text { Bismuth tripotassium dicitrate } \\
\text { results in increased expression } \\
\text { of ID3 } \mathrm{mRNA}\end{array}$ & 15912405 & $\begin{array}{l}\text { Magnusson } \\
\text { et al. }\end{array}$ & $\begin{array}{l}\text { Gene expression changes } \\
\text { induced by bismuth in a } \\
\text { macrophage cell line. }\end{array}$ & 2005 & $\begin{array}{c}\text { Cell Tissue Res. } \\
\text { 2005 Aug; 321(2): } \\
\text { 195-210. }\end{array}$ & $\begin{array}{c}\text { Rattus } \\
\text { norvegicus }\end{array}$ \\
\hline tert-Butylhydroperoxide & D020122 & $75-91-2$ & 1 & 1 & $\begin{array}{l}\text { tert-Butylhydroperoxide } \\
\text { results in increased expression } \\
\text { of ID3 mRNA }\end{array}$ & 15003993 & Ma et al. & $\begin{array}{l}\text { The effect of stress } \\
\text { withdrawal on gene } \\
\text { expression and certain } \\
\text { biochemical and cell } \\
\text { biological properties of } \\
\text { peroxide-conditioned cell } \\
\text { lines. }\end{array}$ & 2004 & $\begin{array}{l}\text { FASEB J. } 2004 \text { Mar; } \\
\text { 18(3): 480-8. }\end{array}$ & $\begin{array}{c}\text { Mus } \\
\text { musculus }\end{array}$ \\
\hline C646 compound & C584509 & & 1 & 1 & $\begin{array}{c}\text { C646 compound results in } \\
\text { decreased expression of ID3 } \\
\text { mRNA }\end{array}$ & 26191083 & Gaddis et al. & $\begin{array}{c}\text { Altering cancer } \\
\text { transcriptomes using } \\
\text { epigenomic inhibitors. }\end{array}$ & 2015 & $\begin{array}{c}\text { Epigenetics } \\
\text { Chromatin. 2015; 8: } \\
9 .\end{array}$ & $\begin{array}{l}\text { Homo } \\
\text { sapiens }\end{array}$ \\
\hline Cadmium sulfate & $\mathrm{C} 037123$ & $\begin{array}{r}10124- \\
36-4\end{array}$ & 1 & 1 & $\begin{array}{l}\text { Cadmium sulfate affects the } \\
\text { reaction [MTF1 affects the } \\
\text { expression of ID } 3 \mathrm{mRNA} \text { ] }\end{array}$ & 16221973 & $\begin{array}{l}\text { Wimmer et } \\
\text { al. }\end{array}$ & $\begin{array}{l}\text { Two major branches of } \\
\text { anti-cadmium defense in the } \\
\text { mouse: } \\
\text { MTF-1/metallothioneins } \\
\text { and glutathione. }\end{array}$ & 2005 & $\begin{array}{l}\text { Nucleic Acids Res. } \\
\text { 2005; 33(18): } \\
5715-27 .\end{array}$ & $\begin{array}{c}\text { Mus } \\
\text { musculus }\end{array}$ \\
\hline
\end{tabular}

TABLE 1: Continued.

\begin{tabular}{|c|c|c|c|c|c|c|c|c|c|c|c|}
\hline Chemical name & $\begin{array}{c}\text { Chemical } \\
\text { ID }\end{array}$ & CAS RN & $\begin{array}{c}\text { Interaction } \\
\text { count }\end{array}$ & $\begin{array}{c}\text { Organism } \\
\text { count }\end{array}$ & Interaction & PubMed ID & Authors & Title & Year & Citation & Organism \\
\hline Cobaltous chloride & C018021 & $\begin{array}{c}7646-79- \\
9\end{array}$ & 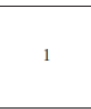 & - & $\begin{array}{c}\text { Cobaltous chloride results in } \\
\text { decreased expression of ID3 } \\
\text { mRNA }\end{array}$ & 19320972 & Hang et al. & $\begin{array}{l}\text { Transcription and splicing } \\
\text { regulation in human } \\
\text { umbilical vein endothelial } \\
\text { cells under hypoxic stress } \\
\text { conditions by exon array. }\end{array}$ & 2009 & $\begin{array}{l}\text { BMC Genomics. } \\
\text { 2009; 10: } 126 .\end{array}$ & $\begin{array}{c}\text { Homo } \\
\text { sapiens }\end{array}$ \\
\hline Copper sulfate & D019327 & $\begin{array}{c}7758-98- \\
7\end{array}$ & 1 & 1 & $\begin{array}{l}\text { Copper sulfate results in } \\
\text { increased expression of ID3 } \\
\text { mRNA }\end{array}$ & 19549813 & Song et al. & $\begin{array}{l}\text { Physiological and } \\
\text { toxicological transcriptome } \\
\text { changes in HepG2 cells } \\
\text { exposed to copper. }\end{array}$ & 2009 & $\begin{array}{l}\text { Physiol Genomics. } \\
\text { 2009 Aug 7; 38(3): } \\
\text { 386-401. }\end{array}$ & $\begin{array}{l}\text { Homo } \\
\text { sapiens }\end{array}$ \\
\hline Cuprizone & D003471 & $370-81-0$ & 1 & 1 & $\begin{array}{l}\text { Cuprizone affects the } \\
\text { expression of ID3 mRNA }\end{array}$ & 26577399 & Abe et al. & $\begin{array}{l}\text { Developmental cuprizone } \\
\text { exposure impairs } \\
\text { oligodendrocyte lineages } \\
\text { differentially in cortical and } \\
\text { white matter tissues and } \\
\text { suppresses glutamatergic } \\
\text { neurogenesis signals and } \\
\text { synaptic plasticity in the } \\
\text { hippocampal dentate gyrus } \\
\text { of rats. }\end{array}$ & 2016 & $\begin{array}{c}\text { Toxicol Appl } \\
\text { Pharmacol. 2016 Jan } \\
\text { 1; 290: 10-20. }\end{array}$ & $\begin{array}{c}\text { Rattus } \\
\text { norvegicus }\end{array}$ \\
\hline Sodium arsenite & C017947 & $\begin{array}{c}13768- \\
07-5\end{array}$ & 9 & 2 & $\begin{array}{l}\text { ID3 protein inhibits the } \\
\text { reaction [sodium arsenite } \\
\text { results in increased expression } \\
\text { of EGR1 mRNA] }\end{array}$ & 23523789 & $\begin{array}{c}\text { Kurooka et } \\
\text { al. }\end{array}$ & $\begin{array}{c}\text { The metalloid arsenite } \\
\text { induces nuclear export of } \\
\text { Id3 possibly via binding to } \\
\text { the N-terminal cysteine } \\
\text { residues. }\end{array}$ & 2013 & $\begin{array}{c}\text { Biochem Biophys } \\
\text { Res Commun. 2013 } \\
\text { Apr 19; 433(4): } \\
\text { 579-85. }\end{array}$ & $\begin{array}{c}\text { Mus } \\
\text { musculus }\end{array}$ \\
\hline
\end{tabular}




\begin{tabular}{|c|c|c|c|c|c|c|c|c|c|c|c|}
\hline Chemical name & $\begin{array}{l}\text { Chemical } \\
\text { ID }\end{array}$ & CAS RN & $\begin{array}{l}\text { Interaction } \\
\text { count }\end{array}$ & $\begin{array}{c}\text { Organism } \\
\text { count }\end{array}$ & Interaction & PubMed ID & Authors & Title & Year & Citation & Organism \\
\hline Sodium arsenite & & & & & $\begin{array}{l}\text { Leptomycin B inhibits the } \\
\text { reaction [sodium arsenite } \\
\text { affects the localization of ID3 } \\
\text { protein] }\end{array}$ & 23523789 & $\begin{array}{l}\text { Kurooka et } \\
\text { al. }\end{array}$ & $\begin{array}{c}\text { The metalloid arsenite } \\
\text { induces nuclear export of } \\
\text { Id3 possibly via binding to } \\
\text { the N-terminal cysteine } \\
\text { residues. }\end{array}$ & 2013 & $\begin{array}{c}\text { Biochem Biophys } \\
\text { Res Commun. 2013 } \\
\text { Apr 19; 433(4): } \\
579-85 .\end{array}$ & $\begin{array}{c}\text { Mus } \\
\text { musculus }\end{array}$ \\
\hline Sodium arsenite & & & & & $\begin{array}{l}\text { Sodium arsenite affects the } \\
\text { localization of ID3 protein }\end{array}$ & 16966095 & $\begin{array}{l}\text { McNeely et } \\
\text { al. }\end{array}$ & $\begin{array}{l}\text { Exit from arsenite-induced } \\
\text { mitotic arrest is p53 } \\
\text { dependent. }\end{array}$ & 2006 & $\begin{array}{l}\text { Environ Health } \\
\text { Perspect. 2006 Sep; } \\
\text { 114(9): 1401-6. }\end{array}$ & $\begin{array}{l}\text { Homo } \\
\text { sapiens }\end{array}$ \\
\hline Sodium arsenite & & & & & $\begin{array}{l}\text { Sodium arsenite binds to ID3 } \\
\text { protein }\end{array}$ & 12760830 & $\begin{array}{l}\text { Andrew et } \\
\text { al. }\end{array}$ & $\begin{array}{l}\text { Genomic and proteomic } \\
\text { profiling of responses to } \\
\text { toxic metals in human lung } \\
\text { cells. }\end{array}$ & 2003 & $\begin{array}{l}\text { Environ Health } \\
\text { Perspect. 2003 May; } \\
\text { 111(6): 825-35. }\end{array}$ & $\begin{array}{c}\text { Homo } \\
\text { sapiens }\end{array}$ \\
\hline Sodium arsenite & & & & & $\begin{array}{l}\text { Sodium arsenite which binds } \\
\text { to ID3 protein promotes the } \\
\text { reaction [XPO1 protein affects } \\
\text { the localization of ID3 protein] }\end{array}$ & 23523789 & $\begin{array}{l}\text { Kurooka et } \\
\text { al. }\end{array}$ & $\begin{array}{l}\text { The metalloid arsenite } \\
\text { induces nuclear export of } \\
\text { Id3 possibly via binding to } \\
\text { the } \mathrm{N} \text {-terminal cysteine } \\
\text { residues. }\end{array}$ & 2013 & $\begin{array}{c}\text { Biochem Biophys } \\
\text { Res Commun. 2013 } \\
\text { Apr 19; 433(4): } \\
\text { 579-85. }\end{array}$ & $\begin{array}{c}\text { Mus } \\
\text { musculus }\end{array}$ \\
\hline Sodium arsenite & & & & & $\begin{array}{c}\text { Sodium arsenite results in } \\
\text { increased expression of ID3 } \\
\text { mRNA }\end{array}$ & 16966095 & $\begin{array}{l}\text { McNeely et } \\
\text { al. }\end{array}$ & $\begin{array}{l}\text { Exit from arsenite-induced } \\
\text { mitotic arrest is p53 } \\
\text { dependent. }\end{array}$ & 2006 & $\begin{array}{l}\text { Environ Health } \\
\text { Perspect. 2006 Sep; } \\
\text { 114(9): 1401-6. }\end{array}$ & $\begin{array}{c}\text { Homo } \\
\text { sapiens }\end{array}$ \\
\hline Cadmium chloride & D019256 & $\begin{array}{c}10108- \\
64-2\end{array}$ & 2 & 2 & $\begin{array}{c}\text { Cadmium chloride results in } \\
\text { increased expression of ID3 } \\
\text { mRNA }\end{array}$ & 16221973 & $\begin{array}{l}\text { Wimmer et } \\
\text { al. }\end{array}$ & $\begin{array}{l}\text { Two major branches of } \\
\text { anti-cadmium defense in the } \\
\text { mouse: } \\
\text { MTF-1/metallothioneins } \\
\text { and glutathione. }\end{array}$ & 2005 & $\begin{array}{l}\text { Nucleic Acids Res. } \\
\text { 2005; 33(18): } \\
\text { 5715-27. }\end{array}$ & $\begin{array}{c}\text { Mus } \\
\text { musculus }\end{array}$ \\
\hline
\end{tabular}

\begin{tabular}{|c|c|c|c|c|c|c|c|c|c|c|c|}
\hline Chemical name & $\begin{array}{l}\text { Chemical } \\
\text { ID }\end{array}$ & CAS RN & $\begin{array}{c}\text { Interaction } \\
\text { count }\end{array}$ & $\begin{array}{c}\text { Organism } \\
\text { count }\end{array}$ & Interaction & PubMed ID & Authors & Title & Year & Citation & Organism \\
\hline Diethylhexyl phthalate & D004051 & $117-81-7$ & 2 & 1 & $\begin{array}{c}\text { Diethylhexyl phthalate results } \\
\text { in decreased expression of ID3 } \\
\text { mRNA }\end{array}$ & 19850644 & Ren et al. & $\begin{array}{l}\text { Characterization of } \\
\text { peroxisome } \\
\text { proliferator-activated } \\
\text { receptor alpha-independent } \\
\text { effects of PPAR-alpha } \\
\text { activators in the rodent liver: } \\
\text { di-(2-ethylhexyl) phthalate } \\
\text { also activates the } \\
\text { constitutive-activated } \\
\text { receptor. }\end{array}$ & 2010 & $\begin{array}{l}\text { Toxicol Sci. } 2010 \\
\text { Jan; 113(1): 45-59. }\end{array}$ & $\begin{array}{c}\text { Mus } \\
\text { musculus }\end{array}$ \\
\hline
\end{tabular}

Table 1. ID3 and Endocrine Disrupting Chemicals (EDCs). ID3 and endocrine disrupting chemical interaction created via Comparative Toxicogenomic Database (CTD).

Adipose tissue is highly connected to steroid hormones (estrogens, androgens, and glucocorticoids) and maintains a close relationship with the immune system via adipokines. Endocrine disruption can interfere with the creation, discharge, breakdown, elimination, and imitation of natural hormones (Jin et al. 2013). EDCs can be cataloged into multiple groupings such as dioxins, organotins, plastics, and pesticides. The increased presence of EDCs in the environment may help explain the incidence of metabolic disorders and associated 
complications. EDCs are found in everyday products (including food, plastic bottles, metal cans, toys, cosmetics, \& pesticides) and used in the manufacture of food. Exposure to EDCs may regulate inflammatory factors via ID3. TCDD and PCB congeners have been shown to up-regulate MCP-1 expression (Kirkley and Sargis. 2014). Bisphenol A exposure has been reported to increase IL-6 (Aremma et al. 2016). Population studies furthermore have reported an association between bisphenol-A plasma levels and pro-inflammatory cytokines including IL-6 (Savastano et al. 2015). Besides inflammation, ID3 may contribute to other risk factors of MetS such as angiogenesis, adipose tissue, blood glucose levels, and insulin resistance. PCBs have been associated with MetS in epidemiological studies (Uemura et al. 2009). In the mouse model, PCB153 has been shown to produce significant metabolic changes when administered with a high fat diet that were consistent with worsened obesity and nonalcoholic fatty liver disease pathology (Wahlang et al. 2013). ID3 may contribute to MetS via visceral fat expansion that was demonstrated in mice fed a high-fat diet (Cutchins et al. 2012). 
ID3 deficiency resulted in greater energy expenditure and higher metabolic rate in mice at rest. With respect to metabolic disorders involving high glucose levels; ID3 may be impacted because it was shown to be regulated by glucose in pancreatic islet $\beta$-cells (Wice and Permutt. 2001) and under chronic hyperglycemic conditions. ID family proteins were stabilized by which in turn activated metabolic genes (Gronning et al. 2006). Since a causal link of diabetes and vascular disease is chronic hyperglycemia, ID3 may also contribute to metabolic perturbations from high blood glucose levels. More importantly, however, is that mitochondrial reactive oxygen species (ROS) produced by vascular endothelial cells under hyperglycemic conditions may share a pathway similar to environmental toxicant induced oxidative stress which converges on ID3. PCBs have been reported to have estrogenic activity (Bitman and Cecil. 1970; Meek and Finch. 1999; Tavolari et al. 2006; Davey et al. 2007). PCB153 is an agonist for the pregnane $X$ receptor (PXR) and the constitutive androstane receptor (CAR) which exert their effects on energy metabolism through gene regulation (Wada et al. 2009). Hence, dysregulation of these receptors by EDCs may contribute to PCB-induced metabolic perturbations. Several epidemiological studies have reported the association of PCB exposure with the increased risk of cardiovascular disease (Hay and Tarrel. 1997; Gustavsson and Hogstedt. 1997; Tokunaga and Kataoka. 2003; Sergeev and Carpenter. 2005; Goncharov et al. 2011). Since cardiovascular disease is a chronic disease affected by metabolic perturbations, we investigated the effects of PCB153 exposure on ID3 in vascular cells. Based on known PCB blood levels from occupational exposure, we showed a significant increase in 
PCB153-induced vascularization at doses of $10-100 \mathrm{ng} / \mathrm{ml}$ which was ID3 dependent (Felty. 2011). We have shown that PCB-induced ROS mediated a highly branched neo-vascular phenotype depended on ID3 and Pyk2 (Das and Felty. 2014). Because the level of ID3 protein is determined by the rates of protein synthesis and protein degradation, we tested if PCB153 treatment affected ID3 protein synthesis. We showed that estrogenic chemical induced ID3 did not depend on protein synthesis, instead PCB153 treatment increased ID3 protein stability in endothelial cells. The role of phosphorylation in the regulation of ID3 protein stability is not known. A search with the PhosphoMotif finder program revealed that ID3 had 38 serine kinase/phosphatase motifs and 8 tyrosine kinase/phosphatase motifs (Amanchy et al 2007). We reported that both E2 and PCB153 induced ID3 phosphorylation. E2 treatment stabilized ID3 protein during the 1-6h treatment time points and increased phosphorylated ID3 levels (Das and Felty. 2014, Das and Felty. 2014). It was noteworthy that we showed data of ID3 tyrosine phosphorylation by PCB153 treatment which was confirmed by MALDITOF MS/MS spectra data. Our findings revealed phosphorylated amino acids Tyr11 and Tyr-48 in peptides from ID3. Interestingly, Tyr-48 is positioned in the helixloop-helix motif that is essential for protein binding. Currently, it is not clear whether PCB153-induced phospho-ID3 leads to protein-protein interactions that may prevent its degradation; however, our findings demonstrated that ID3 is a target of post-translational modifications by the endocrine disruptor PCB153 in vascular endothelial cells. Based on these lines of evidence, estrogenic chemical-induced ID3 signaling contributes to hyperplastic vascular lesions. This vascular cell 
dysfunction may be a pathway by which EDCs and ID3 contribute to cardiovascular disease (Felty and Porther. 2008). Based on these findings, we propose that ID3 is a target of EDCs that can activate inflammatory and energy pathways susceptible to metabolic perturbation during chronic disease pathogenesis. In the next section, we intend to discuss the current mechanistic understanding of how ID3 may influence chronic diseases associated with metabolic perturbations.

\section{ID3 \& Disease Outcomes}

Vascular Diseases. ID3 involvement in vascular disease has been studied together with the lipoxygenase (12/15-LO) which is known to generate proinflammatory changes in blood vessels that precede the development of atherosclerosis (Chakrabarti et al. 2009). 12/15-LO is an important mediator of VSMC growth and its growth-promoting effects were shown to be mediated by ID3 transcription (Taylor et al. 2005). Increased expression of 12/15-LO in the vessel wall enhanced ID3-dependent cell proliferation, fibronectin deposition, and neointimal formation. Population based studies have found a SNP (single nucleotide polymorphisms) rs11574 in the coding region of the human ID3 gene associated with subclinical atherosclerosis in the Diabetes Heart study (Doran et al 2010). ID3 SNP rs11574 showed a significant association of coronary artery disease for caucasians and to a lesser extent in African Americans and Hispanics (Manichaikul et al. 2014).

Ectopic expression of ID3 in VSMC (vascular smooth muscle cells) regulates the cell-cycle (Yang et al. 2013). ID3 has also been shown to play a 
complex role with atherosclerosis. ID3 expression is increased by hyperlipidemia and oxidized LDL (Taylor et al. 2006). ID3 regulates angiotensin II and carotid intima-media thickness. Angiotensin II promotes hyperplasia through up-regulating ID3 (Owens. 2009). The ID3 SNP could be a potential loss of function mutation if it inhibits the functioning of $E$ proteins, thus being an atheroprotective factor. As shown in Figure 1.2, ID3 may impact vascular cell dysfunction leading to intimal lesions.

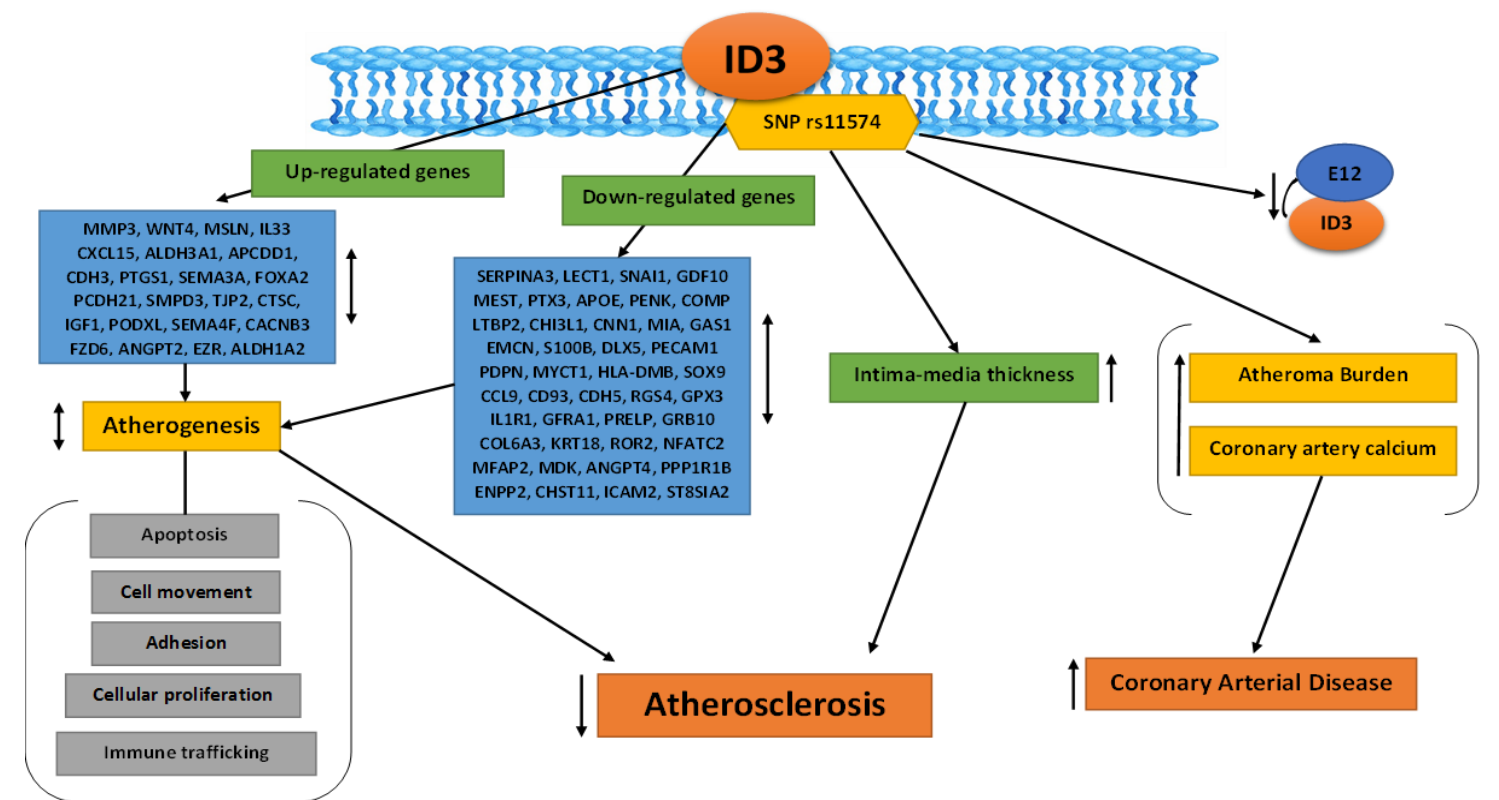

Figure 1.2 ID3 molecular mechanism \& vascular diseases. Summary illustration of ID3 signaling involved in vascular disease pathogenesis. ID3 signaling can lead to neo-intimal lesions or vascular remodeling by transcriptional regulation of the target genes described above.

ID3 stimulates visceral adipose VEGFA expression, depot expansion and micro-vascular blood volume (Cutchins et al. 2012). ID3 promotes angiogenesis in HFD (high-fat diet)-induced visceral adiposity (Cutchins et al. 2012). ID3 KO shows a protective effect from HFD-induced visceral fat depot expansion. Furthermore, HFD-induced VEGFA expression in visceral adipose tissue was completely 
abolished by loss of ID3. BMP9 induces both ID1 and ID3 which are necessary for induction of EphrinB2 (Kim et al. 2012). A summary in Figure 1.3 shows an ID3 signaling pathway involved in vascular malformations.

ID1

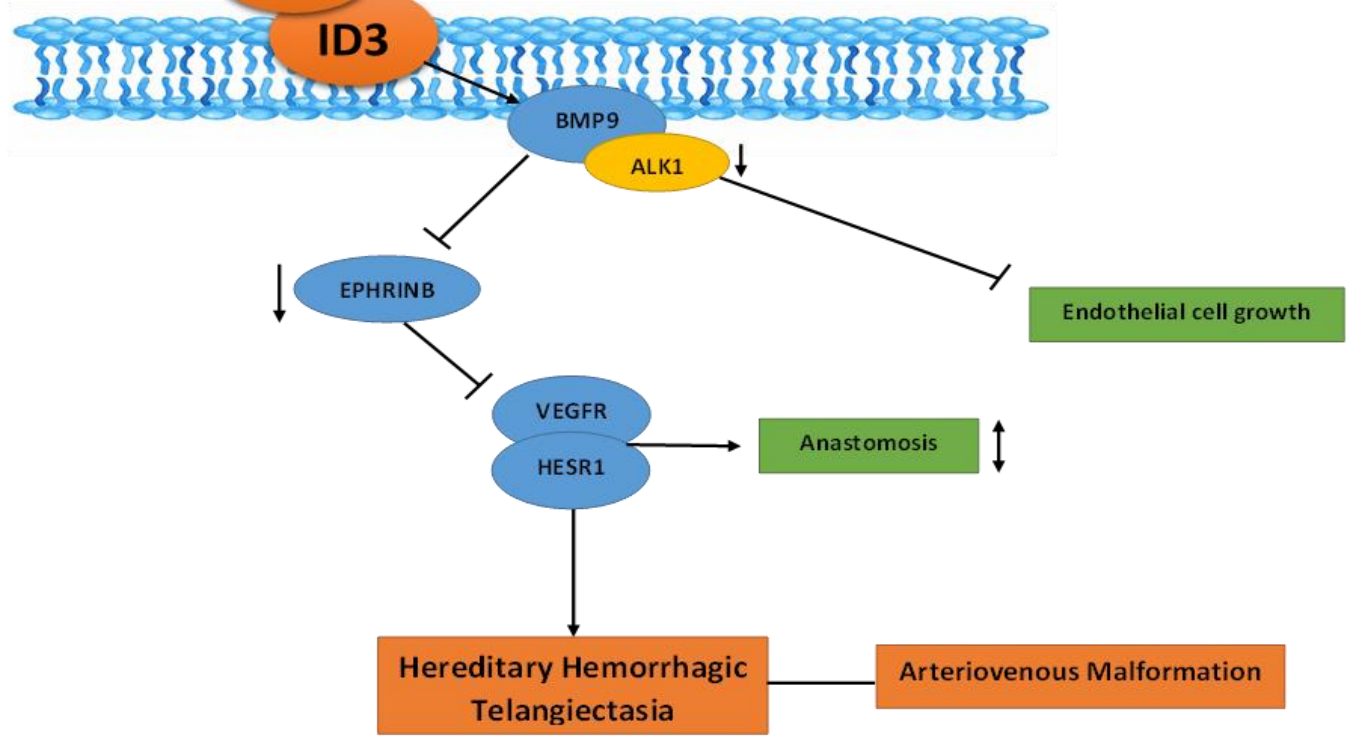

Figure 1.3 ID3 involvement in arteriovenous malformation. Summary of experimental studies showing impact of ID3 in vascular cell dysfunction.

Neurological Disorders. The ID3 gene is biologically relevant to neurological and behavior research because of its involvement in the stress response, neural plasticity, and neural circuitry. Molecular genetic studies in mice have shown that ID3 is required for embryonic neurovascular development. Genetic loss of ID1 and ID3 led to deviant neurovascular formations resulting in death (Lyden et al. 1999). ID1 and ID3 mutants showed premature differentiation of CNS radial glial cells that greatly increased neurons. Since radial glial cells, function as scaffolds for developing blood vessels in the CNS, alterations to their development in ID1/ID3 
knockout mice may contribute to deviant blood vessel morphogenesis and hemorrhage. ID1 and ID3 may function beyond maturation of the CNS neurovasculature because other pathways such as Notch1 activation do not support neurovascular disorders (O'Brien et al. 2012; Solozobova et al. 2012). Psychopathologies such as anxiety and depression have been associated with ID3 methylation status. Epigenetic changes in ID3 have been associated with maltreatment of children as well as demonstrated as a predictor for depression. Montalvo-Ortiz et al reported epigenetic alterations in DNA derived from saliva in three genes predicted depression in a cohort of maltreated children: ID3, Glutamate NMDA Receptor (GRIN1), and Tubulin Polymerization Promoting Protein (TPPP) (Montalvo-Ortiz et al. 2016). Studies of the expression of these genes from medial prefrontal cortex (mPFC) tissue of mice subjected to a model of maternal neglect, which comprised of maternal separation and early weaning (MSEW). Behavioral tests were performed in MSEW and control adult male mice by the higher plus maze (EPM) and forced swimming test (FST), respectively (Montalvo-Ortiz et al. 2016). Behavioral differences in the EPM and FST tests showed that these genes ID3, GRIN1 and TPPP gene could predict anxiety and depression. Based on these studies, ID3 may contribute to the etiology of anxiety and depressive phenotypes when exposed to early life stress (Montalvo-Ortiz et al. 2016) (Figure 1.4). 


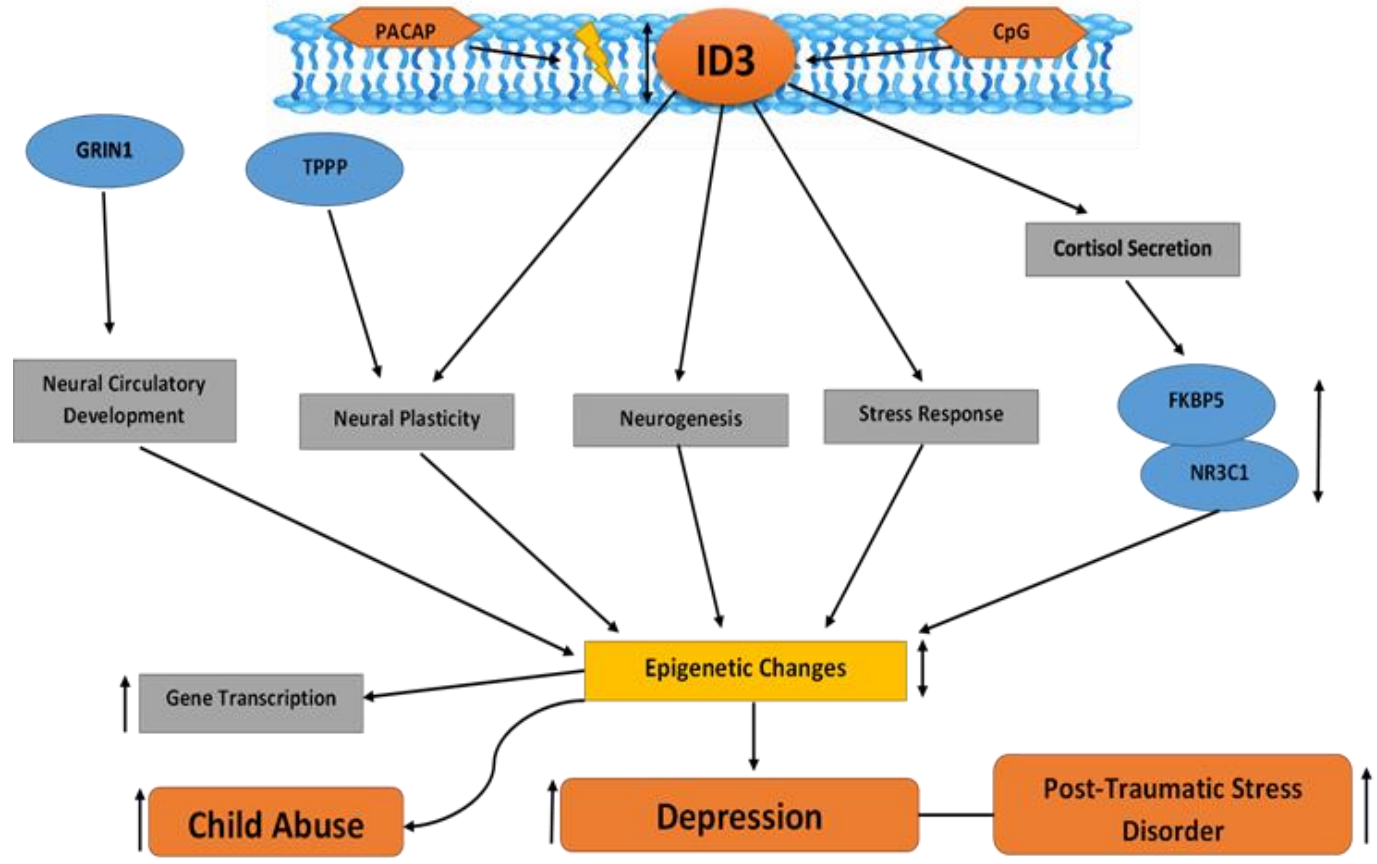

Figure 1.4 Epigenetic mechanism of ID3 in neurological disorders. Summary of ID3 involvement in neurological disorders is presented.

Both environmental \& genetic factors contribute to the progression of MetS and neurodegenerative disorders (Campos-Peña et al. 2017). Numerous studies have demonstrated that pre-diabetes and diabetes mellitus support cognitive decline related to Alzheimer's disease (AD) and vascular dementia (Campos-Peña et al. 2017). For example, sucrose-treated mice develop mitochondrial abnormalities with significant increase in $A \beta$ levels, and slight increase in pTau levels which links metabolic perturbations from sucrose consumption with the ADlike pathology. Epigenetic changes in ID3 have been associated with maltreatment of children as well as demonstrated as a predictor for depression (Weder et al. 2014). Another epigenetic study of individuals with Autism spectrum disorders (ASD) revealed a significant association with a microRNA that targets ID3 (Sarachana et al. 2010). This is interesting as ID3 is also a neuronal target of 
MeCP2 which is the causative gene for Rett syndrome in which afflicted children often exhibit autistic-like behaviors (Peddada et al. 2006). The overlap in the clinical symptoms of ASD, ADHD, and neurodegenerative disorders raises the question of whether epigenetic regulation of ID3 plays a role.

Population-based studies have demonstrated an association between toxic environmental chemical exposures and impaired neurodevelopment that may impact neurobehavioral disorders (Rossignol et al. 2014). Exposure to air pollutants from traffic and coal emissions are well-known risk factors for both attention deficit hyperactivity disorder (ADHD) and autism spectrum disorders (ASD) (Heilbrun et al. 2015). Polychlorinated biphenyls (PCBs) are endocrinedisrupting chemicals shown to adversely affect cognitive performance. Children exposed to PCBs have shown behavioral impairments as well as significant deficits in verbal and full-scale IQ (Chen et al. 1994). Urban areas are important regional sources of airborne PCBs and population-scale airborne exposure. Although PCBs have not been intentionally produced in the U.S. since the late 1970s, they continue to be detected in ambient air samples throughout the world (NIEHS, NIH). PCBs are measurable in the blood of nearly $80 \%$ of Americans over age 50 years (Shanahan et al. 2015). Hence, exposure to PCBs has been proposed to disrupt developing neuronal circuits that may cause developmental brain disorders such as learning disorders (LD), ADHD, and autism.

Endothelial cells of the blood-brain barrier (BBB) may provide clues in the study of brain health, behavior, and the environment (He et al. 2014). Inhaled air pollutants can disrupt the BBB by inducing pro-inflammatory cytokines that act on 
endothelial cells (Genc et al. 2012). We have shown evidence for how PCBinduced reactive oxygen species (ROS) may contribute to cerebral vascular phenotype changes with the goal of understanding consequences of environmental exposures have on the BBB (Das and Felty. 2015). Toxic chemical exposures can change brain gene expression through regulatory epigenetic mechanisms involving alterations in DNA methylation and histone acetylation. Evidence from animal studies show that epigenetic programming by fetal exposure to toxicants has long-lasting consequences for gene expression in the brain as well as behavior (Kundakovic et al. 2015). Epigenetic changes in ID3 have been associated with maltreatment of children as well as demonstrated as a predictor for depression (Weder et al. 2014). Epigenetic biomarkers in peripheral tissues (blood, saliva, or buccal cells) may be useful to predict neurodevelopmental disorders in humans. Exposures to prenatal stress, famine, and pollution/toxins, factors known to affect brain development, have been associated with epigenetic variation in human peripheral tissues (Perera et al. 2011). Based on these evidences, we postulate that ID3 can be a useful biological marker of epigenetic perturbations caused by toxic chemical exposure in children/adolescents (Figure 1.5). 


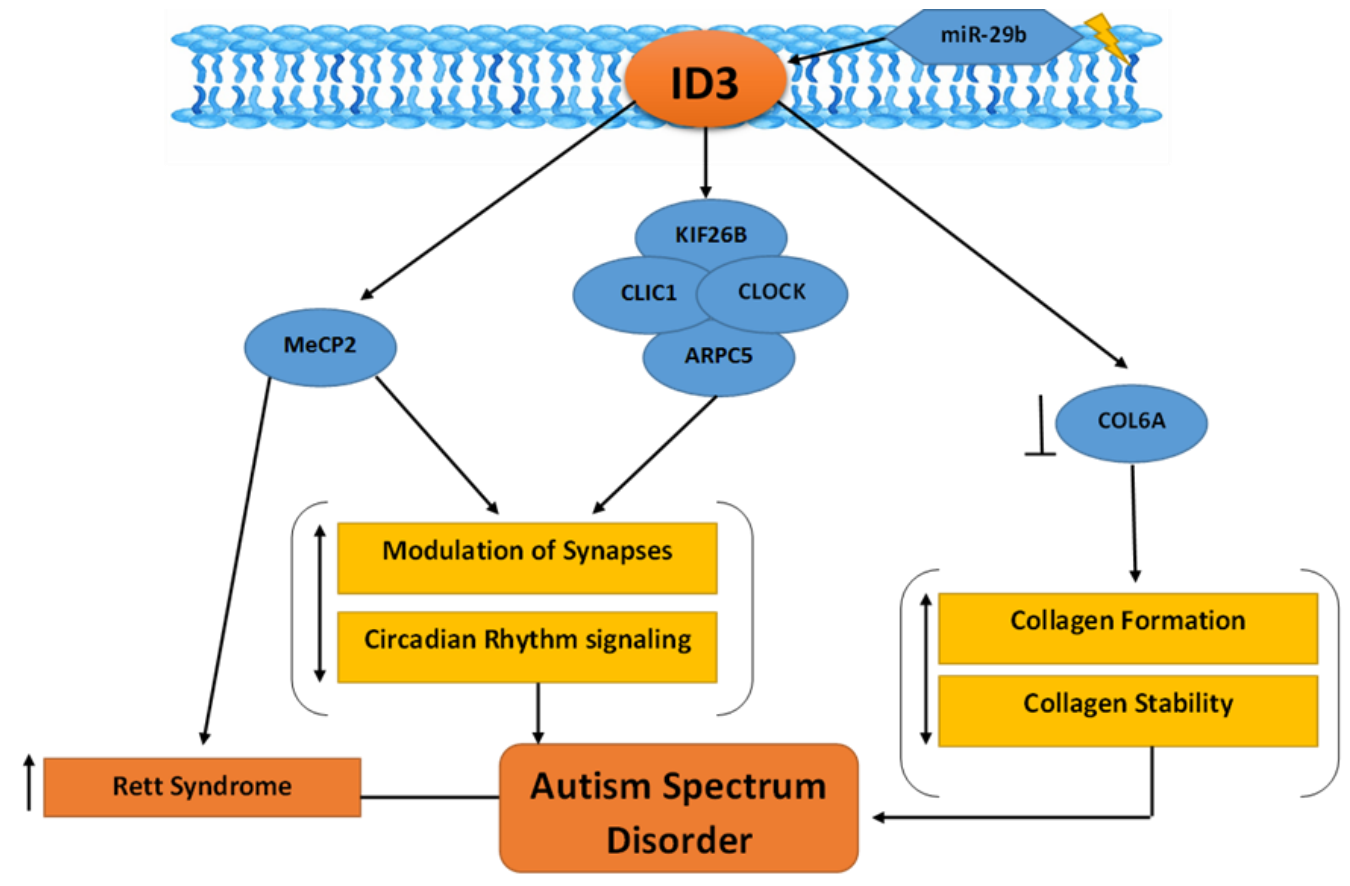

Figure 1.5 ID3 signaling pathway proposed in development of Autism Spectrum Disorder. Summary of ID3 involvement shows regulation of various genes causing changes in various processes such as modulation of synapses, circadian rhythm signaling, and collagen formation/stability.

Kidney disease. Lipoprotein abnormalities have been reportedly linked to renal dysfunction in chronic kidney disease patients. Nackiewicz et al reviewed the prominent characteristics of kidney disease previously stated in ApoE-/-ID3-/double knockout mice; and show that ID3 in hyperlipidemic mice directly effects vulnerability to kidney disease. ID3 deficiency may intensify CXCL1 production by glomerular cells in response to inflammatory lipids and the resulting macrophage recruitment. Because ID3 is present in multiple cell types, it is also conceivable that other glomerular cells lacking ID3 may contribute to cytokine production in vivo (Tenger and Zhou. 2003). Therefore, the reno-protective effect of ID3 may be through regulation of local chemokine production. ID3 is known to directly interact with more than 30 different transcription factors (Lynn et al. 2010). Noticeably, a 
change in the ID3 function may impact a wide range of protein-protein interactions with potentially significant consequences (Nackiewicz et al. 2014). In dissimilarity to the findings of Nachkiewicz et al, in ApoE-/-ID3-/- mice with glomerulonephritis, the hyperlipidemic ID3-/- mice did not express meaningful increase in glomerular immune complex deposition associated to hyperlipidemic WT mice. Apoliprotein E deficiency is known to cause enlarged immune responsiveness (Zhao et al. 2016) and these results add significance to the study in dissecting the effects of ID3 alone on kidney disease.

Clinical studies deliver indication for the relationship between lipids and chronic kidney disease. Nevertheless, they fail to elucidate why certain individuals (in the absence of diabetes or MetS) are probable to develop chronic kidney disease (Liu et al. 2012). Increased susceptibility to atherosclerosis has been reported to be associated with an ID3 single nucleotide polymorphism (SNP) (Doran et al. 2010). The overall preliminary findings in humans suggest a significant association between the same ID3 SNP and proteinuria, specifically influenced by small low density lipoproteins $(p=0.0024)$ (Tenger and Zhou. 2003). C57BL/6 male mice on high fat diets (60\% calorie from fat) develop MetS connected with obesity, elevated plasma glucose, proteinuria and glomerulonephritis (GN) and this may be due to decrease in renal AMP activated protein kinase, a cellular energy sensor (Declèves et al. 2011). However, C57BL/6 female mice on high fat diets develop GN and proteinuria only in the absence of ID3 suggesting distinct pathogenic mechanisms between females and males. Examining molecular mechanisms in mice has recognized ID3 as a unique 
transcription factor that may contribute to kidney disease and provide mechanistic links between atherosclerosis, hyperlipidemia, and kidney disease in humans. A summary of ID3 pathway contributing to chronic kidney disease is shown in Figure 1.6.

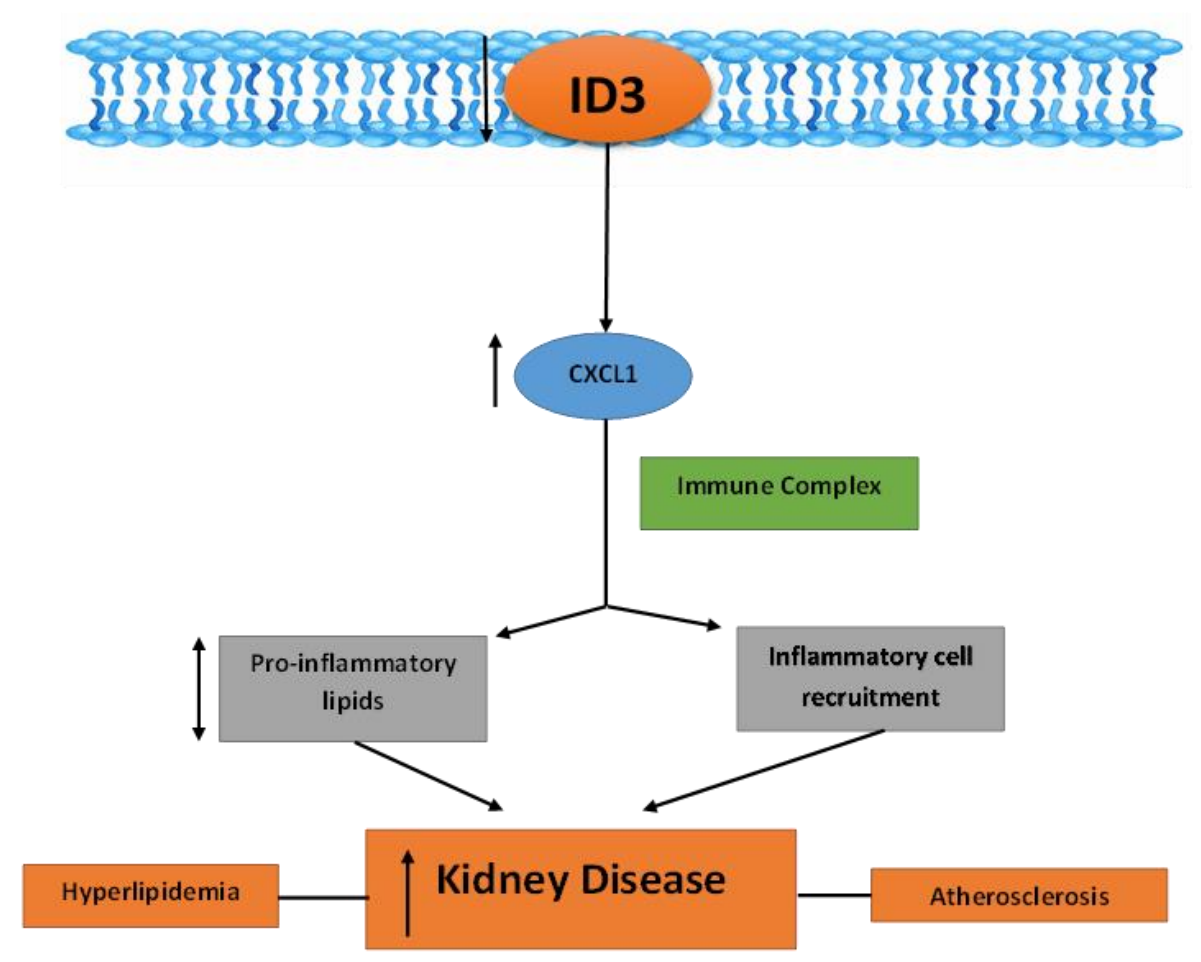

Figure 1.6 ID3 involvement in kidney disease. Summary illustration shows a link to hyperlipidemia and atherosclerosis.

Cancer. Deregulation of ID genes are reported in in human cancers such as nonsmall cell lung cancer (NSCLC) and colon cancer. ID3 contributes in generation of hematopoietic stem and progenitor cells (HSPC) associated with myeloproliferative disease (MPD) (Keller, NCI Division of Basic Sciences). ID1 and ID3 associated with the tumor promotion and metastasis (Castanon. 2013). Poor 
response to chemo-radiotherapy have been reported in NSCLC patients with elevated ID1 and ID3 protein expression (Castanon et al. 2013). Regulation of p21 by ID1 and ID3 has been seen as the vital mechanism inhibiting the accumulation of additional DNA damage and subsequent functional low energy of colon-initiating cells (CC-ICs). Genetic silencing of ID1 and ID3 increases chemotherapy sensitivity in CC-ICs suggesting that these molecules allow cancer cells to be drug resistant (O'Brien et al. 2012). Summary illustration of ID3 signaling involved in various cancer pathways is shown in Figure 1.7.

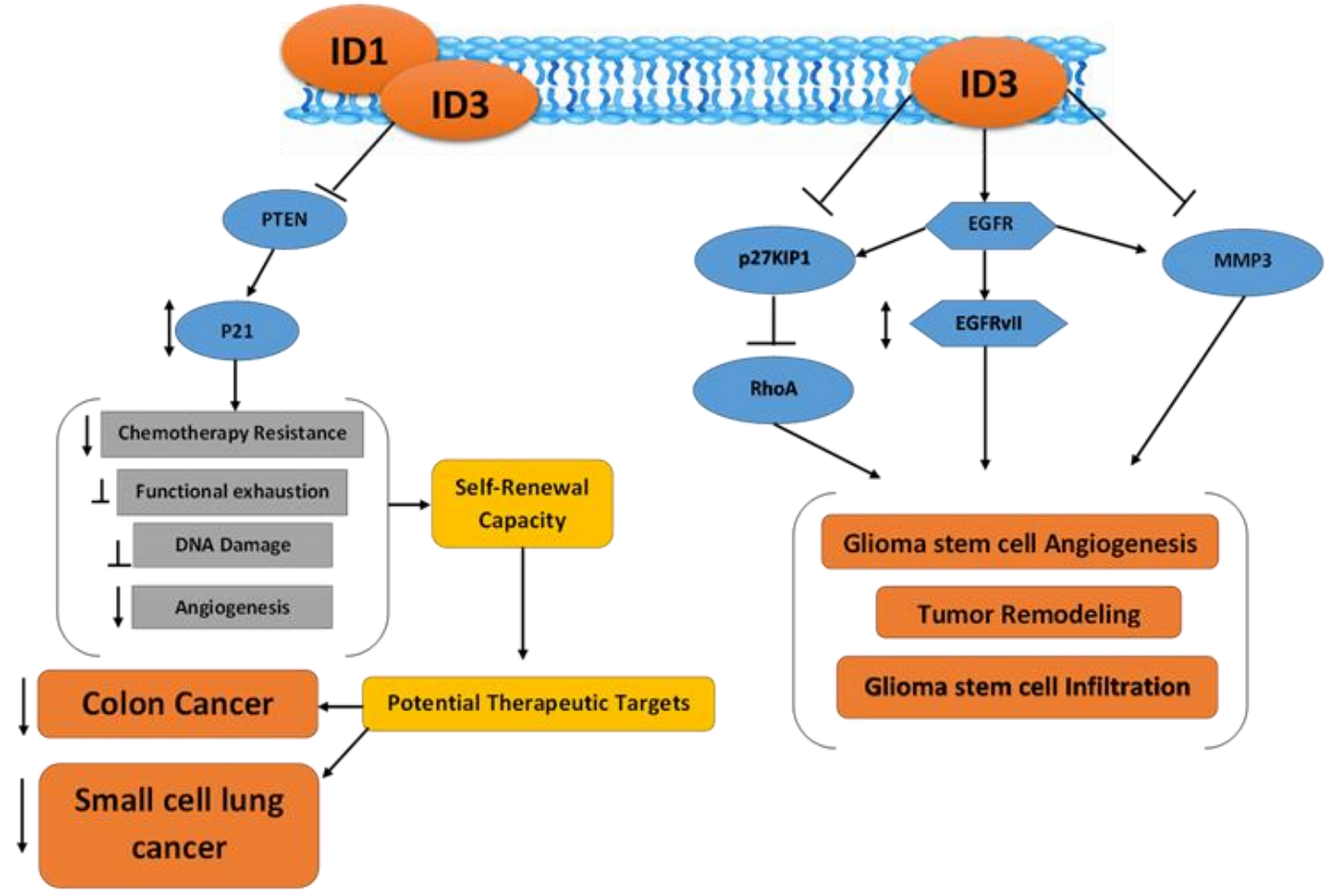

Figure 1.7 ID3 involvement in various types of cancer. Summary of ID3 signaling pathways involved in Colon and Lung Cancer (Left panel). ID3 contribution to tumor angiogenesis in brain cancer (Right panel). 
Glioblastoma multiforme (GBM) tumors contain glioma stem cells or GSCs which are an implicated for glioma resistance to treatment (Bao et al. 2006; Nakano and Kornblum. 2006; Chalmers. 2007; Esposito et al. 2012; Phi et al. 2013). ID3 is also shown to be connected with medullobastoma in children (Phi et al. 2013). Inhibition of ID3 reduced proliferation, migration, and increased apoptosis of medullobastoma cells. Potential molecular mechanisms of ID3 in brain cancer are shown in Figure 1.8.

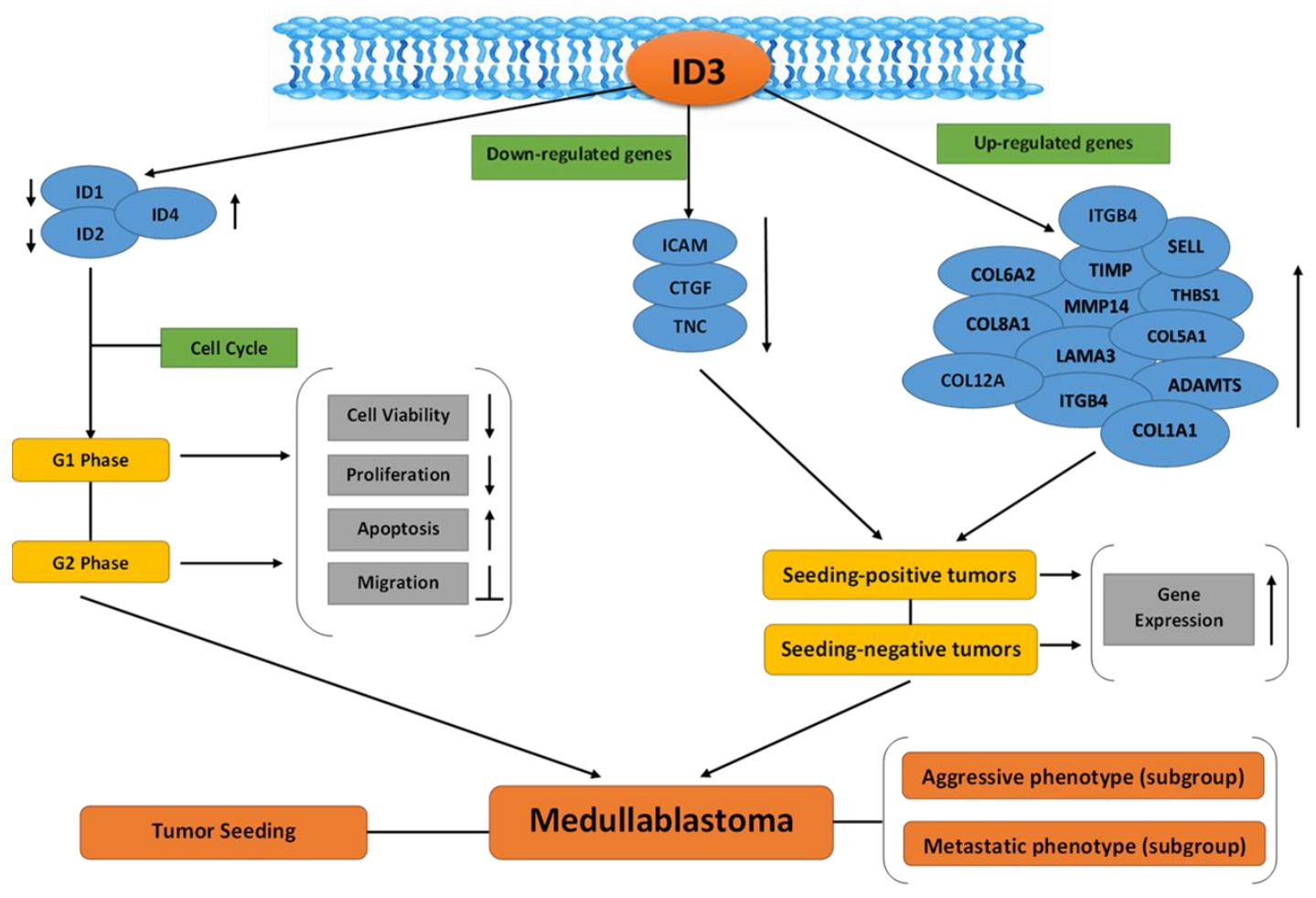

Figure 1.8 ID3 and brain cancer mechanisms. Signaling pathways of ID3 involved in brain cancer are summarized in the illustration.

Bone Disease. Osteogenesis imperfecta $(\mathrm{OI})$ is a condition of fragile or brittle bones that break easily. Ol affects 1 in 15,000 live births resulting in recurrent fractures and reduced mobility, with significant influence on quality of life (Balasubramanian et al. 2016). BMPs (bone morphogenetic proteins) are 
morphogenetic signaling molecules vital for embryonic modelling. To find molecular understanding into the effect of BMPs on morphogenesis, Hollnagel et al examined novel genes directly activated by BMP signaling. CDM (chemically distinct growth medium)-cultured ES cells reacted very stringently to stimulation by numerous activin $A$, mesoderm inducers (BMP2/4), as well as fibroblast growth factor (Hollnagel et al. 1999). Using cDNA cloning, six BMP target genes were recognized. These include ID3, which exhibited convincing mRNA initiation, and the relatively stimulated Cyr61, DEK, and elF4All genes, as well as a gene translating a GC-binding protein. Alongside ID1, ID2, and ID3 genes were initiated by BMP4 in both ES cells and arrangement of various cell lines. ID genes encode negative regulators of basic helix-loop-helix transcription factors. In vivo, ectopic expression was observed of ID3 and Msx-2 mRNAs in Ft/1 embryos at intersecting regions of ectopic Bmp4 misexpression. As a result, Hollnagel et al proposed that the target genes of BMP4 signaling demonstrated here are part of BMP-stimulated initial processes of mammalian development. The expression arrangements of Msx-1, Msx-2, c-jun, ID1, ID2, and ID3 in normal mice versus those lacking in BMP2, BMP4, and BMP2/4-type I receptor will be of distinctive interest to compare. The promoters of the genes recognized in the analysis will aid as valuable tools to illustrate the molecular governing circuits that are overseen by BMP signaling (Hollnagel et al. 1999).

ID proteins, including ID1, ID2, and ID3, are involved with essential binding factor $\alpha-1$ (Cbfa1) to trigger debilitated transcription of the osteocalcin $(\mathrm{OCL})$ and alkaline phosphatase (ALP) gene, commanding to weakened ALP 
action and osteocalcin (OCL) production. ID acts by hindering the specificsequence binding of Cbfa1 to DNA and diminishing the expression of Cbfa1 in cells experiencing osteogenic differentiation (Luan et al. 2008). Summary illustration of ID3 signaling in OI or brittle bone disease shown in Figure 6. p204, an interferoninducible protein that acts with both Cbfa1 and ID2, debilitated the ID2-mediated inhibition of Cbfa1-induced ALP action and OCL production. Luan et al establish that p204 interrupted the binding of ID2 to Cbfa1 and facilitated Cbfa1 to bind to the promoters of its target genes. Furthermore p204 stimulated the translocation from nucleus to the cytoplasm and enhanced the degradation of ID2 by ubiquitinproteasome pathway during osteogenesis. Nucleus export signal (NES) of p204 is necessary for the p204-enhanced cytoplasmic translocation and degradation of ID2, since a p204 mutant-requiring NES lost these activities. Taken together, ID 
proteins help to shape a regulatory circuit and take part to control osteoblast differentiation (Luan et al. 2008).

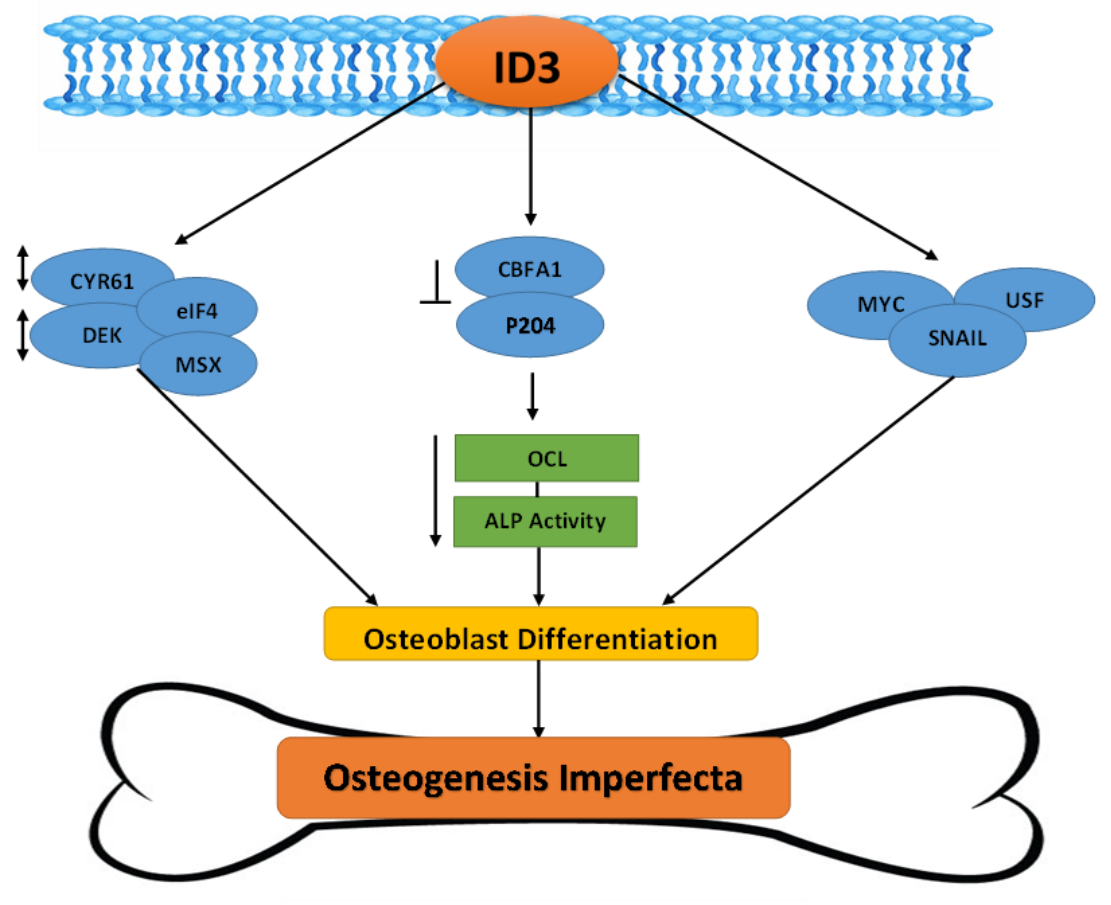

Figure 1.9 ID3 involvement in brittle bone disease pathogenesis. ID3 regulates various genes leading to osteoblast differentiation, which can contribute to osteogenesis imperfecta as described in the summary illustration.

ID1 and ID3 function to regulate bone metabolism in vivo (Maeda et al. 2004). ID1/ID3 heterozygous knock out mice, showed that the thickness of calvarial junctions was attenuated by more than 50\% (Maeda et al. 2004). Suppression of proliferation and mineralization in osteoblasts resultant from ID1/ID3 heterozygous knock out mice was proposed as a mechanism. Moreover, ID1/ID3 heterozygous knock out mice inhibited BMP-stimulated bone development in-vivo. Hence, ID1 and ID3 are critical regulators that support bone formation in vivo (Maeda et al. 2004). 
The connection between mechanisms of MetS and bone mineral density (BMD) is controversial (Muhlen et al. 2007). Muhlen et al examined the association of MetS with osteoporosis, osteoporotic fractures, and BMD. MetS was associated with decreased, not increased BMD. Frequency of osteoporotic non-vertebral breakages was greater in members with MetS. MetS may be an additional risk factor for osteoporotic fractures (Muhlen et al. 2007). Occurrence of MetS at reference was $23.5 \%$ in men and $18.2 \%$ in women. Age-adjusted analyses demonstrated in both men and women with MetS had increased BMD at total hip when compared to those without MetS $(p<0.001$ and $p=0.01$, respectively). Men not women with MetS furthermore had greater BMD at femoral neck $(p=0.05)$. Subsequently modifying for BMI, these connections were inverted, such that MetS was linked with decreased and not increased BMD. Occurrence of osteoporotic non-vertebral breakages was increased in participants with MetS. The connection of MetS with increased BMD was explained by the increased BMI in those with MetS (Muhlen et al. 2007).

Autoimmune Diseases. MetS has been involved in autoimmune diseases. One particular autoimmune disease is Primary Sjögren's syndrome (pSS), which is primarily categorized by inflammatory association of the exocrine glands important to dry eye and mouth. Numerous organ systems can be disturbed which can cause a wide variety of extra-glandular indicators, such as small airway disorders, multiple sclerosis-like disease, peripheral neuropathy glomerulonephritis, and lymphoma (Maeda et al. 2004). pSS predominately affects females (9:1), with a 
frequency in the overall population from 0.1 to $0.6 \%$. Studies evaluating patients with rheumatoid arthritis (RA) (Sakurai et al. 2004) and systemic lupus erythematosus (SLE) (Sinicato et al. 2013) have shown that inflammation plays a role in the progression of hypertension, diabetes mellitus, and MetS (Pereira et al. 2009).

The ID3 gene is involved in the growth and function of B and T cells. Deficient ID3 mice develop autoimmune disease comparable to human Sjögren's syndrome (pSS). Together B and T lymphocytes have been involved to contribute to the disease phenotype in this model (Guo et al. 2011). The up-regulation of ID1 and ID3 genes has been reported in patients with rheumatoid arthritis (RA) (Sakurai et al. 2001). Elevated expression of ID1 and ID3 in endothelial cells has been proposed to contribute to severe angiogenesis found in RA.

\section{Conclusion}

We have comprehensively reviewed the existing evidence to illustrate the association between ID3 and metabolic perturbations. Furthermore, we extended this understanding of how ID3 and metabolic perturbations by environmental factors such as EDCs can modify chronic disease risk and health outcomes. ID3 has been seen to interact with multiple diseases such as cancer, vascular, neurological, autoimmune, \& bone. Epidemiological and animal model studies have shown connections between ID3 and metabolic perturbations in chronic disease. Research is warranted to better define the influence of EDCs to ID3induced metabolic perturbations. This may lead to novel pathways for how the 
interaction of ID3, EDCs, and metabolic disorders exacerbate complex chronic disease; and can help public health professionals control these metabolic disorders.

References:

1. Felty $Q$, Porther N. Estrogen-induced redox sensitive Id3 signaling controls the growth of vascular cells. Atherosclerosis. 2008; 198(1): 12-21.

2. Sakurai D, Tsuchiya N, Yamaguchi A, Okaji Y, Tsuno NN, Kobata T, Takahashi $\mathrm{K}$. Crucial role of inhibitor of DNA binding/differentiation in the vascular endothelial growth factor-induced activation and angiogenic processes of human endothelial cells. Journal of Immunology. 2004; 173(9): 5801-5809.

3. Eelen G, de Zeeuw P, Simons M, Carmeliet P. Endothelial Cell Metabolism in Normal and Diseased Vasculature. Circulation Research. 2015; 116:1231-1244.

4. He Y, Y. Yao Y, Tsirka SE, Cao Y. Cell-Culture Models of the Blood-Brain Barrier. Stroke. 2014; 45(8): 2514-2526.

5. Cutchins A, Harmon DB, Kirby JL, Doran AC, Oldham SN, Skaflen M, Klibanov AL, Meller N, S. R. Keller, Garmey J, McNamara CA. Inhibitor of differentiation-3 mediates high fat diet-induced visceral fat expansion. Arteriosclerosis, Thrombosis and Vascular Biology. 2012; 32(2): 317-24.

6. Doran AC, Meller N, Cutchins A, H. Deliri H, R. P. Slayton RP, Stephanie N. Oldham N, Kim JB, Keller SR, McNamara CA. The Helix-Loop-Helix Factors Id3 and E47 are Novel Regulators of Adiponectin. Circulation Research. 2008; 103(6): 624-634.

7. Hatch EE, Nelson JW, Stahlhut RW, Webster TF. Association of endocrine disruptors and obesity: perspectives from epidemiological studies. International Journal of Andrology. 2010; 33 (2): 324-32.

8. Swedenborg E, Rüegg J, Mäkelä S, Pongratz I. Endocrine disruptive chemicals: mechanisms of action and involvement in metabolic disorders. Journal of Molecular Endocrinology. 2003; 43, 1-10.

9. Casals-Casas C, Desvergne B. Endocrine Disruptors: From Endocrine to Metabolic Disruption. Annual Review of Physiology. 73:135-62, 2011.

10. Das JK, Felty Q. PCB153-Induced Overexpression of ID3 Contributes to the Development of Microvascular Lesions. PLoS One. 2014; 9(8):e104159. 
11. Felty Q. Proteomic 2-D DIGE profiling of human vascular endothelial cells exposed to environmentally relevant concentration of endocrine disruptor PCB153 and physiological concentration of 17ß-estradiol. Cell Biology and Toxicology. 2011; 27(1): 49-68.

12. Lyden D, Young AZ, Zagzag D, Yan W, Gerald W, O'Reilly R, Bader BL, Hynes $\mathrm{RO}, \mathrm{Y}$. Zhuang, K. Manova, R. Benezra. Id1 and Id3 are required for neurogenesis, angiogenesis and vascularization of tumour xenografts. Nature. 1999; (6754): 670677.

13. Yang J, Li X, Morrell NW. Id proteins in the vasculature: from molecular biology to cardiopulmonary medicine. Cardiovascular Research. 2014; 104(3): 388-398.

14. Lasorella A, Benezra R, Lavarone A. The ID proteins: master regulators of cancer stem cells and tumour aggressiveness. Nature Reviews Cancer, 2014; 14, 77-91.

15. Pan L, Sato S, Frederick JP, Sun XH, Zhuang Y. Impaired Immune Responses and B-Cell Proliferation in Mice Lacking the Id3 Gene. Molecular and Cellular Biology. 1999; 19(9): 5969-5980.

16. Poulsen P, Vaag A, Kyvik K, Beck-Nielsen H. Genetic versus environmental etiology of the metabolic syndrome among male and female twins. Diabetologia. 2001; 44(5): 537-43.

17. Fraidenraich D, Stillwell E, Romero E, Wilkes D, Manova K, Basson CT, Benezra R. Rescue of cardiac defects in id knockout embryos by injection of embryonic stem cells. Science. 2004; 306 (5694): 247-52.

18. Lim RWS, Wu JM. Molecular mechanisms regulating expression and function of transcription regulator inhibitor of differentiation 3. Acta Pharmacologica Sinica. 2005; 26, 1409-1420.

19. Lasorella A, Uo T, Lavarone A. Id proteins at the cross-road of development and cancer. Oncogene 2001; 20(58):8326-33.

20. Das JK, Felty Q. Microvascular Lesions by Estrogen-Induced ID3: Its Implications in Cerebral and Cardiorenal Vascular Disease. Journal of Molecular Neuroscience. 2015, 55 (3); 618-31.

21. Loveys DA, Streiff MB, Kato GJ. E2A Basic-Helix-Loop-Helix Transcription Factors are Negatively Regulated by Serum Growth Factors and by the Id3 Protein. Nucleic Acids Research. 1996; (14): 2813-2820.

22. Liu Y, Encinas M, Comella JX, Aldea M, Gallego C. Basic helix-loop-helix proteins bind to TrkB and p21(Cip1) promoters linking differentiation and cell cycle 
arrest in neuroblastoma cells. Molecular and Cellular Biology. 2004; 24(7): 266272.

23. Sherr CJ, Roberts JM. Inhibitors of mammalian G1 cycling-dependent kinases. Genes \& Development. 1995; 9(10): 1149-63.

24. Forrest $S$, McNamara $C$. Id family of transcription factors and vascular lesion formation. Arteriosclerosis, Thrombosis, and Vascular Biology. 2004; 24(11): 2014-20.

25. Taylor AM, Li F, Thimmalapura P, Gerrity RG, Sarembock IJ, Forrest S, Rutherford S, McNamara CA. Hyperlipemia and oxidation of LDL induce vascular smooth muscle cell growth: an effect mediated by the HLH factor Id3. Journal of Vascular Research. 2006; 43(2): 123-30, 2006.

26. Langlands K, Yin X, Anand G, Prochownik EV. Differential interactions of Id proteins with basic-helix-loop-helix transcription factors. Journal of Biological Chemistry. 1997; 272 (32):19785-93.

27. Das JK, Voelkel NF, Felty Q. ID3 contributes to the acquisition of molecular stem cell-like signature in microvascular endothelial cells: its implication for understanding microvascular diseases. Microvascular Research. 2015; 98:126-38.

28. Ji Y, Pos Z, Rao M, Klebanoff CA, Yu Z, Sukumar M, Reger RN, Palmer DC, Borman ZA, Muranski P, Wang E, Schrump DS, Marincola FM, Restifo NP, Gattinoni GL. Repression of the DNA-binding inhibitor Id3 by Blimp-1 limits the formation of memory CD8+ T cells. Nature Immunology. 2011; (12): 1230-1237.

29. Zhang X, Ling MT, Wang Q, Lau CK, Leung SC, Lee TK, Cheung AL, Wong $Y C$, Wang $X$. Identification of a novel inhibitor of differentiation-1 (ID-1) binding partner, caveolin-1, and its role in epithelial-mesenchymal transition and resistance to apoptosis in prostate cancer cells. Journal of Biological Chemistry. 2007; 282(46): 33284-94.

30. Arita Y, Kihara S, Ouchi N, Takahashi M, Maeda K, Miyagawa J, Hotta K, Shimomura I, Nakamura T, Miyaoka K, Kuriyama H, Nishida M, Yamashita S, Okubo K, Matsubara K, Muraguchi M, Ohmoto Y, Funahashi T, Matsuzawa Y. Paradoxical decrease of an adipose-specific protein, adiponectin, in obesity. Biochemical and Biophysical Research Communications. 1999; 257(1): 79-83.

31. Steinberg GR, B. E. Kemp BE. AMPK in Health and Disease. Physiological Review. 2009; 89: 1025-1078.

32. Wice BM, Bernal-Mizrachi E, Permutt MA. Glucose and other insulin secretagogues induce, rather than inhibit, expression of Id-1 and Id-3 in pancreatic islet beta cells. Diabetologia. 2001; 44: 453-463. 
33. Lee SH, Hao E, Levine F, Itkin-Ansari P. Id3 upregulates BrdU incorporation associated with a DNA damage response, not replication, in human pancreatic $\beta$ cells. Islets. 2011; 3(6): 358-366.

34. Ford ES, Giles WH, Dietz WH. Prevalence of the metabolic syndrome among US adults: findings from the third National Health and Nutrition Examination Survey. JAMA. 2002; 287(3): 356-9.

35. Edwardson CL, Gorely T, Davies MJ, Gray LJ, Khunti K, Wilmot EG, Yates T, Biddle SJ. Association of sedentary behavior with metabolic syndrome: a metaanalysis. PLoS One. 2012; 7(4): e34916.

36. Malik VS, Popkin BM, Bray GA, Després JP, Willett WC, Hu FB. Sugarsweetened beverages and risk of metabolic syndrome and type 2 diabetes: a meta-analysis. Diabetes Care. 2010; 33(11): 2477-83.

37. Pollex RL, Hegele RA. Genetic determinants of the metabolic syndrome. Nature Clinical Practice Cardiovascular Medicine. 2006; 3(9): 482-9.

38. Kapla JL, Marshall MA, McSkimming CC, Harmon DB, Garmey JC, Oldham $\mathrm{SN}$, Hallowell P, McNamara CA. Adipocyte progenitor cells initiate monocyte chemoattractant protein-1-mediated macrophage accumulation in visceral adipose tissue. Molecular Metabolism. 2015; 4(11): 779-794.

39. Panee J. Monocyte Chemoattractant Protein 1 (MCP-1) in Obesity and Diabetes. Cytokine. 2012; 60(1): 1-12.

40. Jin X, Yin J, Kim SH, Sohn YW, Beck S, Lim YC, Nam DH, Choi YJ, Kim H. EGFR-AKT-Smad signaling promotes formation of glioma stem-like cells and tumor angiogenesis by ID3-driven cytokine induction," Cancer Research. 2011; 71(22):7125-34.

41. Perry HM, Oldham SN, Fahl SP, Que X, Gonen A, Harmon DB, Tsimikas S, Witztum JL, Bender TP, McNamara CA. Helix-loop-helix factor inhibitor of differentiation 3 regulates interleukin-5 expression and B-1a B cell proliferation. Arteriosclerosis, Thrombosis, and Vascular Biology. 2012; 33(12):2771-9.

42. Kuo PL, Hung JY, Huang SK, Chou SH, Cheng DE, Jong YJ, Hung CH, Yang CJ, Tsai YM, Hsu YL, Huang MS. Lung cancer-derived galectin-1 mediates dendritic cell anergy through inhibitor of DNA 3/IL-10 signaling pathway. Journal of Immunology. 2011; 186(3):1521-30.

43. Mueller C, Baudler S, Welzel H, Bohm M, Nickenig G. Identification of a Novel Redox-Sensitive Gene, Id3, Which Mediates Angiotensin II-Induced Cell Growth. Circulation. 2002; 105: 2423-2428. 
44. Mattingly CJ, Colby GT, Rosenstein MC, Forrest Jr JN, Boyer JL. Promoting comparative molecular studies in environmental health research: an overview of the comparative toxicogenomics database (CTD). The Pharmacogenomics Journal. 2004 4, 5-8.

45. X. Jin, X. Jin, Y. W. Sohn, Yin J, S. H. Kim, K. Joshi, D. H. Nam, I. Nakano, H. Kim. Blockade of EGFR signaling promotes glioma stem-like cell invasiveness by abolishing ID3-mediated inhibition of p27KIP1 and MMP3 expression. Cancer Letters, Volume 328, Issue 2, pages 235-242, 2013.

46. Kirkley AG, Sargis RM. Environmental Endocrine Disruption of Energy Metabolism and Cardiovascular Risk. Current Diabetes Reports. 2014; 14 (6): 494.

47. Aremma F, D'Esposito V, Liquoro D, Oriente F, Cabaro S, Liotti A, Cimmino I, Longo M, Bequinot F, Formisano P, Valentino R. Low-Dose Bisphenol-A Impairs Adipogenesis and Generates Dysfunctional 3T3-L1 Adipocytes. Plos One. 2016; 11(3):e0150762.

48. Savastano S, Taratino G, D'Esposito V, Passaretti F, Cabaro S, Liotti A, Liquoro D, Perruolo G, Ariemma F, Finelli C, Bequinot F, Formisano P, Valentino $R$. Bisphenol-A plasma levels are related to inflammatory markers, visceral obesity and insulin-resistance: a cross-sectional study on adult male population. Journal of Translational Medicine. 2015; 13:169.

49. Uemura H, Arisawa K, Hiyoshi M, A. Kitayama A, H. Takami H, F. Sawachika F, Dakeshita S, Nii K, Satoh H, Sumiyoshi Y, Morinaga K, Kodama K, Suzuki T, Nagai M, Suzuki T. Prevalence of metabolic syndrome associated with body burden levels of dioxin and related compounds among Japan's general population," Environmental Health Perspectives. 2009; 117(4): 568-73.

50. Wahlang B, Falkner KC, Gregory B, Ansert D, Young D, Conklin DJ, Bhatnagar A, McClain CJ, Cave M. Polychlorinated biphenyl 153 is a diet-dependent obesogen that worsens nonalcoholic fatty liver disease in male C57BL6/J mice. Journal of Nutritional Biochemistry. 2013; 24(9): 1587-95.

51. Gronning LM, Tingsabadh R, Hardy K, Dalen KT, Jat PS, Gnudi L, Shepherd PR. Glucose induces increases in levels of the transcriptional repressor Id2 via the hexosamine pathway. American Journal of Physiology Endocrinology Metabolism. 2006; 290(4): E599-E606.

52. Bitman J, Cecil HC. Estrogenic activity of DDT analogs and polychlorinated biphenyls. Journal of Agricultural Food Chemistry. 1970; 18 (6): 1108-12.

53. Davey JC, Bodwell JE, Gosse JA, Hamilton JW. Arsenic as an endocrine disruptor: effects of arsenic on estrogen receptor-mediated gene expression in vivo and in cell culture," Toxicological Sciences. 2007; 98(1):75-86. 
54. Meek, MD, Finch GL. Diluted mainstream cigarette smoke condensates activate estrogen receptor and aryl hydrocarbon receptor-mediated gene transcription. Environmental Research. 1999; 80(1): 9-17. 17.

55. Tavolari S, Bucci L, Tomasi V, Guarnieri T. Selected polychlorobiphenyls congeners bind to estrogen receptor alpha in human umbilical vascular endothelial (HUVE) cells modulating angiogenesis. Toxicology. 2006; 218(1): 67.

56. Wada T, Gao J, W. Xie W. PXR and CAR in energy metabolism. Trends in Endocrinology \& Metabolism. 2009; (6):273-9.

57. Goncharov A, Pavuk M, Foushee HR, Carpenter DO. Blood Pressure in Relation to Concentrations of PCB Congeners and Chlorinated Pesticides. Environmental Health Perspectives. 2011; 119 (3):319-25.

58. Hay A, Tarrel J. Mortality of power workers exposed to phenoxy herbicides and polychlorinated biphenyls in waste transformer oil. Annals of the New York Academy of Sciences. 1997; 837:138-156.

59. Gustavsson P, Hogstedt C. A cohort study of Swedish capacitor manufacturing workers exposed to polychlorinated biphenyls (PCBs). American Journal of Industrial Medicine. 1997; 32(3): 234-239.

60. Sergeev AV, Carpenter DO. Hospitalization rates for coronary heart disease in relation to residence near areas contaminated with persistent organic pollutants and other pollutants. Environmental Health Perspectives. 2005; 113(6):756-761.

61. Tokunaga S, Kataoka K. A longitudinal analysis on the association of serum lipids and lipoproteins concentrations with blood polychlorinated biphenyls level in chronic "Yusho" patients," Fukuoka Igaku Zasshi. 2003; 94(5):110-7.

62. Amanchy R, Periaswamy B, Mathivanan S, Reddy R, Tattikota SG, Pandey A. A compendium of curated phosphorylation-based substrate and binding motifs. Nature Biotechnology. 2007; 25, 285-286.

63. S. K. Chakrabarti SK, B. K. Cole BK, Y. Wen Y, S. R. Keller SR, J. L. Nadler JL. 12/15-lipoxygenase products induce inflammation and impair insulin signaling in 3T3-L1 adipocytes. Obesity. 2009; (9):1657-63.

64. Taylor AM, Hanchett R, Natarajan R, Hedrick CC, Forrest S, Nadler JL, McNamara CA. The effects of leukocyte-type 12/15-lipoxgenase on Id3-mediated vascular smooth muscle cell growth. Arteriosclerosis, Thrombosis, and Vascular Biology. 2005; 25(10):2069-74.

65. Doran AC, Lehtinen AB, Meller N, Lipinski MJ, Slayton RP et al. Id3 is a novel atheroprotective factor containing a functionally significant single-nucleotide 
polymorphism associated with intima-media thickness in humans. Circular Research. 2010; 106: 1303-1311.

66. Manichaikul A, Rich SS, Perry H, Yeboah J, Law M et al. A Functionally Significant Polymorphism in ID3 Is Associated with Human Coronary Pathology. PLOS ONE. 2014; 9(3): e90222.

67. Yang J, Li X, Li Y, Southwood M, Ye L, Long L, Al-Lamki RS, Morrell NW. Id proteins are critical downstream effectors of BMP signaling in human pulmonary arterial smooth muscle cells. American Journal of Physiology Lung Cellular Molecular Physiology. 2013; 305:L312-L321.

68. Owens III AP. Angiotensin II Induction of Regional Effects in Murine Vasculature. University of Kentucky Doctoral Dissertations. 2009; 683, 2009.

69. Kim JH, Peacock MR, George SC, Hughes CCW. BMP9 induces EphrinB2 expression in endothelial cells through an Alk1-BMPRII/ActRII-ID1/ID3-dependent pathway: implications for hereditary hemorrhagic telangiectasia type II. Angiogenesis. 2012; Volume 15, Issue 3, pp 497-509.

70. O'Brien CA, Kreso A, Ryan P, Hermans KG, Gibson L, Wang Y et al. ID1 and ID3 regulate the self-renewal capacity of human colon cancer-initiating cells through p21. Cancer Cell. 2012; 21:777-792, 2012.

71. Solozobova V, Wyvekens NN, Pruszak J. Lessons from the Embryonic Neural Stem Cell Niche for Neural Lineage Differentiation of Pluripotent Stem Cells. Stem Cell Review. 2012; Sep; 8(3): 813-829.

72. Montalvo-Ortiz JL, Bordner KA, Carlyle BC, J. Gelernter J, Simen AA, J. Kaufman J. The role of genes involved in stress, neural plasticity, and brain circuitry in depressive phenotypes: Convergent findings in a mouse model of neglect. Behavioral Brain Research. 2016; 315:71-4.

73. Campos-Peña $V$, Toral-Rios D, Becerril-Pérez F, Sánchez-Torres C, DelgadoNamorado Y, Torres-Ossorio E, Franco-Bocanegra D, Carvajal K. Metabolic Syndrome as a Risk Factor for Alzheimer's Disease: Is $A \beta$ a Crucial Factor in Both Pathologies? Antioxidants \& Redox Signal, 2017; 26 (10):542-560.

74. Weder N, Zhang H, Jensen K, Yang BZ, Simen A, Jackowski A, Lipschitz D, Douglas-Palumberi H, Ge M, Perepletchikova F, O'Laughlin K, Hudziak JJ, Gelernter J, Kaufman J. Child Abuse, Depression, and Methylation in Genes Involved with Stress, Neural Plasticity, and Brain Circuitry. Journal of the American Academy of Child \& Adolescent Psychiatry. 2014; (4): 417-24.e5, 2014.

75. Sarachana Zhou TR, Chen G, Manji HK, Hu VW. Investigation of posttranscriptional gene regulatory networks associated with autism spectrum 
disorders by microRNA expression profiling of lymphoblastoid cell lines. Genome Medicine. 2010; 2(4):23.

76. Peddada S, Yasui DH, LaSalle JM. Inhibitors of differentiation (ID1, ID2, ID3 and ID4) genes are neuronal targets of MeCP2 that are elevated in Rett syndrome. Human Molecular Genetics. 2006; 15(12): 2003-14.

77. Rossignol DA, Genuis SJ, Frye RE. Environmental toxicants and autism spectrum disorders: a systematic review. Translational Psychiatry. 2014; 4(2): e360.

78. Heilbrun LP, Palmer RF, Jaen CR, Svoboda MD, Perkins J, Miller CS. Maternal Chemical and Drug Intolerances: Potential Risk Factors for Autism and Attention Deficit Hyperactivity Disorder (ADHD). Journal of the American Board of Family Medicine. 2015; vol. 28, no 4, 461-470.

79. Chen YC, Yu ML, Rogan WJ, Gladen BC, Hsu CC. A 6-year follow-up of behavior and activity disorders in the Taiwan Yu-cheng children. American Journal of Public Health. 1994; 84(3):415-21.

80. Endocrine Disruptors, Environmental Health Topics, NIH National Institute of Environmental Health Sciences, http://www.niehs.nih.gov/.

81. Shanahan CE, Spak SN, Martinez A, Hornbuckle KC. Inventory of PCBs in Chicago and Opportunities for Reduction in Airborne Emissions and Human Exposure. Environmental Science Technology. 2015; (23): 13878-13888.

82. Genc S, Zadeoglulari Z, Fuss SH, Genc K. The Adverse Effects of Air Pollution on the Nervous System. Journal of Toxicology. 2012; Volume 2012, Article ID 782462, 23 pages.

83. Kundakovic M, Gudsnuk K, Herbstman JB, Tang D, Perera FP, Champagnea FA. DNA methylation of BDNF as a biomarker of early-life adversity. Proceedings of the National Academy of Sciences of the United States of America. 2015; 112(22): 6807-6813.

84. Perera F, Herbstman J. Prenatal environmental exposures, epigenetics, and disease. Reproductive Toxicology. 2011; (3): 363-373.

85. Tenger $\mathrm{C}$, Zhou Z. Apolipoprotein $\mathrm{E}$ modulates immune activation by acting on the antigen-presenting cell. Immunology. 2003; 109(3): 392-7.

86. Lynn DJ, Chan C, Naseer M, Yau M, Lo R, Sribnaia A, G. Ring, J. Que, Wee K, Winsor GL, Laird MR, Breuer K, Foroushani AK, Brinkman FS, Hancock REW. Curating the innate immunity interactome. BMC Systematic Biology. 2010; 4:117. 
87. Nackiewicz D, Dey P, Szczerba B, Mohammad S, Kaplan JL, McNamara CA, Deshmukh US, H. Bagavant $\mathrm{H}$. Inhibitor of differentiation 3, a transcription factor, regulates hyperlipidemia-associated kidney disease. Nephron Experimental Nephrology. 2014; 126(3): 141-7.

88. Zhao Q, Chang C, Gonzalez JP, Alzahrani K, Button JL, Fraidenraich D. Combined Id1 and Id3 Deletion Leads to Severe Erythropoietic Disturbances. PLOS ONE. 2016; 11(4): e0154480.

89. Liu JH, Lin ST, Hsu CY, Lin HH, Liang CC, Sung FC, Huang CC. The risk for chronic kidney disease in patients with heart diseases: a 7-year follow-up in a cohort study in Taiwan. BMC Nephrology. 2012; 13:77.

90. Declèves AE, Mathew AV, Cunard R, Sharma K. AMPK mediates the initiation of kidney disease induced by a high-fat diet. Journal of the American Society of Nephrology. 2011; 22:1846-1855.

91. J.K. Keller, Molecular Cellular Regulation of Hematopoiesis, National Cancer Institute Division of Basic Sciences, http://grantome.com/grant/NIH/ZIABC010001-17.

92. Castanon E, Bosch-Barrera J, Lopez I, Collado V, Moreno M, Lopez-Picazo JM, L. Arbea L, Lozano MD, Calvo A, Gil-Bazo I. ID1 and ID3 co-expression correlates with clinical outcome in stage III-N2 non-small cell lung cancer patients treated with definite chemoradiotherapy. Journal of Translational Medicine. 2013; 11:13.

93. Bao S, Wu W, McLendon RE, Hao Y, Shi Q, Hjelmeland AB, Dewhirst MW, Bigne DD, Rich JN. Glioma stem cells promote radioresistance by preferential activation of the DNA damage response. Nature. 2006; 444 (7120) 756-760.

94. Chalmers AJ. Radioresistant glioma stem cells-therapeutic obstacle or promising target? DNA repair. 2007; 6(9) 1391-1394.

95. Nakano I, Kornblum HI. Brain tumor stem cells. Pediatric Research. 2006; 59, 54R-58R.

96. Phi JH, Choi A, Lim SH, Lee J, Wang KC, Park SH, Kim SK. ID3 contributes to cerebrospinal fluid seeding and poor prognosis in medulloblastoma," BMC Cancer. 2013; 13:291.

97. Esposito K, Chiodini P, Colao A, Lenzi A, Giugliano D. Metabolic Syndrome and Risk of Cancer," Diabetes Care. 2012; 35(11): 2402-2411.

98. Muhlen DV, Safii S, Jassal SK, Svartberg J, Barrett-Connor E. Associations between the metabolic syndrome and bone health in older men and women: the Rancho Bernardo Study. Osteoporosis International. 2007; 18:1337-1344. 
99. Balasubramanian M, Hurst J, Brown S, Bishop NJ, Arundel P, DeVile C, Pollitt $\mathrm{RC}$, Crooks L, Longman D, Caceres JF, Shackley F, Connolly S, Payne JH, Offiah AC, Hughes D, DDD Study, Parker MJ, Hide W, Skerry TM. Compound heterozygous variants in NBAS as a cause of atypical osteogenesis imperfect. Bone. 2016; 94:65-74.

100. Hollnagel A, Oehlmann V, Heymer J, Rüther U, Nordheim A. Id genes are direct targets of bone morphogenetic protein induction in embryonic stem cells," Journal of Biological Chemistry. 1999; 274(28): 19838-45.

101. Luan Y, Yu XP, Yang N, Frenkel S, Chen L, Liu CJ. Molecular Biology of the Cell. 2008; Vol. 19, 2113-2126.

102. Maeda Y, Tsuji K, Nifuji A, Noda M. Inhibitory helix-loop-helix transcription factors Id1/ld3 promote bone formation in vivo. Journal of Cellular Biochemistry. 2004; 93:337-344.

103. Sinicato NA, Da Silva Cardoso PA, Appenzeller S. Risk Factors in Cardiovascular Disease in Systemic Lupus Erythematosus. Current Cardiology Reviews. 2013; 9(1): 15-19.

104. Pereira RMR, De Carvalho JF, Bonfá E. Metabolic syndrome in rheumatological diseases. Autoimmunity Reviews. 2009; 8(5); 415-419.

105. Guo Z, Li H, Han M, Xu T, Wu X, Zhuang Y. Modeling Sjögren's Syndrome with Id3 Conditional Knockout Mice. Immunolgy Letters. 2011; 135(1-2): 34-42.

106. Sakurai D, Yamaguchi A, Tsuchiya N, Yamamoto Tokunaga K. Expression of ID family genes in the synovia from patients with rheumatoid arthritis. Biochemical Biophysical Research Communications. 2001; 284, 436-442.

107. Edhayan G, Ohara RA, Stinson AW, Amin MA, Isozaki T, Ha CM, Haines III GK, Morgan R, Campbell PL, Arbab AS, Friday SC, Fox DA, Ruth JH. Inflammatory properties of inhibitor of DNA binding 1 secreted by synovial fibroblasts in rheumatoid arthritis. Arthritis Research Therapy. 2016; (18): 87.

108. Pudata V, Jhansi K. Metabolic Syndrome in Endocrine System. Journal of Diabetes Metabolism 2011; 2: 163,

109. Svendstrup $M$, Vestergaard $H$. The potential role of inhibitor of differentiation3 in human adipose tissue remodeling and metabolic health. Molecular Genetics and Metabolism. 2014; 113, 149-154. 


\section{CHAPTER III}

\section{MANUSCRIPT 2}

Association of PCB exposure in Peripheral Arterial Disease (PAD) Among the U.S. Population: NHANES 1999-2004

Background. Peripheral arterial disease (PAD) is a subclinical hallmark of coronary artery disease and identifies asymptomatic individuals at high risk for cardiovascular disease events. Current reports have shown association with a number of chemicals suspected to act as endocrine disruptors (EDs) by emulating synthetic or natural estrogen resultant in an increase in disease risk such as cancer, cardiovascular \& vascular, and neuro-degenerative disorders. Polychlorinated biphenyls (PCBs) have been recognized as an endocrine disruptor due to their capability to affect \& interfere with reproductive function and development in animals and humans by increasing estrogen activity or blocking estrogen action. Recent animal studies have suggested that PCB exposure may have a role in several mechanisms involved in the development of CVD including oxidative stress, vascular \& endothelial dysfunction, weight gain, and insulin resistance. We conducted an Environmental-Wide Association Study (EWAS), in which epidemiological data are systematically and compressively interpreted in a method corresponding to a Genome Wide Association Study (GWAS).

Objectives. The purpose of this study is to examine association between exposure to PCBs \& peripheral arterial disease (PAD) in a nationally represented sample of the U.S. population. 
Methods. We utilized participants in the National Health and Nutritional Examination Survey (NHANES) 1999-2004. We estimated associations between exposure to polychlorinated biphenyls (PCBs) and PAD (ankle-brachial index < 0.9) using complex survey and logistic regression models adjusted for potential confounders.

Results. Analysis demonstrated higher geometric levels of all 6 PCB congeners in both PAD diagnosed participants and defined AS participants when compared to the rest of the population. Furthermore PCB153 was shown to have the highest geometric mean amongst all PCB congeners in both participants diagnosed with PAD (53.38 ng/g) and AS defined participants (38.66 ng/g). Furthermore adjusted models for PAD confounders (diabetes, smoking, \& alcohol use), with gender, age, and race showed significant association with higher exposure of PCBs and increased risk of PAD and AS.

Conclusion. Our results suggest an association between environmental exposure to polychlorinated biphenyls (PCBs) \& increased risk of peripheral arterial disease (PAD) and atherosclerosis (AS) among the U.S. population. Although the use of PCBs have been discontinued, exposure via the environment still remains to pose threats on the general population's health.

Key words: ankle-brachial index, endocrine disrupting chemicals, NHANES, peripheral arterial disease, polychlorinated biphenyls, vascular disease 


\section{Introduction}

Humans are exposed to a variety of environmental exposures and these exposures may interact with one another to modify health risk outcomes. The cardiovascular system is a significant target of these environmental exposures via genomic and non-genomic pathways (Chambliss et al., 2002). The estrogen receptor $(E R \alpha / \beta)$ has been shown in endothelial cells, human coronary arteries, and cardiomyocytes (Kim-Schulze et al., 1996; Yang et al., 2004). Peripheral arterial disease (PAD) can lead to lasting disability but general diagnosis of the disease frequently appears late in the process. The first nationally representative community survey done in the U.S. sponsored by the PAD coalition established $75 \%$ of respondents were unaware PAD existed and the remaining $25 \%$ knew minimal correct information (Hirsch et al., 2007). Previous studies reported an association between Bisphenol A (BPA), an endocrine disrupting chemical produced in very large volume ( $>2$ million metric tons manufactured globally in 2003) and used in the creation of polycarbonate plastics and containers used for

food and beverages (Vandenberg et al., 2009). Nevertheless, the association of other endocrine disrupting chemicals with cardiovascular disease risk has never been without debate.

One particular compound that has been known to show estrogenic-like attributes are polychlorinated biphenyls (PCBs). We previously demonstrated that planar and co-planar PCBs induce the expression of different genes compared to estradiol. Furthermore PCBs can promote vascular lesion formation by activating 
gene networks involved in endothelial cell adhesion, cell growth, and proinflammatory molecules which were dissimilar from natural estrogen. (Felty et al., 2010). Peripheral arterial disease (PAD) is a subclinical measure of atherosclerotic vascular disease (Newman et al. 1993) that is an independent predictor of following CVD incidence (Murabito et al. 2003; Newman et al. 1993). Criqui et al. (1992) reported that individuals among originally free of CVD, an ankle-brachial index $(\mathrm{ABI})$ of $<0.9$ was associated with a hazard ratio of 6.6 for future risk of death from coronary heart disease even after adjusting for cardiovascular risk factors including age, sex, body mass index (BMI), smoking, and high cholesterol levels. Guidelines (American Diabetes Association 2003; Hirsch et al. 2006) exist for defining PAD based on the ABI, which can be measured even in large populationbased studies (Selvin and Erlinger 2004).

In this study, we examined the independent association between 6 individual PCBs, the sum of non-dioxin-like PCBs, and the sum of dioxin-like-PCBs with diagnosis of peripheral arterial disease and participants defined with atherosclerosis in the NHANES (National Health and Nutrition Examination Survey) in three year cycles: $1999-2000,2001-2002$, and $2003-2004$. The aim of this study is to asses: 1) the mean PCB levels in PAD defined participants and atherosclerosis compared to non-diagnosed participants; and 2) the association between higher PCB exposure and increased risk of PAD/AS. 


\section{Methods}

Study design and population. The current study is based on data from NHANES 1999-2004. NHANES survey includes a stratified multistage probability sample representative of the civilian non-institutionalized U.S. population. Selection was based on counties, blocks, households, and individuals within households and included the oversampling of non-Hispanic blacks and Mexican Americans in order to provide stable estimates of these groups. Participants provided written informed consent before their participation. Furthermore approval was obtained from the Human Subjects Committee in the U.S. Department of Health and Human Services. Measurements of $A B I$, a subclinical measure of atherosclerosis (Criqui et al. 1992; Newman et al. 1993), were obtained for the subsample of participants $\geq 40$ years of age. The current study sample consisted of participants $\geq 40$ years of age among whom polychlorinated biphenyls was available. This resulted in participants (461), of whom had PAD and participants (390) whom were indicated as having atherosclerosis. Subjects who were excluded because of missing covariates were in general similar to the NHANES cohort in terms of age, sex, race/ethnicity, and education (data not shown). Secondary analysis of the nationally collected data was done using variables of interest, which were only measured concurrently during the three NHANES cycles from 1999-2000, 20012002, and 2003-2004. NHANES uses a multifaceted sampling design (multistage, probability, cluster and stratified) for continuous collection and release of 2-year cross-sectional data sets. Approval for these questionnaires, age, appropriate examinations and laboratory testing were given to NHANES by the CDC/ATSDR 
institutional review board of the CDC. The current study was considered exempt from review by the local institutional review board.

Peripheral Arterial Disease (PAD) identification. The NHANES ABI is routinely calculated by their computer system and verified by the National Center for Health Statistics before data release. Systolic pressure is measured on the right arm (brachial artery) and both ankles (posterior tibial arteries). If the participant has a rash or open wound on the right arm, dialysis shunt, right-sided radical mastectomy or any additional condition that would interfere with accurate measurement or cause discomfort to the participant, the left arm is used for the brachial pressure measurement. Systolic blood pressure is measured twice at each site for participants aged $40-59$ years and once at each site for participants aged 60 years and older. If a health technician is unable to acquire a reading at a site they may attempt an additional reading at the same site after a short-term resting period. The right $A B P I$ was obtained by dividing the mean systolic blood pressure in the right ankle by the mean blood pressure in the arm. The left ABPI was obtained by dividing the mean systolic blood pressure in the left ankle by the mean blood pressure in the arm. The mean blood pressure value for the arm and ankles are computed based on the first and second reading at each site. Since the second reading for all participants $60+$ years of age is missing the mean values are in fact the first recorded blood pressure reading at a site. This may also be true for 40-59 year old participants who have a missing value for the first or second blood pressure reading. Individuals are excluded from the exam if they have bilateral amputations or weigh over 400 pounds (due to equipment limitations). In addition 
to these exclusion criteria, some participants who were eligible for the exam (40 years of age and older) might not have received the exam due to various reasons: 1) casts, ulcers, dressings, or other conditions of the participant interfered with testing, 2) participant could not understand the test instructions, 3) participant became ill and the test could not be performed, 4) there was an equipment failure, 5) participant refused, 6) participant came late or left early from the MEC and the LED exam could not be performed, or 7) some other reason. As a result, these eligible individuals will have missing data for the ABPI variables. PAD was defined as an $\mathrm{ABI}<0.7$. Values $0.9<\mathrm{ABI}<1.3$ were considered normal. Measurements $0.7<\mathrm{ABI}<0.9$ were defined as indication of atherosclerosis as seen in Table 2.1.

$\begin{array}{ll}\text { ABI Value } & \text { Reading Interpretation } \\ A B I<0.7 & \text { Peripheral Arterial Disease (PAD) } \\ 0.7<\mathrm{ABI} & \\ <0.9 & \text { Atherosclerosis (AS) } \\ 0.9<\mathrm{ABI}< & \text { Normal } \\ 1.3 & \quad \text { Ankle-Brachial Index) }\end{array}$

Polychlorinated Biphenyl (PCBs) measurements. Individual PCB congeners were measured through blood serum concentration in a demonstrative, random one-third subsample of people 12 years of age older in three survey cycles: 1999 - 2000, 2001 - 2002, and 2003 - 2004. Each survey cycle sampled for various PCB congeners. NHANES sampled for 22 PCB congeners in the $1999-2000$ survey, 34 PCBs congeners in the 2001-2002 cycle, and 38 PCB congeners in the 2003-2004 cycle. PCB congeners were measured in blood serum by highresolution gas chromatography/isotope-dilution high-resolution mass spectrometry 
(HRGS/ID-HRMS). Both wet-weight and lipid adjusted values for each sample, corrected for sample weight and analyte recovery was provided by NHANES. However we used lipid adjusted values in our analysis. Results for PCBs are reported on a whole weight (ng/g or ppb) and a lipid-adjusted basis (ng/g or ppb). Laboratory methods were consistent between survey cycles and are fully available online (CDC 2013b). A detection limit variable (LOD) is specified for all PCB congeners in the dataset. The variable LOD has two numerical values: "1" designates that the results was below the limit of detection and "2" designates that the results was equal to or above the limit of detection. To account for bias with PCBs below the LOD, we selected 6 individual PCB congeners that were represented \& available from 1999 - 2004 and had concentrations above the LOD in at least $60 \%$ of the study subjects. The overall analysis explored the association between peripheral arterial disease variables in the U.S. population using the following 6 PCB congeners: 2,2',3,4,4,5,5'-heptachlorobiphenyl (PCB180), 2,2',4,4',5,5'-hexachlorobiphenyl (PCB153), 2,2',3,4,4',5-hexachlorobiphenyl (PCB138), 2,3',4,4',5- pentachlorobiphenyl (PCB118), 2,2'4,4',5pentachlorobiphenyl (PCB99), and 2,4,4',5 tetrachlorobiphenyl (PCB74). We also conducted analysis on the sum of dioxin-like PCBs (074 and 118) and non-dioxinlike PCBs $(099,138,153,180)$.

Covariates. We considered a variety of potential confounders based on wellestablished risk factors for peripheral arterial disease and review of the literature. The resulting potential confounders were either taken as a laboratory measurement or self-reported in the questionnaire interviews. The demographic 
variables of gender (male/female), race (Mexican American, Other Hispanic, NonHispanic White, Non-Hispanic Black, and other race) and age ( $\geq 40-59,60-74$, and $\geq 75$ ) were obtained during the NHANES home interview (CDC, 2012). Others obtained include: smoking, alcohol use (yes/no), BMI (18.5 to $<25,25$ to $<30$, $\geq$ 30), diabetes (yes/no), estradiol levels, sex hormone binding globulin, testosterone, education, and annual income.

Statistical Analysis. All statistical analysis were performed using SAS 9.4 (SAS Institute Inc., Cary, NC, USA). These analyses used $5 \%$ significance level ( $p \leq$ 0.05). We used logistic regression models to calculate odds ratios (ORs) and their $95 \% \mathrm{Cl}$ (confidence intervals) to investigate the risk between PCBs and peripheral arterial disease. According to the National Center for Health Statistics guides a six year subsample weight was calculated to adjust for oversampling of minority groups in the merged 1999-2004 NHANES data cycles (CDC 2013b). Non-missing values for serum concentrations below the LOD were assigned a serum level of the LOD divided by the square root of two. In our analysis, all lipid adjusted serum PCB concentrations were log transformed to satisfy normality assumptions. Participants were categorized as the following methods depending on data analysis: < LOD vs. $\geq$ LOD; < LOD to 50 th percentile vs. $\geq 50$ th percentile; and < LOD to 50 th percentile vs. 50 th percentile to 75 th percentile vs. $\geq 75$ th percentile. We also conducted separate analyses on all participants with serum PCB levels > LOD where PAD \& AS cases were compared with normal cases. Significance was set at $p<0.05$ for all analyses. 
We utilized survey means analysis (PROC SURVEYMEANS) to account for the complex sampling design of NHANES and to obtain weighted means, $95 \%$ confidence intervals, and standard errors of individual PCBs, the sum of dioxin-like PCBs, and the sum of non-dioxin-like PCBs. A two-sided student t-test was calculated using PROC SURVEYREG to test if the mean PCB levels between participants who were identified with PAD, AS, and normal participants were significantly different. Geometric mean (GM) PCB levels and geometric standard errors (GSE) were reported for peripheral arterial disease (PAD) status, atherosclerosis (AS) status, age at interview, and race/ethnicity for all participants with individual serum PCB levels. Computational mean serum levels of dioxin-like and non-dioxin-like PCBs and $95 \% \mathrm{Cls}$ were reported for PAD status and select confounding variables. Age was divided into three groups ( $\geq 40-59$ years, $60-74$ years, and $\geq 75$ years) that were selected based on the age distribution of PAD cases, AS cases, and normal cases in the population. Race/ethnicity was divided into five groups (Mexican American, other Hispanic, Non-Hispanic White, NonHispanic Black, and other race). We furthermore calculated both crude and age standardized GMs for PAD cases and non-cases in the population with PCB levels above the LOD. We used the direct technique for age adjustment provided by the CDC (CDC 2014).

\section{Results}

Descriptive Statistics. The study population includes 6,624 participants $\geq 40$ years of age. Among the 6,624 participants, 461 (6.96\%) were defined with PAD, $390(5.89 \%)$ for atherosclerosis (AS), \& $5773(87.15 \%)$ were defined as normal 
(Table 2.2). Participants were equally distributed among gender: males $-3,489$ $(49.77 \%)$ to females $-3,135(50.23 \%)$. The majority of the participants in each of the categories were predominantly Non-Hispanic White: 268 (3.72\%), 236 (4.90\%), and 3125 (69.64\%) respectively. Participants in age group 60-74 years old were over-represented with defined PAD (199) and $\geq 40-59$ years old with atherosclerosis (180). When asked if PAD identified participants ever smoked 72 (1.84\%) said "yes," 10 (0.24\%) said "sometimes," and 150 (3.68\%) said "no." Various hormone levels were also assessed. Estradiol levels between $5-95 \mathrm{pg} / \mathrm{mL}$ were overrepresented 21 (3.18\%) for participants with PAD; 31 (9.20\%) for participants defined with AS; and 323 (85.44\%) for normal participants. For sex hormone binding globulin (nmol/L) ranges from $0.350-90 \mathrm{nmol} / \mathrm{L}$ were most represented by the population: $20(2.88 \%)$ for PAD identified participants; 31 (9.31\%) for participants with AS; and 306 (82.69\%) normal participants. Lastly testosterone levels $(\mathrm{ng} / \mathrm{mL})$ were also assessed for the population. Measurement range from $0.020-9 \mathrm{ng} / \mathrm{mL}$ were overrepresented. Participants with PAD represented 22 (3.24\%) participants; AS participants with 32 (9.36\%); and 318 $(84.49 \%)$ for normal participants. 
Table 2.2 Descriptive statistics for PAD \& selected covariates among participants $\geq \mathbf{4 0}$ years of age, NHANES $1999-2004$.

\begin{tabular}{|c|c|c|c|}
\hline \multicolumn{4}{|l|}{ Variable } \\
\hline & $\mathrm{ABI}<0.7^{\star} \mathrm{n}(\%)$ & $0.7<\mathrm{ABI}<0.9^{\star} \mathrm{n}(\%)$ & $0.9<\mathrm{ABI}<1.3^{\star} \mathrm{n}(\%)$ \\
\hline Total Population n (\%) & $461(6.96 \%)$ & $390(5.888 \%)$ & $5773(87.152 \%)$ \\
\hline \multicolumn{4}{|l|}{ Gender } \\
\hline Male & $228(1.947 \%)$ & $275(3.9918 \%)$ & $2986(43.8267 \%)$ \\
\hline Female & $233(2.7315 \%)$ & $115(1.7774 \%)$ & $2787(45.7256 \%)$ \\
\hline \multicolumn{4}{|l|}{ Race/Ethnicity } \\
\hline Mexican American & $72(0.1567 \%)$ & $103(0.3131 \%)$ & $1231(4.1428 \%)$ \\
\hline Other Hispanic & $12(0.1152 \%)$ & $11(0.2016 \%)$ & $221(4.0714 \%)$ \\
\hline Non-Hispanic White & $268(3.7214 \%)$ & $236(4.894 \%)$ & $3125(69.6389 \%)$ \\
\hline Non-Hispanic Black & $100(0.5863 \%)$ & $31(0.1975 \%)$ & $1013(7.8865 \%)$ \\
\hline Other Race & $9(0.0989 \%)$ & $9(0.1622 \%)$ & $183(3.8127 \%)$ \\
\hline \multicolumn{4}{|l|}{ Age at interview (years) } \\
\hline$\geq 40-59$ & $67(1.1721 \%)$ & $180(3.7787 \%)$ & $3078(61.729 \%)$ \\
\hline $60-74$ & $199(2.0057 \%)$ & $155(1.5675 \%)$ & $1924(20.8257 \%)$ \\
\hline$\geq 75$ & $195(1.5007 \%)$ & $55(0.423 \%)$ & $771(6.9976 \%)$ \\
\hline \multicolumn{4}{|l|}{ Ever Smoked } \\
\hline Yes & $72(1.8416 \%)$ & $31(1.134 \%)$ & $764(30.244 \%)$ \\
\hline Sometimes & $10(0.2441 \%)$ & $10(0.2571 \%)$ & $117(3.9327 \%)$ \\
\hline No & $150(3.6785 \%)$ & $140(5.0162 \%)$ & $1493(53.6517 \%)$ \\
\hline \multicolumn{4}{|l|}{ Alcohol Use } \\
\hline Yes & $0(0.00 \%)$ & $2(0.0411 \%)$ & $24(0.5721 \%)$ \\
\hline No & $333(4.5564 \%)$ & $324(6.2234 \%)$ & $4415(88.6069 \%)$ \\
\hline \multicolumn{4}{|l|}{ BMI } \\
\hline Normal Weight $(18.5$ to $<25)$ & $105(1.3733 \%)$ & $86(1.7261 \%)$ & $1205(26.2679 \%)$ \\
\hline Overweight $(25$ to $<30)$ & $129(1.6091 \%)$ & $120(2.3676 \%)$ & $1755(34.4198 \%)$ \\
\hline Obese $(\geq 30)$ & $88(1.3574 \%)$ & $119(2.1868 \%)$ & $1450(28.692 \%)$ \\
\hline \multicolumn{4}{|l|}{ Diabetes } \\
\hline Yes & $81(0.9209 \%)$ & $46(0.5002 \%)$ & $520(7.4332 \%)$ \\
\hline No & $251(3.527 \%)$ & $283(5.6672 \%)$ & $3903(80.3218 \%)$ \\
\hline Boarderline & $9(0.1072 \%)$ & $3(0.0905 \%)$ & $84(1.3882 \%)$ \\
\hline Don't know & $0(0.00 \%)$ & $0(0.00 \%)$ & $2(0.0437 \%)$ \\
\hline \multicolumn{4}{|l|}{ Estradiol (pg/mL) } \\
\hline$<5$ & $1(0.0545 \%)$ & $1(0.1399 \%)$ & $4(1.1599 \%)$ \\
\hline May-95 & $21(3.1751 \%)$ & $31(9.1967 \%)$ & $323(85.4413 \%)$ \\
\hline $95-185$ & $1(0.0867 \%)$ & $0(0.00 \%)$ & $2(0.6376 \%)$ \\
\hline$>185$ & $0(0.00 \%)$ & $0(0.00 \%)$ & $1(0.1084 \%)$ \\
\hline \multicolumn{4}{|c|}{ Sex Hormone Binding Globulin (nmol/L) } \\
\hline $0.350-90$ & $20(2.8754 \%)$ & $31(9.3131 \%)$ & $306(82.6883 \%)$ \\
\hline $90-180$ & $2(0.3553 \%)$ & $1(0.0267 \%)$ & $21(4.3095 \%)$ \\
\hline$>180$ & $1(0.0867 \%)$ & $0(0.00 \%)$ & $2(0.3449 \%)$ \\
\hline
\end{tabular}




\begin{tabular}{|c|c|c|c|}
\hline \multicolumn{4}{|l|}{ Testostosterone (ng/mL) } \\
\hline $0.020-9$ & $22(3.2402 \%)$ & $32(9.3673 \%)$ & $318(84.4869 \%)$ \\
\hline 12-Sep & $0(0.00 \%)$ & $0(0.00 \%)$ & $8(2.5649 \%)$ \\
\hline$>12$ & $1(0.087 \%)$ & $0(0.00 \%)$ & $2(0.2538 \%)$ \\
\hline \multicolumn{4}{|l|}{ Education } \\
\hline$<9$ th Grade & $120(0.6988 \%)$ & $74(0.3937 \%)$ & $976(6.1832 \%)$ \\
\hline 9-11th Grade (Includes 12th grade with no diploma) & $76(0.7538 \%)$ & $45(0.5289 \%)$ & $860(10.5315 \%)$ \\
\hline High School Grad/GED or Equivalent & $117(1.4821 \%)$ & $65(1.1016 \%)$ & $1382(23.692 \%)$ \\
\hline Some College or AA degree & $91(1.0934 \%)$ & $103(1.7124 \%)$ & $1403(25.4172 \%)$ \\
\hline College Graduate or above & $54(0.6319 \%)$ & $102(2.0203 \%)$ & $1142(23.6305 \%)$ \\
\hline Refused & $0(0.00 \%)$ & $0(0.00 \%)$ & $3(0.0219 \%)$ \\
\hline Don't Know & $3(0.0186 \%)$ & $1(0.0124 \%)$ & $6(0.0757 \%)$ \\
\hline \multicolumn{4}{|l|}{ Income } \\
\hline$\$ 0$ to $\$ 4,999$ & $14(0.0897 \%)$ & $12(0.1544 \%)$ & $161(1.7935 \%)$ \\
\hline$\$ 5,000$ to $\$ 9,999$ & $56(0.4762 \%)$ & $22(0.1865 \%)$ & $378(4.1621 \%)$ \\
\hline$\$ 10,000$ to $\$ 14,999$ & $77(0.6941 \%)$ & $33(0.2147 \%)$ & $580(6.1557 \%)$ \\
\hline$\$ 15,000$ to $\$ 19,999$ & $55(0.4726 \%)$ & $22(0.1933 \%)$ & $459(5.1039 \%)$ \\
\hline$\$ 20,000$ to $\$ 24,999$ & $40(0.3538 \%)$ & $29(0.3374 \%)$ & $473(5.5343 \%)$ \\
\hline$\$ 25,000$ to $\$ 34,999$ & $67(0.7037 \%)$ & $35(0.5199 \%)$ & $670(9.4058 \%)$ \\
\hline$\$ 35,000$ to $\$ 44,999$ & $30(0.3397 \%)$ & $37(0.462 \%)$ & $524(8.463 \%)$ \\
\hline$\$ 45,000$ to $\$ 54,999$ & $27(0.3059 \%)$ & $32(0.4788 \%)$ & $458(8.3173 \%)$ \\
\hline$\$ 55,000$ to $\$ 64,999$ & $15(0.276 \%)$ & $21(0.379 \%)$ & $322(6.6019 \%)$ \\
\hline$\$ 65,000$ to $\$ 74,999$ & $10(0.1592 \%)$ & $22(0.3727 \%)$ & $253(5.1088 \%)$ \\
\hline$\$ 75,000$ and over & $25(0.3829 \%)$ & $93(2.0818 \%)$ & $995(22.9582 \%)$ \\
\hline Over $\$ 20,000$ & $19(0.3009 \%)$ & $14(0.2414 \%)$ & $194(3.2409 \%)$ \\
\hline Under $\$ 20,000$ & $9(0.0873 \%)$ & $7(0.0566 \%)$ & $99(1.1958 \%)$ \\
\hline Refused & $6(0.0394 \%)$ & $5(0.0464 \%)$ & $90(1.0123 \%)$ \\
\hline Don't know & $6(0.0238 \%)$ & $5(0.0711 \%)$ & $51(0.4455 \%)$ \\
\hline
\end{tabular}

Estimated percent distribution after applying NHANES sampling weights

${ }^{*} \mathrm{ABI}<0.7$ (PAD). $0.7<\mathrm{ABI}<0.9$ (AS), \& $0.9<\mathrm{ABI}<1.3$ (Normal)

Table 2.3 presents GMs and GSE of PCB concentrations (lipid-adjusted)

by PAD status, AS status, and normal status. GM PCB levels were demonstrated

as higher for all 6 PCB congeners for both participants defined with PAD as well

as participants identified with AS when compared to the normal population (Table

2.3). Overall GM levels of PCBs ranged from $13.47 \mathrm{ng} / \mathrm{g}$ (PCB074) being the

lowest and $53.38 \mathrm{ng} / \mathrm{g}$ (PCB153) being the highest in participants with PAD. 
Furthermore it was demonstrated that $6.19 \mathrm{ng} / \mathrm{g}$ (PCB099) and $38.66 \mathrm{ng} / \mathrm{g}$ (PCB153) were demonstrated as the lowest and highest GM levels in AS participants.

Table 2.3 Geometric Mean PCB levels ( $\mathrm{ng} / \mathrm{g}$ ) above the LOD by PAD status among participants $\geq 40$ years of age, NHANES 1999-2004.

\begin{tabular}{|l|c|c|c|c|c|c|}
\hline \multicolumn{3}{|c}{ Cases/Non-Cases } & \multicolumn{3}{c|}{ Geometric $\mathbf{M e a n}_{\mathbf{2}}(\mathbf{n g} \mathbf{g} \mathbf{g})(\mathbf{G S E})$} \\
\hline Analyte $_{1}$ & $\mathrm{ABI}<0.7^{*}$ & $0.7<\mathrm{ABI}<0.9^{*}$ & $0.9<\mathrm{ABI}<1.3^{*}$ & $\mathrm{ABI}<0.7$ & $0.7<\mathrm{ABI}<0.9$ & $0.9<\mathrm{ABI}<1.3$ \\
\hline PCB074 & 65 & 49 & 2871 & $13.47(8.80,20.61)$ & $8.82(7.15,10.88)$ & $7.82(7.54,8.11)$ \\
\hline PCB099 & 57 & 76 & 3767 & $9.95(7.078,14.00)$ & $6.19(5.35,7.16)$ & $5.70(5.53,5.87)$ \\
\hline PCB118 & 40 & 75 & 2866 & $15.02(8.94,25.24)$ & $10.53(8.20,13.52)$ & $8.90(8.56,9.26)$ \\
\hline PCB138 & 58 & 76 & 3794 & $37.05(28.04,48.97)$ & $25.18(20.48,30.96)$ & $19.79(19.11,20.49)$ \\
\hline PCB153 & 69 & 66 & 3803 & $53.38(40.68,70.04)$ & $38.66(30.64,48.78)$ & $27.68(26.70,28.70)$ \\
\hline PCB180 & 62 & 72 & 3800 & $42.13(33.00,53.78)$ & $31.11(23.84,40.60)$ & $20.50(19.71,21.31)$ \\
\hline
\end{tabular}

1 Lipid Adjusted and log transformed polychlorinated biphenyls (ng/g)

2 Geometric Means calculated after applying NHANES sampling weights

${ }^{*} \mathrm{ABI}<0.7$ (PAD). $0.7<\mathrm{ABI}<0.9$ (AS), \& $0.9<\mathrm{ABI}<1.3$ (Normal)

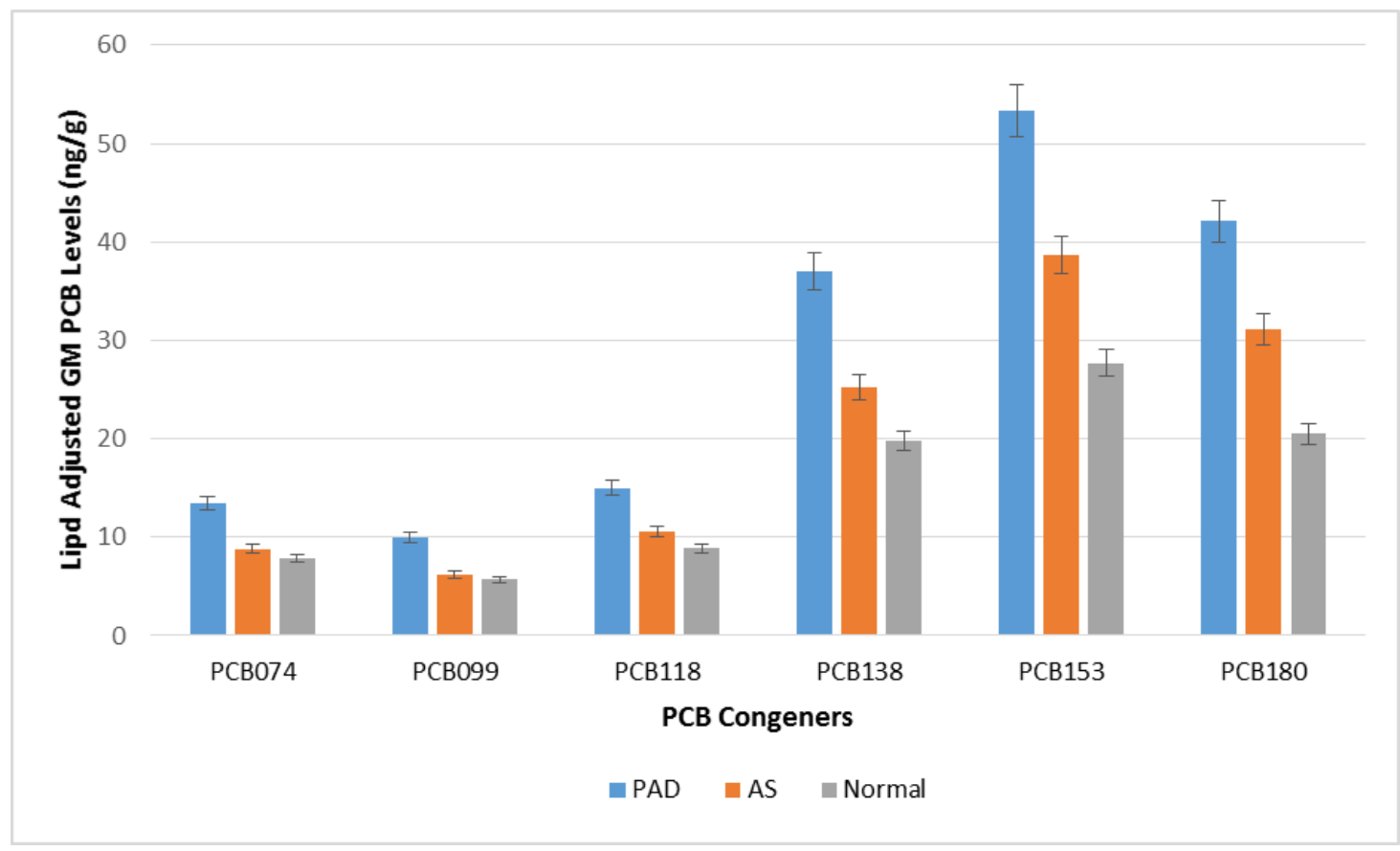

Figure 2.1 Geometric mean PCB levels (ng/g) by PAD status for participants $\geq \mathbf{4 0}$ years of age, NHANES 1999-2004.

Geometric mean PCB levels were also examined by age group of participants (Table 2.4). The overall GM levels of PCBs increased significantly in 
PAD participants as age group progressed except PCB099 which demonstrated a non-consistent trend (10.04 ng/g vs. $8.82 \mathrm{ng} / \mathrm{g}$ vs. $18.99 \mathrm{ng} / \mathrm{g})$. In the first age group ( $\geq 40-59$ ) GM levels of PCBs are demonstrated to be higher in PAD defined participants when compared to normal participant levels. Additionally the same trend is shown when comparing AS participants to the normal group. In the second age group (60 - 74 years old), participants had higher GM PCB levels of congeners with the exception of PCB congener 180 that demonstrated lower GM PCB levels in normal participants when compared to PAD participants (Table 2.4). The population who were AS defined when compared to the normal population were shown as being higher. In the third age group ( $\geq 75$ years old) all PCB congeners were shown to be higher in PAD identified participants when compared to normal participants. Furthermore higher PCB levels of participants whom were at defined AS participants were demonstrated with PCB congeners 74 and 118. Interestingly PCB 099, 138, 153, and 180 were shown to have higher PCB GM in normal participants when compared to AS participants.

Table 2.4 Geometric Mean PCB levels ( $\mathrm{ng} / \mathrm{g}$ ) above the LOD by peripheral arterial disease status by age groups, NHANES 1999-2004

\begin{tabular}{|c|c|c|c|c|c|c|c|c|c|}
\hline \multicolumn{10}{|c|}{ Geometric Mean $\mathbf{2}(\mathrm{ng} / \mathrm{g})(\mathrm{GSE}, \mathrm{n})$} \\
\hline & & Age: $\geq 40-59$ & & & Age: $60-74$ & & & Age: $\geq 75$ & \\
\hline & $\mathrm{ABI}<0.7^{*}$ & $0.7<\mathrm{ABI}<0.9^{*}$ & $0.9<\mathrm{AB} \mid<1.3^{*}$ & $\mathrm{ABI}<0.7$ & $0.7<\mathrm{AB} \mid<0.9$ & $0.9<\mathrm{ABI}<1.3$ & $\mathrm{ABI}<0.7$ & $0.7<\mathrm{ABI} \mid<0.9$ & $0.9<\mathrm{ABI}<1.3$ \\
\hline \multicolumn{10}{|l|}{ Analyte $_{1}$} \\
\hline РСв074 & $9.41(2.59)$ & $7.10(0.73)$ & $6.58(0.14)$ & $14.78(0.50)$ & $19.87(2.53)$ & $12.12(4.02)$ & $40.06(5.46)$ & $25.53(5.54)$ & $22.32(1.05)$ \\
\hline РСB099 & $10.04(2.52)$ & $5.54(0.47)$ & $5.14(0.10)$ & $8.82(0.30)$ & $8.69(1.11)$ & $7.61(2.53)$ & 18.99 (3.13) & $10.27(2.97)$ & $11.65(0.52)$ \\
\hline PCB118 & $9.01(2.13)$ & $8.48(1.15)$ & $7.56(0.18)$ & $17.42(0.76)$ & 22.96 (3.32) & $13.18(5.67)$ & $54.77(10.36)$ & $50.02(13.18)$ & 24.40 (1.32) \\
\hline PCB138 & $36.90(9.13)$ & 22.75 (2.54) & $18.20(0.39)$ & $39.46(1.20)$ & 40.84 (4.63) & 36.78 (7.43) & $64.60(8.86)$ & $46.38(11.75)$ & $51.76(2.06)$ \\
\hline PCB153 & $52.80(10.55)$ & 35.51 (4.38) & $25.61(0.57)$ & $58.18(1.59)$ & 64.95 (8.62) & $55.36(10.15)$ & 97.05 (12.95) & $63.22(10.94)$ & 75.76 (2.71) \\
\hline PCB180 & $38.98(8.45)$ & $28.80(4.69)$ & $18.91(0.46)$ & $48.13(1.19)$ & $50.25(6.84)$ & $49.84(7.19)$ & $65.00(9.02)$ & $44.38(10.29)$ & $60.77(2.08)$ \\
\hline
\end{tabular}

${ }^{1}$ Lipid Adjusted and log transformed polychlorinated biphenyls (ng/g);

2 Geometric Means calculated after applying NHANES sampling weights

${ }^{*} \mathrm{ABI}<0.7$ (PAD), $0.7<\mathrm{ABI}<0.9$ (AS), \& $0.9<\mathrm{ABI}<1.3$ (Normal) 


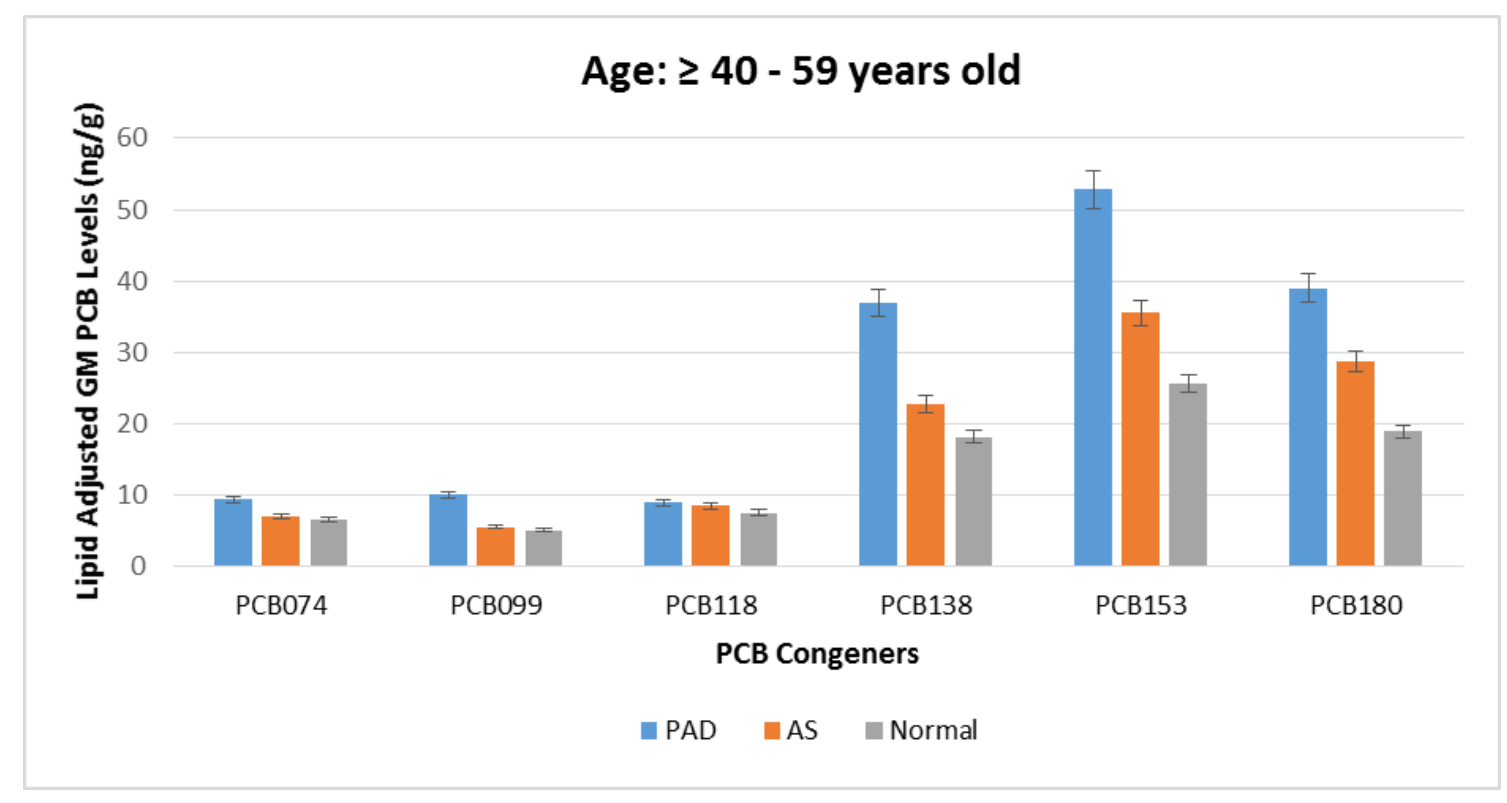

Figure 2.2.1 Geometric mean PCB levels (ng/g) by PAD status for participants $\geq 40-59$ years of age, NHANES 1999-2004.

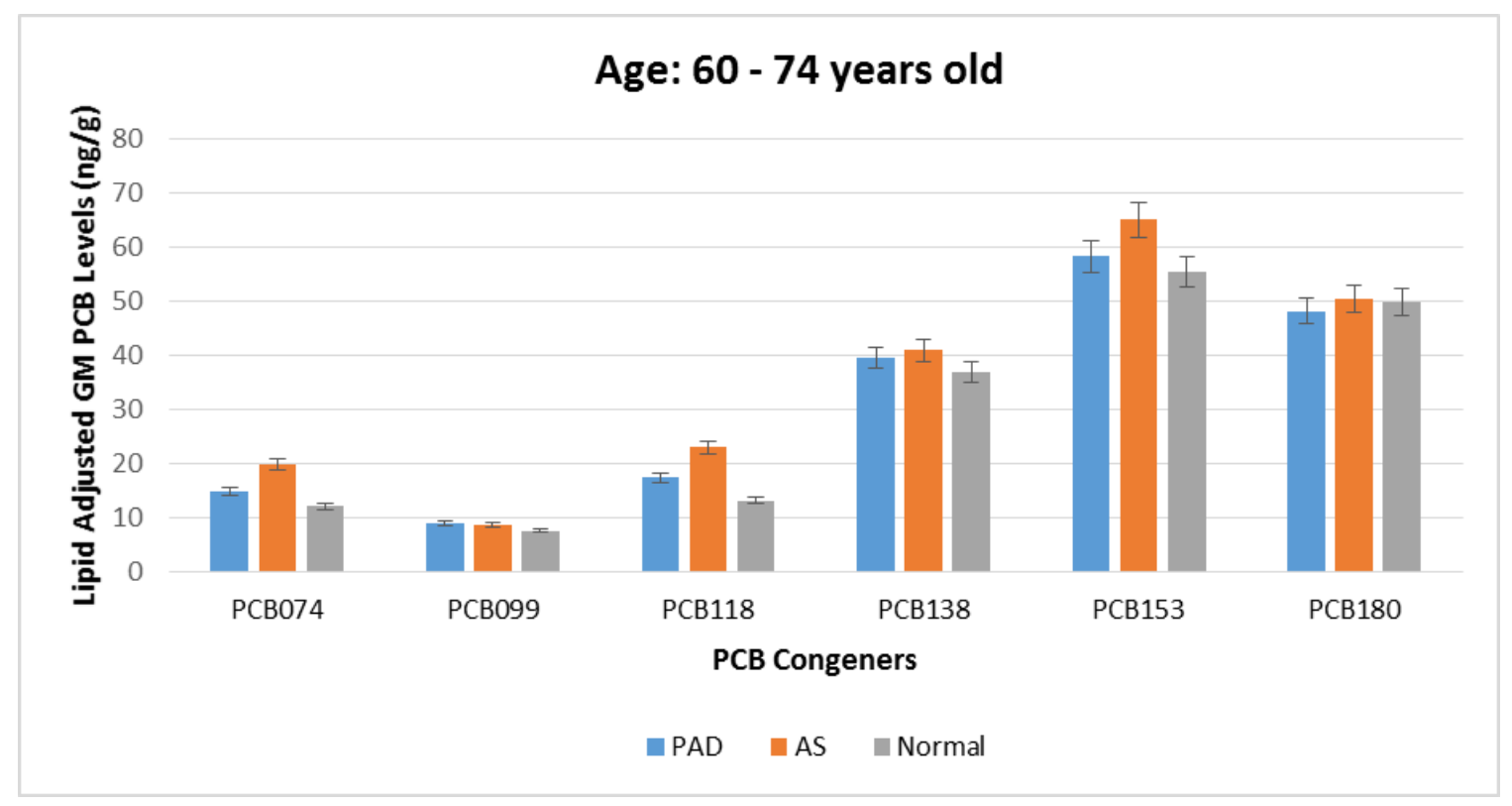

Figure 2.2.2 Geometric mean PCB levels (ng/g) by PAD status for participants 60 - 74 years of age, NHANES 1999-2004. 


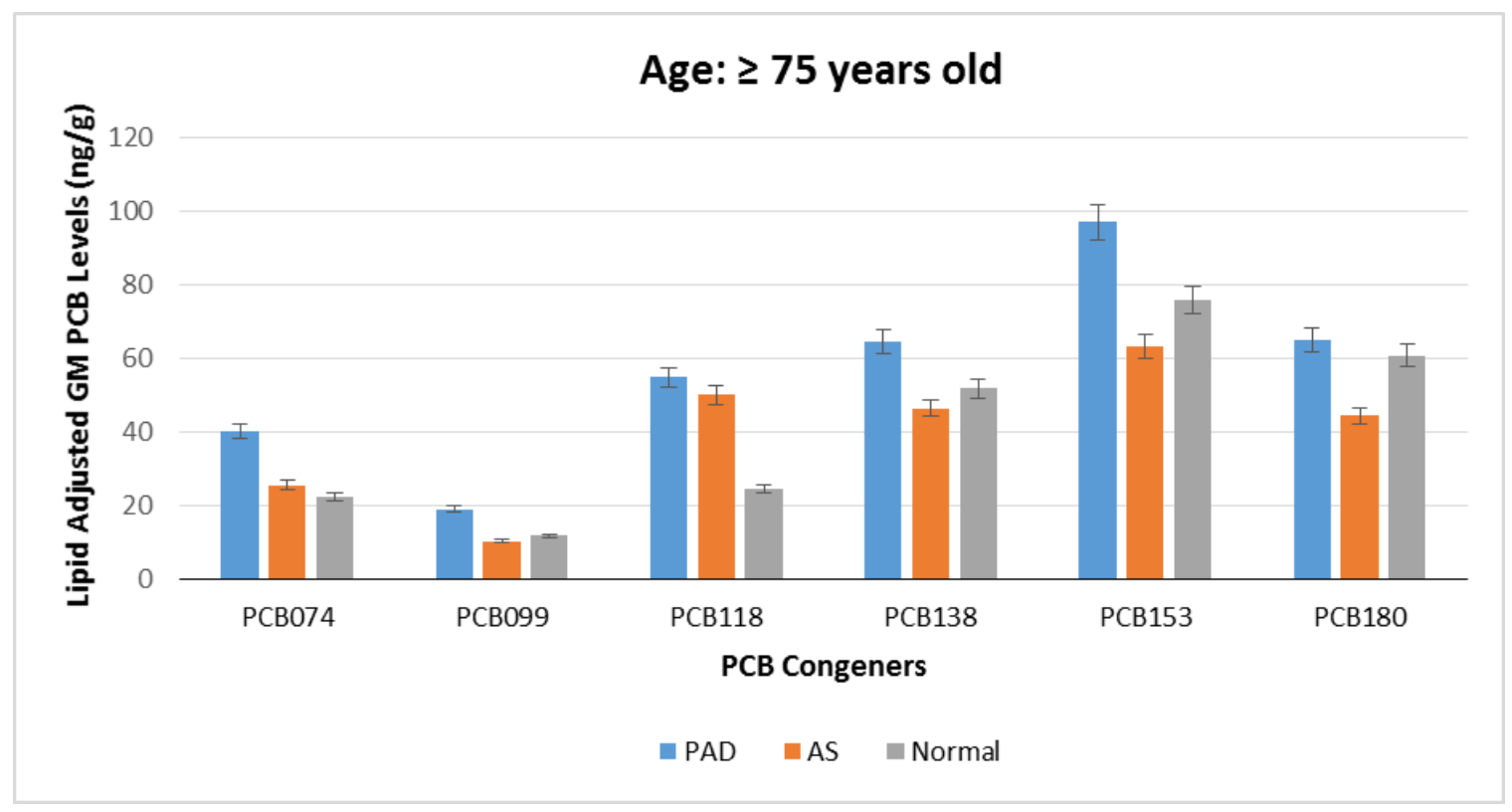

Figure 2.2.3 Geometric mean PCB levels (ng/g) by PAD status for participants $\geq 75$ years of age, NHANES 1999-2004.

Table 2.5 presents age standardized GMs and GSEs of PCBs by race/ethnicity in participants with individual concentrations of PCBs above the LOD. Ethnic backgrounds that were demonstrated to have higher PCB concentrations when having PAD compared to normal participants include: "Mexican American," "Non-Hispanic White," "Other Race," and "Non-Hispanic Black." "Other Hispanic" demonstrated lower levels of PCB concentrations in PAD participants when compared to normal participants. Furthermore participants with AS in ethnic groups include: "Mexican American," "Non-Hispanic White," "NonHispanic Black," and "Other Race" demonstrated higher levels of PCBs when compared to normal participants. "Other Hispanic" AS participants showed lower PCB concentrations when compared to normal participants. 
Table 2.5 Age standardized geometric mean PCB levels (ng/g) above the LOD by race/ethnicity among participants $\geq 40$ years old PAD by age groups, NHANES 1999-2004.

\begin{tabular}{|c|c|c|c|c|c|c|c|}
\hline \multicolumn{8}{|c|}{ Geometric Mean $_{2}(\mathrm{ng} / \mathrm{g})(\mathrm{GSE}, \mathrm{n})$} \\
\hline \multicolumn{5}{|c|}{ Mexican American } & \multicolumn{3}{|c|}{ Other Hispanic } \\
\hline & $\mathrm{ABI}<0.7^{\star}$ & $0.7<\mathrm{ABI}<0.9^{*}$ & $0.9<\mathrm{ABI}<1.3^{*}$ & & $A B \mid<0.7$ & $0.7<\mathrm{ABI}<0.9$ & $0.9<A B \mid<1.3$ \\
\hline Analyte $_{1}$ & & & & Analyte & & & \\
\hline РСВ074 & $10.46(6.56-16.69)$ & $7.68(5.50-10.72)$ & $4.60(4.29-4.93)$ & РСB074 & $3.90(3.87-4.01)$ & $5.98(2.20-16.22)$ & $7.03(5.95-8.31)$ \\
\hline РСв099 & $7.53(4.97-11.43)$ & $5.50(4.28-7.08)$ & $3.55(3.35-3.77)$ & РСB099 & $4.52(4.10-4.35)$ & $4.82(2.65-8.77)$ & $5.63(5.00-6.35)$ \\
\hline PCB118 & $10.83(6.03-19.46)$ & $10.05(6.96-14.52)$ & $5.71(5.34-6.12)$ & PCB118 & $3.54(3.42-3.98)$ & $6.85(1.96-23.96)$ & $9.81(8.28-11.62)$ \\
\hline PCB138 & $28.70(17.25-47.72)$ & $23.30(17.39-31.21)$ & $9.72(9.02-10.47)$ & PCB138 & 6.59 (6.43-8.42) & $7.40(1.84-29.80)$ & $19.56(16.64-22.98)$ \\
\hline PCB153 & $36.97(23.34-58.55)$ & $37.56(28.53-49.44)$ & $12.57(11.61-13.61)$ & PCB153 & $7.97(3.42-8.15)$ & $8.33(1.66-41.87)$ & $26.36(22.21-31.29)$ \\
\hline \multirow[t]{3}{*}{ PCB180 } & $24.46(14.99-39.90)$ & $27.73(19.04-40.41)$ & $9.02(8.25-9.87)$ & PCB180 & $3.42(3.14-3.88)$ & $6.66(2.01-22.04)$ & $18.39(15.48-21.85)$ \\
\hline & & Non-Hispanic White & & & \multicolumn{3}{|c|}{ Non-Hispanic Black } \\
\hline & $A B \mid<0.7$ & $0.7<\mathrm{ABI}<0.9$ & $0.9<\mathrm{ABI}<1.3$ & & $A B \mid<0.7$ & $0.7<\mathrm{ABI}<0.9$ & $0.9<\mathrm{ABI}<1.3$ \\
\hline Analyte & & & & Analyte & & & \\
\hline РСВ074 & $13.17(7.67-22.61)$ & $9.05(7.14-11.48)$ & $8.45(8.08-8.84)$ & PCB074 & $18.56(10.53-32.70)$ & $8.91(6.61-12.00)$ & $7.69(7.07-8.36)$ \\
\hline РСв099 & $9.53(6.28-14.48)$ & $6.27(5.32-7.38)$ & $5.75(5.54-5.96)$ & РСB099 & $14.15(7.58-26.40)$ & $7.53(5.99-9.47)$ & $7.40(6.88-7.95)$ \\
\hline PCB118 & $14.54(7.42-28.53)$ & $10.78(8.13-14.30)$ & $9.13(8.70-9.59)$ & PCB118 & $21.73(12.04-39.20)$ & $12.12(7.94-18.51)$ & $9.80(8.87-10.82)$ \\
\hline PCB138 & $35.72(25.63-49.80)$ & $26.78(21.74-32.99)$ & $20.65(19.80-21.55)$ & PCB138 & 54.59 (32.07-92.93) & $31.61(14.00-71.36)$ & $23.93(22.01-26.02)$ \\
\hline PCB153 & $52.22(37.92-71.90)$ & $41.52(33.01-52.22)$ & $29.32(28.07-30.62)$ & PCB153 & 78.34 (45.95-133.56 & $39.37(15.94-97.22)$ & $32.53(29.82-35.49)$ \\
\hline \multirow[t]{3}{*}{ PCB180 } & $42.66(32.36-56.24)$ & $33.69(25.47-44.56)$ & $22.27(21.24-23.35)$ & PCB180 & $54.35(30.65-96.39)$ & $38.61(15.76-94.60)$ & $21.91(20.04-23.95)$ \\
\hline & & Other Race & & & & & \\
\hline & $A B \mid<0.7$ & $0.7<A B \mid<0.9$ & $0.9<A B \mid<1.3$ & & & & \\
\hline \multicolumn{8}{|l|}{ Analyte } \\
\hline РСВ074 & $10.43(10.22-11.23)$ & $11.73(11.70-11.88)$ & $5.86(5.02-6.85)$ & & & & \\
\hline РСв099 & $5.77(4.42-5.96)$ & $8.02(8.00-8.10)$ & 5.64 (4.94-6.43) & & & & \\
\hline PCB118 & $10.21(10.15-10.45)$ & $11.01(11.00-11.02)$ & $8.28(6.89-9.94)$ & & & & \\
\hline PCB138 & $21.21(18.32-23.32)$ & $21.70(21.74-21.89)$ & $19.01(16.21-22.29)$ & & & & \\
\hline PCB153 & $30.43(29.23-31-75)$ & $40.00(40.0-40.2)$ & $26.25(22.15-31.11)$ & & & & \\
\hline PCB180 & $24.42(22.32-25.32)$ & $26.20(26.19-26.24)$ & $18.28(15.08-22.17)$ & & & & \\
\hline
\end{tabular}

1 Lipid Adjusted and log transformed polychlorinated biphenyls (ng/g)

2 Geometric Means calculated after applying NHANES sampling weight

${ }^{*} \mathrm{ABI}<0.7$ (PAD), $0.7<\mathrm{ABI}<0.9$ (AS), \& $0.9<\mathrm{ABI}<1.3$ (Normal

Table 2.6 demonstrates the computational means and $95 \%$ Cls of dioxinlike serum levels of PCBs for PAD, atherosclerosis, normal, and selected covariates in the study population. Computational means of dioxin-like PCBs were higher in participants diagnosed with PAD $(1.57 \mathrm{ng} / \mathrm{g})$ compared to participants without PAD (1.35 ng/g). Furthermore PCBs were lower in participants with AS $(1.33 \mathrm{ng} / \mathrm{g})$ compared to normal participants. Mean dioxin-like PCBs increased with age in all three groups: PAD, AS, \& normal participants. Other Hispanic was demonstrated to be the highest race diagnosed with PAD (1.68 ng/g) and NonHispanic Black with AS (1.51 ng/g). Additionally all three age groups demonstrated a higher mean of PCB levels in both PAD participants \& AS participants when compared to normal participants. 
Table 2.6 Serum levels of dioxin-like PCBs $(\mathrm{ng} / \mathrm{g})$ in the study population, participants $\geq \mathbf{4 0}$ years of age, NHANES 1999-2004.

\begin{tabular}{|c|c|c|c|c|c|c|}
\hline \multirow[t]{2}{*}{ Variable } & \multicolumn{3}{|c|}{ Cases/Non - Cases } & \multicolumn{3}{|c|}{ Mean' (ng/g) $(95 \% \mathrm{Cl})$} \\
\hline & $A B I<0.7^{\star}(n)$ & $0.7<A B \mid<0.9^{*}(n)$ & $0.9<A B \mid<1.3^{*}(n)$ & $A B \mid<0.7 n(\%)$ & $0.7<A B \mid<0.9 n(\%)$ & $0.9<A B \mid<1.3 n(\%)$ \\
\hline Dioxin-like PCBs $(074+118)$ & 107 & 106 & 1324 & $1.57(1.46-1.67)$ & $1.37(1.25-1.40)$ & $1.35(1.33-1.37)$ \\
\hline \multicolumn{7}{|l|}{ Race/Ethnicity } \\
\hline Mexican American & 13 & 35 & 271 & $1.31(1.12-1.49)$ & $1.29(1.14-1.44)$ & $1.20(1.16-1.24)$ \\
\hline Other Hispanic & 2 & 3 & 53 & $1.68(1.59-1.76)$ & $1.33(0.84-1.47)$ & $1.37(1.26-1.47)$ \\
\hline Non-Hispanic White & 64 & 63 & 742 & $1.57(1.44-1.70)$ & $1.39(1.25-1.42)$ & $1.35(1.32-1.37)$ \\
\hline Non-Hispanic Black & 27 & 4 & 208 & $1.58(1.44-1.73)$ & $1.51(1.22-1.8)$ & $1.50(1.44-1.56)$ \\
\hline Other Race & 1 & 1 & 50 & $1.45(1.45-1.45)$ & $1.36(1.35-1.36)$ & $1.30(1.21-1.39)$ \\
\hline \multicolumn{7}{|l|}{ Age at interview (years) } \\
\hline$>40-59$ & 19 & 53 & 697 & $1.28(1.12-1.44)$ & $1.22(1.14-1.30)$ & $1.25(1.23-1.28)$ \\
\hline $60-74$ & 45 & 39 & 450 & $1.58(1.43-1.73)$ & $1.51(1.43-1.61)$ & $1.52(1.48-1.55)$ \\
\hline$\geq 75$ & 43 & 14 & 177 & $1.82(1.72-1.91)$ & $1.77(1.62-1.92)$ & $1.65(1.60-1.70)$ \\
\hline \multicolumn{7}{|l|}{ Ever Smoked } \\
\hline Yes & 20 & 10 & 218 & $1.38(1.13-1.63)$ & $1.25(0.89-1.45)$ & $1.21(1.17-1.26)$ \\
\hline Sometimes & 1 & 4 & 35 & $0.99(0.96-1.00)$ & $1.08(1.01-1.15)$ & $1.26(1.16-1.36)$ \\
\hline No & 55 & 44 & 454 & $1.54(1.43-1.67)$ & $1.27(1.17-1.37)$ & $1.39(1.35-1.43)$ \\
\hline \multicolumn{7}{|l|}{ Alcohol Use } \\
\hline Yes & 0 & 0 & 7 & N/A & N/A & $1.20(1.00-1.40)$ \\
\hline No & 46 & 67 & 2868 & $1.46(1.26-167)$ & $1.29(1.19-1.40)$ & $1.23(1.21-1.25)$ \\
\hline \multicolumn{7}{|l|}{ BMI } \\
\hline Normal Weight $(18.5$ to $<25)$ & 25 & 24 & 380 & $1.44(1.31-1.58)$ & $1.28(1.11-1.45)$ & $1.34(1.30-1.38)$ \\
\hline Overweight $(25$ to $<30)$ & 41 & 39 & 514 & $1.57(1.35-1.78)$ & $1.30(1.20-1.39)$ & $1.33(1.29-1.37)$ \\
\hline Obese $(\geq 30)$ & 33 & 40 & 405 & $1.59(1.48-1.70)$ & $1.40(1.29-1.51)$ & $1.38(1.35-1.42)$ \\
\hline \multicolumn{7}{|l|}{ Diabetes } \\
\hline Yes & 24 & 13 & 160 & $1.65(1.46-1.85)$ & $1.55(1.29-1.65)$ & $1.52(1.46-1.58)$ \\
\hline No & 81 & 92 & 1146 & $1.55(1.43-1.67)$ & $1.32(1.24-1.40)$ & $1.33(1.31-1.35)$ \\
\hline Boarderline & 2 & 1 & 17 & $1.62(1.52-1.71)$ & $1.27(1.27-1.28)$ & $1.46(1.33-1.59)$ \\
\hline Don't know & 0 & 0 & 1 & N/A & N/A & $2.23(2.22-2.23)$ \\
\hline \multicolumn{7}{|l|}{ Estradiol (pg/mL) } \\
\hline$<5$ & 0 & 19 & 0 & N/A & N/A & $1.26(1.02-1.50)$ \\
\hline $5.1-95$ & 6 & 491 & 19 & $1.30(0.95-1.66)$ & $1.22(1.08-1.37)$ & $1.20(1.16-1.23)$ \\
\hline $95.1-185$ & 1 & 1 & 0 & $2.67(2.67-2.67)$ & N/A & $0.92(0.92-0.93)$ \\
\hline$>185$ & 0 & 1 & 0 & N/A & N/A & $2.22(2.21-2.22)$ \\
\hline \multicolumn{7}{|l|}{ Education } \\
\hline$<$ 9th Grade & 24 & 21 & 221 & $1.67(1.43-1.91)$ & $1.43(1.25-1.60)$ & $1.36(1.29-1.44)$ \\
\hline 9-11th Grade (Includes 12 th grade with no & 24 & 10 & 206 & $1.37(1.13-1.61)$ & $1.36(1.12-1.60)$ & $1.42(1.35-1.48)$ \\
\hline High School Grad/GED or Equivalent & 30 & 11 & 291 & $1.63(1.44-1.82)$ & $1.14(0.92-1.37)$ & $1.36(1.31-1.41)$ \\
\hline Some College or AA degree & 15 & 27 & 347 & $1.50(1.39-1.61)$ & $1.36(1.19-1.53)$ & $1.33(1.29-1.37)$ \\
\hline College Graduate or above & 13 & 37 & 257 & $1.70(1.54-1.85)$ & $1.35(1.26-1.44)$ & $1.33(1.29-1.37)$ \\
\hline Refused & 0 & 0 & 0 & N/A & N/A & N/A \\
\hline Don't Know & 1 & 0 & 2 & $2.15(2.15-2.16)$ & N/A & $0.88(0.78-0.98)$ \\
\hline \multicolumn{7}{|l|}{ Income } \\
\hline$\$ 0$ to $\$ 4,999$ & 1 & 3 & 120 & $1.55(1.55-1.56)$ & $1.14(0.88-1.41)$ & $1.11(1.04-1.18)$ \\
\hline$\$ 5,000$ to $\$ 9,999$ & 8 & 4 & 182 & $1.89(1.57-2.21)$ & $1.12(0.94-1.31)$ & $1.31(1.23-1.40)$ \\
\hline$\$ 10,000$ to $\$ 14,999$ & 7 & 9 & 284 & $1.65(1.20-2.10)$ & $1.64(1.56-1.72)$ & $1.33(1.27-1.39)$ \\
\hline$\$ 15,000$ to $\$ 19,999$ & 3 & 1 & 255 & $1.34(0.75-1.94)$ & $1.36(1.36-1.37)$ & $1.22(1.16-1.27)$ \\
\hline$\$ 20,000$ to $\$ 24,999$ & 3 & 4 & 262 & $0.93(0.407-1.45)$ & $1.04(0.73-1.36)$ & $1.26(1.20-1.32)$ \\
\hline$\$ 25,000$ to $\$ 34,999$ & 5 & 7 & 346 & $1.44(0.81-2.07)$ & $1.46(1.32-1.59)$ & $1.23(1.18-1.28)$ \\
\hline$\$ 35,000$ to $\$ 44,999$ & 2 & 3 & 252 & $1.59(1.18-2.00)$ & $1.87(1.69-2.04)$ & $1.25(1.20-1.31)$ \\
\hline$\$ 45,000$ to $\$ 54,999$ & 5 & 7 & 236 & $1.13(0.86-1.40)$ & $1.10(0.87-1.33)$ & $1.19(1.14-1.23)$ \\
\hline$\$ 55,000$ to $\$ 64,999$ & 1 & 3 & 174 & $1.76(1.76-1.77)$ & $1.00(0.81-1.18)$ & $1.19(1.12-1.25)$ \\
\hline$\$ 65,000$ to $\$ 74,999$ & 0 & 5 & 111 & N/A & $1.51(1.05-1.97)$ & $1.14(1.07-1.20)$ \\
\hline$\$ 75,000$ and over & 5 & 19 & 426 & $1.25(0.94-1.56)$ & $1.35(1.20-1.50)$ & $1.21(1.17-1.24)$ \\
\hline Over $\$ 20,000$ & 4 & 2 & 88 & $1.52(1.09-1.95)$ & $1.41(1.18-1.65)$ & $1.38(1.29-1.47)$ \\
\hline Under $\$ 20,000$ & 0 & 1 & 51 & N/A & $1.03(1.03-1.04)$ & $1.28(1.13-1.42)$ \\
\hline Refused & 0 & 0 & 42 & N/A & N/A & $1.36(1.25-1.47)$ \\
\hline Don't know & 0 & 1 & 19 & N/A & $0.97(0.96-0.97)$ & $1.19(0.92-1.45)$ \\
\hline
\end{tabular}

${ }^{1}$ Means calculated after applying NHANES sampling weights; lipid-adjusted and log transformed PCBs

${ }^{*} \mathrm{ABI}<0.7$ (PAD). $0.7<\mathrm{ABI}<0.9$ (AS), \& $0.9<\mathrm{ABI}<1.3$ (Normal)

Table 2.7 demonstrates the computational means and $95 \%$ Cls of nondioxin-like PCBs for diagnosis of PAD, AS, and normal population. Computational means was seen higher in diagnosed PAD participants exposed to non-dioxin-like PCBs compared to the normal population $(2.18 \mathrm{ng} / \mathrm{g}$ vs.2.00 $\mathrm{ng} / \mathrm{g})$. Interestingly, 
means was seen lower in AS participants when compare to the normal population (1.95 ng/g vs. $2.00 \mathrm{ng} / \mathrm{g})$. Additionally all individual races/ethnicities demonstrated higher non-dioxin-like PCB concentrations in PAD diagnosed participants when compared to the normal population. Individual races/ethnicities including: "Mexican American" and "Non-Hispanic Black" showed higher non-dioxin-like PCB exposure in participants with AS when compared to the normal population.

Table 2.7 Serum levels of non-dioxin like PCBs $(\mathrm{ng} / \mathrm{g})$ in the study population, participants $\geq 40$ years of age, NHANES 1999-2004

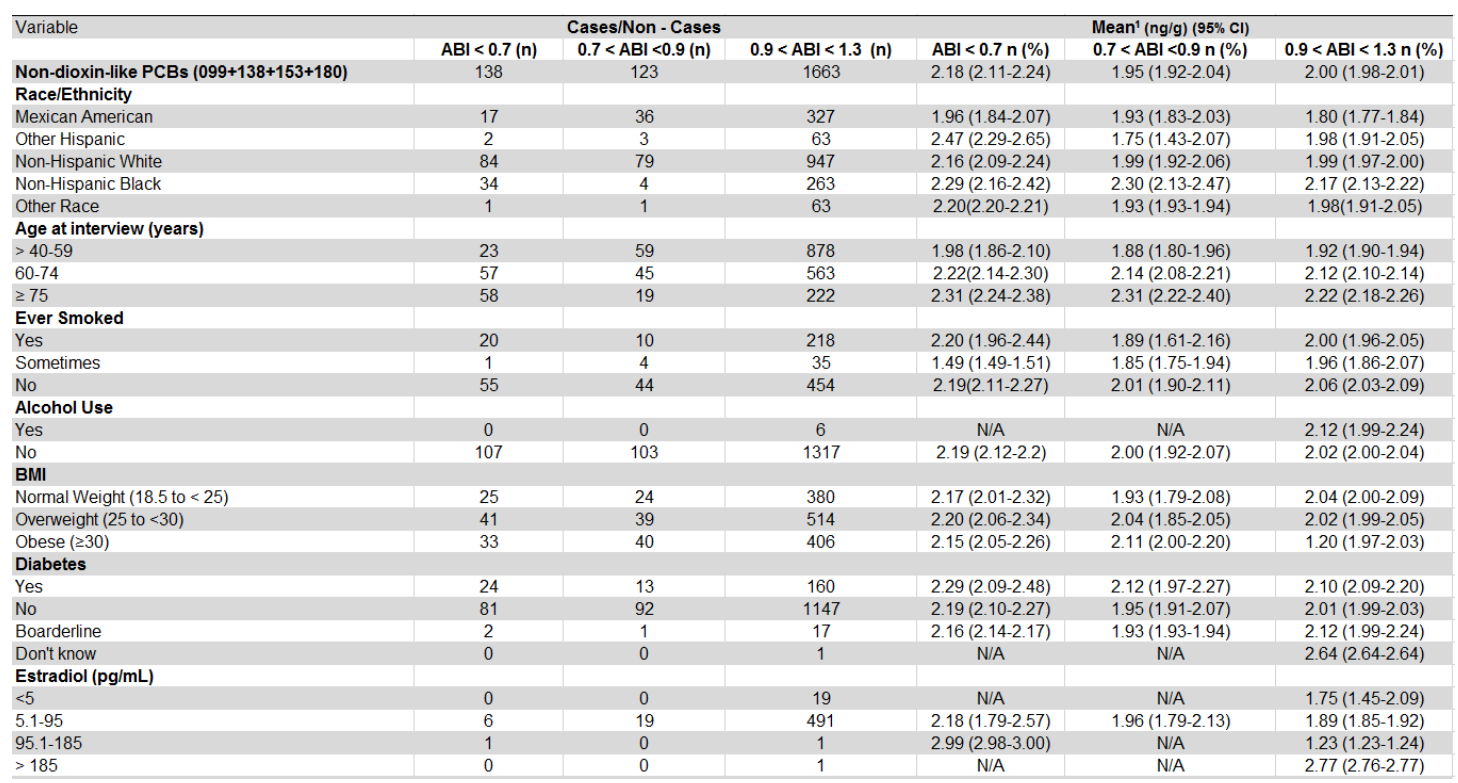

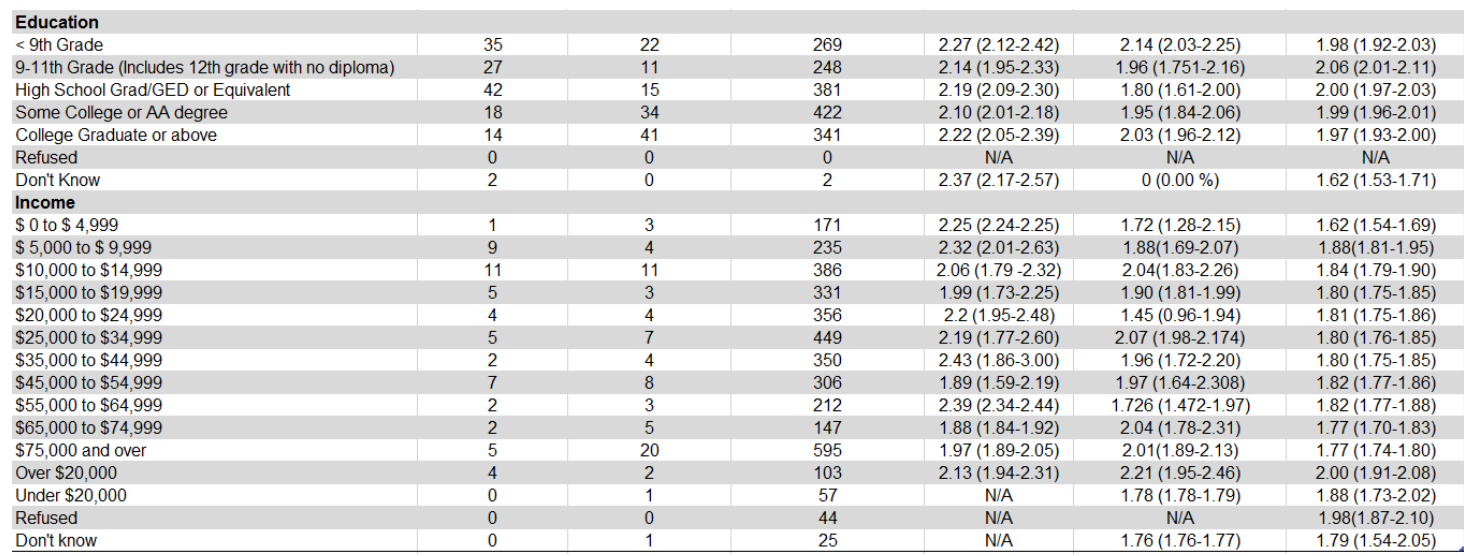


${ }^{1}$ Means calculated after applying NHANES sampling weights; lipid-adjusted and log transformed PCBs

${ }^{*} \mathrm{ABI}<0.7$ (PAD). $0.7<\mathrm{ABI}<0.9$ (AS), \& $0.9<\mathrm{ABI}<1.3$ (Normal)

Geometric Means and 95\% Cl's of PCB levels (lipid-adjusted) are reported in Table 2.8 for participants with PCB levels $<$ LOD and $\geq$ LOD. All participants who reported concentrations of $\geq$ LOD who were diagnosed with PAD had higher GM levels of PCB congeners. Similarly, participants who reported concentrations of $\geq$ LOD who were AS participants had higher PCB congener levels $(074,099$, 158, and 180). PCB congener 074 had higher GM in normal participants vs. ones who were AS participants (14.07 ng/g vs. $13.19 \mathrm{ng} / \mathrm{g}$ ) and congener 118 demonstrated comparable GM levels (11.51 ng/g vs. $11.32 \mathrm{ng} / \mathrm{g}$ ) (Table 2.8)

2.8 Geometric Mean PCB levels (ng/g) by PAD status among participants $\geq \mathbf{4 0}$ years of age, NHANES 1999-2004. 


\begin{tabular}{|c|c|c|c|c|c|c|}
\hline \multicolumn{4}{|c|}{ Cases/Non-cases } & \multicolumn{3}{|c|}{ Geometric Mean $_{2}(\mathrm{ng} / \mathrm{g})(95 \% \mathrm{Cl})$} \\
\hline & $\mathrm{ABI}<0.7^{*}$ & $0.7<\mathrm{ABI}<0.9^{*}$ & $0.9<\mathrm{ABI}<1.3^{*}$ & $\mathrm{ABI}<0.7$ & $0.7<\mathrm{ABI}<0.9$ & $0.9<\mathrm{ABI}<1.3$ \\
\hline \multicolumn{7}{|c|}{ Analyte $_{1}$} \\
\hline \multicolumn{7}{|c|}{ PCB074 } \\
\hline$<$ LOD & 16 & 22 & 1467 & $4.27(3.83-4.75)$ & $4.12(3.87-4.40)$ & $3.71(3.63-3.79)$ \\
\hline$\geq$ LOD & 29 & 47 & 1382 & $25.70(19.36-34.12)$ & $13.186(11.47-15.15)$ & $14.07(13.66-14.49)$ \\
\hline \multicolumn{7}{|c|}{ PCB099 } \\
\hline$<$ LOD & 11 & 13 & 1267 & $2.85(2.44-3.34)$ & 3.35 (3.16-3.54) & $2.63(2.57-2.70)$ \\
\hline$\geq$ LOD & 28 & 35 & 1322 & $21.21(15.96-28.18)$ & $10.06(8.72-11.61)$ & $12.29(11.90-12.70)$ \\
\hline \multicolumn{7}{|c|}{ PCB118 } \\
\hline$<$ LOD & 3 & 3 & 574 & $2.39(1.55-3.69)$ & $3.63(3.50-3.76)$ & $2.94(2.85-3.033)$ \\
\hline$\geq$ LOD & 41 & 66 & 2250 & $18.28(10.88-30.71)$ & $11.51(8.97-14.76)$ & $11.32(10.89-11.77)$ \\
\hline \multicolumn{7}{|c|}{ PCB138 } \\
\hline$<$ LOD & 0 & 0 & 78 & $\mathrm{~N} / \mathrm{A}$ & $\mathrm{N} / \mathrm{A}$ & $1.98(1.89-2.07)$ \\
\hline$\geq$ LOD & 58 & 76 & 3708 & $37.05(28.03-48.97)$ & $25.18(20.48-30.96)$ & $20.40(19.72-21.10)$ \\
\hline \multicolumn{7}{|c|}{ PCB153 } \\
\hline$<L O D$ & 6 & 5 & 1080 & 4.07 (3.65-4.54) & $4.99(3.18-7.84)$ & $5.58(5.39-5.78)$ \\
\hline$\geq$ LOD & 52 & 71 & 2530 & $62.71(49.79-78.98)$ & $44.28(36.43-53.80)$ & $40.82(39.59-42.09)$ \\
\hline \multicolumn{7}{|c|}{ PCB180 } \\
\hline$<$ LOD & 0 & 0 & 217 & $\mathrm{~N} / \mathrm{A}$ & $\mathrm{N} / \mathrm{A}$ & $1.53(1.39-1.69)$ \\
\hline$\geq \mathrm{LOD}$ & 58 & 76 & 3571 & $42.13(33.00-53.78)$ & $31.11(23.84-40.60)$ & $22.10(21.28-22.93)$ \\
\hline
\end{tabular}

1 Lipid adjusted and log transformed polychlorinated biphenyls ( $\mathrm{ng} / \mathrm{g}$ )

2 Geometric means calculated after applying NHANES sampling weights

${ }^{*} \mathrm{ABI}<0.7$ (PAD), $0.7<\mathrm{ABI}<0.9$ (AS), \& $0.9<\mathrm{ABI}<1.3$ (Normal)

We also adjusted the PCB levels into the following two groups $<$ LOD to $50^{\text {th }}$ percentile and $\geq 50^{\text {th }}$ percentile (Table 2.9). Participants in the first group ( $<$ LOD to $50^{\text {th }}$ percentile) with PAD showed higher GM PCB levels compared to participants who were defined as normal participants: PCB congener 074 (3.65 $\mathrm{ng} / \mathrm{g}$ vs. $3.10 \mathrm{ng} / \mathrm{g}) ; 099$ (2.85 ng/g vs. $2.61 \mathrm{ng} / \mathrm{g}) ; 118$ (3.82 ng/g vs. $3.60 \mathrm{ng} / \mathrm{g})$. PCB congeners 138 (7.06 ng/g vs. $7.66 \mathrm{ng} / \mathrm{g}) ; 153$ (6.51 ng/g vs. $9.59 \mathrm{ng} / \mathrm{g})$; and 180 (5.78 ng/g vs. $6.99 \mathrm{ng} / \mathrm{g}$ ) showed higher levels of PCB GMs in normal participants then in participants defined with PAD. Furthermore a significant increase was seen in the second group ( $\geq 50$ th percentile) for PCB congener 074 (17.68 vs. 11.20$) ; 099$ (13.06 vs. 8.03$) ; 118$ (28.26 vs. 14.09$) ; 138$ (45.30 vs. 35.53); 153 (64.87 vs. 50.47$) 180$ (51.69 vs. 41.63 ). GM PCB concentrations between AS participants and normal participants were demonstrated to have little to no change between the two groups with the exception of PCB 153 (12.94 vs. 
9.59 for $<$ LOD to $50 \% ; 54.29$ vs. 50.47 for $\geq 50 \%$ ) and PCB 180 (44.85 vs. 41.63

for $\geq 50 \%$ ) (Table 2.9).

Table 2.9 Geometric mean PCB levels (ng/g) by PAD status among participants $\geq \mathbf{4 0}$ years of age, NHANES 1999-2004

\begin{tabular}{|c|c|c|c|c|c|c|}
\hline & \multicolumn{3}{|c|}{ Cases/Non-cases } & \multicolumn{3}{|c|}{ 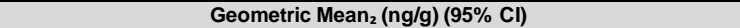 } \\
\hline & $\mathrm{ABI}<0.7^{\star}$ & $0.7<\mathrm{ABI}<0.9^{*}$ & $0.9<\mathrm{ABI}<1.3^{*}$ & $\mathrm{ABI}<0.7$ & $0.7<\mathrm{ABI}<0.9$ & $0.9<\mathrm{ABI}<1.3$ \\
\hline \multicolumn{7}{|l|}{ Analyte $_{1}$} \\
\hline \multicolumn{7}{|l|}{ РСB074 } \\
\hline$<$ LOD to $50 \%$ & 8 & 11 & 962 & $3.65(3.15-4.23)$ & $3.70(3.48-3.94)$ & $3.10(3.02-3.18)$ \\
\hline$\geq 50 \%$ & 37 & 58 & 1904 & $17.68(11.43-27.35)$ & $11.04(9.10-13.40)$ & $11.20(10.82-11.59)$ \\
\hline \multicolumn{7}{|l|}{ РСВ099 } \\
\hline$<$ LOD to $50 \%$ & 11 & 13 & 1215 & $2.85(2.44-3.33)$ & $3.35(3.17-3.54)$ & $2.61(2.55-2.68)$ \\
\hline$\geq 50 \%$ & 46 & 63 & 2549 & $13.06(9.41-18.11)$ & $7.14(6.11-8.34)$ & $8.03(7.80-8.26)$ \\
\hline \multicolumn{7}{|l|}{ PCB118 } \\
\hline$<$ LOD to $50 \%$ & 16 & 14 & 1181 & $3.82(3.06-4.78)$ & $4.14(3.85-4.45)$ & $3.60(3.52-3.68)$ \\
\hline$\geq 50 \%$ & 30 & 55 & 1686 & $28.26(16.81-47.52)$ & $15.26(12.45-18.70)$ & $14.09(13.54-14.66)$ \\
\hline \multicolumn{7}{|l|}{ PCB138 } \\
\hline$<$ LOD to $50 \%$ & 11 & 16 & 1776 & $7.06(4.42-11.29)$ & $10.48(7.94-13.83)$ & 7.66 (7.41-7.92) \\
\hline$\geq 50 \%$ & 47 & 60 & 2018 & $45.30(34.93-58.75)$ & $34.77(29.88-40.46)$ & $35.53(34.49-36.60)$ \\
\hline \multicolumn{7}{|l|}{ PCB153 } \\
\hline$<$ LOD to $50 \%$ & 10 & 12 & 1751 & $6.51(3.86-10.96)$ & $12.94(8.76-19.12)$ & $9.59(9.23-9.96)$ \\
\hline$\geq 50 \%$ & 49 & 64 & 2050 & $64.87(51.40-81.85)$ & $54.29(47.20-62.44)$ & $50.47(49.05-51.93)$ \\
\hline \multicolumn{7}{|l|}{ PCB180 } \\
\hline$<$ LOD to $50 \%$ & 11 & 15 & 1840 & $5.78(4.02-8.32)$ & $7.67(5.71-10.30)$ & 6.99 (6.69-7.29) \\
\hline$\geq 50 \%$ & 47 & 60 & 1953 & $51.69(42.09-63.47)$ & $44.85(37.38-53.81)$ & $41.63(40.51-42.78)$ \\
\hline
\end{tabular}

${ }_{1}$ Lipid adjusted and log transformed polychlorinated biphenyls (ng/g)

${ }_{2}$ Geometric means calculated after applying NHANES sampling weights

${ }^{*} \mathrm{ABI}<0.7$ (PAD), $0.7<\mathrm{ABI}<0.9$ (AS), \& $0.9<\mathrm{ABI}<1.3$ (Normal)

We additionally divided lipid adjusted PCB GMs to three groups: < LOD to $50 \%, 50 \%$ to $75 \%$, and $\geq 75 \%$ (Table 2.10 ). Participants in groups $<$ LOD to $50 \%$ demonstrated higher PCB concentrations in PAD defined participants when compared to normal participants (PCB congeners 074, 099, 118). PCB congeners 138,153 , and 180 showed the reverse results and demonstrated higher PCB concentration levels in normal participants when compared to the participants defined with PAD. When comparing AS participants to normal, all PCB congeners were higher than PCB GM levels in normal participants for < LOD to 50\% $(074$, 099, 118, 138, 153, 180). GM PCB concentrations did not significantly differ in group $50 \%$ to $75 \%$ for both PAD diagnosed \& participants with AS when compared to the normal group. In the final group $\geq 75 \%$, a significant change was 
demonstrated through all the participants with PAD when compared to the normal group. However PCB congener 180 was only shown at being higher in AS participants compared to normal ones (Table 2.10).

Table 2.10 Serum levels of PCBs (ng/g) in the study population, participants $\geq 40$ years of age, NHANES 1999 - 2004.

\begin{tabular}{|c|c|c|c|c|c|c|}
\hline & \multicolumn{3}{|c|}{ Cases/Non-cases } & \multicolumn{3}{|c|}{ 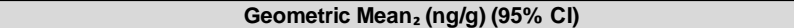 } \\
\hline & $\mathrm{ABI}<0.7^{*}$ & $0.7<\mathrm{ABI}<0.9^{*}$ & $0.9<\mathrm{ABI}<1.3^{*}$ & $\mathrm{ABI}<0.7$ & $0.7<\mathrm{ABI}<0.9$ & $0.9<\mathrm{ABI}<1.3$ \\
\hline \multicolumn{7}{|l|}{ Analyte $_{1}$} \\
\hline \multicolumn{7}{|l|}{ РCB074 } \\
\hline$<$ LOD to $50 \%$ & 8 & 11 & 962 & $3.65(3.15-4.23)$ & $3.70(3.48-3.94)$ & $3.10(3.02-3.18)$ \\
\hline $50 \%$ to $75 \%$ & 13 & 19 & 803 & $5.63(4.91-6.44)$ & $6.15(5.302-7.14)$ & $6.05(5.94-6.17)$ \\
\hline$\geq 75 \%$ & 24 & 39 & 1101 & $31.81(24.21-41.79)$ & $15.95(13.57-18.74)$ & $16.83(16.25-17.43)$ \\
\hline \multicolumn{7}{|l|}{ PCB099 } \\
\hline$<$ LOD to $50 \%$ & 11 & 13 & 1215 & $2.85(2.44-3.33)$ & $3.35(3.17-3.54)$ & $2.61(2.55-2.68)$ \\
\hline $50 \%$ to $75 \%$ & 19 & 41 & 1621 & $4.43(4.22-4.65)$ & $5.28(4.78-5.83)$ & $5.41(5.33-5.50)$ \\
\hline$\geq 75 \%$ & 27 & 22 & 928 & $21.30(16.02-28.33)$ & $12.38(10.50-14.582)$ & $15.72(15.20-16.26)$ \\
\hline \multicolumn{7}{|l|}{ PCB118 } \\
\hline$<$ LOD to $50 \%$ & 16 & 14 & 1181 & $3.82(3.06-4.78)$ & $4.14(3.85-4.45)$ & $3.60(3.52-3.68)$ \\
\hline $50 \%$ to $75 \%$ & 4 & 15 & 614 & $5.87(4.78-7.22)$ & 7.04 (6.04-8.21) & $7.24(7.09-7.40)$ \\
\hline$\geq 75 \%$ & 26 & 40 & 1072 & $34.52(22.10-53.93)$ & $19.09(15.52-23.48)$ & $21.64(20.78-22.53)$ \\
\hline \multicolumn{7}{|l|}{ PCB138 } \\
\hline$<$ LOD to $50 \%$ & 11 & 16 & 1776 & $7.06(4.42-11.29)$ & $10.48(7.93-13.83)$ & 7.66 (7.41-7.92) \\
\hline $50 \%$ to $75 \%$ & 19 & 25 & 817 & $21.63(18.62-25.13)$ & $20.40(18.03-23.09)$ & $21.70(21.31-22.09)$ \\
\hline$\geq 75 \%$ & 28 & 35 & 1198 & 75.44 (59.77-95.22) & $47.29(42.38-52.77)$ & $54.04(52.47-55.66)$ \\
\hline \multicolumn{7}{|l|}{ PCB153 } \\
\hline$<$ LOD to $50 \%$ & 9 & 11 & 1268 & $6.51(3.86-10.96)$ & $12.94(8.76-19.12)$ & 9.59 (9.23-9.96) \\
\hline $50 \%$ to $75 \%$ & 11 & 19 & 588 & $30.98(26.72-35.93)$ & $32.36(27.87-7.58)$ & $30.73(30.17-31.31)$ \\
\hline$\geq 75 \%$ & 24 & 39 & 997 & $92.40(73.10-116.79)$ & $68.28(61.11-76.30)$ & $74.12(72.12-76.17)$ \\
\hline \multicolumn{7}{|l|}{ PCB180 } \\
\hline$<$ LOD to $50 \%$ & 11 & 15 & 1840 & $5.78(4.02-8.32)$ & $7.67(5.71-10.30)$ & $6.99(6.69-7.29)$ \\
\hline $50 \%$ to $75 \%$ & 10 & 20 & 765 & $23.44(20.60-26.68)$ & 26.79 (23.64-30.35) & $26.49(26.03-26.96)$ \\
\hline$\geq 75 \%$ & 36 & 40 & 1188 & $67.27(56.16-80.57)$ & $61.44(51.93-72.715)$ & $60.60(59.00-62.25)$ \\
\hline
\end{tabular}

1 Lipid adjusted and log transformed polychlorinated biphenyls $(\mathrm{ng} / \mathrm{g})$ 2 Geometric means calculated after applying NHANES sampling weight ${ }^{*} \mathrm{ABI}<0.7$ (PAD), $0.7<\mathrm{ABI}<0.9$ (AS), \& $0.9<\mathrm{ABI}<1.3$ (Normal)

Table 2.11 summarized adjusted odds ratios (ORs) and 95\% confidence interval $(\mathrm{Cl})$ models for individual PCB congeners $(074,099,118,138,153$, and 180 ) in two groups: $<$ LOD to $50 \% \& \geq 50 \%$. Adjusted models for $<$ LOD to $50 \%$ showed no association between PCB exposure and PAD. However adjusted models for $\geq 50 \%$ showed significant associations for PCB congeners $(074,099$, 118, 138, 153, and 180) and PAD. Table 2.12 demonstrated adjusted ORs and $95 \% \mathrm{Cl}$ models for individual PCB congeners $(074,099,118,138,153$, and 180$)$ 
in three groups: < LOD to $50 \%, 50 \%$ to $75 \%$, and $\geq 75 \%$. Adjusted models for PAD confounders; gender and PAD confounders; age, race, and PAD confounders; and gender, age, race, and PAD confounders showed a significant association between exposure and increased risk of PAD in groups $50 \%$ to $75 \%$ and $\geq 75 \%$. Group < LOD to $50 \%$ showed no association. Table 2.13 shows adjusted ORs and 95\% Cl models for individual PCB congeners in four groups: < LOD to $50 \%, \geq 50 \%,<$ LOD to $75 \%$, and $\geq 75 \%$. Adjusted models in groups $\geq 50 \%$ $\& \geq 75 \%$ showed association between higher exposure of PCBs and increased risk of PAD.

In the adjusted model for PAD confounders (diabetes, smoking, \& alcohol use) at $\geq 50 \% \& \geq 75 \%$, dioxin-like PCBs were significantly associated with PAD [(OR: 2.04; 95\% Cl: $1.81-3.57),(\mathrm{OR}: 2.46 ; 95 \% \mathrm{Cl}: 2.01-11.87)]$ as well as nondioxin-like PCBs [(OR: 1.07; 95\% Cl: 1.02 - 32.59), (OR: 2.64; 95\% Cl: 1.62 10.67)] . After adjusting the model for gender and PAD confounders, dioxin-like PCBs showed association with PAD [(OR: 1.35; 95\% Cl: 1.05 - 1.36), (OR: 3.35; 95\% Cl: $1.35-10.36)$ ] as well as non-dioxin-like PCBs [(OR: 2.38; 95\% Cl: 2.35 - 29.40), OR: $2.59 ; 95 \% \mathrm{Cl}: 2.57$ - 10.62)]. Adjusting the model for age, race, \& PAD confounders the model demonstrated dioxin-like PCBs association with PAD [(OR: $1.95 ; 95 \% \mathrm{Cl}: 0.94-2.36),(\mathrm{OR}: 2.95 ; 95 \% \mathrm{Cl}: 0.94-6.00)]$ together with non-dioxin-like PCBs [(OR: 2.07; 95\% Cl: 0.96 - 12.97), (OR: 2.37; 95\% Cl: 0.96 - 6.97)]. After adjusting the model for gender, age, race, and PAD confounders; dioxin-like PCBs remained significantly associated with PAD [(OR: 1.68; 95\% Cl: 
1.38 - 2.58), (OR: 3.88; 95\% Cl: $1.01-5.08)]$ as well as non-dioxin-like PCBs

[(OR: 2.09; 95\% Cl: 2.09- 14.10), OR: 3.01; 95\% Cl: $1.10-8.13)]$. 
Table 2.11 Estimated ORs \& 95\% Cl of PAD status by concentration of PCB levels among participants $\geq 40$ years of age, NHANES $1999-2004$

\begin{tabular}{|c|c|c|c|c|c|c|c|}
\hline & $A B \mid<0.7^{\star}$ & $0.7<\mathrm{ABI}<0.9^{\star}$ & $0.9<A B \mid<1.3^{*}$ & Adjusted OR $(95 \% \mathrm{Cl})^{2}$ & Adjusted OR $(95 \% \mathrm{Cl})^{3}$ & Adjusted OR $(95 \% \mathrm{Cl})^{4}$ & Adjusted OR $(95 \% \mathrm{Cl})^{5}$ \\
\hline \multicolumn{8}{|l|}{ Analyte' } \\
\hline \multicolumn{8}{|l|}{ РСB074 } \\
\hline$<$ LOD to $50 \%$ & 8 & 11 & 962 & 1 & 1 & 1 & 1 \\
\hline$\geq 50 \%$ & 37 & 58 & 1904 & $1.61(0.64-8.65)$ & $2.72(1.72-4.73)$ & $2.63(1.63-11.64)$ & $2.76(1.75-11.77)$ \\
\hline \multicolumn{8}{|l|}{ РСв099 } \\
\hline$<$ LOD to $50 \%$ & 11 & 13 & 1215 & 1 & 1 & 1 & 1 \\
\hline$\geq 50 \%$ & 46 & 63 & 2549 & $2.92(1.91-5.92)$ & $2.95(1.94-5.95)$ & $1.91(1.60-3.92)$ & $1.95(1.94-2.96)$ \\
\hline \multicolumn{8}{|l|}{ PCB118 } \\
\hline$<$ LOD to $50 \%$ & 16 & 14 & 1181 & 1 & 1 & 1 & 1 \\
\hline$\geq 50 \%$ & 30 & 55 & 1686 & $2.26(0.75-11.26)$ & $3.31(1.31-10.32)$ & $4.08(3.08-9.09)$ & $4.17(1.16-9.17)$ \\
\hline \multicolumn{8}{|l|}{ PCB138 } \\
\hline$<$ LOD to $50 \%$ & 11 & 16 & 1776 & 1 & 1 & 1 & 1 \\
\hline$\geq 50 \%$ & 47 & 60 & 2018 & $1.38(2.37-17.39)$ & $3.39(2.38-12.40)$ & $3.71(1.71-7.72)$ & $3.73(1.72-6.70)$ \\
\hline \multicolumn{8}{|l|}{ PCB153 } \\
\hline$<$ LOD to $50 \%$ & 10 & 12 & 1751 & 1 & 1 & 1 & 1 \\
\hline$\geq 50 \%$ & 49 & 64 & 2050 & $3.45(1.47-25.66)$ & $4.64(2.63-42.65)$ & $2.16(1.95-31.97)$ & $3.33(1.92-29.94)$ \\
\hline \multicolumn{8}{|l|}{ PCB180 } \\
\hline$<$ LOD to $50 \%$ & 11 & 15 & 1840 & 1 & 1 & 1 & 1 \\
\hline$\geq 50 \%$ & 47 & 60 & 1953 & $2.33(1.52-19.55)$ & $3.49(3.47-30.50)$ & $2.00(1.59-17.02)$ & $2.89(2.87-17.90)$ \\
\hline
\end{tabular}

${ }^{1}$ Lipid adjusted and log transformed polychlorinated biphenyls (ng/g)

2 Adjusted for PAD confounders (Diabetes, Smoking, and Alcohol Use)

${ }^{3}$ Adjusted for Gender, \& PAD confounders

${ }^{4}$ Adjusted for Age, Race, \& PAD confounders

${ }^{5}$ Adjusted for Gender, Age, Race, \& PAD confounders

${ }^{*} \mathrm{ABI}<0.7$ (PAD), $0.7<\mathrm{ABI}<0.9$ (AS), \& $0.9<\mathrm{ABI}<1.3$ (Normal)

Table 2.12 Estimated ORs \& 95\% Cl of PAD status by concentration of PCB levels among participants $\geq 40$ years of age, NHANES $1999-2004$

\begin{tabular}{|c|c|c|c|c|c|c|c|}
\hline & $\mathrm{ABI}<0.7^{\star}$ & $0.7<\mathrm{ABI}<0.9^{*}$ & $0.9<\mathrm{ABI}<1.3^{*}$ & Adjusted OR $(95 \% \mathrm{Cl})^{2}$ & Adjusted OR $(95 \% \mathrm{Cl})^{3}$ & Adjusted OR $(95 \% \mathrm{Cl})^{4}$ & Adjusted OR $(95 \% \mathrm{Cl})^{5}$ \\
\hline \multicolumn{8}{|l|}{ Analyte $_{1}$} \\
\hline \multicolumn{8}{|l|}{ РСВ074 } \\
\hline$<$ LOD to $50 \%$ & 8 & 11 & 962 & 1 & 1 & 1 & 1 \\
\hline $50 \%$ to $75 \%$ & 13 & 19 & 803 & $1.78(1.12-10.13)$ & $2.11(1.09-4.21)$ & $1.35(0.54-6.95)$ & $2.45(1.04-4.05)$ \\
\hline$\geq 75 \%$ & 24 & 39 & 1101 & $2.02(1.71-19.73)$ & $3.26(1.45-6.87)$ & $2.59(0.58-7.60)$ & $3.80(1.39-6.99)$ \\
\hline \multicolumn{8}{|l|}{ РСB099 } \\
\hline$<$ LOD to $50 \%$ & 11 & 13 & 1215 & 1 & 1 & 1 & 1 \\
\hline $50 \%$ to $75 \%$ & 19 & 41 & 1621 & $2.58(1.38-4.59)$ & $2.63(1.62-3.63)$ & $1.37(0.13-2.85)$ & $2.24(0.44-3.45)$ \\
\hline$\geq 75 \%$ & 27 & 22 & 928 & $3.50(2.22-6.51)$ & $2.58(1.57-3.59)$ & $1.32(0.31-2.34)$ & $2.46(0.35-2.78)$ \\
\hline \multicolumn{8}{|l|}{ PCB118 } \\
\hline$<$ LOD to $50 \%$ & 16 & 14 & 1181 & 1 & 1 & 1 & 1 \\
\hline $50 \%$ to $75 \%$ & 4 & 15 & 614 & $2.21(1.66-6.68)$ & $2.80(1.80-5.81)$ & $1.76(0.49-3.51)$ & $3.00(0.68-4.70)$ \\
\hline$\geq 75 \%$ & 26 & 40 & 1072 & $2.50(2.73-10.75)$ & $2.89(2.88-6.91)$ & $2.59(2.58-5.60)$ & $3.79(2.77-5.80)$ \\
\hline \multicolumn{8}{|l|}{ PCB138 } \\
\hline$<$ LOD to $50 \%$ & 11 & 16 & 1776 & 1 & 1 & 1 & 1 \\
\hline $50 \%$ to $75 \%$ & 19 & 25 & 817 & $1.75(1.38-10.39)$ & $2.39(1.39-9.40)$ & $1.76(1.26-7.47)$ & $2.48(0.47-5.48)$ \\
\hline$\geq 75 \%$ & 28 & 35 & 1198 & $2.03(1.32-12.74)$ & $3.75(2.33-19.76)$ & $2.28(1.19-23.09)$ & $3.10(2.07-26.11)$ \\
\hline \multicolumn{8}{|l|}{ PCB153 } \\
\hline$<$ LOD to $50 \%$ & 9 & 11 & 1268 & 1 & 1 & 1 & 1 \\
\hline $50 \%$ to $75 \%$ & 11 & 19 & 588 & $3.69(1.03-9.74)$ & $5.64(2.23-10.74)$ & $3.07(1.06-10.08)$ & $3.04(1.03-9.05)$ \\
\hline$\geq 75 \%$ & 24 & 39 & 997 & $4.81(2.24-13.17)$ & $6.84(3.23-14.45)$ & $4.81(1.70-13.73)$ & $4.85(2.64-10.66)$ \\
\hline \multicolumn{8}{|l|}{ PCB180 } \\
\hline$<$ LOD to $50 \%$ & 11 & 15 & 1840 & 1 & 1 & 1 & 1 \\
\hline $50 \%$ to $75 \%$ & 10 & 20 & 765 & $2.67(1.23-8.68)$ & $2.96(1.65-30.66)$ & $3.25(1.66-25.68)$ & $3.62(1.61-19.62)$ \\
\hline$\geq 75 \%$ & 36 & 40 & 1188 & $2.95(1.87-10.33)$ & $3.04(2.23-14.26)$ & $3.92(0.86-16.90)$ & $3.98(0.66-21.71)$ \\
\hline
\end{tabular}

${ }^{1}$ Lipid adjusted and log transformed polychlorinated biphenyls (ng/g)

${ }^{2}$ Adjusted for PAD confounders (Diabetes, Smoking, and Alcohol Use)

${ }^{3}$ Adjusted for Gender, \& PAD confounders

${ }^{4}$ Adjusted for Age, Race, \& PAD confounders

${ }^{5}$ Adjusted for Gender, Age, Race, \& PAD confounders

${ }^{*} \mathrm{ABI}<0.7$ (PAD), $0.7<\mathrm{ABI}<0.9$ (AS), \& $0.9<\mathrm{ABI}<1.3$ (Normal) 
Table 2.13 Estimated ORs (95\% Cls) of PAD status by concentration of dioxin-like \& nondioxin like PCB levels among participants $\geq 40$ years of age, NHANES $1999-2004$

\begin{tabular}{|c|c|c|c|c|c|c|c|}
\hline & $A B I<0.7^{*}$ & $0.7<\mathrm{ABI}<0.9^{*}$ & $0.9<\mathrm{ABI}<1.3^{*}$ & Adjusted OR $(95 \% \mathrm{Cl})^{4}$ & Adjusted OR $(95 \% \mathrm{Cl})^{5}$ & Adjusted OR $(95 \% \mathrm{Cl})^{6}$ & Adjusted OR $(95 \% \mathrm{Cl})^{7}$ \\
\hline \multirow{2}{*}{\multicolumn{8}{|c|}{ Dioxin-like PCBs_50² }} \\
\hline & & & & & & & \\
\hline$<$ LOD to $50 \%$ & 4 & 6 & 71 & 1 & 1 & 1 & 1 \\
\hline$\geq 50 \%$ & 45 & 69 & 1342 & $2.04(1.81-3.57)$ & $1.35(1.05-1.36)$ & $1.95(0.94-2.36)$ & $1.68(1.38-2.58)$ \\
\hline \multicolumn{8}{|c|}{ Dioxin-like PCBs_75² } \\
\hline$<$ LOD to $75 \%$ & 10 & 15 & 90 & 1 & 1 & 1 & 1 \\
\hline$\geq 75 \%$ & 58 & 76 & 1288 & $2.46(2.01-11.87)$ & $3.35(1.35-10.36)$ & $2.95(0.94-6.00)$ & $3.88(1.01-5.08)$ \\
\hline \multicolumn{8}{|c|}{ Non-dioxin-like PCBs_503 } \\
\hline$<$ LOD to $50 \%$ & 15 & 18 & 65 & 1 & 1 & 1 & 1 \\
\hline$\geq 50 \%$ & 61 & 55 & 1710 & $1.07(1.02-32.59)$ & $2.38(2.35-29.40)$ & $2.07(0.96-12.97)$ & $2.09(2.09-14.10)$ \\
\hline \multicolumn{8}{|c|}{ Non-dioxin-like PCBs_75 $75^{3}$} \\
\hline$<$ LOD to $75 \%$ & 6 & 4 & 951 & 1 & 1 & 1 & 1 \\
\hline$\geq 75 \%$ & 59 & 76 & 828 & $2.64(1.62-10.67)$ & $2.59(2.57-10.62)$ & $2.37(0.96-6.97)$ & $3.01(1.10-8.13)$ \\
\hline \multicolumn{8}{|c|}{${ }^{1}$ Lipid adjusted and log transformed polychlorinated biphenyls (ng/g) } \\
\hline \multicolumn{8}{|c|}{2 Adjusted for PAD confounders (Diabetes, Smoking, and Alcohol Use) } \\
\hline \multicolumn{8}{|c|}{${ }^{3}$ Adjusted for Gender \& PAD confounders } \\
\hline \multicolumn{8}{|c|}{${ }^{4}$ Adjusted for Age, Race, \& PAD confounders } \\
\hline \multicolumn{8}{|c|}{${ }^{5}$ Adjusted for Gender, Age, Race, \& PAD confounders } \\
\hline \multicolumn{8}{|c|}{${ }^{*} \mathrm{ABI}<0.7$ (PAD), $0.7<\mathrm{ABI}<0.9$ (AS), \& $0.9<\mathrm{ABI}<1.3$ (Normal) } \\
\hline
\end{tabular}

\section{Discussion}

This cross sectional study representing a sample of the United States demonstrated that higher levels of PCB concentration were associated with participants defined with PAD and atherosclerosis in the general population. We assessed 6 individual PCB congeners, the sum of dioxin-like PCBs, and the sum of non-dioxin like PCBs. Overall analysis of geometric mean levels of PCBs represented by participants identified with PAD, atherosclerosis, age, race, and various covariates was done to assess PCB concentrations in subpopulations. All PCB congeners showed a higher concentration level in both PAD participants and at AS when comparing to the normal population. Although to our knowledge this is the first study investigating PCB association with PAD and AS, our results adds developing evidence to the environmental exposure of PCBs similar to the effects of BPA, another type of endocrine disrupting chemical in cardiovascular disease (Lang et al., 2008; Melzer et al., 2010). Furthermore because PAD is a subclinical 
marker for atherosclerosis, our findings may elucidate that possible effects of PCBs on atherosclerosis may be an essential mechanism previously reporting an association between PCB exposure and the development of obesity and obesityassociated atherosclerosis (Arsenescu et al., 2008).

Polychlorinated Biphenyls are a group of man-made organic chemicals that consist of chlorine, hydrogen, and carbon atoms. Today PCBs can still be released in the environment from illegal dumping of PCB wastes, burning wastes in industrial and municipal incinerators, leaks from electrical transformers containing PCBs, and improper or poorly maintained hazardous sites containing PCBs (EPA). While there has not been any previously studies done in NHANES linking PCB exposure to PAD and AS recent studies have linked exposure to BPA to peripheral arterial disease (Shankar et al., 2012) and heart disease (Melzer et al., 2010).

Numerous lines of evidence suggest that a link between levels of PCB concentrations and PAD and/or AS may be biologically conceivable. Significant associations between PCBs, lipids, age, BMI, and CVD in a Native American population demonstrate a consistency with a model in which age is considered both a biological driving mechanism and exogenous explanatory variable (Goncharov et al., 2008). Dioxin-like PCB 126 effects CVD risk factors on female experimental rodents such as blood pressure, heart weight, and serum cholesterol (Lind et al., 2004). Furthermore higher levels of PCB concentration in HDL demonstrated links to CVD (Ljunggren et al., 2014). Previously we have reported planar and coplanar PCBs induce expression of various genes compared to 
estradiol that have biological relevance to signaling in pulmonary vascular lesions (Felty et al., 2010). Additionally, ID3 a molecule that has been demonstrated to be involved in vascular diseases has provided evidence linking its vital role in regulating both vascular endothelial cell survival and microvascular lesion development by endocrine disrupting chemicals such as PCB153 (Das \& Felty., 2014).

Our study includes a nationally representative sample of the United States population and provides a rigorous methodology of collecting, analyzing, and having multiple confounding data point's accessible to the public. (NCHS 2010a, 2010b). Further strengths include availability of biological measurements of endocrine disrupting chemicals and oversampling of minority populations making it possible to have a complete representation of the US population. However a limitation that we have on our study is since it is a cross-sectional study, it makes it difficult to validate the exposure ensued the overall outcome. Additionally observed associations could be potentially confounded by lack of data on geographical location of family history and/or geographic location of some variables.

\section{Conclusion}

In a nationally representative sample of the U.S. population higher levels of PCB exposure were associated with increased risk of PAD as well as atherosclerosis subsequently adjusting for covariate factors. While our results must be established in other studies, they provide preliminary evidence that 
environmental exposure to PCBs may contribute to increased risk of PAD and/or

AS.

References

1. Newman AB, Siscovick DS, Manolio TA, Polak J, Fried LP, Borhani NO, et al. Cardiovascular Heart Study (CHS) Collaborative Research Group. Ankle-arm index as a marker of atherosclerosis in the Cardiovascular Health Study. Circulation. 1993; 88:837-845.

2. Felty Q. Yoo C. Kennedy A. Gene expression profile of endothelial cells exposed to estrogenic environmental compounds: implications to pulmonary vascular lesions. Life Sciences. 2010; 86 (25-26):919-27.

3. Murabito JM, Evans JC, Larson MG, Nieto K, Levy D, Wilson PW. The anklebrachial index in the elderly and risk of stroke, coronary disease, and death: the Framingham Study. JAMA Archives of Internal Medicine. 2003; 163:1939-1942.

4. Criqui MH, Langer RD, Fronek A, Feigelson HS, Klauber MR, McCann TJ, et al. Mortality over a period of 10 years in patients with peripheral arterial disease. New England Journal of Medicine. 1992; 326:381-386.

5. American Diabetes Association. Peripheral arterial disease in people with diabetes. Diabetes Care. 2003; 26:3333-3341.

6. Hirsch AT, Haskal ZJ, Hertzer NR, Bakal CW, Creager MA, Halperin JL, et al. ACC/AHA 2005 Practice Guidelines for the management of patients with peripheral arterial disease (lower extremity, renal, mesenteric, and abdominal aortic): a collaborative report from the American Association for Vascular Surgery/Society for Vascular Surgery, Society for Cardiovascular Angiography and Interventions, Society for Vascular Medicine and Biology, Society of Interventional Radiology, and the ACC/AHA Task Force on Practice Guidelines (Writing Committee to Develop Guidelines for the Management of Patients With Peripheral Arterial Disease). Circulation. 2006; 113:e463-e654.

7. Selvin E, Manzi J, Stevens LA, Van Lente F, Lacher DA, Levey AS, et al. Calibration of serum creatinine in the National Health and Nutrition Examination Surveys (NHANES) 1988-1994, 1999-2004. American Journal of Kidney Diseases. 2007; 50:918-926.

8. NCHS (National Center for Health Statistics). 2010a. 2003-2004 National Health and Nutrition Examination Survey: 2003-2004 Data Documentation, Codebook, and Frequencies-Lower Extremity Disease-Ankle Brachial Blood Pressure Index (LEXAB_C). Available: http://www.cdc.gov/nchs/nhanes/nhanes2003-2004/LEXAB C.htm. 
9. Morgan M, Deoraj A, Felty Q, Roy D. Environmental estrogen-like endocrine disrupting chemicals and breast cancer. Molecular and Cellular Endocrinology. 2016; http://dx.doi.org/10.1016/j.mce.2016.10.003.

10. Roy D, Morgan M, Yoo C, Deoraj A, Roy S, Yadav VK, Garoub M, Assaggaf H, Doke M. Integrated Bioinformatics, Environmental Epidemiologic and Genomic Approaches to Identify Environmental and Molecular Links between Endometriosis and Breast Cancer. International Journal of Molecular Sciences. 2015; 16, 2528525322.

11. Sacks D, Bakal CW, Beatty PT, et al. Position statement on the use of the ankle-brachial index in the evaluation of patients with peripheral vascular disease: a consensus statement developed by the standards division of the Society of Cardiovascular \& Interventional Radiology. Journal of Vascular and Interventional Radiology. 2002; 13: 353.

12. CDC (Centers for Disease Control and Prevention). 2013b. National Health and Nutrition Examination Survey: Analytic Guidelines, 1999-2010. Vital Health Stat 2 (161). Available: http://www.cdc.gov/nchs/data/series/sr 02/sr02 161.pdf.

13. Hirsch AT, Murphy TP, Lovell MB, et al. Gaps in public knowledge of peripheral arterial disease. The first national PAD public awareness survey. Circulation. 2007; 116: 2086-94.

14. Vandenberg LN, Maffini MV, Sonnenschein C, Rubin BS, Soto AM. Bisphenol$A$ and the great divide: a review of controversies in the field of endocrine disruption. Endocrine Reviews. 2009; 30:75-95.

15. CDC (Centers for Disease Control and Prevention). National Health and Nutrition Examination Survey Questionnaires, Datasets, and Related Documentation. 2012; Available: https://www.cdc.gov/nchs/nhanes/nhanes_questionnaires.htm

16. CDC (Centers for Disease Control and Prevention). 2013b. National Health and Nutrition Examination Survey: Analytic Guidelines, 1999-2010. Vital Health Stat 2 (161). Available: http://www.cdc.gov/nchs/data/series/sr 02/sr02 161.pdf.

17. CDC (Centers for Disease Control and Prevention). Fourth National Report on Human Exposure to Environmental Chemicals.

18. Lang IA, Galloway TS, Scarlett A, Henley WE, Depledge M, Wallace RB, et al. Association of urinary bisphenol $A$ concentration with medical disorders and laboratory abnormalities in adults. JAMA. 2008; 300:1303-1310.

19. Melzer D, Rice NE, Lewis C, Henley WE, Galloway TS. Association of Urinary Bisphenol A Concentration with Heart Disease: Evidence from NHANES 2003/06. PLoS One. 2010; 5(1): e8673. 
20. Goncharov A, Haase RF, Santiago-Rivera A, Morse G, Akwesasne Task Force on the Environment, McCaffrey RJ, Rej R, Carpenter DO. High serum PCBs are associated with elevation of serum lipids and cardiovascular disease in a Native American population. Environmental Research. 2008; Volume 106, Issue 2, Pages 226-239.

21. Lind PM, Örberg J, Edlund UB, Sjöblom L, Lind L. The dioxin-like pollutant PCB 126 (3,3',4,4',5-pentachlorobiphenyl) affects risk factors for cardiovascular disease in female rats. Toxicology Letters. 2004; Volume 150, Issue 3, Pages 293-299.

22. Ljunggren SA, Helmfrid I, Salihovic S, van Bavel B, Wingren G, Lindahl M, Karlsson H. Persistent organic pollutants distribution in lipoprotein fractions in relation to cardiovascular disease and cancer. Environment International. 2014; Volume 65, Pages 93-99. 


\title{
CHAPTER IV
}

\section{MANUSCRIPT 3}

Association of endocrine disrupting chemical exposure in Peripheral Arterial

Disease (PAD) Among the U.S. Population: NHANES $1999-2004$

\begin{abstract}
Background. Recent reports have continuously shown that the human population get exposed to a wide range of endocrine disrupting chemicals. In particular phthalates \& bisphenol A (BPA) have been detected in more than $90 \%$ of urine and blood samples collected (Silva et al 2004; Woodruff et al 2011; Calafat et al 2008). Although previous reports from various data have demonstrated association between phthalates \& BPA with various diseases the bridge between phthalates \& BPA with peripheral arterial disease is limited.
\end{abstract}

Objectives. The purpose of this study is to examine association between exposure to endocrine disrupting chemicals (EDCs) \& peripheral arterial disease (PAD) in a nationally represented sample of the U.S. population.

Methods. We utilized participants in the National Health and Nutritional Examination Survey (NHANES) in 1999 - 2004. We estimated associations between exposure to EDCs (phthalates in 1999 - 2004 \& bisphenol A in 2003 2004) respectively and PAD using complex survey and logistic regression models adjusted for potential confounders. 
Results. Individual analyses showed phthalate metabolites: MnBP and MBzP alongside BPA to be higher among participants with PAD and AS when compared to the rest of the study population. Adjusted models for PAD confounders showed association between phthalate metabolites $\geq$ LOD and participants with PAD and AS: MnBP (OR: 1.33; 95\%: 1.00 - 2.34); MBzP (OR: 1.16; 95\% Cl: $1.08-2.01$ ) and BPA (OR: 1.22; 95\% Cl: $1.02-5.07)$. Furthermore after adjusting the model for gender and PAD confounders; age, race, and PAD confounders; and gender, age, race, and PAD confounders we demonstrated association between phthalate metabolites \& BPA with PAD participants and AS.

Conclusion. Our findings suggest a relationship between higher environmental exposure of certain phthalate metabolites \& BPA and increased risk of peripheral arterial disease (PAD) and atherosclerosis (AS).

Key words: ankle - brachial index, bisphenol A, endocrine disrupting chemicals, NHANES, peripheral arterial disease, phthalates 


\section{Introduction}

The US EPA (United States Environmental Protection Agency) outlines endocrine disrupting chemicals (EDCs) as "agents that interferes with the synthesis, transport, elimination, binding, or secretion of natural hormones in the body that are responsible for the maintenance of reproduction, homeostasis, behavior, and/or development." (Kavlock et al., 1996). While numerous chemicals have EDC activity the most studied chemicals today include phthalates and bisphenol A (BPA). Phthalates consist of a wide variety of products that include medical tubing, cosmetics, plastics, and coatings. (Gore et al., 2015). Bisphenol A is used in products such as toys, food packaging, manufacturing, and other applications. Due to the fact that essentially everyone uses these day-to-day products, the overall population is continually exposed. (Meeker and Ferguson. 2011). While earlier research has concentrated on the role of phthalates and bisphenol A (BPA) in cancer, reproductive, and developmental health problems; existing research has established associations between diabetes, obesity, and cardiovascular disease (Anway et al. 2005; Lang et al. 2008; Melzer et al. 2010; Morgan et al., 2016). Although these establishments have been seen throughout the literature it is warranted to extend that investigation to peripheral arterial disease in order to further bridge the gap in knowledge

In this study, we examined the independent association between individual phthalates and bisphenol A (BPA) with diagnosis of peripheral arterial disease and participants with atherosclerosis with participants in the NHANES (National Health 
and Nutrition Examination Survey) 3-year cycle for phthalates: 1999 - 2004 and 1year cycle 2003-2004 for bisphenol A (BPA). The aim of this study is to assess: 1) the mean phthalate levels in PAD defined participants and defined with atherosclerosis compared to non-diagnosed participants; and 2) the mean bisphenol A (BPA) levels in PAD defined participants and atherosclerosis compared to non-diagnosed participants, and 3) the association between higher EDC exposure and increased risk of PAD/AS respectively.

\section{Methods}

Study design and population. NHANES survey encompasses stratified multistage probability sample representative of the civilian non-institutionalized U.S. population. The study is recognized based on data from NHANES 1999 2004. Selection was based on individuals within households, households, blocks, counties and included the oversampling of non-Hispanic blacks and Mexican Americans in order to deliver consistent evaluations of these groups. Participants provided written informed consent before their participation. Additionally approval was acquired from the Human Subjects Committee in the U.S. Department of Health and Human Services. ABI measurements which is a subclinical measure of atherosclerosis (Criqui et al. 1992; Newman et al. 1993), were acquired for the subsample of participants $\geq 40$ years of age. The current study sample consisted of participants $\geq 40$ years of age among whom endocrine disrupting chemicals was available. This resulted in participants (461), of whom had PAD and participants (390) whom were atherosclerosis defined in NHANES 1999 - 2004 and 178 PAD 
defined participants; 94 atherosclerosis participants; and 1850 normal participants respectively. Subjects who were omitted because of missing covariates were in general comparable to the NHANES group in terms of sex, age, race/ethnicity, and education (data not shown). Secondary examination of the nationally collected data was done using variables of interest, which were only measured concurrently during the three NHANES cycles from 1999 - 2000, 2001 - 2002, and 2003 - 2004. NHANES uses a multifaceted sampling design (multistage, probability, cluster and stratified) for continuous collection and release of 2-year cross-sectional data sets. Approval for these suitable examinations and laboratory testing were given to NHANES by the CDC/ATSDR institutional review board of the CDC. The current study was considered exempt from review by the local institutional review board.

Peripheral Arterial Disease (PAD) diagnosis. The NHANES ABI is regularly calculated, verified, and released by the National Center for Health Statistics. Systolic pressure is measured on the right arm (brachial artery) and both ankles (posterior tibial arteries). If the participant has one of the following: 1) a rash; 2 ) open wound on the right arm; 3) dialysis shunt; 4) right-sided radical mastectomy; or any extra condition that would obstruct with correct measurement or cause discomfort to the participant, the left arm is utilized for the brachial pressure measurement. Systolic blood pressure is measured twice at each site for participants 40-59 years old and once at each site for participants $\geq 60$ years old and older. If a health technician cannot obtain a reading at a site they may attempt an additional reading at the same site after a short-term resting period. The right ABPI was obtained by dividing the mean systolic blood pressure in the right ankle 
by the mean blood pressure in the arm. The left ABPI was obtained by dividing the mean systolic blood pressure in the left ankle by the mean blood pressure in the arm. The mean blood pressure value for the arm and ankles are computed based on the first and second reading at each site. As the second reading for all participants $\geq 60$ years old is missing the mean values are in fact the first recorded blood pressure reading at a site. This may furthermore be correct for participants 40-59 years old who have a missing value for the first or second blood pressure reading. Individuals are omitted from the exam if they weigh over 400 pounds (weight limitations of equipment) or have bilateral amputations. Additionally to some participants who were eligible for the exam ( $\geq 40$ years old) might not have received the exam due to various reasons including: casts, ulcers, dressings, or other conditions of the participant interfered with testing; participant could not understand the test instructions or became ill \& the test could not be performed; there was an equipment failure; participant refused; participant came late or left early from the MEC \& the LED exam could not be performed; and some other reason. As a result, these eligible individuals will have missing data for the ABPI variables. Peripheral arterial disease diagnosis was defined as having an ankle brachial index $(\mathrm{ABI})<0.7$. Values $0.9<\mathrm{ABI}<1.3$ were considered normal. Individuals whom demonstrated $0.7<\mathrm{ABI}<0.9$ was defined as atherosclerosis.

Measurements of phthalates \& bisphenol A. Both phthalates and bisphenol A were calculated in urine by the SPE (solid phase extraction) coupled to reverse phase HPLC-MS/MS (high performance liquid chromatography-tandem mass spectrometry). Laboratory methods and quality control were reliable across survey 
years and in which documentation is available online (CDC, 2012). Overall we investigated 7 phthalate metabolites measured in NHANES years 1999 - 2004: mono-n-butyl phthalate (MnBP), mono-cyclohexyl phthalate (MCHP), mono-ethyl phthalate (MEP), mono-2-ethylhexyl phthalate (MEHP), mono-isobutyl phthalate (MiBP), mono-n-octyl phthalate (MOP), and mono-bezyl phthalate (MBzP). BPA (bisphenol A) was the only phenol included in this study. In order to adjust for urine dilution, we divided all phthalate metabolites and BPA by urinary creatinine concentration and used the resultant corrected creatinine concentrations $(\mathrm{mg} / \mathrm{g})$ for all of our analyses. Urine samples with creatinine that represented levels $>300$ $\mathrm{mg} / \mathrm{dL}$ or $<30 \mathrm{mg} / \mathrm{dL}$ were excluded in the analysis because the sample(s) were over-concentrated for an accurate examination (Sata et al., 1995). Furthermore we provided a limit of detection (LOD) variable for each phthalate metabolite and BPA in the datasets. The variable is defined with two values: "1" represents the result was below the limit of detection and "2" represents the result was equal or above the limit of detection.

Covariates. We considered a range of confounders based on well-established risk factors for peripheral arterial disease and review of the literature. The resultant confounders were self-reported in the questionnaire interviews or taken as laboratory measurements. The demographic variables of gender (men/women), race (Mexican American, Other Hispanic, Non-Hispanic White, Non-Hispanic Black, and other race) and age ( $\geq 40-59,60-74$, and $\geq 75)$ were obtained during the NHANES home interview (CDC, 2012). Others obtained include: smoking, BMI 
(18.5 to $<25,25$ to $<30, \& \geq 30$ ), diabetes (yes/no), estradiol levels, sex hormone binding globulin, testosterone, and education.

Statistical Analysis. Analysis were performed using SAS 9.4 (SAS Institute Inc.; Cary, NC, USA). Appropriate subsampling weights were calculated according to the National Center for Health Statistics guidelines to adjust for oversampling of minority groups (CDC, 2013b). All urinary chemicals and metabolites were log transformed and creatinine adjusted. PROC SURVEYMEANS was used to account for the complex sampling design of NHANES and furthermore obtain means (weighted), 95\% confidence intervals, and standard errors of individual phthalate metabolites and BPA. Age was divided into three groups ( $\geq 40-59,60-$ 74 , and $\geq 75$ years old). A two-sided student t-test was measured using PROC SURVEYREG to test if the mean EDC (phthalates/BPA) levels between participants who were defined with PAD, AS, and normal participants were significantly different. Geometric mean (GM) levels and geometric standard errors (GSE) were reported for peripheral arterial disease status, AS status, age at interview, and race/ethnicity for all participants with individual phthalate metabolites \& BPA levels. Age was divided into three groups ( $\geq 40-59$ years, 6074 years, and $\geq 75$ years) that were selected based on the age distribution of PAD cases, cases of AS, and normal cases in the population. Race/ethnicity was divided into five groups (Mexican American, other Hispanic, Non-Hispanic White, Non-Hispanic Black, and other race). 


\section{Results}

Phthalate and Bisphenol A Descriptive Statistics. The study population for phthalates includes 3,489 men and 3,125 women from NHANES cycles 1999 2004 with available data and who are either identified with peripheral arterial disease $(n=461)$, atherosclerosis defined $(n=390)$, or as a normal participant ( $n$ $=5773)$ as shown in Table 3.1. Bisphenol A population from NHANES $2003-2004$ includes 868 men and 946 women from NHANES cycle 2003 - 2004 with available data (Table 3.2). Overall 178 participants are diagnosed with PAD; 94 whom are at identified with atherosclerosis; and 1850 whom are considered normal participants. The majority of the participants in the phthalate population was NonHispanic White: 268 (3.72\%) for PAD participants; 236 (4.90\%) for participants with AS; and 3,125 (69.64\%) normal diagnosed participants. Table 3.3 displays Cases/Non-Cases, geometric means (GM), and geometric standard error (GSE). GM of particular phthalate metabolites were significantly higher in participants diagnosed with PAD and AS when compared to normal diagnosed participants. Those phthalate metabolites include: MnBP (27.12 \& 24.99 vs. 24.16) and MBzP (13.63 \& 12.21 vs. 11.69). Furthermore, BPA also showed significant higher GM in diagnosis of PAD and AS when compared to normal participants (4.65 \& 7.67 vs. 2.73). Table 3.4 illustrates estimated odds ratios (ORs) and $95 \%$ confidence intervals (Cls) for phthalate metabolites and bisphenol A adjusted for 1) PAD confounders (diabetes, smoking, and alcohol use); 2) gender and PAD confounders 3) age, race, BMI, \& PAD confounders; and 4) gender, age, race, BMI and PAD confounders. In the PAD confounders adjusted model phthalate 
metabolites: MnBP (OR: 1.33; 95\% Cl: $1.00-2.34$ ) and MBzP (OR: 1.16; 95\% Cl: $1.08-2.01$ ) showed significant association with PAD and AS when exposure is $\geq$ LOD. Furthermore bisphenol A also showed significant association with PAD and AS when exposure is $\geq$ LOD (OR: $1.22 ; 95 \% \mathrm{Cl}: 1.02-5.07$ ). In the gender and PAD confounders adjusted model phthalate metabolites: MnBP (OR: 1.83; 95\% Cl: 1.00 - 2.34); MCHP (OR: 1.54; 95\% Cl: $1.00-2.10)$, MEP (OR: $1.01 ; 95 \% \mathrm{Cl}$ : $0.44-1.09$ ) and MBzP (OR: 1.76; 95\% Cl: 1.58 - 2.91) showed significant association with PAD and AS when exposure is $\geq$ LOD. BPA showed significant association with PAD and AS when exposure is $\geq$ LOD (OR: $2.8995 \% \mathrm{Cl}: 1.50$ 10.19). The age, race, BMI, and PAD confounders model demonstrated that phthalate metabolites: MnBP (OR: 1.33; 0.89 - 2.95); MCHP (OR: 1.39; 95\% Cl: 1.00 - 1.65); and MiBP (OR: 1.48; 95\% Cl: 1.12 - 1.87) showed significant association with PAD and AS when exposure is $\geq$ LOD. In the final model adjusted for gender, age, race, BMI, and the PAD confounders phthalate metabolites MCHP (OR: $1.34 ; 95 \% \mathrm{Cl}: 1.22-1.59)$ and MiBP (OR: $1.41 ; 95 \% \mathrm{Cl}: 0.99-1.83)$ showed significant association with PAD and AS when exposure is $\geq$ LOD. BPA also showed significant association (OR: $3.02 ; 95 \% \mathrm{Cl}: 0.14-12.15)$ with PAD and AS when exposure is $\geq L O D$. 
Table 3.1 Descriptive statistics for PAD \& selected covariates among participants $\geq \mathbf{4 0}$ years of age, NHANES $1999-2004$.

\begin{tabular}{|c|c|c|c|}
\hline \multicolumn{4}{|l|}{ Variable } \\
\hline & $\mathrm{ABI}<0.7^{\star} \mathrm{n}(\%)$ & $0.7<\mathrm{ABI}<0.9^{\star} \mathrm{n}(\%)$ & $0.9<\mathrm{ABI}<1.3^{\star} \mathrm{n}(\%)$ \\
\hline Total Population n (\%) & $461(6.96 \%)$ & $390(5.888 \%)$ & $5773(87.152 \%)$ \\
\hline \multicolumn{4}{|l|}{ Gender } \\
\hline Male & $228(1.947 \%)$ & $275(3.9918 \%)$ & $2986(43.8267 \%)$ \\
\hline Female & $233(2.7315 \%)$ & $115(1.7774 \%)$ & $2787(45.7256 \%)$ \\
\hline \multicolumn{4}{|l|}{ Race/Ethnicity } \\
\hline Mexican American & $72(0.1567 \%)$ & $103(0.3131 \%)$ & $1231(4.1428 \%)$ \\
\hline Other Hispanic & $12(0.1152 \%)$ & $11(0.2016 \%)$ & $221(4.0714 \%)$ \\
\hline Non-Hispanic White & $268(3.7214 \%)$ & $236(4.894 \%)$ & $3125(69.6389 \%)$ \\
\hline Non-Hispanic Black & $100(0.5863 \%)$ & $31(0.1975 \%)$ & $1013(7.8865 \%)$ \\
\hline Other Race & $9(0.0989 \%)$ & $9(0.1622 \%)$ & $183(3.8127 \%)$ \\
\hline \multicolumn{4}{|l|}{ Age at interview (years) } \\
\hline$\geq 40-59$ & $67(1.1721 \%)$ & $180(3.7787 \%)$ & $3078(61.729 \%)$ \\
\hline $60-74$ & $199(2.0057 \%)$ & $155(1.5675 \%)$ & $1924(20.8257 \%)$ \\
\hline$\geq 75$ & $195(1.5007 \%)$ & $55(0.423 \%)$ & $771(6.9976 \%)$ \\
\hline \multicolumn{4}{|l|}{ Ever Smoked } \\
\hline Yes & $72(1.8416 \%)$ & $31(1.134 \%)$ & $764(30.244 \%)$ \\
\hline Sometimes & $10(0.2441 \%)$ & $10(0.2571 \%)$ & $117(3.9327 \%)$ \\
\hline No & $150(3.6785 \%)$ & $140(5.0162 \%)$ & $1493(53.6517 \%)$ \\
\hline \multicolumn{4}{|l|}{ Alcohol Use } \\
\hline Yes & $0(0.00 \%)$ & $2(0.0411 \%)$ & $24(0.5721 \%)$ \\
\hline No & $333(4.5564 \%)$ & $324(6.2234 \%)$ & $4415(88.6069 \%)$ \\
\hline \multicolumn{4}{|l|}{ BMI } \\
\hline Normal Weight $(18.5$ to $<25)$ & $105(1.3733 \%)$ & $86(1.7261 \%)$ & $1205(26.2679 \%)$ \\
\hline Overweight $(25$ to $<30)$ & $129(1.6091 \%)$ & $120(2.3676 \%)$ & $1755(34.4198 \%)$ \\
\hline Obese $(\geq 30)$ & $88(1.3574 \%)$ & $119(2.1868 \%)$ & $1450(28.692 \%)$ \\
\hline \multicolumn{4}{|l|}{ Diabetes } \\
\hline Yes & $81(0.9209 \%)$ & $46(0.5002 \%)$ & $520(7.4332 \%)$ \\
\hline No & $251(3.527 \%)$ & $283(5.6672 \%)$ & $3903(80.3218 \%)$ \\
\hline Boarderline & $9(0.1072 \%)$ & $3(0.0905 \%)$ & $84(1.3882 \%)$ \\
\hline Don't know & $0(0.00 \%)$ & $0(0.00 \%)$ & $2(0.0437 \%)$ \\
\hline \multicolumn{4}{|l|}{ Estradiol (pg/mL) } \\
\hline$<5$ & $1(0.0545 \%)$ & $1(0.1399 \%)$ & $4(1.1599 \%)$ \\
\hline May-95 & $21(3.1751 \%)$ & $31(9.1967 \%)$ & $323(85.4413 \%)$ \\
\hline $95-185$ & $1(0.0867 \%)$ & $0(0.00 \%)$ & $2(0.6376 \%)$ \\
\hline$>185$ & $0(0.00 \%)$ & $0(0.00 \%)$ & $1(0.1084 \%)$ \\
\hline \multicolumn{4}{|c|}{ Sex Hormone Binding Globulin (nmol/L) } \\
\hline $0.350-90$ & $20(2.8754 \%)$ & $31(9.3131 \%)$ & $306(82.6883 \%)$ \\
\hline $90-180$ & $2(0.3553 \%)$ & $1(0.0267 \%)$ & $21(4.3095 \%)$ \\
\hline$>180$ & $1(0.0867 \%)$ & $0(0.00 \%)$ & $2(0.3449 \%)$ \\
\hline
\end{tabular}




\begin{tabular}{|c|c|c|c|}
\hline \multicolumn{4}{|l|}{ Testostosterone (ng/mL) } \\
\hline $0.020-9$ & $22(3.2402 \%)$ & $32(9.3673 \%)$ & $318(84.4869 \%)$ \\
\hline 12-Sep & $0(0.00 \%)$ & $0(0.00 \%)$ & $8(2.5649 \%)$ \\
\hline$>12$ & $1(0.087 \%)$ & $0(0.00 \%)$ & $2(0.2538 \%)$ \\
\hline \multicolumn{4}{|l|}{ Education } \\
\hline$<9$ th Grade & $120(0.6988 \%)$ & $74(0.3937 \%)$ & $976(6.1832 \%)$ \\
\hline 9-11th Grade (Includes 12th grade with no diploma) & $76(0.7538 \%)$ & $45(0.5289 \%)$ & $860(10.5315 \%)$ \\
\hline High School Grad/GED or Equivalent & $117(1.4821 \%)$ & $65(1.1016 \%)$ & $1382(23.692 \%)$ \\
\hline Some College or AA degree & $91(1.0934 \%)$ & $103(1.7124 \%)$ & $1403(25.4172 \%)$ \\
\hline College Graduate or above & $54(0.6319 \%)$ & $102(2.0203 \%)$ & $1142(23.6305 \%)$ \\
\hline Refused & $0(0.00 \%)$ & $0(0.00 \%)$ & $3(0.0219 \%)$ \\
\hline Don't Know & $3(0.0186 \%)$ & $1(0.0124 \%)$ & $6(0.0757 \%)$ \\
\hline \multicolumn{4}{|l|}{ Income } \\
\hline$\$ 0$ to $\$ 4,999$ & $14(0.0897 \%)$ & $12(0.1544 \%)$ & $161(1.7935 \%)$ \\
\hline$\$ 5,000$ to $\$ 9,999$ & $56(0.4762 \%)$ & $22(0.1865 \%)$ & $378(4.1621 \%)$ \\
\hline$\$ 10,000$ to $\$ 14,999$ & $77(0.6941 \%)$ & $33(0.2147 \%)$ & $580(6.1557 \%)$ \\
\hline$\$ 15,000$ to $\$ 19,999$ & $55(0.4726 \%)$ & $22(0.1933 \%)$ & $459(5.1039 \%)$ \\
\hline$\$ 20,000$ to $\$ 24,999$ & $40(0.3538 \%)$ & $29(0.3374 \%)$ & $473(5.5343 \%)$ \\
\hline$\$ 25,000$ to $\$ 34,999$ & $67(0.7037 \%)$ & $35(0.5199 \%)$ & $670(9.4058 \%)$ \\
\hline$\$ 35,000$ to $\$ 44,999$ & $30(0.3397 \%)$ & $37(0.462 \%)$ & $524(8.463 \%)$ \\
\hline$\$ 45,000$ to $\$ 54,999$ & $27(0.3059 \%)$ & $32(0.4788 \%)$ & $458(8.3173 \%)$ \\
\hline$\$ 55,000$ to $\$ 64,999$ & $15(0.276 \%)$ & $21(0.379 \%)$ & $322(6.6019 \%)$ \\
\hline$\$ 65,000$ to $\$ 74,999$ & $10(0.1592 \%)$ & $22(0.3727 \%)$ & $253(5.1088 \%)$ \\
\hline$\$ 75,000$ and over & $25(0.3829 \%)$ & $93(2.0818 \%)$ & $995(22.9582 \%)$ \\
\hline Over $\$ 20,000$ & $19(0.3009 \%)$ & $14(0.2414 \%)$ & $194(3.2409 \%)$ \\
\hline Under $\$ 20,000$ & $9(0.0873 \%)$ & $7(0.0566 \%)$ & $99(1.1958 \%)$ \\
\hline Refused & $6(0.0394 \%)$ & $5(0.0464 \%)$ & $90(1.0123 \%)$ \\
\hline Don't know & $6(0.0238 \%)$ & $5(0.0711 \%)$ & $51(0.4455 \%)$ \\
\hline
\end{tabular}

Estimated percent distribution after applying NHANES sampling weights

${ }^{*} \mathrm{ABI}<0.7$ (PAD). $0.7<\mathrm{ABI}<0.9$ (AS), \& $0.9<\mathrm{ABI}<1.3$ (Normal) 
Table 3.2 Descriptive statistics for PAD \& selected covariates among participants $\geq \mathbf{4 0}$ years of age with bisphenol A (BPA) measurements NHANES 2003 - 2004.

\begin{tabular}{|c|c|c|c|}
\hline \multicolumn{4}{|l|}{ Variable } \\
\hline & $\mathrm{ABI}<0.7^{\star} \mathrm{n}(\%)$ & $0.7<\mathrm{ABI}<0.9^{\star} \mathrm{n}(\%)$ & $0.9<\mathrm{ABI}<1.3^{\star} \mathrm{n}(\%)$ \\
\hline Total Population n (\%) & $178(8.40 \%)$ & $94(4.40 \%)$ & $1850(87.20 \%)$ \\
\hline \multicolumn{4}{|l|}{ Gender } \\
\hline Male & $81(4.01 \%)$ & $39(2.26 \%)$ & $748(41.03 \%)$ \\
\hline Female & $76(4.62 \%)$ & $42(2.00 \%)$ & $828(46.11 \%)$ \\
\hline \multicolumn{4}{|l|}{ Race/Ethnicity } \\
\hline Mexican American & $49(0.84 \%)$ & $24(0.45 \%)$ & $467(2.03 \%)$ \\
\hline Other Hispanic & $12(0.77 \%)$ & $0(0.00 \%)$ & $60(3.08 \%)$ \\
\hline Non-Hispanic White & $62(5.32 \%)$ & $45(4.01 \%)$ & $695(58.81 \%)$ \\
\hline Non-Hispanic Black & $37(0.81 \%)$ & $20(0.36 \% 0$ & $471(11.05 \%)$ \\
\hline Other Race & $10(0.78 \%)$ & $4(0.18 \%)$ & $77(5.03 \%)$ \\
\hline \multicolumn{4}{|l|}{ Age at Interview (years) } \\
\hline$\geq 40-59$ & $23(5.65 \%)$ & $8(1.91 \%)$ & $22453.36 \%)$ \\
\hline $60-74$ & $23(4.50 \%)$ & $12(1.68 \%)$ & $197(22.11 \%)$ \\
\hline$\geq 75$ & $10(0.79 \%)$ & $7(0.66 \%)$ & $129(11.34 \%)$ \\
\hline \multicolumn{4}{|l|}{ Smoking } \\
\hline Yes & $35(3.80 \%)$ & $20(2.09 \%)$ & $300(32.52 \%)$ \\
\hline Sometimes & $2(0.27 \%)$ & $1(0.027 \%)$ & $65(7.16 \%)$ \\
\hline No & $45(4.95 \%)$ & $13(1.47 \%)$ & $435(47.72 \%)$ \\
\hline \multicolumn{4}{|l|}{ BMI } \\
\hline Normal Weight $(18.5$ to < 25) & $47(4.12 \%)$ & $25(1.89 \%)$ & $451(33.44 \%)$ \\
\hline Overweight $(25$ to $<30)$ & $27(2.10 \%)$ & $12(0.80 \%)$ & $310(23.68 \%)$ \\
\hline Obese $(\geq 30)$ & $35(3.09 \%)$ & $55(4.77 \%)$ & $1133(85.97 \%)$ \\
\hline \multicolumn{4}{|l|}{ Diabetes } \\
\hline Yes & $6(0.40 \%)$ & $3(0.26 \%)$ & $91(4.51 \%)$ \\
\hline No & $150(8.15 \%)$ & $78(3.97 \%)$ & $1470(81.80 \%)$ \\
\hline Boarderline & $1(0.08 \%)$ & $0(0.00 \%)$ & $15(0.83 \%)$ \\
\hline \multicolumn{4}{|l|}{ Estradiol (pg/mL) } \\
\hline$<5$ & $0(0.00 \%)$ & $1(0.04 \%)$ & $10(4.40 \%)$ \\
\hline 5 to 95 & $30(8.94 \%)$ & $23(8.47 \%)$ & $253(72.56 \%)$ \\
\hline $95-185$ & $2(0.57 \%)$ & $0(0.00 \%)$ & $14(5.03 \%)$ \\
\hline$>185$ & $0(0.00 \%)$ & $0(0.00 \%)$ & $0(0.00 \%)$ \\
\hline
\end{tabular}




\begin{tabular}{|c|c|c|c|}
\hline \multicolumn{4}{|l|}{ Sex Hormone Binding Globulin (nmol/L) } \\
\hline $0.350-90$ & $30(9.37 \%)$ & $21(7.85 \%)$ & $267(78.87 \%)$ \\
\hline $90-180$ & $2(0.11 \%)$ & $3(0.62 \%)$ & $11(3.18 \%)$ \\
\hline$>180$ & $0(0.00 \%)$ & $0(0.00 \%)$ & $0(0.00 \%)$ \\
\hline \multicolumn{4}{|l|}{ Testosterone (ng/mL) } \\
\hline $0.020-9$ & $26(8.75 \%)$ & $23(8.49 \%)$ & $247(77.44 \%)$ \\
\hline 9 to 12 & $3(0.67 \%)$ & $1(0.53 \%)$ & $15(2.72 \%)$ \\
\hline$>12$ & $1(0.29 \%)$ & $0(0.00 \%)$ & $2(1.11 \%)$ \\
\hline \multicolumn{4}{|l|}{ Education } \\
\hline$<$ 9th Grade & $11(0.49 \%)$ & $5(0.14 \%)$ & $129(0.62 \%)$ \\
\hline 9-11th Grade (Includes 12th grade with no diploma) & $11(0.47 \%)$ & $10(0.46 \%)$ & $133(10.76 \%)$ \\
\hline High School Grad/GED or Equivalent & $25(3.14 \%)$ & $6(0.74 \% 0$ & $200(21.43 \%)$ \\
\hline Some College or above & $11(1.92 \%)$ & $9(1.55 \%)$ & $159(20.09 \%)$ \\
\hline Refused & $0(0.00 \%)$ & $0(0.00 \%)$ & $1(0.05 \%)$ \\
\hline Don't Know & $0(0.00 \%)$ & $0(0.00 \%)$ & $1(0.03 \%)$ \\
\hline \multicolumn{4}{|l|}{ Income } \\
\hline$\$ 0$ to $\$ 4,999$ & $2(0.02 \%)$ & $6(0.08 \%)$ & $44(1.62 \%)$ \\
\hline$\$ 5,000$ to $\$ 9,999$ & $9(0.29 \%)$ & $3(0.03 \%)$ & $102(3.53 \%)$ \\
\hline$\$ 10,000$ to $\$ 14,999$ & $12(0.44 \%)$ & $12(0.37 \%)$ & $142(4.77 \%)$ \\
\hline$\$ 15,000$ to $\$ 19,999$ & $20(0.68 \%)$ & $9(0.37 \%)$ & $147(5.23 \%)$ \\
\hline$\$ 20,000$ to $\$ 24,999$ & $17(0.71 \%)$ & $7(0.26 \%)$ & $159(6.56 \%)$ \\
\hline$\$ 25,000$ to $\$ 34,999$ & $28(1.24 \%)$ & $9(0.57 \%)$ & $249(11.70 \%)$ \\
\hline$\$ 35,000$ to $\$ 44,999$ & $16(0.73 \%)$ & $6(0.36 \%)$ & $182(10.68 \%)$ \\
\hline$\$ 45,000$ to $\$ 54,000$ & $14(0.90 \%)$ & $4(0.21 \%)$ & $144(8.16 \%)$ \\
\hline$\$ 55,000$ to $\$ 64,999$ & $5(0.30 \%)$ & $6(0.49 \%)$ & $88(5.79 \%)$ \\
\hline$\$ 65,000$ to $\$ 74,999$ & $11(0.99 \%)$ & $2(0.12 \%)$ & $71(5.61 \%)$ \\
\hline$\$ 75,000$ and Over & $27(2.41 \%)$ & $22(2.06 \%)$ & $310(21.76 \%)$ \\
\hline Over $\$ 20,000$ & $0(0.00 \%)$ & $0(0.00 \%)$ & $6(0.60 \%)$ \\
\hline Under $\$ 20,000$ & $1(0.03 \%)$ & $1(0.02 \%)$ & $10(0.23 \%)$ \\
\hline Don't Know & $0(0.00 \%)$ & $0(0.00 \%)$ & $7(0.08 \%)$ \\
\hline
\end{tabular}

Estimated percent distribution after applying NHANES sampling weights

${ }^{*} \mathrm{ABI}<0.7$ (PAD). $0.7<\mathrm{ABI}<0.9$ (AS), \& $0.9<\mathrm{ABI}<1.3$ (Normal)

Table 3.3. Geometric mean of urinary phthalate metabolites and BPA levels above the LOD by PAD status among participants $\geq 40$ years of age, NHANES $1999-2004$

\begin{tabular}{|c|c|c|c|c|c|c|}
\hline & \multicolumn{3}{|c|}{ Cases/Non-Cases } & \multicolumn{3}{|c|}{ 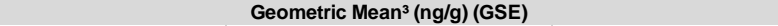 } \\
\hline & $\mathrm{ABI}<0.7^{*}$ & $0.7<\mathrm{ABI}<0.9^{*}$ & $0.9<\mathrm{AB} \mid<1.3^{*}$ & $\mathrm{ABI}<0.7$ & $0.7<\mathrm{ABI}<0.9$ & $0.9<\mathrm{ABI}<1.3$ \\
\hline \multicolumn{7}{|c|}{ Phthlate Metabolites' } \\
\hline $\mathrm{MnBP}$ & 384 & 320 & 5198 & $27.12(22.21,33.10)$ & $24.99(20.58,31.12)$ & $24.16(23.24,25.12)$ \\
\hline MCHP & 456 & 250 & 5196 & $0.55(0.50,0.60)$ & $0.62(0.55,0.70)$ & $0.58(0.56,0.60)$ \\
\hline MEP & 175 & 223 & 5504 & $127.33(102.40,158.34)$ & $120.80(98.68,147.86)$ & $136.31(129.59,143.38)$ \\
\hline MEHP & 210 & 520 & 5172 & $3.58(2.87,4.45)$ & $2.97(2.48,3.55)$ & $3.44(3.28,3.62)$ \\
\hline MiBP & 180 & 869 & 4853 & $1.05(0.99,1.11)$ & $1.03(0.97,1.09)$ & $1.04(1.01,1.07)$ \\
\hline MOP & 384 & 320 & 5198 & $1.22(1.18,1.27)$ & $1.21(1.18,1.25)$ & $1.23(1.21,1.24)$ \\
\hline MBzP & 400 & 380 & 5122 & $13.63(11.26,16.50)$ & $12.21(10.13,14.71)$ & $11.69(11.13,12.28)$ \\
\hline \multicolumn{7}{|c|}{ Bisphenol A2 } \\
\hline BPA & 142 & 77 & 1427 & $4.65(3.27-6.04)$ & $7.67(5.75-9.59)$ & $2.73(2.64-5.82)$ \\
\hline
\end{tabular}

1 Log transformed and creatinine corrected phthalate metabolites (ng/mg); NHANES 1999 - 2004

2 Log transformed and creatinine corrected BPA (ng/mg); NHANES 2003 - 2004

${ }^{3}$ Geometric means calculated after applying NHANES sampling weights

${ }^{*} \mathrm{ABI}<0.7$ (PAD), $0.7<\mathrm{ABI}<0.9$ (AS), \& $0.9<\mathrm{ABI}<1.3$ (Normal) 
Table 3.4 Estimated ORs (95\% Cls) of PAD status by concentration of creatinine adjusted urinary phthalate metabolites \& BPA among participants $\geq 40$ years of age, NHANES 1999 $2004 \& 2003-2004$.

\begin{tabular}{|c|c|c|c|c|c|c|c|}
\hline & $A B \mid<0.7^{*}$ & $0.7<\mathrm{ABI}<0.9^{*}$ & $0.9<\mathrm{ABI}<1.3^{*}$ & Adjusted OR $(95 \% \mathrm{Cl})^{3}$ & Adjusted OR $(95 \% \mathrm{Cl})^{4}$ & Adjusted OR $(95 \% \mathrm{CI})^{5}$ & Adjusted OR $(95 \% \mathrm{Cl})^{6}$ \\
\hline \multicolumn{8}{|c|}{ Phthlate Metabolites' } \\
\hline \multicolumn{8}{|c|}{ MnBP } \\
\hline$<L O D$ & 294 & 239 & 4032 & 1 & 1 & 1 & 1 \\
\hline$\geq$ LOD & 90 & 81 & 1166 & $1.33(1.00-2.34)$ & $1.83(1.00-2.34)$ & $1.33(0.89-2.95)$ & $0.96(0.85-1.99)$ \\
\hline \multicolumn{8}{|l|}{ МСHP } \\
\hline$\angle L O D$ & 400 & 341 & 5400 & 1 & 1 & 1 & 1 \\
\hline$\geq$ LOD & 10 & 3 & 86 & $0.54(0.25-2.10)$ & $1.54(1.00-2.10)$ & $1.39(1.00-1.65)$ & $1.34(1.22-1.59)$ \\
\hline \multicolumn{8}{|l|}{ MEP } \\
\hline$<L O D$ & 49 & 44 & 603 & 1 & 1 & 1 & 1 \\
\hline$\geq$ LOD & 360 & 297 & 4876 & $0.99(0.44-1.05)$ & $1.01(0.44-1.09)$ & $0.85(0.55-1.09)$ & $0.98(0.51-1.28)$ \\
\hline \multicolumn{8}{|l|}{ MEHP } \\
\hline$\angle L O D$ & 407 & 339 & 5429 & 1 & 1 & 1 & 1 \\
\hline$\geq$ LOD & 3 & 1 & 48 & $0.72(0.40-0.93)$ & $0.92(0.40-0.93)$ & $0.94(0.92-0.95)$ & $0.92(0.93-0.96)$ \\
\hline \multicolumn{8}{|l|}{ MiBP } \\
\hline$<L O D$ & 410 & 341 & 5457 & 1 & 1 & 1 & 1 \\
\hline$\geq$ LOD & 7 & 13 & 21 & $0.79(0.18-0.80)$ & $0.59(0.18-0.80)$ & $1.48(1.12-1.87)$ & $1.41(0.99-1.83)$ \\
\hline \multicolumn{8}{|l|}{ MOP } \\
\hline$<L O D$ & 410 & 341 & 5489 & 1 & 1 & 1 & 1 \\
\hline$\geq$ LOD & 10 & 9 & 34 & $0.95(0.95-1.60)$ & $0.97(0.95-1.60)$ & $0.92(0.70-1.49)$ & $0.98(0.47-1.57)$ \\
\hline \multicolumn{8}{|l|}{ MBzP } \\
\hline$<L O D$ & 131 & 103 & 1916 & 1 & 1 & 1 & 1 \\
\hline$\geq$ LOD & 277 & 236 & 3551 & $1.16(1.08-2.01)$ & $1.76(1.58-2.91)$ & $0.91(0.84-0.97)$ & $1.73(0.92-3.18)$ \\
\hline \multicolumn{8}{|c|}{ Bisphenol $\mathrm{A}^{2}$} \\
\hline \multicolumn{8}{|c|}{ BPA } \\
\hline$<L O D$ & 8 & 8 & 118 & 1 & 1 & 1 & 1 \\
\hline$\geq \mathrm{LOD}$ & 141 & 71 & 1315 & $1.22(1.02-5.07)$ & $2.89(1.50-10.19)$ & $2.17(1.65-7.17)$ & $3.02(0.14-12.15)$ \\
\hline
\end{tabular}

${ }^{1}$ Log transformed and creatinine corrected phthalate metabolites (ng/mg); NHANES 1999 - 2004

${ }^{2}$ Log transformed and creatinine corrected BPA (ng/mg); NHANES 2003 - 2004

${ }^{3}$ Adjusted for PAD confounders (Diabetes, Smoking, and Alcohol Use)

${ }^{4}$ Adjusted for Gender \& PAD confounders

${ }^{5}$ Adjusted for Age, Race, \& PAD confounders

${ }^{6}$ Adjusted for Gender, Age, Race, \& PAD confounders

${ }^{*} \mathrm{ABI}<0.7$ (PAD), $0.7<\mathrm{ABI}<0.9$ (AS), \& $0.9<\mathrm{ABI}<1.3$ (Normal)

Discussion. In this cross-sectional study of participants aged $\geq 40$ years old, we separately investigated 7 individual phthalate metabolites and BPA in association with peripheral arterial disease (PAD) and atherosclerosis (AS). In participants with detectable levels of phthalates and BPA, higher exposures were found in participants diagnosed with PAD and AS when compared to normal participants and phthalate metabolites: MnBP and MBzP. Furthermore when ORs and 95\% Cl models were adjusted for various models higher exposure phthalate metabolites \& BPA ( $\geq$ LOD) showed significant association with participants diagnosed with PAD and AS (1) PAD confounders model: MnBP and MBzP; 2) gender and PAD confounders model: $\mathrm{MnBP}, \mathrm{MCHP}, \mathrm{MEP}$, and $\mathrm{MBzP}$ 3) age, race, $\mathrm{BMI}$, and $\mathrm{PAD}$ 
confounders model: MnBP, MCHP, and MiBP and 4) gender, age, race, BMI, \& PAD confounders model: MCHP, MiBP, and MBzP].

Previous epidemiological studies showed that phthalate metabolite MMP was associated with atherosclerotic plaques in an inverted U-shaped manner (low levels of MMP have an effect) independently of cardiovascular risk factors. Some phthalates and BPA were also correlated to the echogenicity of the plaques, suggesting a role for plaque-associated chemicals in atherosclerosis (Lind and Lind. 2011). Furthermore irregular associations between phthalates and hyperlipidemia were shown with self-reported diabetes and CVD in Shanghai adults (Dong et al. 2017). BPA levels were demonstrated to be significantly associated with PAD before and after adjusting for confounders (Shankar et al. 2012). There is additional evidence that individuals with higher urinary BPA levels are more inclined to suffer from general or abdominal obesity, hypertension, and diabetes when compared with individuals having lower urinary concentrations (Rancière et al. 2015). Common carotid artery intima-media thickness (CIMT) measured by ultrasonography is a recognized indicator of subclinical atherosclerosis and independent predictor of myocardial infarction, coronary events, and stroke (Bots et al. 1997; Hodis et al. 1998; Su et al. 2006; Chien et al. 2008; Su et al. 2012). It was reported that in a cross-sectional investigation of a representative population sample of subjects aged 60 - 80 years old showed a significant association between small changes in IMT and both symptomatic and asymptomatic peripheral arterial disease (Allan et al. 1997). Lin et al further determined the relationship between levels of BPA and carotid-media thickness 
(CIMT) and discovered higher serum concentrations of BPA were associated with increased CIMT in a cross-sectional study of adolescents and young adults (Lin et al. 2015). Although previous studies and our current study show significant associations between EDCs (phthalates and BPA) with peripheral arterial disease further research is warranted to elucidate mechanisms of these associations.

The main strengths of our study include oversampling of minority populations that make it highly representative and generalizable to the United States population and availability of biological measurements of environmental pollutants. Additionally this study is nationally representative and uses stringent methods to collect available data on confounders. One limitation of this study is since it is a cross - sectional design with self - reported data, it does not permit for causal inferences to be concluded. Self - reported data increases the likelihood of misclassification bias of cases and controls contributing to the possibility of incorrectly or undiagnosed reported PAD and/or AS cases. Another limitation is that BPA measurements are more likely to result in misclassification due to variability.

\section{Conclusion}

Based on our analysis of phthalate metabolites from 1999 - 2004 and BPA from 2003 - 2004 higher exposure of particular phthalate metabolites and BPA did demonstrate association with participants who are diagnosed with PAD alongside AS. Given earlier and existing research demonstrates exposure to other EDCs such as polychlorinated biphenyls are associated with cardiovascular disease, it is 
biologically plausible that exposure to phthalates and BPA may contribute to higher risk of the disease. Our research findings coupled with previous epidemiological evidence concerning EDCs and peripheral arterial disease warrants the necessity for prospective future studies.

\section{References}

1. Kavlock RJ, Daston GP, DeRosa C, Fenner-Crisp P, Gray LE, Kaattari S, Lucier G, Luster M, Mac MJ, Maczka C, Miller R, Moore J, Rolland R, Scott G, Sheehan DM, Sinks T, Tilson HA. Research needs for the assessment of health and environmental effects of endocrine disruptors: a report of the U.S. EPA-sponsored workshop. Environmental Health Perspectives. 1996; 104:715-74.

2. Gore AC, Chappell VA, Fenton SE, Flaws JA, Nadal A, Prins GS, Toppari J, Zoeller RT. EDC-2: the Endocrine Society's second scientific statement on endocrine-disrupting chemicals. Endocrine Reviews. 2015; 36:E1-E150.

3. Meeker JD, Ferguson KK. Relationship between urinary phthalate and bisphenol a concentrations and serum thyroid measures in U.S. adults and adolescents from the National Health and nutrition examination survey (NHANES) 2007-2008. Environmental Health Perspectives. 2011; 119:1396-1402

4. Sata F, Araki S, Yokoyama K, Murata K. Adjustment of creatinine adjusted values in urine to urinary flow rate: a study of eleven heavy metals andorganic substances. International Archives of Occupational and Environmental Health. 1995; 68(1): 64-68.

5. Calafat AM, Xiaoyun X, Wong LY, Reidy JA, Needham LL. Exposure of the U.S. Population to Bisphenol A and 4-tertiary-Octylphenol: 2003-2204. Environmental Health Perspectives. 2008; 116: 39-44.

6. Silva MJ, Barr DB, Reidy JA, Malek NA, Hodge CC, Caudill AP, Brock JW, Needham LL, Calafat AM. Urinary levels of seven phthalate metabolites in the U.S. population from the National Health and Nutrition Examination Survey (NHANES) 1999-2000. Environmental Health Perspectives. 2004; 112:331-338.

7. Woodruff TJ, Zota AR, Schwartz JM. Environmental chemicals in pregnant women in the US: NHANES 2003-2004. Environmental Health Perspectives. 2011; 119:878-885. 
8. Lang IA, Galloway TS, Scarlett A, Henley WE, Depledge M, Wallace RB, et al. 2008. Association of urinary bisphenol A concentration with medical disorders and laboratory abnormalities in adults. JAMA 300:1303-1310.

9. Melzer D, Rice NE, Lewis C, Henley WE, Galloway TS. Association of urinary bisphenol A concentration with heart disease: evidence from NHANES 2003/06. PLoS One. 2010; 5 (1):e8673.

10. Anway, M. D., Cupp, A. S., Uzumcu, M., \& Skinner, M. K. Epigenetic transgenerational actions of endocrine disruptors and male fertility. Science. 2005; 308 (5727), 1466-1469.

11. Morgan, M., Deoraj, A., Felty, Q., \& Roy, D. (2016). Environmental estrogenlike endocrine disrupting chemicals and breast cancer. Molecular and Cellular Endocrinology. 2016; S0303-7207 (16)30411-7.

12. Roy D, Morgan M, Yoo C, Deoraj A, Roy S, Yadav VK, Garoub M, Assaggaf H, Doke M. Integrated Bioinformatics, Environmental Epidemiologic and Genomic Approaches to Identify Environmental and Molecular Links between Endometriosis and Breast Cancer. International Journal of Molecular Sciences. 2015; 16, 2528525322.

13. Lind $P M$, Lind $L$. Circulating levels of bisphenol $A$ and phthalates are related to carotid atherosclerosis in the elderly. Atherosclerosis. 2011 Sep; 218(1):207-13.

14. Dong $\mathrm{R}$, Zhao $\mathrm{S}$, Zhang $\mathrm{H}$, et al. Sex Differences in the Association of Urinary Concentrations of Phthalates Metabolites with Self-Reported Diabetes and Cardiovascular Diseases in Shanghai Adults. Odland JØ, ed. International Journal of Environmental Research and Public Health. 2017; 14(6):598.

15. Rancière F, Lyons JG, Loh VHY, Botton J, Galloway T, Wang T, Shaw JE and Magliano DJ. Bisphenol A and the risk of cardiometabolic disorders: a systematic review with meta-analysis of the epidemiological evidence. Environmental Health (2015) 14:46. DOI 10.1186/s12940-015-0036-5.

16. K.L. Chien, T.C. Su, J.S. Jeng, et al. Carotid artery intima-media thickness, carotid plaque and coronary heart disease and stroke in Chinese. PloS One, 3 (2008), p. e3435.

17. Hodis HN, Mack WJ, LaBree $L$ et al. The role of carotid arterial intima-media thickness in predicting clinical coronary events. Ann. Intern. Med., 128 (1998), pp. 262-269. 
18. Bots ML, Hoes AW, P.J. Koudstaal, et al. Common carotid intima-media thickness and risk of stroke and myocardial infarction: the Rotterdam Study. Circulation, 96 (1997), pp. 1432-1437.

19. Su TC, Lee YT, Chou S, et al. Twenty-four-hour ambulatory blood pressure and duration of hypertension as major determinants for intima-media thickness and atherosclerosis of carotid arteries. Atherosclerosis. 2006; 184:151-156.

20. Su TC, Chien KL, Jeng JS, et al. Age-and gender-associated determinants of carotid Intima-Media thickness: a community-based study. Journal of Atherosclerosis and Thrombosis. 2012; 19: 872-880.

21. Allan PL, Mowbray PI, Lee AJ, Fowkes FG. Relationship between carotid intima-media thickness and symptomatic and asymptomatic peripheral arterial disease. The Edinburgh Artery Study. Stroke. 1997; 28(2):348-53. 


\section{CHAPTER V}

\section{MANUSCRIPT 4}

Genome-wide gene expression profiling of Inhibitor of DNA binding/Differentiation-3 (ID3) candidate targets in vascular-intimal lesions 


\begin{abstract}
Obliterative and proliferative vascular intimal lesions are categorized by perturbations of cellular constituents \& their normal patterning of vessels. The pathophysiologic pathways that transition to these end-stages are infrequently distinct. Because they may suggest the normal assembly of vessels during development, developmental biology, which combines embryologic analyses of cellular origins, lineage, and cell-cell interactions with genetic studies, holds the prospect of revealing the role of individual genes in the pathogenesis of vascular disease. The Inhibitor of DNA binding/Differentiation-3 (ID3), a member of the ID family of transcriptional regulators, has been shown to play a role in lipoxygenase (12/15-LO) which is known to produce pro-inflammatory alterations in blood vessels that lead to the development of atherosclerosis. Furthermore studies have shown overexpression of ID3 increasing OCT4 and SOX2 expression in microvascular endothelial cells. Therefore we determined the functional role of ID3 and ID3 candidate target genes in obliterative and proliferative vascular-intimal lesions. We performed a meta-analysis on published whole genome microarray datasets comparing transcriptional patterns of blood cells \& tissue samples to controls. Bioinformatics network analysis identified statistically the most overrepresented processes and signaling pathways. Deciphering the pattern \& role of genes involved with ID3 \& ID3 targets in obliterative and proliferative vascular diseases may provide a new model by which ID3 may contribute to the growth regulation of these vascular intimal-lesions. Keywords: bioinformatics, ID3, vascular diseases, vascular-intimal lesions
\end{abstract}




\section{Introduction}

Although poorly understood, obliterative \& proliferative vascular-intimal lesions are a significant health problem that may lead to blocked blood vessels and can cause threatening end organ damage such as ischemic stroke, blindness, right-sided heart failure, or myocardial infarction. Obliterative \& proliferative vascular-intimal lesions manifest in numerous vascular diseases such as arteriosclerosis, idiopathic pulmonary arterial hypertension, peripheral arterial disease, and lymphangioleiomyomatosis. The endothelium plays an essential role in classifications of obliterative and proliferative diseases. A vital foundation of vascular biology is that the lining of the endothelial is dynamically a changeable interface. This is locally responsive to multiple types of stimuli that can originate from the emigrating \& circulating cells and/or neighboring tissues and thus can actively participate in the physiologic variation or vascular dysfunction of a certain section of the vasculature. The endothelium appears to be best suited to function in this capacity, given its distinctive anatomic location between tissue $\&$ blood and ability to generate various biological effectors such as cytokines, growth stimulators \& inhibitors, vasoactive peptides, pro- \& anti-coagulants, and nitric oxide. Disruption in the production or interactions of these different mediators appear to effect various vital functions of the endothelium, specifically its role as a non-thrombogenic vessel for antithrombotic, growth inhibitory, and antiinflammatory activities; and blood that aids to preserve the integrity of the vascular wall, when facing injury-related stimuli and various disease risk factors (Fishman et al. 1998). 
Conceivably the most well-known studied model of activation of vascular endothelium are the effects of pro-inflammatory cytokines such as tumor necrosis factor (TNF) and interleukin-1 (IL-1). These have provided a widely used experimental model, which have been studied at the tissue level (various diseased human tissues \& animal models) and cellular level (receptors, genetic regulatory events, \& signaling pathways) (Fishman et al.1998; Cuthins et al. 2012; Sakurai et al. 2004). Additionally, the effects of the biochemical dynamisms produced by pulsatile blood flow including pressures, wall shear stress, \& cyclic strains on endothelial structure and function as been seen as another model of vascular cell activation. The capability of laminar shear stresses to up-regulate atheroprotective endothelial genes and significantly influence the functional phenotype of endothelial cells indicates that this model of activation may be playing a significant pathophysiologic role. Although the evidence implicates tissue and cellular levels as an influence on obliterative \& proliferative vascular intimal-lesions, the pathogenesis is far from clarified to date.

At the molecular level, Inhibitor of DNA binding/Differentiation-3 is a member of the ID family (ID1-ID4) of helix-loop-helix proteins encoded by an immediate-early gene responsive to mitogenic signals and oxidative stress. Besides the regulation of cell differentiation, ID proteins are also positive regulators of cell growth and play a major role in neovascularization. An increasing body of evidence suggests that ID3 may be involved in disruptions characterized by abdominal obesity, insulin resistance, hyperglycemia, dyslipidemia, and hypertension. Interactions across multiple organ systems that contribute to 
disruption presents a challenge to ongoing research attempting to elucidate biological mechanisms of chronic disease such as vascular. For example, insulin resistance and systemic low-grade inflammation result from complex interactions between the vasculature, metabolic tissue, and immune cells. In the vasculature, ID3 is essential to embryonic vasculogenesis and endothelial cell activation (Sakurai et al., 2004; Felty \& Porther, 2008; Elen et al., 2015). ID3 involvement in vascular disease has been studied together with the lipoxygenase (12/15-LO), which is a vital mediator of VSMC growth and its growth-promoting effects were shown to be mediated by ID3 transcription (Taylor et al., 2015). Increased expression of 12/15-LO in the vessel wall enhanced ID3-dependent cell proliferation, fibronectin deposition, and neo-intimal formation (Taylor et al., 2015). Population established studies have found an SNP (single nucleotide polymorphisms) rs11574 in the coding region of the human ID3 gene associated with subclinical atherosclerosis in the Diabetes Heart study (Doran et al., 2010). Furthermore two cohorts determined the link between the SNP directly with coronary artery pathology. ID3 has also been shown as a key mechanism of high fat diet stimulated through visceral adipose VEGFA expression, depot expansion and micro-vascular blood volume (Cuthins et al., 2012). ID3 is important to obesity because it has been suggested to stimulate angiogenesis, a major factor of HFD (high-fat diet)-induced visceral adiposity (Cuthins et al., 2012).

Our research has recently shown that ectopic overexpression of ID3 increased OCT4 and SOX2 expression in endothelial cells as well as resulted in a population of cells that were positive for the molecular stemness signature CD133+ 
VEGFR3+ CD34+ (Das et al., 2015). These endothelial stem cells were morphologically distinguished into smooth muscle cells and neuron cells. Based on these findings, ID3 maintains cells in a non-committed state by inhibiting the repression of pluripotency factors by TCF3. Furthermore we also recently reported that ID3 overexpression increased endothelial cell neovascularization, resistance to apoptosis, cell migration, and increased size of endothelial spheroids. In vivo, we reported that ID3 expression is higher in pulmonary vascular lesions. Our studies have also shown ID3 protein and oxidative damage highly expressed in benign and malignant cardiovascular tissues in patients (Das \& Felty, 2014). In this study, we have elucidated the role of ID3 and ID3 candidate target genes in vascular-intimal lesions with the specific focus on how ID3 may play a critical role in regulating various genes and signaling pathways that are involved in cell adhesion, extracellular matrix proteolysis, \& cell growth which predisposes the vessel to vascular dysfunction. A better understanding of how vascular-intimal lesions depend on ID3 regulation may open up novel approaches for both prevention \& treatment of diseases these intimal-lesions manifest from.

\section{Materials \& Methods}

Identification of microarray datasets \& analysis. Our study was based on multiple studies carried out and deposited in NCBI Gene Express Omnibus (GEO), a public functional genomics data repository supporting MIAME-compliant data submissions in which both sequence-based and array data are accepted. Datasets were compiled on vascular diseases and respectively divided into blood \& tissue studies. The following tables represents information on data collected \& accessible 
demographics of individual datasets. Note not all datasets are represented in the tables. Figure 3.1 represents a flow chart of our current study. 


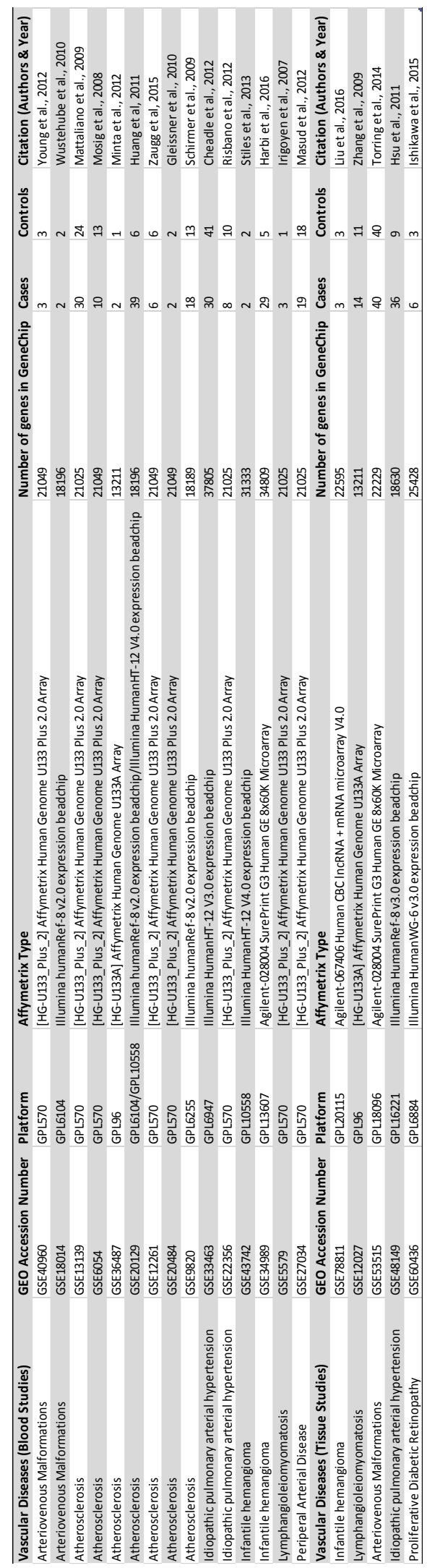


Table 4.1 NCBI GEO datasets represented in study. Table is divided into two cohorts: blood and tissue samples.

\section{Blood studies}

\begin{tabular}{lll}
\multicolumn{1}{c}{ Characteristics } & \multicolumn{1}{c}{$\begin{array}{c}\text { Samples } \\
\text { Cases }(\mathbf{n = 1 9 )}\end{array}$} & Controls (n=18) \\
& & \\
Age, years & $69.57 \pm 9.18$ & $66.88 \pm 9.44$ \\
Men, \% & $13(68 \%)$ & $13(72 \%)$ \\
Ever smoker, \% & $17(89 \%)$ & $12(66 \%)$ \\
BMI, $\mathrm{kg} \cdot \mathrm{m}^{-2}$ & $28.53 \pm 5.25$ & $30.6 \pm 5.99$ \\
Systolic BP, mm Hg & $139.2 \pm 23.27$ & $132.4 \pm 20.1$ \\
Diastolic BP, mm Hg & $74.2 \pm 11.66$ & $80.1 \pm 12.3$ \\
HDL cholesterol, mg/dl & $44.12 \pm 8.59$ & $49.7 \pm 15$ \\
Hypertension, \% & $17(89.4 \%)$ & $13(72 \%)$ \\
Diabetes, \% & $5(26 \%)$ & $4(22 \%)$ \\
Lipid-lowering medication, \% & $11(57 \%)$ & $12(66 \%)$ \\
Ankle-brachial index & $0.48 \pm 0.20$ & $1.12 \pm 0.07$ \\
WBC count, $\mu \mathrm{L}$ & $8.03 \pm 2.34$ & $7.26 \pm 1.10$ \\
\hline Values are expressed as either & & \\
'mean \pm standard deviation' or & & \\
as 'n (\%)' & & \\
\hline
\end{tabular}

Table 4.2.1 Characteristics of peripheral arterial disease dataset.

\begin{tabular}{|c|c|c|c|c|}
\hline Patient ID & Lesions & Age at time of resection & Location \& Size & Comments \\
\hline 1 & hemcEC-1 & 8 months & $1.8 \times 0.8 \mathrm{~cm}$, right eyelid & Normal karyotype* \\
\hline 4 & hemEC-4 & 3 months & $3 \times 3$, right flank & \\
\hline 5 & hemEC-5 & 4 months & $5 \mathrm{~mm}$, lower abdomen & Multiple hemangiomas \\
\hline \multirow[t]{4}{*}{8} & heomaEC-8B & 2 years & B - ankle & Normal karyotype*, multiple \\
\hline & heomaEC-8C & & C-knee & hemanigoendothelioma lesions of variable size, new lesions still appearing at 2 years \\
\hline & heomaEC-8F & & F- right foot & \\
\hline & heomaEC-8G & & G - inner thigh & \\
\hline 10 & hemEC-10 & 2 years & $4 \mathrm{~cm}$, forehead & \\
\hline 12 & hemEC-12 & 4 months & $1.5 \mathrm{~cm}$, left cheek & \\
\hline 13 & hemEC-13 & 9 months & $3 \mathrm{~cm}$, left upper eyelid & Other hemangiomas on neck and labia \\
\hline \multirow[t]{2}{*}{17} & hemEC-17A & 10 months & A. $3 \mathrm{~cm}$, scalp & \\
\hline & hemEC-17B & & B. $3.5 \times 4 \mathrm{~cm}$, forehead & \\
\hline 20 & 8 months & 8 months & $2.5 \mathrm{~cm}$, neck & Multiple hemangiomas \\
\hline 21 & 9 months & 9 months & $6.5 \times 5.5 \mathrm{~cm}$, scalp & Other hemangiomas on right ear and forehead \\
\hline
\end{tabular}

Table 4.2.2 Characteristics of infantile hemangioma dataset. 


\begin{tabular}{|c|c|c|c|}
\hline & Homozygous FH & Heterozygous FH & Controls \\
\hline \multirow[t]{2}{*}{ Gender } & Female $(n=6)$ & Female $(n=5)$ & Female $(n=16)$ \\
\hline & Male $(n=20)$ & Male $(n=3)$ & Male $(n=10)$ \\
\hline Age (years) & $30.2 \pm 11.1$ & $28.8 \pm 7.5$ & $33.8 \pm 11.2$ \\
\hline $\mathrm{LDL}(\mathrm{mg} / \mathrm{dl})$ & $413.82 \pm 92.33(* * *)$ & $220.64 \pm 27.81\left(^{* * *}\right)$ & $107.03 \pm 17.78$ \\
\hline $\mathrm{HDL}(\mathrm{mg} / \mathrm{dl})$ & $60.33 \pm 8.09$ & $54.17 \pm 3.71$ & $61.17 \pm 6.60$ \\
\hline Triglycerides (mg/dl) & $141.31 \pm 39.89$ & $233.61 \pm 132.80$ & $107.63 \pm 33.04$ \\
\hline $\operatorname{Lp}(\mathrm{a})(\mathrm{mg} / \mathrm{dl})$ & $676.67 \pm 347.06$ & $442.73 \pm 420.11$ & $187.53 \pm 153.59$ \\
\hline Leukocytes (Gpt/I) & $7.64 \pm 0.95$ & $5.45 \pm 0.57$ & $6.38 \pm 0.8$ \\
\hline Thrombocytes (Gpt/l) & $253.12 \pm 22.2$ & $277.39 \pm 37.51$ & $258.12 \pm 21.97$ \\
\hline Values are means $\pm S D$ & & & \\
\hline
\end{tabular}

Table 4.2.3 Characteristics of atherosclerosis dataset.

\begin{tabular}{|c|c|c|c|c|}
\hline Variable & Africian American & White & Africian American & White \\
\hline CAC (coronary artery calcification) & $\mathrm{CAC}<10$ & $C A C<10$ & $C A C>100$ & $C A C>100$ \\
\hline$n$ (number of patients) & 17 & 41 & 13 & 26 \\
\hline Gender (male or female) & female & female & female & female \\
\hline Age (years) & $64.1 \pm 7.7$ & $62.9 \pm 6.8$ & $68.3 \pm 8.5$ & $69.0 \pm 6.5$ \\
\hline Body mass index $\left(\mathrm{kg} / \mathrm{m} 2^{*}\right)$ & $32.0 \pm 6.4$ & $25.5 \pm 4.2$ & $30.9 \pm 7.1$ & $27.4 \pm 4.6$ \\
\hline Systolic BP (mmHg) & $119.1 \pm 17.3$ & $114.4 \pm 18.7$ & $130.6 \pm 18.2$ & $130.0 \pm 22.6$ \\
\hline Diastolic BP (mmHg) & $68.6 \pm 7.8$ & $65.9 \pm 11.1$ & $71.4 \pm 9.5$ & $67.1 \pm 8.7$ \\
\hline Total cholesterol (mg/dl) & $191.8 \pm 32.4$ & $197.5 \pm 31.0$ & $199.7 \quad 29.7$ & $204.0 \quad 37.0$ \\
\hline LDL cholesterol (mg/dl) & $113.5 \pm 27.7$ & $110.2 \pm 27.5$ & $122.6 \quad 30.4$ & $119.0 \quad 39.1$ \\
\hline HDL cholesterol (mg/dl) & $61.6 \quad 13.1$ & 65.015 .6 & $61.3 \quad 13.5$ & 59.112 .6 \\
\hline Triglycerides $\left(\mathrm{mg} /\left.\mathrm{d}\right|^{*} \S\right)$ & $83.7 \quad 32.8$ & $111.3 \quad 67.5$ & $78.6 \quad 29.8$ & $129.2 \quad 72.3$ \\
\hline Fasting glucose (mg/dl) & 91.58 .0 & $89.7 \quad 8.5$ & 90.67 .5 & 91.08 .7 \\
\hline HOMA insulin resistance & $0.92 \quad 0.45$ & $0.74 \quad 0.39$ & $1.04 \quad 0.55$ & $1.06 \quad 0.70$ \\
\hline Insulin (ulU/ml) & $4.4 \quad 2.0$ & $3.6 \quad 1.8$ & $4.8 \quad 2.4$ & $4.9 \quad 3.1$ \\
\hline Current smoker (\%) & 23.5 & 37.5 & 53.8 & 48 \\
\hline Lipid-lowering medication use (\%) & 5.8 & 15.3 & 38.4 & 52 \\
\hline Antihypertension medication use (\%) & 47 & 25.6 & 53.8 & 48 \\
\hline \multicolumn{5}{|c|}{$* \mathrm{p}<0.05$ comparing African American with white among women with coronary artery calcification $(\mathrm{CAC})<10$} \\
\hline$\S \mathrm{P}<0.05$ comparing African American $\mathrm{n}$ & & & & \\
\hline
\end{tabular}

Table 4.2.4 Characteristics of atherosclerosis dataset.

\begin{tabular}{|c|c|c|}
\hline \multicolumn{3}{|l|}{ Baseline characteristics } \\
\hline & Atherosclerotic patients $(n=18)$ & Control patients $(n=13)$ \\
\hline Age (years) & $55.8 \pm 7.9$ & $52.2 \pm 7.2$ \\
\hline Male sex-no (\%) & $8(44.4)$ & $5(38.5)$ \\
\hline Body mass index (BMI) & $25.2 \pm 3.5$ & $27.4 \pm 3.5$ \\
\hline Body surface area (BSA) & $1.90 \pm 0.21$ & $1.97 \pm 0.25$ \\
\hline Family history of CAD - no. (\%) & $14(77.8)$ & $6(46.2)$ \\
\hline Current smoker - no. (\%) & $4(22.2)$ & $4(30.8)$ \\
\hline Ex smoker -no. (\%) & $7(38.9)$ & $4(30.8)$ \\
\hline Beta-blockers-no. (\%) & $15(83.3)$ & 10 (76.9) \\
\hline Statins-no. (\%) & $18(100)$ & $13(100)$ \\
\hline Aspirin-no. (\%) & $18(100)$ & $13(100)$ \\
\hline Calcium antagonists - no. (\%) & $6(33.3)$ & $2(16.4)$ \\
\hline Nitrates-no. (\%) & $8(44.4)$ & $4(30.8)$ \\
\hline ACE-inhibitors/ARBs-no. (\%) & $8(44.4)$ & $7(53.8)$ \\
\hline Diuretics - no. (\%) & $4(22.2)$ & $4(30.8)$ \\
\hline C-reactive protein. $-\mathrm{mg} / \mathrm{dl}$ & $1.0[1.0 ; 1.4]$ & $1.1[1.0 ; 1.7]$ \\
\hline Troponin T-ng/ml & $<0.03$ & $<0.03$ \\
\hline Glucose - mmol/l & $5.5 \pm 1.7$ & $5.7 \pm 0.6$ \\
\hline Triglycerides - mmol/l & $1.17 \pm 0.90$ & $0.90 \pm 0.63$ \\
\hline Lipoprotein (a) - mg/dl & $343[63,569]$ & $90[49 ; 163]$ \\
\hline LDL-cholesterol-mmol/I & $2.20 \pm 0.79$ & $1.87 \pm 0.53$ \\
\hline HDL-cholesterol-mmol/I & $1.39 \pm 0.46$ & $0.90 \pm 0.63$ \\
\hline \multicolumn{3}{|c|}{ 1) Patients with triple-vessel coronary artery disease and control patients } \\
\hline \multicolumn{3}{|c|}{ did not show differences in clinical characteristics except for lipoprotein } \\
\hline \multicolumn{3}{|c|}{ 2) $C A D=$ coronary artery disease } \\
\hline \multicolumn{3}{|l|}{ ARB $=$ Angiotensin receptor blockers } \\
\hline \multicolumn{3}{|l|}{$\mathrm{ACE}=$ angiotensin converting enyzme } \\
\hline * Data expressed as median [1. quartile, 3. quartile] & & \\
\hline
\end{tabular}

Table 4.2.5 Characteristics of atherosclerosis dataset. 


\section{Tissue Studies}

\begin{tabular}{llllll} 
Patient ID & \multicolumn{1}{c}{ Age } & \multicolumn{1}{c}{ Gender } & \multicolumn{1}{c}{ Position } & \multicolumn{1}{c}{ Previous treatment } & Pathology \\
1 & 2 months 15 days & Female & Left axilla & NO & IH \\
2 & 2 months 13 days & Female & Right posterior neck & Oral propranolol & IH \\
3 & 1 year & Female & Abdomen & Sclerotherapy & IH \\
4 & 8 months & Female & Right thoracic wall & Sclerotherapy & IH \\
5 & 3 months & Male & Thoracic wall & NO & IH \\
\hline
\end{tabular}

Table 4.2.6 Characteristics of infantile hemangioma dataset.

\begin{tabular}{|c|c|c|c|}
\hline Family No. & Age & Sex & Phenotype \\
\hline 9 & 49 & $M$ & $E, T, P, G, F$ \\
\hline 9 & 53 & $\mathrm{~F}$ & $E, T, F$ \\
\hline 13 & 54 & $\mathrm{~F}$ & $E, T, P, G, F$ \\
\hline 13 & 30 & $\mathrm{~F}$ & $E, T, P, F$ \\
\hline 15 & 47 & $\mathrm{~F}$ & $\mathrm{E}, \mathrm{T}, \mathrm{G}, \mathrm{F}$ \\
\hline 15 & 38 & M & $E, T, P, F$ \\
\hline 15 & 40 & $\mathrm{~F}$ & $E, T, F$ \\
\hline 24 & 40 & $\mathrm{~F}$ & $\mathrm{E}, \mathrm{T}, \mathrm{F}$ \\
\hline 24 & 46 & $\mathrm{~F}$ & $E, T, P, G, F$ \\
\hline 37 & 51 & $M$ & $E, T, P, F$ \\
\hline 38 & 37 & $\mathrm{~F}$ & $\mathrm{E}, \mathrm{T}, \mathrm{F}$ \\
\hline 49 & 47 & $\mathrm{~F}$ & $E, T, F$ \\
\hline 61 & 49 & $\mathrm{~F}$ & $\mathrm{E}, \mathrm{T}, \mathrm{F}$ \\
\hline 65 & 35 & $\mathrm{~F}$ & $T, P, F$ \\
\hline 87 & 38 & $M$ & $\mathrm{~T}, \mathrm{P}, \mathrm{F}$ \\
\hline 92 & 44 & $M$ & $E, T, P$ \\
\hline 93 & 37 & $M$ & $\mathrm{E}, \mathrm{T}, \mathrm{F}$ \\
\hline 94 & 30 & $M$ & $E, T, F$ \\
\hline 96 & 46 & $M$ & $E, T, P, F$ \\
\hline 8 & 55 & $M$ & $\mathrm{E}, \mathrm{T}, \mathrm{F}$ \\
\hline 8 & 28 & $M$ & $E, T, F$ \\
\hline 18 & 43 & M & $E, T, F$ \\
\hline 18 & 44 & $\mathrm{~F}$ & $E, T, P, F$ \\
\hline 18 & 41 & $M$ & $E, T, F$ \\
\hline 20 & 47 & $M$ & $\mathrm{E}, \mathrm{T}$ \\
\hline 42 & 32 & $\mathrm{~F}$ & $E, T, F$ \\
\hline 43 & 38 & $\mathrm{~F}$ & $E, T, F$ \\
\hline 43 & 36 & $\mathrm{~F}$ & $\mathrm{~T}, \mathrm{~F}$ \\
\hline 46 & 39 & $M$ & $\mathrm{E}, \mathrm{T}, \mathrm{F}$ \\
\hline 47 & 40 & $\mathrm{~F}$ & $E, T, F$ \\
\hline 56 & 44 & $\mathrm{~F}$ & $\mathrm{E}, \mathrm{T}, \mathrm{F}$ \\
\hline 57 & 34 & $M$ & $E, T, F$ \\
\hline 57 & 32 & $\mathrm{~F}$ & $\mathrm{~T}, \mathrm{~F}$ \\
\hline 67 & 24 & $\mathrm{~F}$ & $E, T, F$ \\
\hline 67 & 31 & $M$ & $E, T, F$ \\
\hline 69 & 39 & M & $E, T, F$ \\
\hline 71 & 44 & $\mathrm{~F}$ & $\mathrm{E}, \mathrm{T}, \mathrm{F}$ \\
\hline 82 & 48 & M & $E, T, F$ \\
\hline 88 & 56 & $\mathrm{~F}$ & $\mathrm{E}, \mathrm{T}, \mathrm{G}, \mathrm{F}$ \\
\hline 88 & 50 & $M$ & $\mathrm{E}, \mathrm{T}, \mathrm{F}$ \\
\hline
\end{tabular}

Abbreviations: AVM, arteriovenous malformation; E, epistaxis; T, Telangiectasia; P, pulmonary AVM; C, cerebral AVM;

$\mathrm{G}$, gastrointestinal telangiectasia/gastrointestinal bleeding; $\mathrm{H}$, Hepatic AVM; F, family history. M, male; F, female.

Table 4.2.7 Characteristics of arteriovenous malformation dataset. 


\begin{tabular}{|c|c|c|c|c|c|c|c|c|c|}
\hline Patient ID & Gender (Age) & $\begin{array}{l}\text { Smoking } \\
\text { (pack years) }\end{array}$ & $\begin{array}{l}\text { Skin disease } \\
\text { (type) }\end{array}$ & Autoantibody & $\begin{array}{l}\text { FVC } \\
(\%)\end{array}$ & $\begin{array}{c}\text { FEV-1 } \\
(\%)\end{array}$ & DLCO (\%) & $\begin{array}{c}\text { FVC\% / DLCO } \\
\%\end{array}$ & $\begin{array}{r}\text { Mean PAP } \\
(\mathrm{mmHg})\end{array}$ \\
\hline 1 & M 56.8 & (pack years) & $\begin{array}{l}\text { (type) } \\
\text { limited }\end{array}$ & Th/To & (\%) & $\begin{array}{ll} & (\%) \\
48 & \end{array}$ & 34 & 1.18 & \\
\hline 3 & F57.8 & 10 & limited & centromere & 88 & 85 & 38 & 2.32 & 51 \\
\hline 4 & F51.3 & 10 & diffuse & $\mathrm{n} / \mathrm{a}$ & 34 & 43 & 22 & 1.55 & 30 \\
\hline 5 & F39.3 & 0 & diffuse & Scl-70 & 24 & 31 & 31 & 1.55 & 22 \\
\hline 6 & M 59.0 & 40 & $\mathrm{n} / \mathrm{a}$ & centromere & 80 & 80 & 24 & 3.33 & 47 \\
\hline 7 & M 46.3 & 0 & limited & centromere & 76 & 80 & 40 & 1.9 & 48 \\
\hline 8 & F26.5 & 0 & sine & U11/U12 RNP & 28 & 33 & 39 & 0.71 & 13 \\
\hline 9 & F41.8 & 0 & limited & centromere & 61 & 69 & 34 & 1.79 & 62 \\
\hline 10 & F56.4 & 60 & limited & $\mathrm{Th} / \mathrm{To}$ & 64 & 34 & 29 & 2.2 & 42 \\
\hline 11 & M 45.3 & 0 & diffuse & Scl-70 & 30 & 34 & 23 & 1.3 & 23 \\
\hline 13 & M 42.5 & 8 & diffuse & U1 RNP & 36 & 45 & 31 & 1.16 & 50 \\
\hline$\overline{14}$ & F 34.6 & 0 & diffuse & U11/U12 RNP & 28 & 33 & 32 & 0.88 & $n / a$ \\
\hline$\overline{15}$ & F 47.7 & 1 & diffuse & Scl-70 & 18 & 17 & $n / a$ & $n / a$ & 14 \\
\hline 16 & F 36.8 & 7 & limited & Th/To & 85 & 91 & 83 & 1.02 & 60 \\
\hline 17 & F56.7 & 0 & limited & centromere & 74 & 74 & 30 & 2.47 & 52 \\
\hline 18 & F 42.3 & 15 & limited & Scl-70 & 46 & 56 & 14 & 3.28 & 24 \\
\hline 19 & F 37.0 & 0 & diffuse & $\mathrm{n} / \mathrm{a}$ & 18 & 21 & $\mathrm{n} / \mathrm{a}$ & $n / a$ & 26 \\
\hline 21 & F56.2 & 55 & $\mathrm{n} / \mathrm{a}$ & $\mathrm{n} / \mathrm{a}$ & 41 & 29 & 25 & 1.64 & 43 \\
\hline 22 & $\mathrm{M} 60.0$ & 0 & diffuse & Scl-70 & 60 & 70 & 36 & 1.67 & 48 \\
\hline 23 & F51.7 & 39 & limited & $\mathrm{n} / \mathrm{a}$ & 36 & 44 & 20 & 1.8 & 22 \\
\hline 24 & M 45.1 & 0 & $\mathrm{n} / \mathrm{a}$ & $n / a$ & 26 & 28 & 30 & 0.87 & 23 \\
\hline 25 & F51.8 & 12 & diffuse & $n / a$ & 23 & 25 & $\mathrm{n} / \mathrm{a}$ & $n / a$ & 20 \\
\hline 26 & M 57.5 & 0 & diffuse & $\mathrm{n} / \mathrm{a}$ & 33 & 46 & 26 & 1.27 & 24 \\
\hline 27 & F41.6 & 5 & diffuse & U11/U12 RNP & 42 & 44 & 31 & 1.35 & 15 \\
\hline 28 & M 58.2 & 30 & diffuse & RNA polymerase & 63 & 77 & 16 & 3.93 & 38 \\
\hline 29 & F60.1 & 0 & limited & Scl-70 & 61 & 70 & 20 & 3.05 & 23 \\
\hline$\overline{30}$ & F58.8 & 0 & $\mathrm{n} / \mathrm{a}$ & $\mathrm{n} / \mathrm{a}$ & 39 & 50 & 14 & 2.79 & 19 \\
\hline 32 & F63.8 & 0 & limited & centromere & 59 & 70 & $\mathrm{n} / \mathrm{a}$ & $n / a$ & 44 \\
\hline 33 & F63.5 & 0 & limited & RNA polymerase & 82 & 95 & 25 & 3.28 & 31 \\
\hline 35 & M 54.2 & 0 & $\mathrm{n} / \mathrm{a}$ & $\mathrm{n} / \mathrm{a}$ & 40 & 47 & $\mathrm{n} / \mathrm{a}$ & $n / a$ & 38 \\
\hline 36 & M 49.0 & 30 & diffuse & U11/U12 RNP & 76 & 67 & $\mathrm{n} / \mathrm{a}$ & $\mathrm{n} / \mathrm{a}$ & 43 \\
\hline 37 & M 47.2 & 0 & diffuse & $\mathrm{n} / \mathrm{a}$ & 52 & 58 & 20 & 2.6 & 35 \\
\hline 38 & F 49.0 & 30 & limited & $n / a$ & 26 & 32 & 19 & 1.37 & 21 \\
\hline
\end{tabular}

Table 4.2.8 Characteristics of idiopathic pulmonary arterial hypertension dataset. 


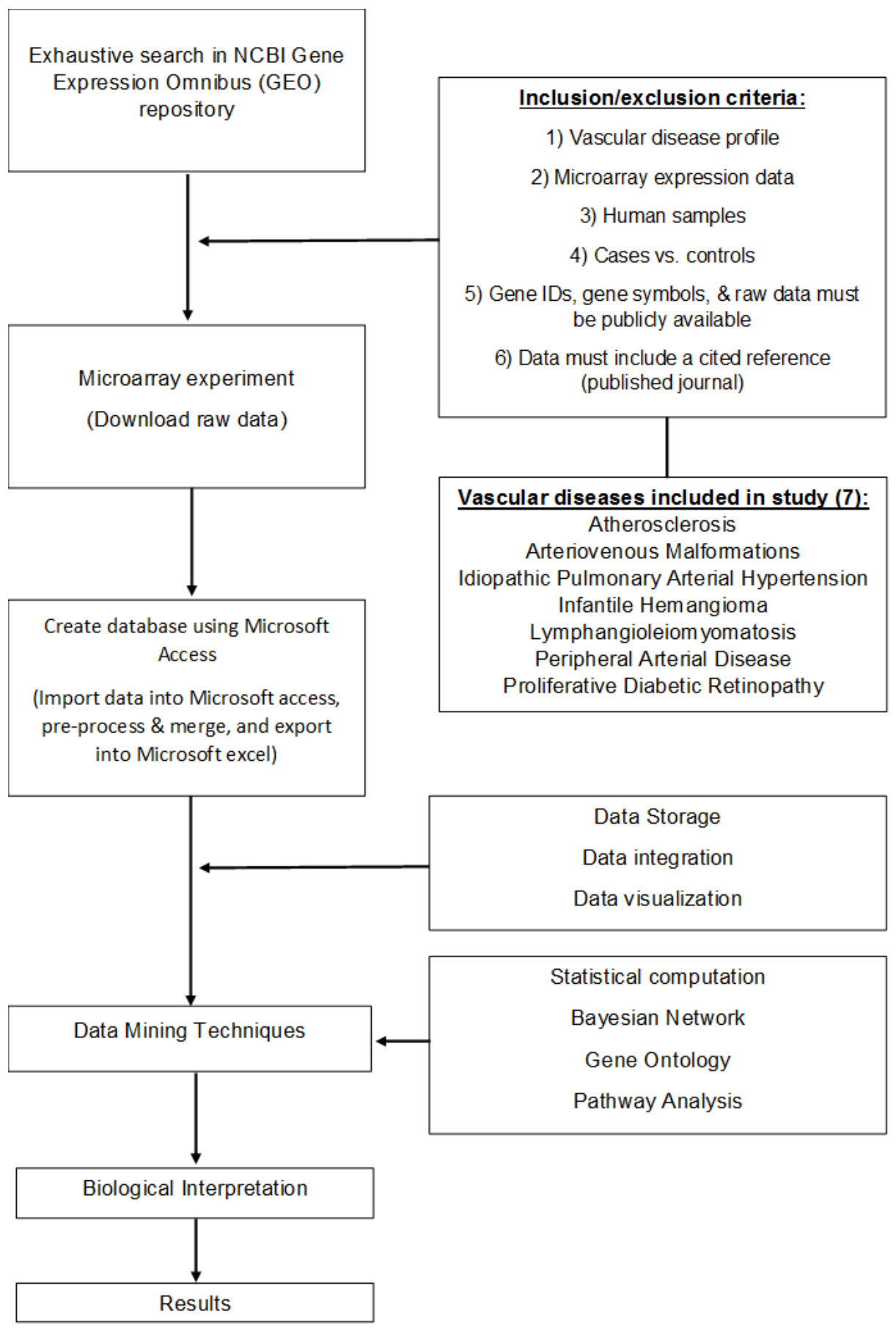

Figure 4.1 Flow chart summarizing the steps in this study. 


\section{Computational identification of ID3 and ID3 candidate target genes.}

Respectively each dataset has a different number of genes signifying the genome $(\sim 13,000-35,000)$. To compare the data, the identification of commonly expressed genes across all studies in both blood and tissue was first established. A total number of 3665 genes were commonly represented in each study. In order to remove systematic variation in the microarray experiments which affects the measured gene expression levels, raw data was discretized using the function: (IF (Sample $>$ Average $+0.5^{\star}$ Standard Deviation, 2, IF (Sample $>$ Average$0.5^{\star}$ Standard $\left.\left.^{*}, 1,0\right)\right)$ ). Expression levels were signified as 0 (under/lowexpression), 1 (normal expression), \& 2 (overexpression). To classify ID3 candidate target genes, a pearson correlation test was conducted. This is a measure of linear correlation between two variables: $X \& Y$ and is represented by a value between -1 and 1 , where -1 is a total negative correlation, 0 is no correlation, \& 1 is a total positive correlation. Additionally the interquartile range (IQR), which is a measure of variability, based on dividing a set of data in quartiles (Q1 $-25^{\text {th }}$ percentile, Q2- $50^{\text {th }}$ percentile, Q3 $-75^{\text {th }}$ percentile, and Q4 $-100^{\text {th }}$ percentile) was calculated. Genes that were measured between Q3 $\left(75^{\text {th }}\right.$ percentile) \& Q4 $\left(100^{\text {th }}\right.$ percentile) were identified as best correlated with ID3. Additionally an independent t-test, which compares the means of two independent groups in order to determine whether there is statistical evidence that the associated population means are significantly different was used to test statistical differences between means of two groups (disease and control). Our common gene list (3665) was used during our t-test and significance value was considered 
at $p \leq 0.05$ and IQR was determined. Genes measured in the Q1 $\left(25^{\text {th }}\right.$ percentile) was represented as significant. In order to generate the conclusive list of ID3 candidate targets, genes that were mutually expressed in Q3 and Q4 of the Pearson correlation analysis and Q1 of the t-test were included as candidate targets. This method was done separately for whole blood and tissue studies. Furthermore the top 10 most significant ID3 targets in both blood and tissue samples were also identified.

Bayesian analysis \& network. Due to the development of biomedical data in biology \& medicine with vast number of variables, Bayesian networks have been successfully used in developing effective algorithms that scale up to datasets connecting numbers of variables in learning high quality predictive models from genomic data (Yoo et al. 2002; Yoo and Cooper, 2004). A Bayesian network is a directed acyclic graph in which each node represents a variable and each arc represents probabilistic influence. In Bayesian Networks, each arc is interpreted as a direct influence between a parent node (variable) and a child node, relative to the other nodes in the network. Structure of Bayesian network with respect to a decomposable score such as $\mathrm{BIC}, \mathrm{BDe}$, or AIC becomes infeasible as the number of variables increases. A much simpler algorithm for finding the globally optimal Bayesian network structure without any structural limitations is used with $n<33$ which is also known as Bene. The approach is broken down into five logical steps: Step 1. Compute the local scores for all $n 2 n-1$ different (variable, variable set) pairs; Step 2. Using the local scores, find the best parents for all n2n-1 (variable, parent candidate set)-pairs; Step 3. Find the best sink for all $2 \mathrm{n}$ variable sets; and 
Step 4. Using the results from Step 3, find a best ordering of the variables. Step 5. Find a best network using results computed in Steps 2 and 4 (Silander \& Myllymak).

Genie. Genie Modular is a graphical user interface to SMILE (Structural Modeling, Interface, \& Learning Engine) is a fully platform independent library of $\mathrm{C}_{++}$classes applying decision-theoretic models \& graphical probabilistic, such as Bayesian networks, influence diagrams, and structural equation models. A graph demonstrates much about the structure of a probabilistic domain but not much about its numerical properties. These are encoded in conditional probability distribution matrices (equivalent to the factors in the factorized form), called conditional probability tables (CPTs) that are associated with the nodes. There will always be nodes in the network with no predecessors. These nodes are categorized by their prior marginal probability distribution. Any probability in the joint probability distribution can be determined from these explicitly represented prior and conditional probabilities.

Gene Ontology \& Pathway Analysis. To understand the functions of the gene list we applied two gene ontology tools: Princeton University Lewis-Sigler Institute for Integrative Genomics Gene Ontology (GO) Tools (http://go.princeton.edu/), \& STRING database version 10 (http://string-db.org/). All tools provide a knowledgebase of functional annotation tools for investigators to understand functional meaning (biological, molecular) behind various sizes of gene lists. 
Comparative Toxicogenomic Database (CTD) Analysis. CTD is a publicly available database that aims to advance understanding about how environmental exposures affect human health (Davis et al. 2016). The database provides curated information about chemical-gene/protein interactions, chemical-disease and gene-disease relationships. The data are integrated with functional and pathway data to support in development of hypotheses about the mechanisms essential environmentally predisposed diseases. To understand the association between endocrine disrupting chemicals (PCBs and BPA) \& ID3/ID3 target genes, CTD was used to investigate the association between PCB/BPA associated genes \& ID3/ID3 target genes identified in both blood and tissue respectively. Furthermore overlapping blood-tissue ID3 target genes and their association with both PCBs and BPA was also examined. Results were summarized in venn diagrams and final lists was provided for each.

\section{Results}

Gene expression of ID3 \& ID3 candidate targets in blood \& tissue studies. We identified ID3 \& ID3 candidate target genes in all blood studies and tissue studies. Table 4.3 and 4.5 shows a listing of ID3 and ID3 candidate target genes. In blood, 217-candidate target genes were identified and in tissue 134-candidate target genes were identified. Top 10 most significant ID3 target genes were identified in blood \& tissue studies summarized in tables 4.4 \& 4.6. Top 10 most significant ID3 targets in blood includes: COL1A2, COL6A1, CYP2C18, DIRAS3, DLG2, DZIP1, GCLM, GDF11, GRP, and KNG1. The top 10 most significant ID3 


\section{targets in tissue includes: ACLY, ACP1, ARPC4, ATP5D, CAMK1, CDKN2B, COPE, CYC1, EIF4EBP2, and MCRS1.}

\begin{tabular}{|c|c|}
\hline Gene Symbol & Entrez Gene Title \\
\hline $\mathrm{ABCA4}$ & ATP binding cassette subfamily A member 4 (ABCA4) \\
\hline ABCB6 & $\begin{array}{l}\text { ATP binding cassette subfamily B member } 6 \text { (Langereis } \\
\text { blood group)(ABCB6) }\end{array}$ \\
\hline ACIN1 & apoptotic chromatin condensation inducer 1 (ACIN1) \\
\hline ACP1 & acid phosphatase 1 , soluble (ACP1) \\
\hline ACTA2 & actin, alpha 2, smooth muscle, aorta (ACTA2) \\
\hline ACTN1 & actinin alpha 1 (ACTN1) \\
\hline ADAMTS3 & $\begin{array}{l}\text { ADAM metallopeptidase with thrombospondin type } 1 \text { motif } \\
\text { 3(ADAMTS3) }\end{array}$ \\
\hline AEBP1 & AE binding protein 1 (AEBP1) \\
\hline AGTR2 & angiotensin II receptor type 2 (AGTR2) \\
\hline ANKRD26 & ankyrin repeat domain 26 (ANKRD26) \\
\hline ANPEP & alanyl aminopeptidase, membrane (ANPEP) \\
\hline APAF1 & apoptotic peptidase activating factor 1 (APAF1) \\
\hline APOF & apolipoprotein F (APOF) \\
\hline $\mathrm{APOH}$ & apolipoprotein $\mathrm{H}(\mathrm{APOH})$ \\
\hline ARID5B & AT-rich interaction domain 5B (ARID5B) \\
\hline ARSA & arylsulfatase $\mathrm{A}(\mathrm{ARSA})$ \\
\hline ASB4 & ankyrin repeat and SOCS box containing 4 (ASB4) \\
\hline ASNS & asparagine synthetase (glutamine-hydrolyzing) (ASNS) \\
\hline ATP7B & ATPase copper transporting beta(ATP7B) \\
\hline COL1A2 & collagen type I alpha 2 chain (COL1A2) \\
\hline COL3A1 & collagen type III alpha 1 chain (COL3A1) \\
\hline COL6A1 & collagen type VI alpha 1 chain (COL6A1) \\
\hline COPB2 & coatomer protein complex subunit beta 2 (COPB2) \\
\hline CREBBP & CREB binding protein (CREBBP) \\
\hline CRYAA & crystallin alpha A (CRYAA) \\
\hline CTGF & connective tissue growth factor (CTGF) \\
\hline CTH & cystathionine gamma-lyase (CTH) \\
\hline CTNNB1 & catenin beta 1 (CTNNB1) \\
\hline CTNNB1 & beta-catenin (ctnnb1) \\
\hline CTSF & cathepsin F (CTSF) \\
\hline CYP26A1 & $\begin{array}{l}\text { cytochrome P450 family } 26 \text { subfamily A member } 1 \\
\text { (CYP26A1) }\end{array}$ \\
\hline CYP2C18 & $\begin{array}{l}\text { cytochrome P450 family } 2 \text { subfamily C member } 18 \\
\text { (CYP2C18) }\end{array}$ \\
\hline CYP4F11 & $\begin{array}{l}\text { cytochrome P450 family } 4 \text { subfamily } F \text { member } 11 \\
\text { (CYP4F11) }\end{array}$ \\
\hline CYR61 & cysteine rich angiogenic inducer 61(CYR61) \\
\hline DAAM1 & $\begin{array}{l}\text { dishevelled associated activator of morphogenesis } 1 \\
\text { (DAAM1) }\end{array}$ \\
\hline DAB2 & DAB2, clathrin adaptor protein(DAB2) \\
\hline DCBLD2 & discoidin, CUB and LCCL domain containing 2 (DCBLD2) \\
\hline DCX & Doublecortin (DCX) \\
\hline DHRS3 & dehydrogenase/reductase 3 (DHRS3) \\
\hline DHRS7 & dehydrogenase/reductase 7 (DHRS7) \\
\hline DIRAS3 & DIRAS family GTPase 3 (DIRAS3) \\
\hline DLG2 & discs large MAGUK scaffold protein 2 (DLG2) \\
\hline DNAJC7 & $\begin{array}{l}\text { DnaJ heat shock protein family (Hsp40) member C7 } \\
\text { (DNAJC7) }\end{array}$ \\
\hline DNMT1 & DNA methyltransferase|1 (DNMT1) \\
\hline DOCK9 & dedicator of cytokinesis 9(DOCK9) \\
\hline
\end{tabular}




\begin{tabular}{|c|c|}
\hline AVPR2 & arginine vasopressin receptor 2 (AVPR2) \\
\hline BCAM & basal cell adhesion molecule (Lutheran blood \\
\hline BCL2L2 & BCL2 like 2 (BCL2L2) \\
\hline BYSL & bystin like (BYSL) \\
\hline C10ORF10 & chromosome 10 open reading frame 10 (C10orf10) \\
\hline CACNB4 & $\begin{array}{l}\text { calcium voltage-gated channel auxiliary subunit beta } 4 \\
\text { (CACNB4) }\end{array}$ \\
\hline CACNG3 & $\begin{array}{l}\text { calcium voltage-gated channel auxiliary subunit gamma } 3 \\
\text { (CACNG3) }\end{array}$ \\
\hline $\begin{array}{l}\text { CAD } \\
\text { CALR }\end{array}$ & $\begin{array}{l}\text { carbamoyl-phosphate synthetase } 2, \\
\text { transcarbamylase, and dihydroorotase (CAD) } \\
\text { calreticulin (CALR) }\end{array}$ \\
\hline $\mathrm{CCL} 7$ & C-C motif chemokine ligand 7(CCL7) \\
\hline ССТ8 & chaperonin containing TCP1 subunit 8(CCT8) \\
\hline $\mathrm{CDH} 12$ & cadherin 12 (CDH12) \\
\hline $\mathrm{CDH} 15$ & cadherin 15 (CDH15) \\
\hline $\mathrm{CDH} 16$ & cadherin $16(\mathrm{CDH} 16)$ \\
\hline $\mathrm{CDH} 17$ & cadherin $17(\mathrm{CDH} 17)$ \\
\hline $\mathrm{CDH} 2$ & cadherin $2(\mathrm{CDH} 2)$ \\
\hline $\mathrm{CDH} 6$ & cadherin $6(\mathrm{CDH} 6)$ \\
\hline CDKL2 & cyclin dependent kinase like 2 (CDKL2) \\
\hline CFDP1 & craniofacial development protein 1 (CFDP1) \\
\hline CFTR & $\begin{array}{l}\text { Cystic fibrosis transmembrane conductance regulator } \\
\text { (CFTR) }\end{array}$ \\
\hline $\mathrm{CH} 25 \mathrm{H}$ & cholesterol 25-hydroxylase $(\mathrm{CH} 25 \mathrm{H})$ \\
\hline CHEK1 & checkpoint kinase 1 (CHEK1) \\
\hline CKM & creatine kinase, M-type (CKM) \\
\hline CNKSR2 & $\begin{array}{l}\text { connector enhancer of kinase suppressor of Ras } 2 \\
\text { (CNKSR2) }\end{array}$ \\
\hline COL17A1 & collagen type XVII alpha 1 chain (COL17A1) \\
\hline DRD1 & dopamine receptor D1 (DRD1) \\
\hline DSCR4 & Down syndrome critical region 4(DSCR4) \\
\hline DTYMK & deoxythymidylate kinase (DTYMK) \\
\hline DUSP14 & dual specificity phosphatase 14 (DUSP14) \\
\hline DYRK3 & $\begin{array}{l}\text { dual specificity tyrosine phosphorylation regulated kinase } \\
3 \text { (DYRK3) }\end{array}$ \\
\hline DZIP1 & DAZ interacting zinc finger protein 1 (DZIP1) \\
\hline EEF1E1 & $\begin{array}{l}\text { eukaryotic translation elongation factor } 1 \text { epsilon } 1 \\
\text { (EEF1E1) }\end{array}$ \\
\hline ETS1 & ETS proto-oncogene 1, transcription factor (ETS1) \\
\hline FBLN2 & fibulin 2 (FBLN2) \\
\hline FBLN5 & fibulin 5 (FBLN5) \\
\hline FBP2 & fructose-bisphosphatase 2 (FBP2) \\
\hline FKBP4 & FK506 binding protein 4 (FKBP4) \\
\hline FNBP1 & formin binding protein 1 (FNBP1) \\
\hline FOXC2 & forkhead box C2 (FOXC2) \\
\hline FUT9 & fucosyltransferase 9 (FUT9) \\
\hline GABRA2 & $\begin{array}{l}\text { gamma-aminobutyric acid type A receptor alpha2 subunit } \\
\text { (GABRA2) }\end{array}$ \\
\hline GAL & galanin and GMAP prepropeptide (GAL) \\
\hline GAS8 & growth arrest specific 8 (GAS8) \\
\hline GCLM & glutamate-cysteine ligase modifier subunit (GCLM) \\
\hline GDF11 & growth differentiation factor 11 (GDF11) \\
\hline GFRA1 & GDNF family receptor alpha 1 (GFRA1) \\
\hline GLRA1 & glycine receptor alpha 1 (GLRA1) \\
\hline GPR135 & G protein-coupled receptor 135 (GPR135) \\
\hline GPR37L1 & G protein-coupled receptor 37 like 1 (GPR37L1) \\
\hline GRIA2 & $\begin{array}{l}\text { glutamate ionotropic receptor AMPA type subunit } 2 \\
\text { (GRIA2) }\end{array}$ \\
\hline GRIK5 & $\begin{array}{l}\text { glutamate ionotropic receptor kainatel type subunit } 5 \\
\text { (GRIK5) }\end{array}$ \\
\hline
\end{tabular}




\begin{tabular}{|c|c|}
\hline GRIN2B & $\begin{array}{l}\text { glutamate ionotropic receptor NMDA type subunit } 2 B \\
\text { (GRIN2B) }\end{array}$ \\
\hline GRP & gastrin releasing peptide(GRP) \\
\hline HDAC4 & histone deacetylase 4 (HDAC4) \\
\hline HDDC2 & HD domain containing 2 (HDDC2) \\
\hline HIST1H4C & histone cluster $1 \mathrm{H} 4$ family member $\mathrm{c}$ (HIST1H4C) \\
\hline HMGB3 & high mobility group box 3 (HMGB3) \\
\hline HMGCS2 & 3-hydroxy-3-methylglutaryl-CoA synthase 2 (HMGCS2) \\
\hline HNF4G & hepatocyte nuclear factor 4 gamma (HNF4G) \\
\hline HOXD3 & homeobox D3 (HOXD3) \\
\hline HS3ST1 & $\begin{array}{l}\text { heparan sulfate-glucosamine 3-sulfotransferase } \\
\text { (HS3ST1) }\end{array}$ \\
\hline HSPB2 & heat shock protein family B (small) member 2 (HSPB2) \\
\hline HTR4 & 5-hydroxytryptamine receptor 4 (HTR4) \\
\hline IBSP & integrin binding sialoprotein (IBSP) \\
\hline ID3 & inhibitor of DNA binding 3, HLH protein (ID3) \\
\hline IFIH1 & interferon induced with helicase C domain 1 (IFIH1) \\
\hline IFNA2 & interferon alpha 2 (IFNA2) \\
\hline IGFBP2 & insulin like growth factor binding protein 2 (IGFBP2) \\
\hline IL13RA2 & interleukin 13 receptor subunit alpha 2 (IL13RA2) \\
\hline IL6 & interleukin 6 (IL6) \\
\hline INHBB & inhibin beta B subunit (INHBB) \\
\hline ITGA8 & integrin subunit alpha 8 (ITGA8) \\
\hline $\mathrm{KCNH} 2$ & $\begin{array}{l}\text { potassium voltage-gated channel subfamily } \mathrm{H} \text { member } 2 \\
(\mathrm{KCNH} 2)\end{array}$ \\
\hline KCNJ4 & $\begin{array}{l}\text { potassium voltage-gated channel subfamily } \mathrm{J} \text { member } 4 \\
\text { (KCNJ4) }\end{array}$ \\
\hline KCNK1 & $\begin{array}{l}\text { potassium two pore domain channel subfamily } \mathrm{K} \text { member } \\
1(\mathrm{KCNK} 1)\end{array}$ \\
\hline KIF1A & kinesin family member $1 \mathrm{~A}(\mathrm{KIF} 1 \mathrm{~A})$ \\
\hline KNG1 & kininogen|1 (KNG1) \\
\hline
\end{tabular}

\begin{tabular}{ll} 
& leucine rich repeat containing G protein-coupled receptor \\
LGR5 & 5 (LGR5) \\
\hline LIFR & leukemia inhibitory factor receptor alpha (LIFR) \\
LMO3 & LIM domain only 3 (LMO3) \\
MAN1A2 & mannosidase alpha class 1A member 2 (MAN1A2) \\
& minichromosome maintenance complex component 4 \\
MCM4 & (MCM4) \\
MLLT10 & myeloid/lymphoid or mixed-lineage leukemia; translocated \\
MMP11 & matrix metallopeptidase 11 (MMP11) \\
MPP3 & membrane palmitoylated protein 3 (MPP3) \\
MPP6 & membrane palmitoylated protein 6 (MPP6) \\
MTTP & microsomal triglyceride transfer protein (MTTP) \\
MYL2 & myosin light chain 2 (MYL2) \\
NDP & NDP, norrin cystine knot growth factor (NDP) \\
NDUFA7 & NADH: ubiquinone oxidoreductase subunit A7 (NDUFA7)
\end{tabular}

Table 4.3 ID3 and ID3 candidate target genes identified in blood studies. 


\begin{tabular}{ll}
\hline Gene Symbol & Entrez Gene Title \\
COL1A2 & collagen type I alpha 2 chain (COL1A2) \\
COL6A1 & collagen type VI alpha 1 chain (COL6A1) \\
\hline CYP2C18 & cytochrome P450 family 2 subfamily C member 18 (CYP2C18) \\
DIRAS3 & DIRAS family GTPase 3 (DIRAS3) \\
\hline DLG2 & discs large MAGUK scaffold protein 2 (DLG2) \\
DZIP1 & DAZ interacting zinc finger protein 1 (DZIP1) \\
GCLM & glutamate-cysteine ligase modifier subunit (GCLM) \\
GDF11 & growth differentiation factor 11 (GDF11) \\
GRP & gastrin releasing peptide (GRP) \\
KNG1 & kininogen 1 (KNG1) \\
\hline
\end{tabular}

Table 4.4 Top 10 most significant ID3 candidate target genes in blood.

\begin{tabular}{|c|c|}
\hline $\begin{array}{l}\text { Gene } \\
\text { Symbol }\end{array}$ & Entrez Gene Title \\
\hline ABCA1 & ATP binding cassette subfamily A member 1 (ABCA1) \\
\hline ABCB6 & $\begin{array}{l}\text { ATP binding cassette subfamily B member } 6 \text { (Langereis blood } \\
\text { group)(ABCB6) }\end{array}$ \\
\hline ACLY & ATP citrate lyase (ACLY) \\
\hline ACOX1 & acyl-CoA oxidase 1 (ACOX1) \\
\hline ACP1 & acid phosphatase 1 , soluble(ACP1) \\
\hline ACTR1A & $\begin{array}{l}\text { ARP1 actin-related protein } 1 \text { homolog } A \text {, centractin } \\
\text { alpha(ACTR1A) }\end{array}$ \\
\hline ACTR2 & ARP2 actin related protein 2 homolog(ACTR2) \\
\hline ADRM1 & adhesion regulating molecule 1 (ADRM1) \\
\hline AGGF1 & angiogenic factor with G-patch and FHA domains 1(AGGF1) \\
\hline AHCTF1 & AT-hook containing transcription factor 1 (AHCTF1) \\
\hline AK2 & adenylate kinase $2(\mathrm{AK} 2)$ \\
\hline ALDH3B1 & aldehyde dehydrogenase 3 family member B1 (ALDH3B1) \\
\hline ALDOC & aldolase, fructose-bisphosphate C(ALDOC) \\
\hline ALPL & alkaline phosphatase, liver/bone/kidney(ALPL) \\
\hline ANAPC10 & anaphase promoting complex subunit 10(ANAPC10) \\
\hline AOX1 & aldehyde oxidase 1 (AOX1) \\
\hline AP2S1 & adaptor related protein complex 2 sigma 1 subunit(AP2S1) \\
\hline API5 & apoptosis inhibitor 5 (API5) \\
\hline APOD & apolipoprotein D(APOD) \\
\hline APRT & adenine phosphoribosyltransferase (APRT) \\
\hline ARCN1 & archain 1 (ARCN1) \\
\hline ARF4 & ADP ribosylation factor $4(\mathrm{ARF} 4)$ \\
\hline ARF5 & ADP ribosylation factor 5 (ARF5) \\
\hline ARFGEF2 & $\begin{array}{l}\text { ADP ribosylation factor guanine nucleotide exchange factor } 2 \\
\text { (ARFGEF2) }\end{array}$ \\
\hline ARID3A & AT-rich interaction domain 3A (ARID3A) \\
\hline ARL1 & ADP ribosylation factor like GTPase 1(ARL1) \\
\hline ARPC1A & actin related protein $2 / 3$ complex subunit $1 \mathrm{~A}$ (ARPC1A) \\
\hline ARPC4 & actin related protein $2 / 3$ complex subunit 4 (ARPC4) \\
\hline
\end{tabular}




\begin{tabular}{|c|c|}
\hline ASGR2 & asialoglycoprotein receptor 2 (ASGR2) \\
\hline ASPHD1 & aspartate beta-hydroxylase domain containing 1 (ASPHD1) \\
\hline ATF6 & activating transcription factor 6 (ATF6) \\
\hline ATM & ATM serine/threonine kinase (ATM) \\
\hline ATOX1 & antioxidant 1 copper chaperone (ATOX1) \\
\hline ATP5D & $\begin{array}{l}\text { ATP synthase, } \mathrm{H}+\text { transporting, mitochondrial F1 complex, delta } \\
\text { subunit (ATP5D) }\end{array}$ \\
\hline ATP5H & $\begin{array}{l}\text { ATP synthase, } \mathrm{H}+\text { transporting, mitochondrial Fo complex } \\
\text { subunit } D(A T P 5 H)\end{array}$ \\
\hline ATP6V0B & ATPase $\mathrm{H}+$ transporting V0 subunit b (ATP6V0B) \\
\hline ATP6V0D1 & ATPase $\mathrm{H}+$ transporting V0 subunit d1 (ATP6V0D1) \\
\hline ATP6V1B2 & ATPase $\mathrm{H}+$ transporting V1 subunit B2 (ATP6V1B2) \\
\hline AXIN1 & $\operatorname{axin} 1(\mathrm{AXIN} 1)$ \\
\hline $\mathrm{BAX}$ & $\mathrm{BCL} 2$ associated $\mathrm{X}$, apoptosis regulator (BAX) \\
\hline BCAP31 & B-cell receptor-associated protein 31 (BCAP31) \\
\hline BCAR3 & breast cancer anti-estrogen resistance 3 (BCAR3) \\
\hline BCAT2 & branched chain amino acid transaminase 2 (BCAT2) \\
\hline BCL7B & BCL tumor suppressor 7B (BCL7B) \\
\hline BNIP3 & BCL2 interacting protein 3 (BNIP3) \\
\hline BOP1 & block of proliferation 1 (BOP1) \\
\hline BYSL & bystin like (BYSL) \\
\hline C18orf25 & chromosome 18 open reading frame 25 (C18orf25) \\
\hline C4BPB & complement component 4 binding protein beta (C4BPB) \\
\hline CAD & $\begin{array}{l}\text { carbamoyl-phosphate synthetase } 2 \text {, aspartate transcarbamylase, } \\
\text { and dihydroorotase (CAD) }\end{array}$ \\
\hline CAMK1 & calcium/calmodulin dependent protein kinase I (CAMK1) \\
\hline CAPNS1 & calpain small subunit 1 (CAPNS1) \\
\hline CASK & calcium/calmodulin dependent serine protein kinase (CASK) \\
\hline CCDC6 & coiled-coil domain containing 6 (CCDC6) \\
\hline CCL23 & $\mathrm{C}-\mathrm{C}$ motif chemokine ligand 23 (CCL23) \\
\hline $\mathrm{CCNI}$ & cyclin I (CCNI) \\
\hline CD2BP2 & CD2 cytoplasmic tail binding protein 2 (CD2BP2) \\
\hline CD99 & CD99 molecule (CD99) \\
\hline
\end{tabular}

$\begin{array}{ll}\text { CDH15 } & \text { cadherin 15(CDH15) } \\ \text { CDK2AP2 } & \text { cyclin dependent kinase 2 associated protein 2 (CDK2AP2) } \\ \text { CDK5 } & \text { cyclin dependent kinase 5 (CDK5) } \\ \text { CDKN2B } & \text { cyclin dependent kinase inhibitor 2B (CDKN2B) } \\ \text { CEBPG } & \text { CCAAT/enhancer binding protein gamma (CEBPG) } \\ \text { CHMP2A } & \text { charged multivesicular body protein 2A (CHMP2A) } \\ \text { CLN3 } & \text { CLN3, battenin (CLN3) } \\ & \text { caseinolytic mitochondrial matrix peptidase proteolytic subunit } \\ \text { CLPP } & \text { (CLPP) } \\ \text { CLTB } & \text { clathrin light chain B (CLTB) } \\ \text { COG7 } & \text { component of oligomeric golgi complex 7 (COG7) } \\ \text { COMMD4 } & \text { COMM domain containing 4 (COMMD4) } \\ \text { COPE } & \text { coatomer protein complex subunit epsilon(COPE) } \\ \text { COPS3 } & \text { COP9 signalosome subunit 3 (COPS3) } \\ \text { COPS7A } & \text { COP9 signalosome subunit 7A (COPS7A) } \\ \text { COX5A } & \text { cytochrome c oxidase subunit 5A (COX5A) } \\ \text { COX7C } & \text { cytochrome c oxidase subunit 7C (COX7C) } \\ \text { COX8A } & \text { cytochrome c oxidase subunit 8A (COX8A) } \\ \text { CSF3R } & \text { colony stimulating factor 3 receptor (CSF3R) } \\ \text { CSPG5 } & \text { chondroitin sulfate proteoglycan 5 (CSPG5) } \\ \text { CTNNBIP1 } & \text { catenin beta interacting protein 1 (CTNNBIP1) } \\ \text { CTSZ } & \text { cathepsin Z (CTSZ) } \\ \text { CYB561D2 } & \text { cytochrome b561 family member D2 (CYB561D2) } \\ \text { CYC1 } & \text { cytochrome c1 (CYC1) } \\ \text { CYHR1 } & \text { cysteine and histidine rich 1(CYHR1) } \\ \text { DAP } & \text { death associated protein(DAP) } \\ \text { DCBLD2 } & \text { discoidin, CUB and LCCL domain containing 2 (DCBLD2) } \\ \text { DCTN2 } & \text { dynactin subunit 2 (DCTN2) } \\ \text { DCTN5 } & \text { dynactin subunit 5 (DCTN5) } \\ \text { DDB1 } & \text { damage specific DNA binding protein 1 (DDB1) } \\ \text { DDN } & \text { Dendrin (DDN) } \\ \text { DDO } & \text { D-aspartate oxidase (DDO) } \\ \text { DEGS1 } & \text { delta 4-desaturase, sphingolipid 1 (DEGS1) } \\ & \end{array}$




\begin{tabular}{|c|c|}
\hline DHCR7 & 7-dehydrocholesterol reductase (DHCR7) \\
\hline DHRS3 & dehydrogenase/reductase 3 (DHRS3) \\
\hline $\mathrm{DHX} 16$ & DEAH-box helicase $16(\mathrm{DHX} 16)$ \\
\hline $\mathrm{DHX8}$ & DEAH-box helicase 8 (DHX8) \\
\hline DNAJB6 & DnaJ heat shock protein family (Hsp40) member B6 (DNAJB6) \\
\hline DNAJC8 & DnaJ heat shock protein family (Hsp40) member C8 (DNAJC8) \\
\hline DNASE2 & deoxyribonuclease 2, lysosomal (DNASE2) \\
\hline DNMT1 & DNA methyltransferase 1 (DNMT1) \\
\hline DPM2 & $\begin{array}{l}\text { dolichyl-phosphate mannosyltransferase subunit 2, regulatory } \\
\text { (DPM2) }\end{array}$ \\
\hline DYRK4 & $\begin{array}{l}\text { dual specificity tyrosine phosphorylation regulated kinase } 4 \\
\text { (DYRK4) }\end{array}$ \\
\hline E2F5 & E2F transcription factor 5 (E2F5) \\
\hline EEF2 & eukaryotic translation elongation factor 2 (EEF2) \\
\hline EIF2B1 & eukaryotic translation initiation factor $2 \mathrm{~B}$ subunit alpha (EIF2B1) \\
\hline EIF4EBP2 & $\begin{array}{l}\text { eukaryotic translation initiation factor } 4 \mathrm{E} \text { binding protein } 2 \\
\text { (EIF4EBP2) }\end{array}$ \\
\hline EIF4G1 & eukaryotic translation initiation factor 4 gamma 1(EIF4G1) \\
\hline EIF5A & eukaryotic translation initiation factor $5 \mathrm{~A}$ (EIF5A) \\
\hline ELAC2 & elaC ribonuclease Z 2 (ELAC2) \\
\hline ELF4 & E74 like ETS transcription factor 4(ELF4) \\
\hline ENO1 & enolase 1 (ENO1) \\
\hline EPHA1 & EPH receptor A1 (EPHA1) \\
\hline EPRS & glutamyl-prolyl-tRNA synthetase (EPRS) \\
\hline ERAL1 & Era like $12 S$ mitochondrial rRNA chaperone 1 (ERAL1) \\
\hline ERCC2 & $\begin{array}{l}\text { ERCC excision repair 2, TFIIH core complex helicase subunit } \\
\text { (ERCC2) }\end{array}$ \\
\hline FAM20B & FAM20B, glycosaminoglycan xylosylkinase (FAM20B) \\
\hline FAM50A & family with sequence similarity 50 member A (FAM50A) \\
\hline FLAD1 & flavin adenine dinucleotide synthetase 1 (FLAD1) \\
\hline FLOT2 & flotillin 2(FLOT2) \\
\hline FPR1 & formyl peptide receptor 1 (FPR1) \\
\hline FRAT2 & frequently rearranged in advanced T-cell lymphomas 2 (FRAT2) \\
\hline
\end{tabular}

\begin{tabular}{|c|c|}
\hline FXR2 & FMR1 autosomal homolog 2 (FXR2) \\
\hline FZD2 & frizzled class receptor 2 (FZD2) \\
\hline G3BP2 & G3BP stress granule assembly factor 2 (G3BP2) \\
\hline GABRD & gamma-aminobutyric acid type A receptor delta subunit (GABRD) \\
\hline GALK2 & galactokinase 2 (GALK2) \\
\hline GATA2 & GATA binding protein 2 (GATA2) \\
\hline GBF1 & $\begin{array}{l}\text { golgi brefeldin A resistant guanine nucleotide exchange factor } \\
1 \text { (GBF1) }\end{array}$ \\
\hline GLB1 & galactosidase beta 1 (GLB1) \\
\hline GOLGA3 & golgin A3 (GOLGA3) \\
\hline GOSR2 & golgi SNAP receptor complex member 2 (GOSR2) \\
\hline GOT1 & glutamic-oxaloacetic transaminase 1(GOT1) \\
\hline GPAA1 & glycosylphosphatidylinositol anchor attachment 1 (GPAA1) \\
\hline GPC5 & glypican 5 (GPC5) \\
\hline GPD1L & glycerol-3-phosphate dehydrogenase 1-like (GPD1L) \\
\hline GPI & glucose-6-phosphate isomerase (GPI) \\
\hline GPR39 & G protein-coupled receptor 39 (GPR39) \\
\hline GPR4 & G protein-coupled receptor 4 (GPR4) \\
\hline GPX1 & glutathione peroxidase 1 (GPX1) \\
\hline GRIN2D & glutamate ionotropic receptor NMDA type subunit 2D (GRIN2D) \\
\hline GTF2F2 & general transcription factor IIF subunit 2 (GTF2F2) \\
\hline $\mathrm{H} 1 \mathrm{F0}$ & $\mathrm{H} 1$ histone family member 0 ( $\mathrm{H} 1 \mathrm{~F} 0)$ \\
\hline $\mathrm{HAGH}$ & hydroxyacylglutathione hydrolase $(\mathrm{HAGH})$ \\
\hline HCLS1 & hematopoietic cell-specific Lyn substrate 1 (HCLS1) \\
\hline HERC3 & $\begin{array}{l}\text { HECT and RLD domain containing E3 ubiquitin protein ligase } 3 \\
\text { (HERC3) }\end{array}$ \\
\hline HERC4 & $\begin{array}{l}\text { HECT and RLD domain containing E3 ubiquitin protein ligase } 4 \\
\text { (HERC4) }\end{array}$ \\
\hline HESX1 & HESX homeobox 1 (HESX1) \\
\hline $\mathrm{HIBCH}$ & 3-hydroxyisobutyryl-CoA hydrolase (HIBCH) \\
\hline HIST1H1B & histone cluster $1 \mathrm{H} 1$ family member $\mathrm{b}$ (HIST1H1B) \\
\hline HIST1H1D & histone cluster $1 \mathrm{H} 1$ family member d (HIST1H1D) \\
\hline HMGCR & 3-hydroxy-3-methylglutaryl-CoA reductase (HMGCR) \\
\hline
\end{tabular}




\begin{tabular}{|c|c|}
\hline HSP90AB1 & $\begin{array}{l}\text { heat shock protein } 90 \text { alpha family class B member } 1 \\
\text { (HSP90AB1) }\end{array}$ \\
\hline HTATIP2 & HIV-1 Tat interactive protein 2 (HTATIP2) \\
\hline HTR2A & 5-hydroxytryptamine receptor 2A (HTR2A) \\
\hline ICA1 & islet cell autoantigen 1 (ICA1) \\
\hline ICAM3 & intercellular adhesion molecule 3 (ICAM3) \\
\hline ID3 & inhibitor of DNA binding 3, HLH protein (ID3) \\
\hline IDH2 & isocitrate dehydrogenase (NADP $(+)) 2$, mitochondrial (IDH2) \\
\hline IDH3B & isocitrate dehydrogenase $3(\mathrm{NAD}(+))$ beta (IDH3B) \\
\hline IDH3G & isocitrate dehydrogenase $3(\mathrm{NAD}(+))$ gamma (IDH3G) \\
\hline IFNGR2 & $\begin{array}{l}\text { interferon gamma receptor } 2 \text { (interferon gamma transducer 1) } \\
\text { (IFNGR2) }\end{array}$ \\
\hline IGFBP5 & insulin like growth factor binding protein 5 (IGFBP5) \\
\hline IL2RA & interleukin 2 receptor subunit alpha (IL2RA) \\
\hline ILF2 & interleukin enhancer binding factor 2 (ILF2) \\
\hline IMP4 & IMP4 homolog, U3 small nucleolar ribonucleoprotein (IMP4) \\
\hline ITGAM & integrin subunit alpha M (ITGAM) \\
\hline ITGB5 & integrin subunit beta 5 (ITGB5) \\
\hline IVD & isovaleryl-CoA dehydrogenase (IVD) \\
\hline KIAA0196 & KIAA0196 (KIAA0196) \\
\hline KIFAP3 & kinesin associated protein 3 (KIFAP3) \\
\hline KLK2 & kallikrein related peptidase 2 (KLK2) \\
\hline KPNA4 & karyopherin subunit alpha 4 (KPNA4) \\
\hline KRT19 & keratin 19 (KRT19) \\
\hline LASP1 & LIM and SH3 protein 1 (LASP1) \\
\hline LGALS1 & galectin 1 (LGALS1) \\
\hline LGALS3BP & galectin 3 binding protein (LGALS3BP) \\
\hline LMAN1 & lectin, mannose binding 1 (LMAN1) \\
\hline LMNA & lamin $\mathrm{A} / \mathrm{C}(\mathrm{LMNA})$ \\
\hline LRRC42 & leucine rich repeat containing 42(LRRC42) \\
\hline LSM3 & $\begin{array}{l}\text { LSM3 homolog, U6 small nuclear RNA and mRNA degradation } \\
\text { associated(LSM3) }\end{array}$ \\
\hline LY96 & lymphocyte antigen 96(LY96) \\
\hline M6PR & mannose-6-phosphate receptor, cation dependent (M6PR) \\
\hline MAPK1 & mitogen-activated protein kinase 1 (MAPK1) \\
\hline MAPK13 & mitogen-activated protein kinase 13(MAPK13) \\
\hline MAPKAPK3 & $\begin{array}{l}\text { mitogen-activated protein kinase-activated protein kinase } 3 \\
\text { (MAPKAPK3) }\end{array}$ \\
\hline MAPRE1 & $\begin{array}{l}\text { microtubule associated protein RP/EB family member } \\
1 \text { (MAPRE1) }\end{array}$ \\
\hline MCM3 & minichromosome maintenance complex component 3 (MCM3) \\
\hline MCM4 & minichromosome maintenance complex component 4 (MCM4) \\
\hline MCRS1 & microspherule protein 1 (MCRS1) \\
\hline MFGE8 & milk fat globule-EGF factor 8 protein (MFGE8) \\
\hline MFSD5 & major facilitator superfamily domain containing 5(MFSD5) \\
\hline MGAT1 & $\begin{array}{ll}\text { Mannosyl (alpha-1,3-)-glycoprotein } & \text { beta-1,2-N- } \\
\text { acetylglucosaminyltransferase(MGAT1) } & \end{array}$ \\
\hline MGST3 & microsomal glutathione S-transferase 3 (MGST3) \\
\hline MIF & $\begin{array}{l}\text { macrophage migration inhibitory factor (glycosylation-inhibiting } \\
\text { factor)(MIF) }\end{array}$ \\
\hline MPDU1 & mannose-P-dolichol utilization defect 1 (MPDU1) \\
\hline MPI & mannose phosphate isomerase(MPI) \\
\hline MPPE1 & metallophosphoesterase 1 (MPPE1) \\
\hline MPV17 & MPV17, mitochondrial inner membrane protein (MPV17) \\
\hline MR1 & major histocompatibility complex, class I-related(MR1) \\
\hline MRPL12 & mitochondrial ribosomal protein L12 (MRPL12) \\
\hline MRPS11 & mitochondrial ribosomal protein S11 (MRPS11) \\
\hline MRPS12 & mitochondrial ribosomal protein S12 (MRPS12) \\
\hline MSN & Moesin (MSN) \\
\hline MTHFS & $\begin{array}{l}\text { 5,10-methenyltetrahydrofolate-synthetase }(5- \\
\text { formyltetrahydrofolate-cyclo-ligase) (MTHFS) }\end{array}$ \\
\hline MTM1 & myotubularin 1 (MTM1) \\
\hline MVK & mevalonate kinase (MVK) \\
\hline MYBPC2 & myosin binding protein $\mathrm{C}$, fast type (MYBPC2) \\
\hline MYO7A & myosin VIIA(MYO7A) \\
\hline NAGLU & N-acetyl-alpha-glucosaminidase (NAGLU) \\
\hline
\end{tabular}




\begin{tabular}{ll} 
NAGPA & $\begin{array}{l}\text { N-acetylglucosamine-1-phosphodiester-alpha-N- } \\
\text { acetylglucosaminidase (NAGPA) }\end{array}$ \\
NCK1 & NCK adaptor protein 1 (NCK1) \\
NCSTN & Nicastrin (NCSTN) \\
NDST1 & N-deacetylase and N-sulfotransferase 1 (NDST1) \\
NDUFA1 & NADH: ubiquinone oxidoreductase subunit A1(NDUFA1) \\
NDUFA7 & NADH: ubiquinone oxidoreductase subunit A7 (NDUFA7) \\
NDUFS4 & NADH: ubiquinone oxidoreductase subunit S4 (NDUFS4) \\
NDUFV1 & NADH: ubiquinone oxidoreductase core subunit V1 (NDUFV1) \\
NDUFV2 & NADH: ubiquinone oxidoreductase core subunit V2 (NDUFV2) \\
& $\begin{array}{l}\text { neural precursor cell expressed, developmentally down- } \\
\text { regulated 8 (NEDD8) }\end{array}$ \\
\hline
\end{tabular}

Table 4.5 ID3 and ID3 candidate target genes in tissue studies.

\begin{tabular}{|l|l|}
\hline Gene Symbol & Entrez Gene Title \\
\hline ACLY & ATP citrate lyase (ACLY) \\
\hline ACP1 & acid phosphatase 1, soluble (ACP1) \\
\hline ARPC4 & actin related protein 2/3 complex subunit 4 (ARPC4) \\
\hline ATP5D & ATP synthase, H+ transporting, mitochondrial F1 complex, delta subunit (ATP5D) \\
\hline CAMK1 & calcium/calmodulin dependent protein kinase I (CAMK1) \\
CDKN2B & cyclin dependent kinase inhibitor 2B (CDKN2B) \\
\hline COPE & coatomer protein complex subunit epsilon (COPE) \\
CYC1 & cytochrome c1 (CYC1) \\
\hline EIF4EBP2 & eukaryotic translation initiation factor 4E binding protein 2 (EIF4EBP2) \\
\hline MCRS1 & microspherule protein 1 (MCRS1) \\
\hline
\end{tabular}

Table 4.6 Top 10 most significant ID3 candidate target genes in tissue.

Gene expression in blood versus tissue studies. Overlapping ID3 \& ID3 candidate target genes were identified between blood \& tissue samples. Genes include: ABCB6, ACP1, BYSL, CAD, CDH15, DCBLD2, DHRS3, DNMT1, ID3, MCM4, and NDUFA7 as shown in Table 4.7 \& Figure 4.3 Furthermore we demonstrated the results in both Bene and Genie models (Figure $4.4 \& 4.5 .1$ 4.5.4) illustrating a fully connected structure and probability distribution of gene expression. 


\begin{tabular}{|ll|}
\hline Gene Symbol & Entrez Gene Title \\
\hline ABCB6 & ATP binding cassette subfamily B member 6 (Langereis blood group) (ABCB6) \\
\hline ACP1 & acid phosphatase 1, soluble (ACP1) \\
\hline BYSL & bystin like (BYSL) \\
CAD & carbamoyl-phosphate synthetase 2, aspartate transcarbamylase, and dihydroorotase (CAD) \\
CDH15 & cadherin 15 (CDH15) \\
DCBLD2 & discoidin, CUB and LCCL domain containing 2 (DCBLD2) \\
\hline DHRS3 & dehydrogenase/reductase 3 (DHRS3) \\
DNMT1 & DNA methyltransferase 1 (DNMT1) \\
ID3 & inhibitor of DNA binding 3, HLH protein (ID3) \\
MCM4 & minichromosome maintenance complex component 4 (MCM4) \\
NDUFA7 & NADH: ubiquinone oxidoreductase subunit A7 (NDUFA7) \\
\hline
\end{tabular}

Table 4.7 ID3 and common candidate target genes between blood and tissue studies.

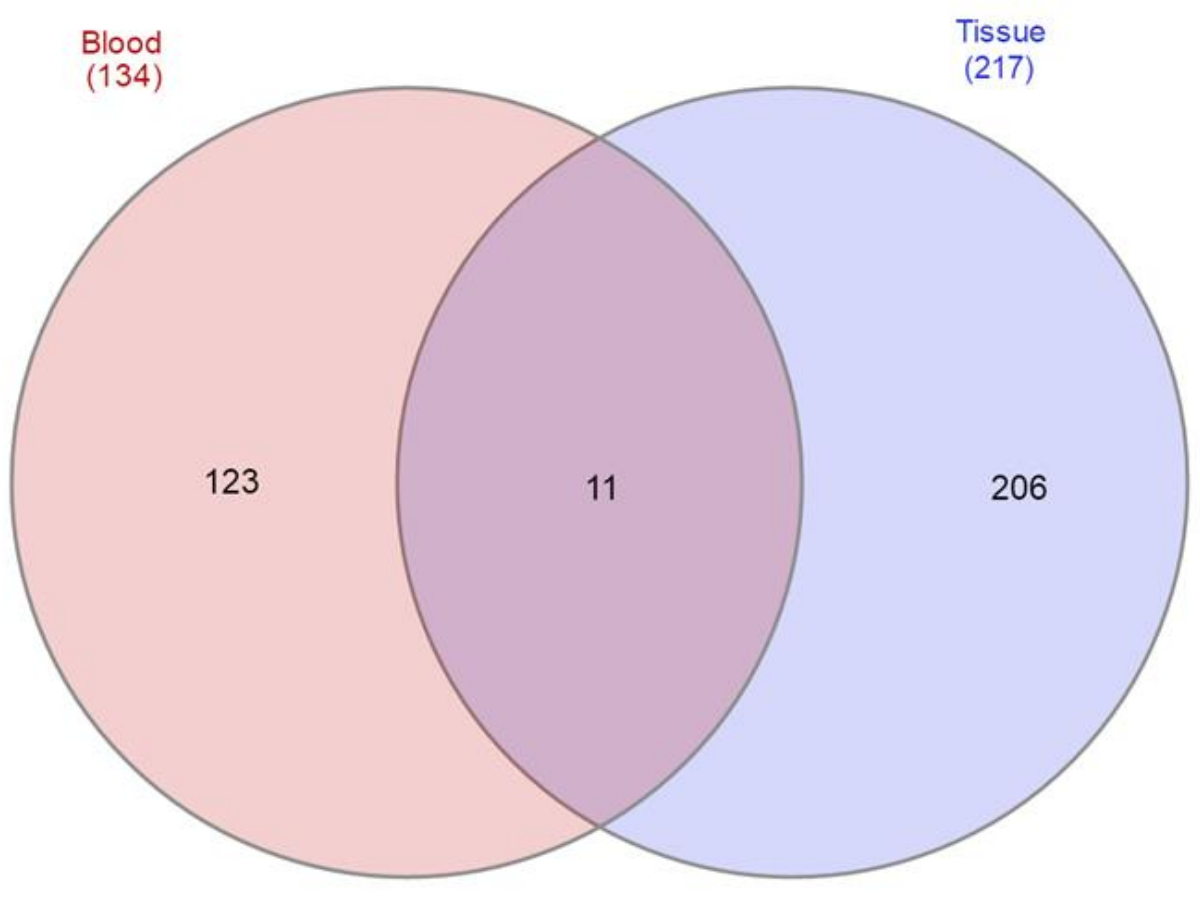

Figure 4.2 Venn diagram illustration summarizes ID3 \& ID3 candidate target genes. Left circle represent genes in blood studies (134), right circle represent genes in tissue studies (217), \& the middle intersection of the two circles represent the shared genes between both blood \& tissue studies (11). 


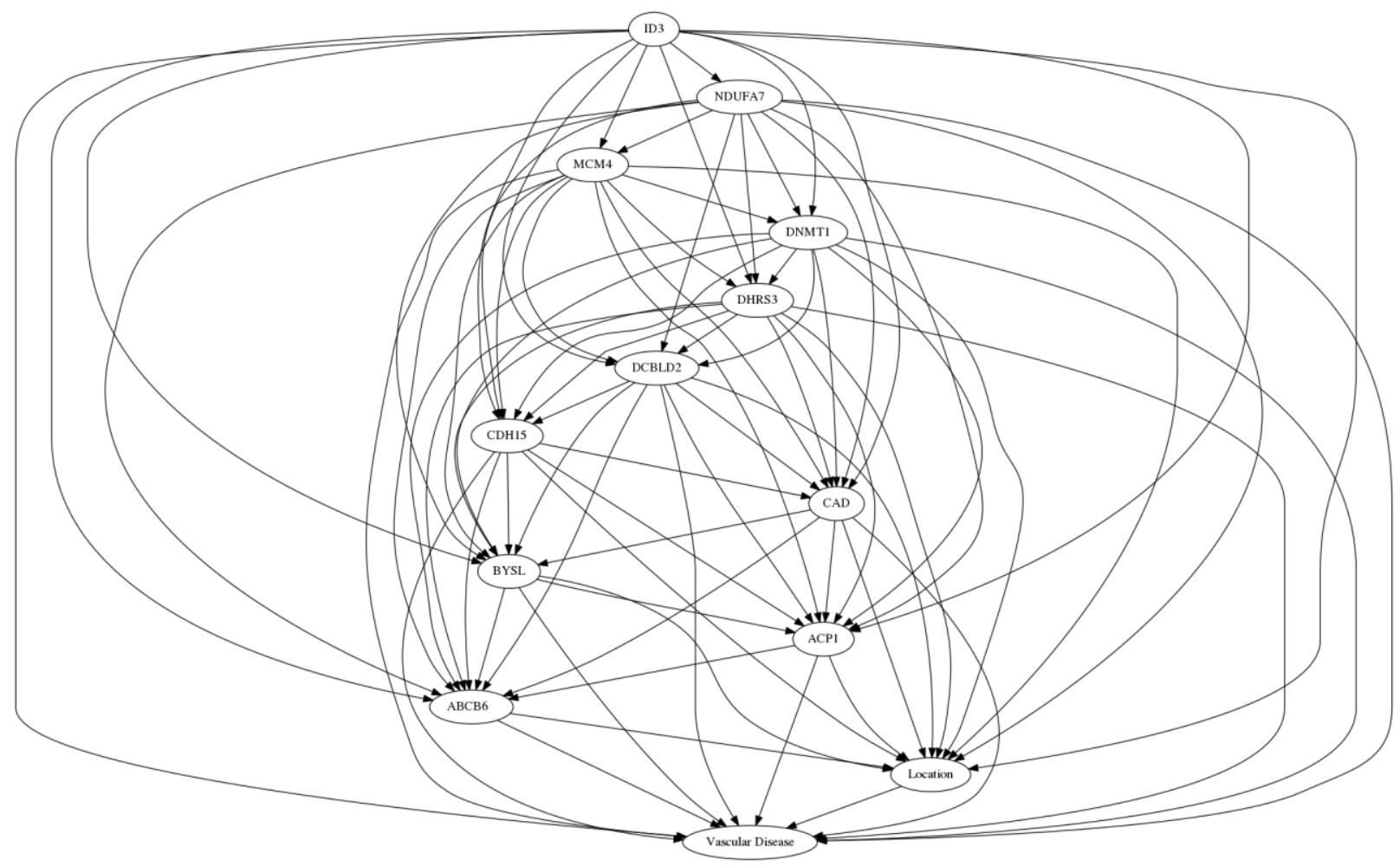

Figure 4.3 Representation of ID3 and overlapping ID3-candidate target genes in both blood and tissue samples. Bene, a method for finding the globally optimal Bayesian network produced a fully connected structure. 


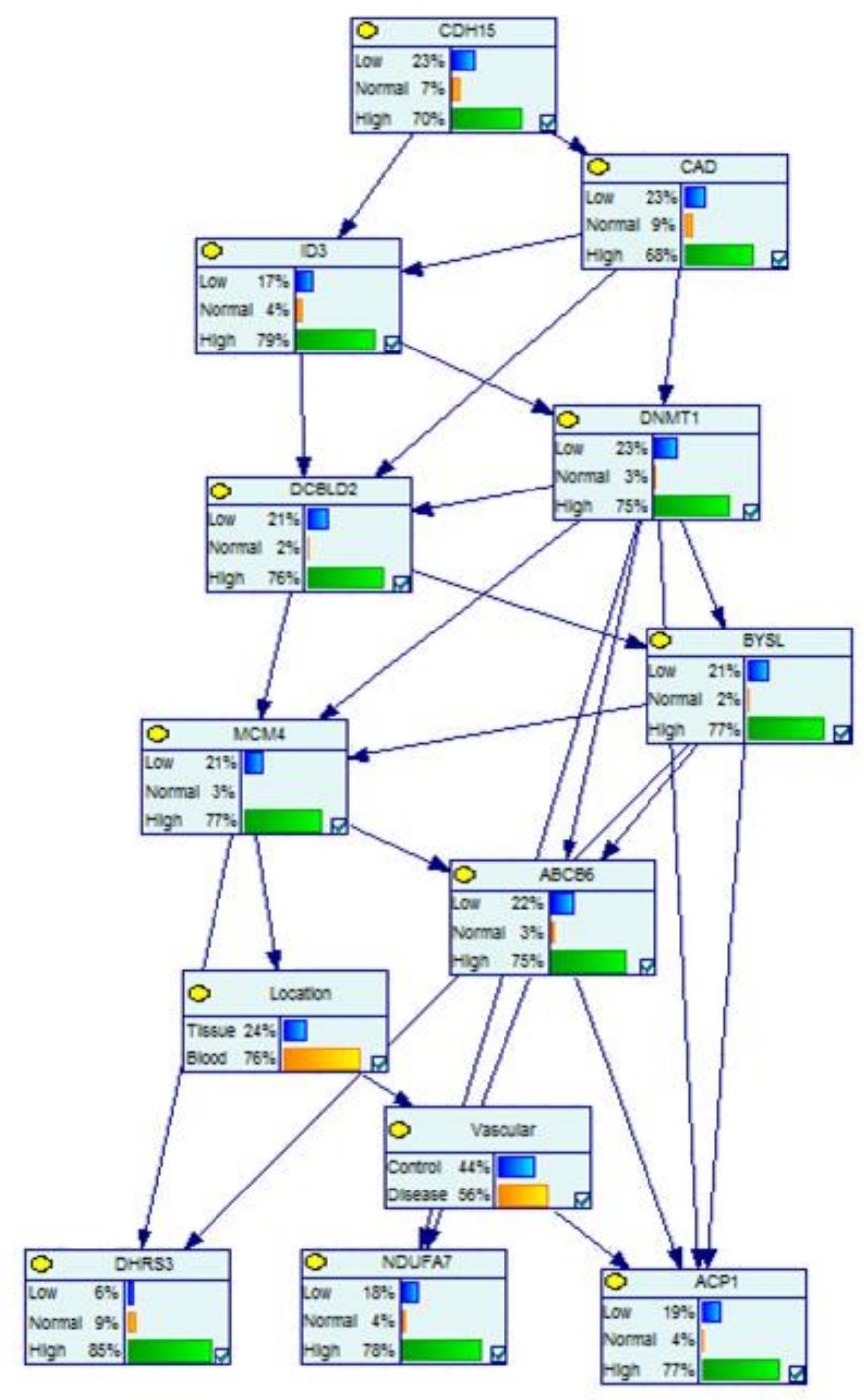

Figure 4.4.1 Best fit model based on Genie Modeler with overlapping ID3 \& ID3-candidate target genes. 

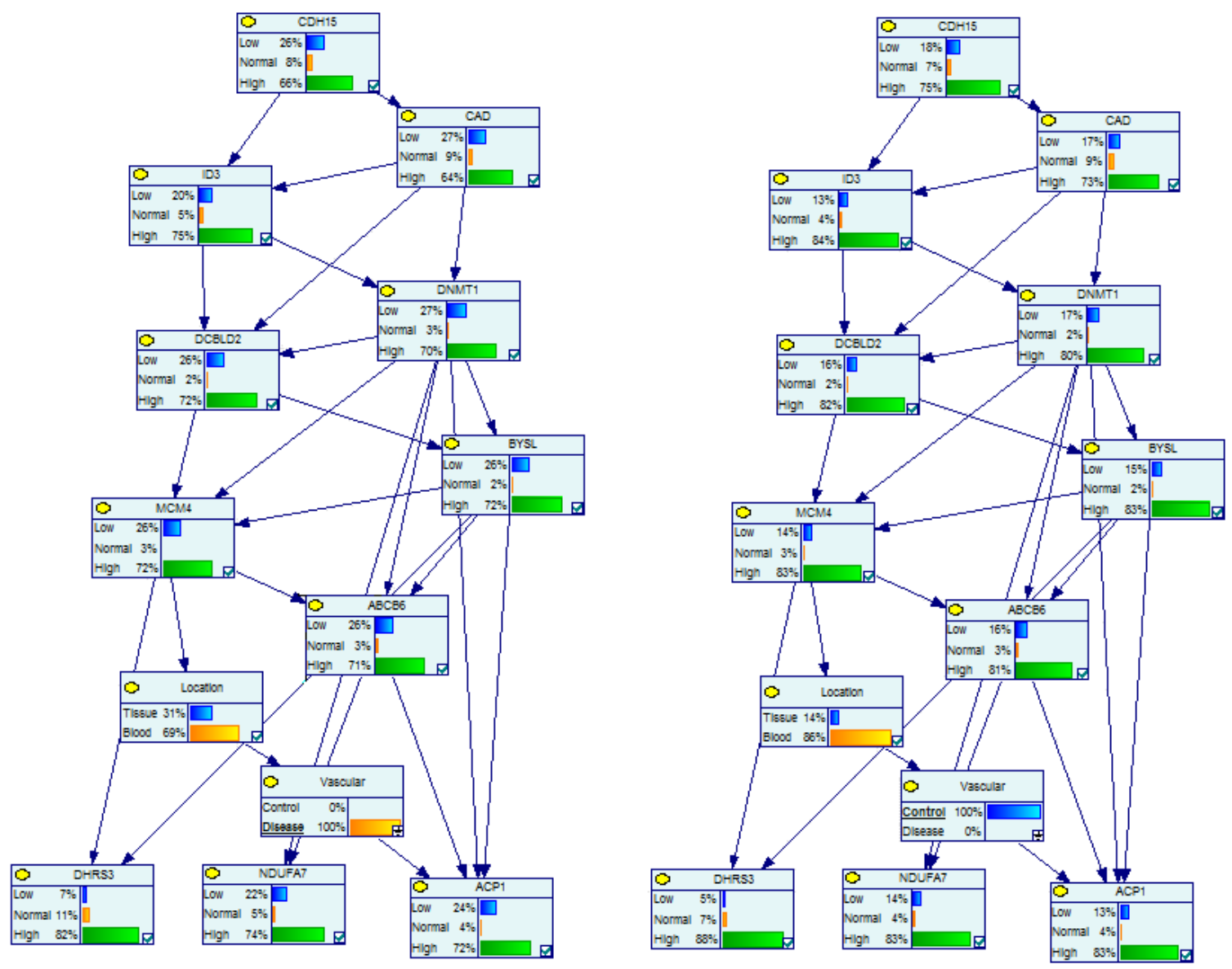

Figure 4.4.2 Representation of ID3 \& ID3-candidate targets in vascular state. Left panel represents model in disease state and right panel represents model in non-disease state. 

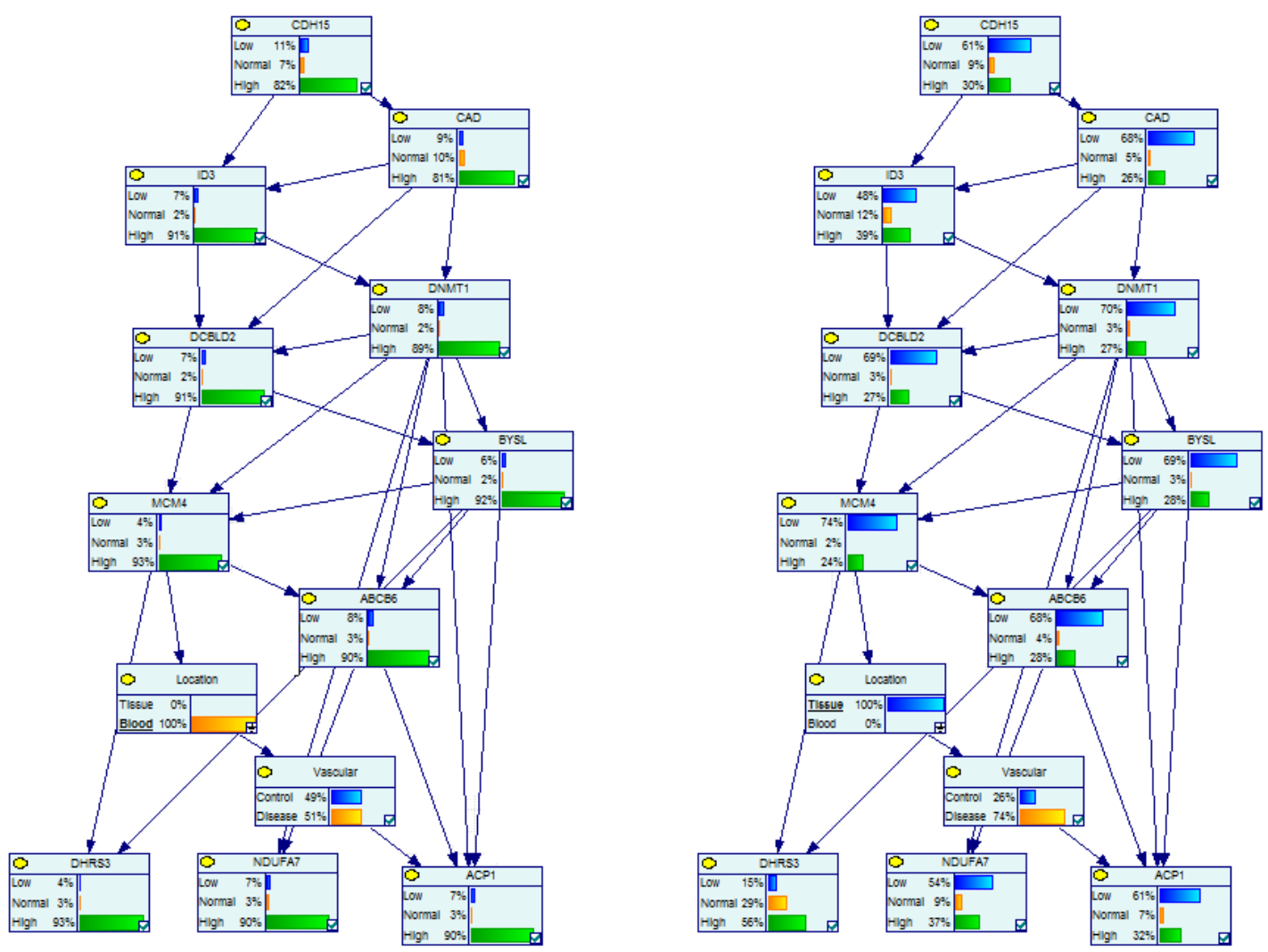

Figure 4.4.3 Representation of ID3 \& ID3-candidate targets in location of vascular disease. Left panel represents model in blood \& right panel represents model in tissue. 

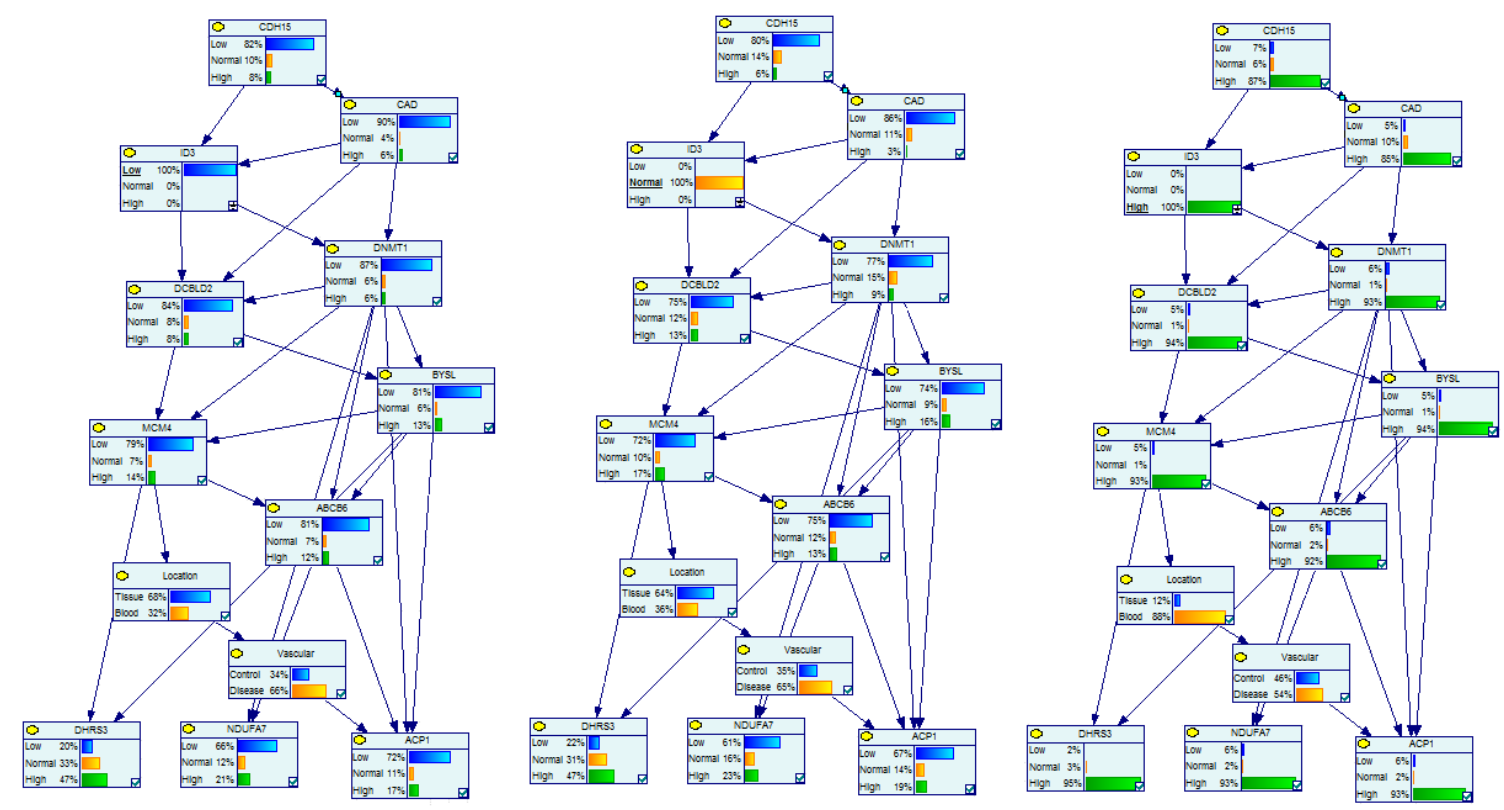

Figure 4.4.4 Representation of models based on expression of ID3. Left panel summarizes ID3 lowexpression, middle panel represents ID3 normal-expression, \& the right panel summarizes ID3-high expression.

\section{Gene expression of ID3 \& ID3 candidate target genes in specific vascular}

diseases in blood \& tissue. Our investigation indicated the expression of ID3 \& ID3 candidate target genes within each vascular disease. Figure 4.6.1 illustrates the diverse number of candidate targets and overlapping genes between each disease in blood studies. Number of candidate targets genes (n) include: atherosclerosis (357); arteriovenous malformation (36); peripheral arterial disease (190); proliferative diabetic retinopathy (403); infantile hemangioma (84); idiopathic pulmonary arterial hypertension (75); \& Lymphangioleiomyomatosis (363).The analysis also identified ID3 \& ID3 candidate target genes within each vascular disease in tissue studies. Figure 4.6.2 illustrates the diverse number of candidate targets and overlapping genes between each disease. Number of candidate targets genes ( $n$ ) include: arteriovenous malformation (277); proliferative diabetic 
retinopathy (403); infantile hemangioma (98); idiopathic pulmonary arterial hypertension (973); \& Lymphangioleiomyomatosis (231).

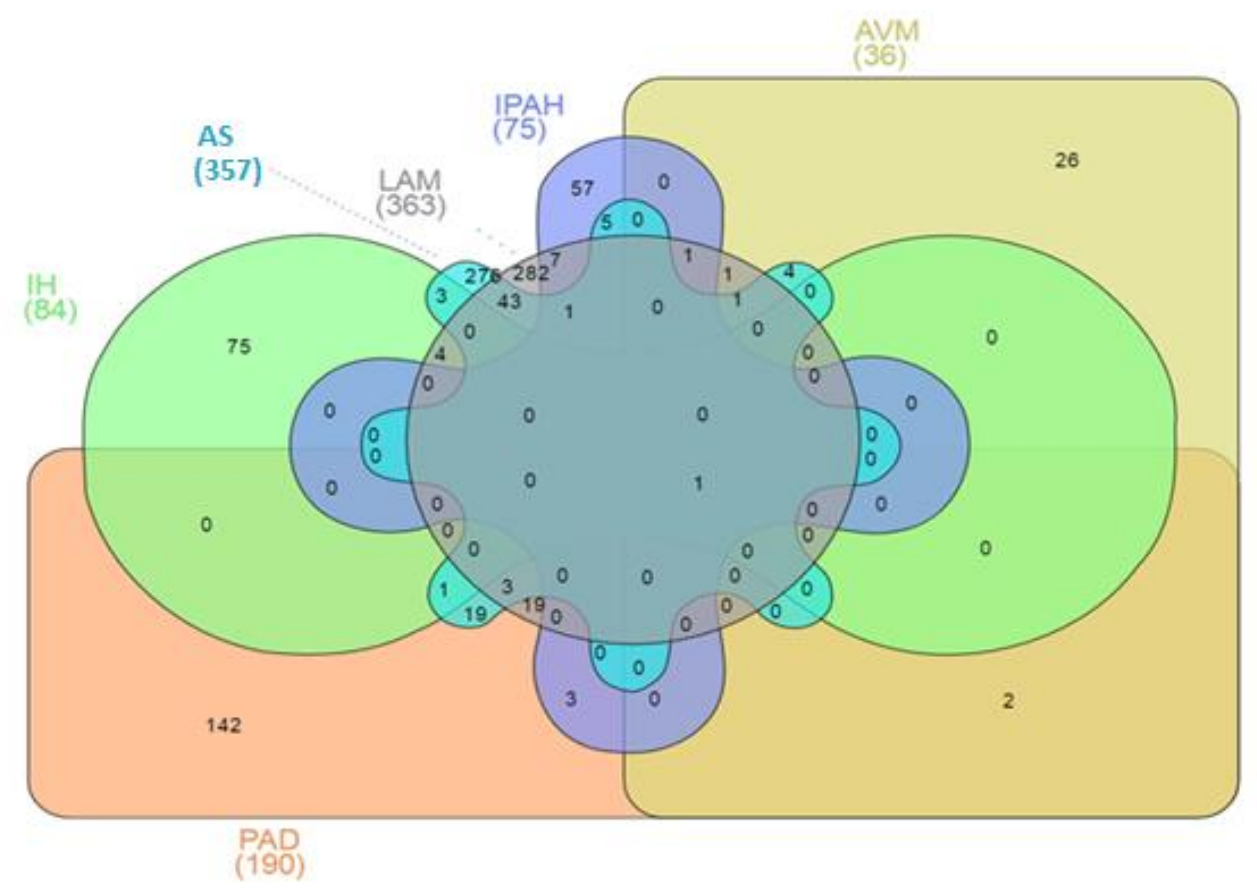

Figure 4.5.1 Venn diagram illustration summarizes ID3 \& ID3 candidate target genes in vascular diseases in blood studies. Each shape represents a different disease that includes blood samples. Diseases include: IH (Infantile Hemangioma), PAD (peripheral arterial disease), AVM (arteriovenous malformation), LAM (Lymphangioleiomyomatosis), IPAH (idiopathic pulmonary arterial hypertension), \& AS (atherosclerosis). 


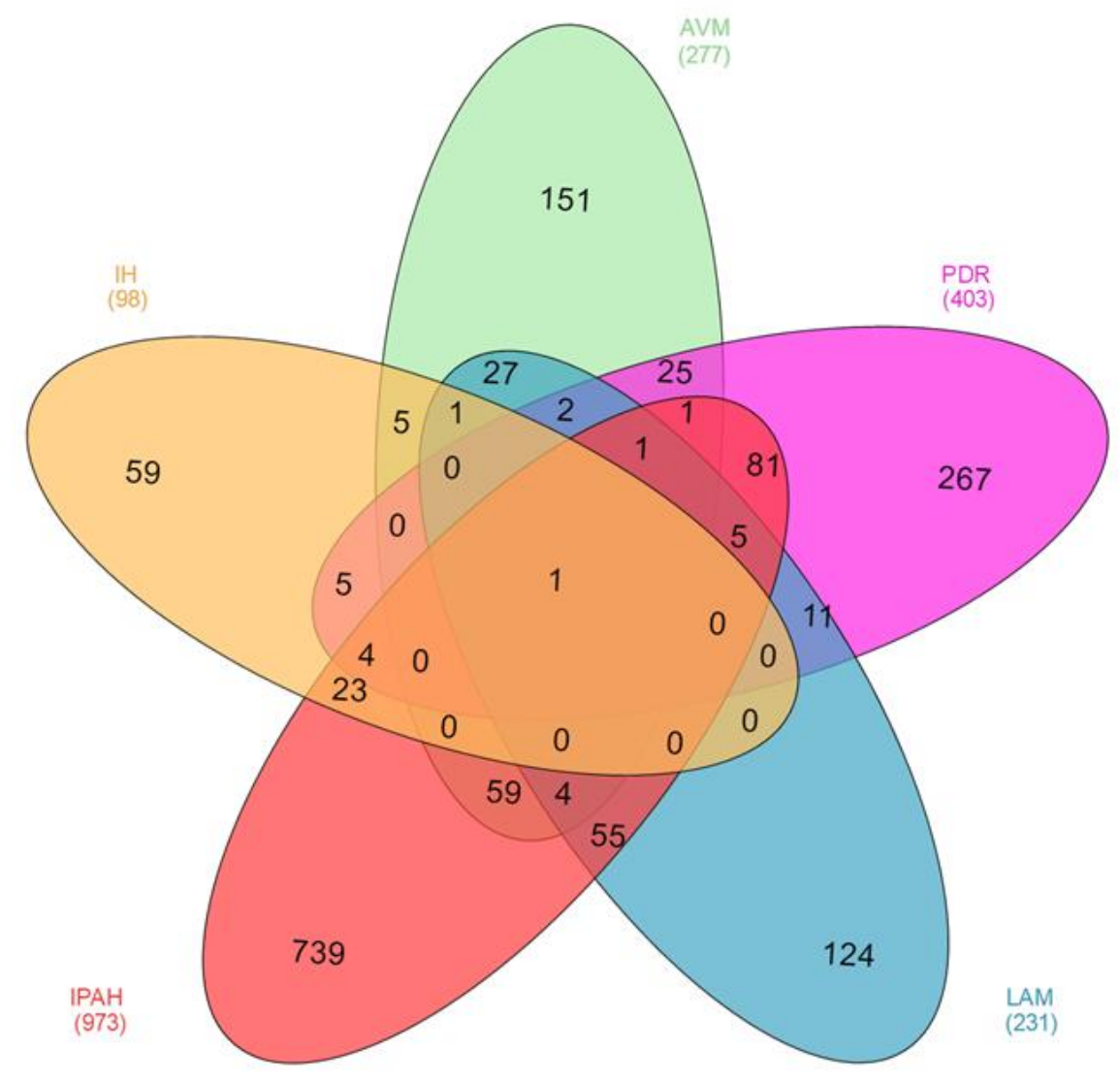

Figure 4.5.2 Venn diagram summarizes ID3 \& ID3 candidate target genes in specific diseases in tissue studies. Each ovular shape represents a vascular disease. Diseases in tissue studies include: IH (Infantile Hemangioma), AVM (arteriovenous malformation), LAM (Lymphangioleiomyomatosis), PDR (Proliferative Diabetic Retinopathy), \& IPAH (Idiopathic pulmonary arterial hypertension). 


\section{ID3 \& ID3 gene-associated biological processes}

ID3 and ID3 candidate target genes in blood. In order to understand the roles of these genes in functional processes a gene ontology approach was used via the Princeton University Lewis-Sigler Institute for Integrative Genomics Gene Ontology (GO) Tool to demonstrate the processes in which ID3 \& ID3 candidate target genes in blood were represented. The genes were demonstrated in 122 biological processes and are represented in Table 4.8.

\begin{tabular}{|c|c|c|c|c|c|c|}
\hline $\begin{array}{l}\text { Gene } \\
\text { Ontology ID }\end{array}$ & $\begin{array}{l}\text { Biological } \\
\text { Process }\end{array}$ & $\begin{array}{l}\text { Corrected } \\
\text { p-value }\end{array}$ & $\begin{array}{l}\text { Number List } \\
\text { Annotation }\end{array}$ & $\begin{array}{l}\text { FDR } \\
\text { Rate }\end{array}$ & $\begin{array}{l}\text { Expected } \\
\text { False } \\
\text { Positive }\end{array}$ & Annotated Genes \\
\hline GO:0048856 & $\begin{array}{l}\text { anatomical } \\
\text { structure } \\
\text { development }\end{array}$ & $9.30 \mathrm{E}-12$ & 34 & $0.00 \%$ & 0 & $\begin{array}{l}\text { IFNA2, NDP, COL3A1, LGR5, DRD1, } \\
\text { CTGF, AGTR2, ACTA2, ARID5B, CTH, } \\
\text { DLG2, APOH, LIFR, DZIP1, ID3, } \\
\text { COL17A1, GAL, IBSP, COL6A1, FUT9, } \\
\text { CCL7, FOXC2, GPR37L1, CDH15, } \\
\text { CFDP1, DAB2, BYSL, GFRA1, HDAC4, } \\
\text { HIST1H4C, HMGCS2, INHBB, ASB4, } \\
\text { ITGA8 }\end{array}$ \\
\hline GO:0009653 & $\begin{array}{l}\text { anatomical } \\
\text { structure } \\
\text { morphogenesis }\end{array}$ & $9.64 \mathrm{E}-07$ & 19 & $0.00 \%$ & 0 & $\begin{array}{l}\text { NDP, CCL7, FOXC2, COL3A1, CFDP1, } \\
\text { LGR5, CTGF, DAB2, BYSL, AGTR2, } \\
\text { ACTA2, ARID5B, APOH, LIFR, ID3, } \\
\text { ASB4, ITGA8, GAL, COL6A1 }\end{array}$ \\
\hline GO:0048513 & $\begin{array}{l}\text { animal organ } \\
\text { development }\end{array}$ & $2.35 \mathrm{E}-08$ & 23 & $0.00 \%$ & 0 & $\begin{array}{l}\text { IFNA2, NDP, GPR37L1, FOXC2, } \\
\text { COL3A1, LGR5, DRD1, CTGF, DAB2, } \\
\text { BYSL, AGTR2, ACTA2, ARID5B, APOH, } \\
\text { LIFR, HDAC4, HIST1H4C, HMGCS2, ID3, } \\
\text { INHBB, ITGA8, GAL, IBSP }\end{array}$ \\
\hline GO:0006915 & $\begin{array}{l}\text { apoptotic } \\
\text { process }\end{array}$ & $1.73 \mathrm{E}-05$ & 16 & $0.00 \%$ & 0 & $\begin{array}{l}\text { IFNA2, GCLM, FOXC2, CFDP1, CTGF, } \\
\text { KNG1, DAB2, AGTR2, CTH, APOH, } \\
\text { HDAC4, LIFR, GRIK5, INHBB, ID3, GAL }\end{array}$ \\
\hline GO:0022610 & $\begin{array}{l}\text { biological } \\
\text { adhesion }\end{array}$ & 0.001153274 & 13 & $0.00 \%$ & 0 & $\begin{array}{l}\text { IFNA2, CDH12, FOXC2, COL3A1, } \\
\text { CFDP1, CDH15, COL17A1, CTGF, } \\
\text { ITGA8, KNG1, BYSL, IBSP, COL6A1 }\end{array}$ \\
\hline GO:0065007 & $\begin{array}{l}\text { biological } \\
\text { regulation }\end{array}$ & 3.15E-05 & 47 & $0.00 \%$ & 0 & $\begin{array}{l}\text { IFNA2, DCBLD2, NDP, GCLM, MPP3, } \\
\text { GPR135, COL3A1, LGR5, DRD1, CTGF, } \\
\text { HSPB2, KNG1, AGTR2, CACNG3, DLG2, } \\
\text { ACTA2, ARID5B, CTH, APOH, LIFR, } \\
\text { IFIH1, DZIP1, GRIN2B, ID3, COL17A1, } \\
\text { GAL, IL13RA2, CCL7, KCN 4, FOXC2, } \\
\text { GPR37L1, CDH15, CFDP1, ADAMTS3, } \\
\text { DAB2, HNF4G, DIRAS3, GFRA1, GRP, } \\
\text { HDAC4, HIST1H4C, INHBB, GRIK5, } \\
\text { CNKSR2, ITGA8, ASB4, GLRA1 }\end{array}$ \\
\hline GO:0008015 & $\begin{array}{l}\text { blood } \\
\text { circulation }\end{array}$ & $2.50 \mathrm{E}-06$ & 10 & $0.00 \%$ & 0 & $\begin{array}{l}\text { ACTA2, KCNJ4, HDAC4, GCLM, FOXC2, } \\
\text { DRD1, CTGF, KNG1, AGTR2, CACNG3 }\end{array}$ \\
\hline
\end{tabular}




\begin{tabular}{|c|c|c|c|c|c|c|}
\hline GO:0072358 & $\begin{array}{l}\text { cardiovascular } \\
\text { system } \\
\text { development }\end{array}$ & 0.00440161 & 8 & $0.02 \%$ & 0.02 & $\begin{array}{l}\text { CTH, ACTA2, NDP, APOH, FOXC2, } \\
\text { COL } 3 \text { A1, CTGF, ASB } 4\end{array}$ \\
\hline GO:0007155 & cell adhesion & 0.001106077 & 13 & $0.00 \%$ & 0 & $\begin{array}{l}\text { IFNA2, CDH12, FOXC2, COL3A1, } \\
\text { CFDP1, CDH15, COL17A1, CTGF, } \\
\text { ITGA8, KNG1, BYSL, IBSP, COL6A1 }\end{array}$ \\
\hline GO:0007154 & $\begin{array}{l}\text { cell } \\
\text { communication }\end{array}$ & $1.50 \mathrm{E}-08$ & 37 & $0.00 \%$ & 0 & $\begin{array}{l}\text { IFNA2, DCBLD2, NDP, GCLM, MPP3, } \\
\text { GPR135, COL 3A1, LGR5, DRD1, CTGF, } \\
\text { AGTR2, CACNG3, ARID5B, CTH, DLG2, } \\
\text { LIFR, IFIH1, DZIP1, GRIN2B, GAL, } \\
\text { IL13RA2, CCL7, FOXC2, GPR37L1, } \\
\text { ADAMTS3, DAB2, HNF4G, DIRAS3, } \\
\text { GFRA1, GRP, HDAC4, GRIK5, INHBB, } \\
\text { CNKSR2, ITGA8, ASB4, GLRA1 }\end{array}$ \\
\hline GO:0008219 & cell death & $6.23 \mathrm{E}-06$ & 17 & $0.00 \%$ & 0 & $\begin{array}{l}\text { IFNA2, GCLM, GPR37L1, FOXC2, } \\
\text { CFDP1, CTGF, KNG1, DAB2, AGTR2, } \\
\text { CTH, APOH, HDAC4, LIFR, ID3, GRIK5, } \\
\text { INHBB, GAL }\end{array}$ \\
\hline GO:0048468 & $\begin{array}{l}\text { cell } \\
\text { development }\end{array}$ & 0.000651109 & 14 & $0.00 \%$ & 0 & $\begin{array}{l}\text { ARID5B, ACTA2, LIFR, HDAC4, } \\
\text { GPR37L1, FOXC2, DZIP1, COL } 3 A 1 \text {, } \\
\text { LGR5, INHBB, DRD1, ITGA8, GAL, } \\
\text { AGTR2 }\end{array}$ \\
\hline GO:0030154 & $\begin{array}{l}\text { cell } \\
\text { differentiation }\end{array}$ & $1.88 \mathrm{E}-08$ & 25 & $0.00 \%$ & 0 & $\begin{array}{l}\text { IFNA2, GPR37L1, FOXC2, COL3A1, } \\
\text { CDH15, LGR5, DRD1, CTGF, DAB2, } \\
\text { BYSL, AGTR2, ACTA2, ARID5B, CTH, } \\
\text { LIFR, HIST1H4C, HDAC4, DZIP1, ID3, } \\
\text { INHBB, ITGA8, ASB4, GAL, IBSP, } \\
\text { COL6A1 }\end{array}$ \\
\hline GO:0008283 & $\begin{array}{l}\text { cell } \\
\text { proliferation }\end{array}$ & 0.000725251 & 14 & $0.00 \%$ & 0 & $\begin{array}{l}\text { IFNA2, NDP, APOH, LIFR, HDAC4, } \\
\text { GPR37L1, FOXC2, CFDP1, LGR5, CTGF, } \\
\text { DAB2, BYSL, GAL, AGTR2 }\end{array}$ \\
\hline & $\begin{array}{l}\text { cell surface } \\
\text { receptor } \\
\text { signaling }\end{array}$ & & & & & $\begin{array}{l}\text { IFNA2, NDP, CCL7, GCLM, GPR37L1, } \\
\text { FOXC2, COL3A1, LGR5, ADAMTS3, } \\
\text { CTGF, DAB2, AGTR2, CACNG3, } \\
\text { ARID5B, GFRA1, LIFR, DZIP1, GRIN2B, }\end{array}$ \\
\hline GO:0007166 & pathway & $1.09 \mathrm{E}-07$ & 23 & $0.00 \%$ & 0 & INHBB, GRIK5, ITGA8, IL13RA2, GLRA1 \\
\hline GO:0007267 & $\begin{array}{l}\text { cell-cell } \\
\text { signaling }\end{array}$ & 0.000107771 & 14 & $0.00 \%$ & 0 & $\begin{array}{l}\text { DLG2, IFNA2, NDP, CCL7, GRIN2B, } \\
\text { LGR5, INHBB, DRD1, GRIK5, CTGF, } \\
\text { DAB2, GAL, AGTR2, GLRA1 }\end{array}$ \\
\hline
\end{tabular}

\begin{tabular}{|c|c|c|c|c|c|c|}
\hline GO:0016043 & $\begin{array}{l}\text { cellular } \\
\text { component } \\
\text { organization }\end{array}$ & 0.000335738 & 28 & $0.00 \%$ & 0 & $\begin{array}{l}\text { DCBLD2, NDP, MPP6, CCL7, GCLM, } \\
\text { FOXC2, COL3A1, CFDP1, CDH15, } \\
\text { ADAMTS3, DRD1, CTGF, DAB2, AGTR2, } \\
\text { ARID5B, CTH, CDH12, LIFR, HIST1H4C, } \\
\text { HDAC4, DZIP1, GRIK5, COL17A1, } \\
\text { ITGA8, GAL, IBSP, COL6A1, GLRA1 }\end{array}$ \\
\hline GO:0071840 & $\begin{array}{l}\text { cellular } \\
\text { component } \\
\text { organization or } \\
\text { biogenesis }\end{array}$ & 0.000170434 & 29 & $0.00 \%$ & 0 & $\begin{array}{l}\text { DCBLD2, NDP, MPP6, CCL7, GCLM, } \\
\text { FOXC2, COL3A1, CFDP1, CDH15, } \\
\text { ADAMTS3, DRD1, CTGF, DAB2, BYSL, } \\
\text { AGTR2, ARID5B, CTH, CDH12, LIFR, } \\
\text { HIST1H4C, HDAC4, DZIP1, GRIK5, } \\
\text { COL17A1, ITGA8, GAL, IBSP, COL6A1, } \\
\text { GLRA1 }\end{array}$ \\
\hline GO:0048869 & $\begin{array}{l}\text { cellular } \\
\text { developmental } \\
\text { process }\end{array}$ & 1.14E-09 & 27 & $0.00 \%$ & 0 & $\begin{array}{l}\text { IFNA2, CCL7, GPR37L1, FOXC2, } \\
\text { COL3A1, CFDP1, CDH15, LGR5, DRD1, } \\
\text { CTGF, DAB2, BYSL, AGTR2, ACTA2, } \\
\text { ARID5B, CTH, LIFR, HIST1H4C, HDAC4, } \\
\text { DZIP1, ID3, INHBB, ITGA8, ASB4, GAL, } \\
\text { IBSP, COL6A1 }\end{array}$ \\
\hline GO:0009987 & $\begin{array}{l}\text { cellular } \\
\text { process }\end{array}$ & 0.000288023 & 57 & $0.00 \%$ & 0 & $\begin{array}{l}\text { IFNA2, DCBLD2, NDP, MPP6, GCLM, } \\
\text { MPP3, GPR135, COL3A1, LGR5, DRD1, } \\
\text { CTGF, KNG1, AGTR2, CACNG3, } \\
\text { CYP2C18, DLG2, CTH, ACTA2, ARID5B, } \\
\text { APOH, LIFR, IFIH1, DZIP1, GRIN2B, ID3, } \\
\text { COL17A1, GAL, IL13RA2, IBSP, } \\
\text { COL6A1, FUT9, CCL7, KCNJ4, } \\
\text { GPR37L1, FOXC2, CDH15, CFDP1, } \\
\text { ADAMTS3, CH25H, DAB2, HNF4G, } \\
\text { BYSL, DIRAS3, GFRA1, CDH12, GRP, } \\
\text { HMGCS2, HIST1H4C, HDAC4, INHBB, } \\
\text { GRIK5, CNKSR2, ITGA8, ASB4, CKM, } \\
\text { FBP2, GLRA1 }\end{array}$ \\
\hline GO:0071229 & $\begin{array}{l}\text { cellular } \\
\text { response to } \\
\text { acid chemical }\end{array}$ & 0.00625897 & 5 & $0.02 \%$ & 0.02 & $\begin{array}{l}\text { ID3, HMGCS2, COL6A1, GLRA1, } \\
\text { COL3A1 }\end{array}$ \\
\hline GO:0071230 & $\begin{array}{l}\text { cellular } \\
\text { response to } \\
\text { amino acid } \\
\text { stimulus }\end{array}$ & 0.001480522 & 4 & $0.00 \%$ & 0 & HMGCS2, COL6A1, GLRA1, COL3A1 \\
\hline
\end{tabular}




\begin{tabular}{|c|c|c|c|c|c|c|}
\hline GO:0070887 & $\begin{array}{l}\text { cellular } \\
\text { response to } \\
\text { chemical } \\
\text { stimulus }\end{array}$ & $8.68 \mathrm{E}-11$ & 25 & $0.00 \%$ & 0 & $\begin{array}{l}\text { IFNA2, CCL7, GPR37L1, FOXC2, } \\
\text { COL3A1, ADAMTS3, DRD1, CTGF, } \\
\text { DAB2, HNF4G, BYSL, AGTR2, CYP2C18, } \\
\text { CTH, LIFR, HDAC4, HMGCS2, ID3, } \\
\text { INHBB, GRIK5, ITGA8, IL13RA2, IBSP, } \\
\text { COL6A1, GLRA1 }\end{array}$ \\
\hline GO:0071495 & $\begin{array}{l}\text { cellular } \\
\text { response to } \\
\text { endogenous } \\
\text { stimulus }\end{array}$ & $3.24 \mathrm{E}-05$ & 13 & $0.00 \%$ & 0 & $\begin{array}{l}\text { HMGCS2, HDAC4, FOXC2, COL3A1, } \\
\text { INHBB, DRD1, CTGF, ITGA8, DAB2, } \\
\text { HNF4G, AGTR2, COL6A1, GLRA1 }\end{array}$ \\
\hline GO:0071363 & $\begin{array}{l}\text { cellular } \\
\text { response to } \\
\text { growth factor } \\
\text { stimulus }\end{array}$ & 0.005538798 & 8 & $0.02 \%$ & 0.02 & $\begin{array}{l}\text { ADAMTS3, CTGF, ITGA8, DAB2, BYSL, } \\
\text { IBSP, AGTR2, COL } 3 \text { A1 }\end{array}$ \\
\hline GO:0032870 & $\begin{array}{l}\text { cellular } \\
\text { response to } \\
\text { hormone } \\
\text { stimulus }\end{array}$ & 0.005482186 & 8 & $0.02 \%$ & 0.02 & $\begin{array}{l}\text { HMGCS2, HDAC4, FOXC2, DRD1, } \\
\text { INHBB, DAB2, HNF4G, AGTR2 }\end{array}$ \\
\hline GO:1901699 & $\begin{array}{l}\text { cellular } \\
\text { response to } \\
\text { nitrogen } \\
\text { compound }\end{array}$ & 0.0018159 & 8 & $0.00 \%$ & 0 & $\begin{array}{l}\text { HMGCS2, FOXC2, COL3A1, DRD1, } \\
\text { INHBB, AGTR2, COL6A1, GLRA1 }\end{array}$ \\
\hline GO:0071310 & $\begin{array}{l}\text { Cellular } \\
\text { response to } \\
\text { organic } \\
\text { substance }\end{array}$ & $1.35 \mathrm{E}-10$ & 23 & $0.00 \%$ & 0 & $\begin{array}{l}\text { IFNA2, CCL7, FOXC2, COL3A1, } \\
\text { ADAMTS3, DRD1, CTGF, DAB2, HNF4G, } \\
\text { BYSL, AGTR2, CTH, LIFR, HDAC4, } \\
\text { HMGCS2, ID3, INHBB, GRIK5, ITGA8, } \\
\text { IL13RA2, IBSP, COL6A1, GLRA1 }\end{array}$ \\
\hline GO:0071417 & $\begin{array}{l}\text { Cellular } \\
\text { response to } \\
\text { organ nitrogen } \\
\text { compound }\end{array}$ & 0.000506385 & 8 & $0.00 \%$ & 0 & $\begin{array}{l}\text { HMGCS2, FOXC2, COL3A1, DRD1, } \\
\text { INHBB, AGTR2, COL6A1, GLRA1 }\end{array}$ \\
\hline GO:1901701 & $\begin{array}{l}\text { cellular } \\
\text { response to } \\
\text { oxygen- } \\
\text { containing } \\
\text { compound }\end{array}$ & $6.01 \mathrm{E}-07$ & 13 & $0.00 \%$ & 0 & $\begin{array}{l}\text { CCL7, HMGCS2, GPR37L1, FOXC2, } \\
\text { COL3A1, ID3, INHBB, GRIK5, DRD1, } \\
\text { BYSL, AGTR2, COL6A1, GLRA1 }\end{array}$ \\
\hline GO:0051716 & $\begin{array}{l}\text { cellular } \\
\text { response to } \\
\text { stimulus }\end{array}$ & $1.72 \mathrm{E}-12$ & 44 & $0.00 \%$ & 0 & $\begin{array}{l}\text { IFNA2, DCBLD2, NDP, GCLM, MPP } 3 \text {, } \\
\text { GPR135, COL3A1, LGR5, DRD1, CTGF, } \\
\text { AGTR2, CACNG3, CYP2C18, ARID5B, } \\
\text { CTH, LIFR, IFIH1, DZIP1, GRIN2B, ID3, }\end{array}$ \\
\hline
\end{tabular}

GAL, IL13RA2, IBSP, COL6A1, CCL7, DAB2, BYSL, HNF4G DIRAS3 GFRA1, GRP, HDAC4, HIST1H4C, HMGCS2, INHBB, GRIK5, CNKSR2, ITGA8, ASB4, INHBB,

\begin{tabular}{|c|c|c|c|c|c|c|}
\hline GO:0072359 & $\begin{array}{l}\text { circulatory } \\
\text { system } \\
\text { development }\end{array}$ & 0.001387394 & 10 & $0.00 \%$ & 0 & $\begin{array}{l}\text { CTH, ACTA2, NDP, APOH, FOXC2, } \\
\text { COL3A1, ID3, CTGF, ASB4, AGTR2 }\end{array}$ \\
\hline GO:0003013 & $\begin{array}{l}\text { circulatory } \\
\text { system } \\
\text { process }\end{array}$ & $2.68 \mathrm{E}-06$ & 10 & $0.00 \%$ & 0 & $\begin{array}{l}\text { ACTA2, KCNJ4, HDAC4, GCLM, FOXC2, } \\
\text { DRD1, CTGF, KNG1, AGTR2, CACNG3 }\end{array}$ \\
\hline GO:0032502 & $\begin{array}{l}\text { developmental } \\
\text { process }\end{array}$ & $9.02 \mathrm{E}-11$ & 34 & $0.00 \%$ & 0 & $\begin{array}{l}\text { IFNA2, NDP, COL3A1, LGR5, DRD1, } \\
\text { CTGF, AGTR2, ACTA2, ARID5B, CTH, } \\
\text { DLG2, APOH, LIFR, DZIP1, ID3, } \\
\text { COL17A1, GAL, IBSP, COL6A1, FUT9, } \\
\text { CCL7, FOXC2, GPR37L1, CDH15, } \\
\text { CFDP1, DAB2, BYSL, GFRA1, HDAC4, } \\
\text { HIST1H4C, HMGCS2, INHBB, ASB4, } \\
\text { ITGA8 }\end{array}$ \\
\hline GO:0007167 & $\begin{array}{l}\text { enzyme linked } \\
\text { receptor } \\
\text { protein } \\
\text { signaling } \\
\text { pathway }\end{array}$ & 4.56E-05 & 12 & $0.00 \%$ & 0 & $\begin{array}{l}\text { GFRA1, ARID5B, LIFR, FOXC2, GRIN2B, } \\
\text { COL3A1, ADAMTS3, INHBB, CTGF, } \\
\text { ITGA8, DAB2, AGTR2 }\end{array}$ \\
\hline GO:0030198 & $\begin{array}{l}\text { extracellular } \\
\text { matrix } \\
\text { organization }\end{array}$ & 0.00036749 & 8 & $0.00 \%$ & 0 & $\begin{array}{l}\text { ADAMTS3, CTGF, ITGA8, FOXC2, IBSP, } \\
\text { ID } 3 \text {, COL } 6 \text { A1, COL } 3 \text { A1 }\end{array}$ \\
\hline GO:0043062 & $\begin{array}{l}\text { extracellular } \\
\text { structure } \\
\text { organization }\end{array}$ & 0.000374985 & 7 & $0.00 \%$ & 0 & $\begin{array}{l}\text { ADAMTS3, CTGF, ITGA8, FOXC2, IBSP, } \\
\text { COL6A1, COL } 3 A 1\end{array}$ \\
\hline GO:0060322 & $\begin{array}{l}\text { head } \\
\text { development }\end{array}$ & 0.008012499 & 8 & $0.02 \%$ & 0.02 & $\begin{array}{l}\text { DRD1, ARID5B, ITGA8, HMGCS2, } \\
\text { GPR37L1, BYSL, AGTR2, COL3A1 }\end{array}$ \\
\hline GO:0001822 & $\begin{array}{l}\text { kidney } \\
\text { development }\end{array}$ & $9.56 \mathrm{E}-05$ & 7 & $0.00 \%$ & 0 & $\begin{array}{l}\text { ID3, ARID5B, ACTA2, ITGA8, HMGCS2, } \\
\text { FOXC2, AGTR2 }\end{array}$ \\
\hline GO:0001656 & $\begin{array}{l}\text { metanephros } \\
\text { development }\end{array}$ & 0.006881579 & 4 & $0.02 \%$ & 0.02 & ID3, ITGA8, FOXC2, AGTR2 \\
\hline GO:0007275 & $\begin{array}{l}\text { multicellular } \\
\text { organism } \\
\text { development }\end{array}$ & $2.56 \mathrm{E}-10$ & 31 & $0.00 \%$ & 0 & $\begin{array}{l}\text { FUT9, IFNA2, NDP, GPR37L1, FOXC2, } \\
\text { COL } 3 \text { A1, CFDP1, LGR5, DRD1, CTGF, } \\
\text { DAB2, BYSL, AGTR2, GFRA1, ACTA2, }\end{array}$ \\
\hline
\end{tabular}


ARID5B CTH DLG2, APOH, LIFR

HMGCS2, HIST1H4C, HDAC4, DZIP1, ID3, INHBB, ITGA8, ASB4, GAL, IBSP, COL6A1

\begin{tabular}{|c|c|c|c|c|c|c|}
\hline GO:0032501 & $\begin{array}{l}\text { multicellular } \\
\text { organismal } \\
\text { process }\end{array}$ & $2.22 \mathrm{E}-12$ & 39 & $0.00 \%$ & 0 & $\begin{array}{l}\text { IFNA2, NDP, GCLM, COL3A1, LGR5, } \\
\text { DRD1, CTGF, KNG1, AGTR2, CACNG3, } \\
\text { ACTA2, ARID5B, CTH, DLG2, APOH, } \\
\text { LIFR, IFIH1, DZIP1, GRIN2B, ID3, GAL, } \\
\text { IBSP, COL6A1, FUT9, KCNJ4, FOXC2, } \\
\text { GPR37L1, CFDP1, ADAMTS3, DAB2, } \\
\text { BYSL, GFRA1, HDAC4, HIST1H4C, } \\
\text { HMGCS2, INHBB, ASB4, ITGA8, GLRA1 }\end{array}$ \\
\hline GO:0061061 & $\begin{array}{l}\text { muscle } \\
\text { structure } \\
\text { development }\end{array}$ & 0.000174968 & 9 & $0.00 \%$ & 0 & $\begin{array}{l}\text { CTH, ARID5B, HDAC4, FOXC2, COL3A1, } \\
\text { CDH15, ID3, ITGA8, AGTR2 }\end{array}$ \\
\hline GO:0003012 & $\begin{array}{l}\text { muscle system } \\
\text { process }\end{array}$ & 0.003487104 & 7 & $0.02 \%$ & 0.02 & $\begin{array}{l}\text { DRD1, ACTA2, CTGF, KNG1, HDAC4, } \\
\text { AGTR2, GLRA1 }\end{array}$ \\
\hline GO:0048519 & $\begin{array}{l}\text { negative } \\
\text { regulation of } \\
\text { biological } \\
\text { process }\end{array}$ & $1.28 \mathrm{E}-05$ & 25 & $0.00 \%$ & 0 & $\begin{array}{l}\text { IFNA2, DCBLD2, GCLM, GPR37L1, } \\
\text { FOXC2, COL3A1, CFDP1, DRD1, CTGF, } \\
\text { KNG1, DAB2, AGTR2, ARID5B, CTH, } \\
\text { DLG2, APOH, LIFR, HIST1H4C, HDAC4, } \\
\text { IFIH1, ID3, INHBB, GAL, IL13RA2, } \\
\text { GLRA1 }\end{array}$ \\
\hline GO:0060548 & $\begin{array}{l}\text { negative } \\
\text { regulation of } \\
\text { cell death }\end{array}$ & 0.006253691 & 9 & $0.02 \%$ & 0.02 & $\begin{array}{l}\text { CTH, APOH, LIFR, GCLM, GPR37L1, } \\
\text { FOXC2, CFDP1, CTGF, DAB2 }\end{array}$ \\
\hline GO:0048523 & $\begin{array}{l}\text { negative } \\
\text { regulation of } \\
\text { cellular } \\
\text { process }\end{array}$ & 8.67E-06 & 24 & $0.00 \%$ & 0 & $\begin{array}{l}\text { IFNA2, DCBLD2, GCLM, GPR37L1, } \\
\text { FOXC2, COL3A1, CFDP1, DRD1, CTGF, } \\
\text { KNG1, DAB2, AGTR2, ARID5B, CTH, } \\
\text { DLG2, APOH, LIFR, HIST1H4C, HDAC4, } \\
\text { ID3, INHBB, GAL, IL13RA2, GLRA1 }\end{array}$ \\
\hline GO:0051093 & $\begin{array}{l}\text { negative } \\
\text { regulation of } \\
\text { developmental } \\
\text { process }\end{array}$ & 0.002394213 & 9 & $0.02 \%$ & 0.02 & $\begin{array}{l}\text { ID3, IFNA2, APOH, HIST1H4C, HDAC4, } \\
\text { GPR37L1, GAL, FOXC2, COL3A1 }\end{array}$ \\
\hline GO:0051241 & $\begin{array}{l}\text { negative } \\
\text { regulation of } \\
\text { multicellular } \\
\text { organismal } \\
\text { process }\end{array}$ & $6.69 \mathrm{E}-09$ & 15 & $0.00 \%$ & 0 & $\begin{array}{l}\text { IFNA2, APOH, HIST1H4C, HDAC4, IFIH1, } \\
\text { GPR37L1, FOXC2, COL3A1, ID3, INHBB, } \\
\text { DRD1, KNG1, GAL, AGTR2, GLRA1 }\end{array}$ \\
\hline
\end{tabular}

\begin{tabular}{|c|c|c|c|c|c|c|}
\hline GO:0048585 & $\begin{array}{l}\text { negative } \\
\text { regulation of } \\
\text { response to } \\
\text { stimulus }\end{array}$ & 0.005272508 & 11 & $0.02 \%$ & 0.02 & $\begin{array}{l}\text { CTH, IFNA2, APOH, GCLM, GPR37L1, } \\
\text { COL3A1, DRD1, KNG1, DAB2, AGTR2, } \\
\text { IL13RA2 }\end{array}$ \\
\hline GO:0007399 & $\begin{array}{l}\text { nervous } \\
\text { system } \\
\text { development }\end{array}$ & 0.000672503 & 15 & $0.00 \%$ & 0 & $\begin{array}{l}\text { GFRA1, FUT9, DLG2, NDP, LIFR, } \\
\text { HMGCS2, HDAC4, GPR37L1, COL3A1, } \\
\text { ID3, DRD1, ITGA8, BYSL, GAL, AGTR2 }\end{array}$ \\
\hline GO:0043065 & $\begin{array}{l}\text { positive } \\
\text { regulation of } \\
\text { apoptotic } \\
\text { process }\end{array}$ & 0.002443163 & 8 & $0.02 \%$ & 0.02 & $\begin{array}{l}\text { HDAC4, GRIK5, INHBB, ID3, CTGF, } \\
\text { KNG1, GAL, AGTR2 }\end{array}$ \\
\hline GO:0048518 & $\begin{array}{l}\text { positive } \\
\text { regulation of } \\
\text { biological } \\
\text { process }\end{array}$ & $2.77 \mathrm{E}-08$ & 30 & $0.00 \%$ & 0 & $\begin{array}{l}\text { IFNA2, NDP, CCL7, GPR37L1, FOXC2, } \\
\text { COL3A1, CDH15, LGR5, ADAMTS3, } \\
\text { DRD1, CTGF, KNG1, DAB2, AGTR2, } \\
\text { ACTA2, ARID5B, CTH, APOH, LIFR, } \\
\text { HIST1H4C, HDAC4, IFIH1, ID3, INHBB, } \\
\text { GRIK5, ITGA8, ASB4, GAL, IL13RA2, } \\
\text { GLRA1 }\end{array}$ \\
\hline GO:0010647 & $\begin{array}{l}\text { positive } \\
\text { regulation of } \\
\text { cell } \\
\text { communication }\end{array}$ & $2.99 \mathrm{E}-05$ & 14 & $0.00 \%$ & 0 & $\begin{array}{l}\text { CTH, IFNA2, CCL7, GPR37L1, COL3A1, } \\
\text { LGR5, ADAMTS3, INHBB, DRD1, CTGF, } \\
\text { ITGA8, DAB2, GAL, AGTR2 }\end{array}$ \\
\hline GO:0010942 & $\begin{array}{l}\text { positive } \\
\text { regulation of } \\
\text { cell death }\end{array}$ & 0.003745574 & 8 & $0.02 \%$ & 0.02 & $\begin{array}{l}\text { HDAC4, GRIK5, INHBB, ID3, CTGF, } \\
\text { KNG1, GAL, AGTR2 }\end{array}$ \\
\hline GO:0048522 & $\begin{array}{l}\text { positive } \\
\text { regulation of } \\
\text { cellular } \\
\text { process }\end{array}$ & $4.39 \mathrm{E}-05$ & 24 & $0.00 \%$ & 0 & $\begin{array}{l}\text { IFNA2, NDP, CCL7, GPR37L1, FOXC2, } \\
\text { COL3A1, CDH15, LGR5, ADAMTS3, } \\
\text { DRD1, CTGF, KNG1, DAB2, AGTR2, } \\
\text { CTH, APOH, LIFR, HDAC4, ID3, GRIK5, } \\
\text { INHBB, ITGA8, ASB4, GAL }\end{array}$ \\
\hline GO.0009893 & $\begin{array}{l}\text { positive } \\
\text { regulation of } \\
\text { metabolic }\end{array}$ & 0.006424653 & 16 & $0.02 \%$ & 0.02 & $\begin{array}{l}\text { IFNA2, NDP, CCL7, GPR37L1, FOXC2, } \\
\text { DRD1, CTGF, DAB2, AGTR2, ACTA2, } \\
\text { APOH, HDAC4, HIST1H4C, INHBB, } \\
\text { ITGA8 GAL }\end{array}$ \\
\hline GO:0044093 & $\begin{array}{l}\text { process } \\
\text { positive } \\
\text { regulation of } \\
\text { molecular } \\
\text { function }\end{array}$ & 0.002933859 & 14 & $0.02 \%$ & 0.02 & $\begin{array}{l}\text { GFRA1, CTH, ARID5B, NDP, CCL7, } \\
\text { APOH, HDAC4, GCLM, GRIN2B, DRD1, } \\
\text { CTGF, HSPB2, GAL, AGTR2 }\end{array}$ \\
\hline
\end{tabular}




\begin{tabular}{|c|c|c|c|c|c|c|}
\hline GO:0051240 & $\begin{array}{l}\text { positive } \\
\text { regulation of } \\
\text { multicellular } \\
\text { organismal } \\
\text { process }\end{array}$ & 0.00065788 & 12 & $0.00 \%$ & 0 & $\begin{array}{l}\text { CTH, APOH, IFIH1, GPR37L1, FOXC2, } \\
\text { INHBB, CTGF, ASB4, KNG1, DAB2, GAL, } \\
\text { AGTR2 }\end{array}$ \\
\hline GO:0043068 & $\begin{array}{l}\text { positive } \\
\text { regulation of } \\
\text { programmed } \\
\text { cell death }\end{array}$ & 0.002588551 & 8 & $0.02 \%$ & 0.02 & $\begin{array}{l}\text { HDAC4, GRIK5, INHBB, ID3, CTGF, } \\
\text { KNG1, GAL, AGTR2 }\end{array}$ \\
\hline GO:0048584 & $\begin{array}{l}\text { positive } \\
\text { regulation of } \\
\text { response to } \\
\text { stimulus }\end{array}$ & 0.000260258 & 15 & $0.00 \%$ & 0 & $\begin{array}{l}\text { CTH, IFNA2, CCL7, APOH, IFIH1, } \\
\text { GPR37L1, FOXC2, COL3A1, LGR5, } \\
\text { ADAMTS3, INHBB, CTGF, ITGA8, DAB2, } \\
\text { AGTR2 }\end{array}$ \\
\hline GO:0009967 & $\begin{array}{l}\text { positive } \\
\text { regulation of } \\
\text { signal } \\
\text { transduction }\end{array}$ & 0.000653226 & 12 & $0.00 \%$ & 0 & $\begin{array}{l}\text { CTH, IFNA2, CCL7, GPR } 37 \text { L1, COL3A1, } \\
\text { LGR5, ADAMTS3, INHBB, CTGF, ITGA8, } \\
\text { DAB2, AGTR2 }\end{array}$ \\
\hline GO:0023056 & $\begin{array}{l}\text { positive } \\
\text { regulation of } \\
\text { signaling }\end{array}$ & $3.10 \mathrm{E}-05$ & 14 & $0.00 \%$ & 0 & $\begin{array}{l}\text { CTH, IFNA2, CCL7, GPR37L1, COL3A1, } \\
\text { LGR5, ADAMTS3, INHBB, DRD1, CTGF, } \\
\text { ITGA8, DAB2, GAL, AGTR2 }\end{array}$ \\
\hline GO:0012501 & $\begin{array}{l}\text { programmed } \\
\text { cell death }\end{array}$ & 2.03E-05 & 16 & $0.00 \%$ & 0 & $\begin{array}{l}\text { IFNA2, GCLM, FOXC2, CFDP1, CTGF, } \\
\text { KNG1, DAB2, AGTR2, CTH, APOH, } \\
\text { HDAC4, LIFR, GRIK5, INHBB, ID3, GAL }\end{array}$ \\
\hline GO:0042981 & $\begin{array}{l}\text { regulation of } \\
\text { apoptotic } \\
\text { process }\end{array}$ & $3.06 \mathrm{E}-06$ & 15 & $0.00 \%$ & 0 & $\begin{array}{l}\text { CTH, APOH, LIFR, HDAC4, GCLM, } \\
\text { FOXC2, CFDP1, ID3, INHBB, GRIK5, } \\
\text { CTGF, KNG1, DAB2, GAL, AGTR2 }\end{array}$ \\
\hline GO:0050789 & $\begin{array}{l}\text { regulation of } \\
\text { biological } \\
\text { process }\end{array}$ & $1.39 \mathrm{E}-05$ & 46 & $0.00 \%$ & 0 & $\begin{array}{l}\text { IFNA2, DCBLD2, NDP, GCLM, MPP3, } \\
\text { GPR135, COL3A1, LGR5, DRD1, CTGF, } \\
\text { KNG1, AGTR2, CACNG3, DLG2, ACTA2, } \\
\text { ARID5B, CTH, APOH, LIFR, IFIH1, } \\
\text { DZIP1, GRIN2B, ID3, COL17A1, GAL, } \\
\text { IL13RA2, CCL7, KCNJ4, FOXC2, } \\
\text { GPR37L1, CDH15, CFDP1, ADAMTS3, } \\
\text { DAB2, HNF4G, DIRAS3, GFRA1, GRP, } \\
\text { HDAC4, HIST1H4C, INHBB, GRIK5, } \\
\text { CNKSR2, ITGA8, ASB4, GLRA1 }\end{array}$ \\
\hline $00 \cdot 0065008$ & $\begin{array}{l}\text { regulation of } \\
\text { biological }\end{array}$ & 000567202 & 18 & $002 \%$ & 002 & $\begin{array}{l}\text { IFNA2, CCL7, GCLM, FOXC2, COL3A1, } \\
\text { CFDP1, DRD1, CTGF, KNG1, AGTR2, } \\
\text { ACTA2, APOH, HIST1H4C, DZIP1, }\end{array}$ \\
\hline
\end{tabular}

\begin{tabular}{|c|c|c|c|c|c|c|}
\hline GO: 1903522 & $\begin{array}{l}\text { regulation of } \\
\text { blood } \\
\text { circulation }\end{array}$ & 0.003207853 & 6 & $0.02 \%$ & 0.02 & $\begin{array}{l}\text { DRD1, CTGF, KCNJ4, HDAC4, AGTR2, } \\
\text { CACNG3 }\end{array}$ \\
\hline GO:0050880 & $\begin{array}{l}\text { regulation of } \\
\text { blood vessel } \\
\text { size }\end{array}$ & $9.19 \mathrm{E}-05$ & 6 & $0.00 \%$ & 0 & $\begin{array}{l}\text { DRD1, ACTA2, KNG1, GCLM, FOXC2, } \\
\text { AGTR2 }\end{array}$ \\
\hline GO:0010646 & $\begin{array}{l}\text { regulation of } \\
\text { cell } \\
\text { communication }\end{array}$ & $9.89 \mathrm{E}-05$ & 19 & $0.00 \%$ & 0 & $\begin{array}{l}\text { IFNA2, CCL7, GCLM, GPR37L1, } \\
\text { COL3A1, LGR5, ADAMTS3, DRD1, } \\
\text { CTGF, DAB2, AGTR2, CACNG3, CTH, } \\
\text { GRIK5, INHBB, CNKSR2, ITGA8, GAL, } \\
\text { GLRA1 }\end{array}$ \\
\hline GO:0010941 & $\begin{array}{l}\text { regulation of } \\
\text { cell death }\end{array}$ & 8.10E-07 & 16 & $0.00 \%$ & 0 & $\begin{array}{l}\text { GCLM, GPR37L1, FOXC2, CFDP1, } \\
\text { CTGF, KNG1, DAB2, AGTR2, CTH, } \\
\text { APOH, HDAC4, LIFR, GRIK5, INHBB, } \\
\text { ID3, GAL }\end{array}$ \\
\hline GO:0045595 & $\begin{array}{l}\text { regulation of } \\
\text { cell } \\
\text { differentiation }\end{array}$ & 0.001437131 & 12 & $0.00 \%$ & 0 & $\begin{array}{l}\text { CTH, IFNA2, HIST1H4C, HDAC4, } \\
\text { GPR } 37 \text { L } 1, \text { COL } 3 A 1, \text { CDH15, ID } 3, \text { CTGF, } \\
\text { ASB } 4 \text {, DAB2, GAL }\end{array}$ \\
\hline GO:0030334 & $\begin{array}{l}\text { regulation of } \\
\text { cell migration }\end{array}$ & 0.006514346 & 8 & $0.02 \%$ & 0.02 & $\begin{array}{l}\text { CCL7, APOH, HDAC4, FOXC2, COL3A1, } \\
\text { DRD1, DAB2, AGTR2 }\end{array}$ \\
\hline GO:0050794 & $\begin{array}{l}\text { regulation of } \\
\text { cellular } \\
\text { process }\end{array}$ & 0.000172246 & 43 & $0.00 \%$ & 0 & $\begin{array}{l}\text { IFNA2, DCBLD2, NDP, GCLM, MPP3, } \\
\text { GPR135, COL3A1, LGR5, DRD1, CTGF, } \\
\text { KNG1, AGTR2, CACNG3, DLG2, } \\
\text { ARID5B, CTH, APOH, LIFR, IFIH1, } \\
\text { DZIP1, GRIN2B, ID3, GAL, IL13RA2, } \\
\text { CCL7, FOXC2, GPR37L1, CDH15, } \\
\text { CFDP1, ADAMTS3, DAB2, HNF4G, } \\
\text { DIRAS3, GFRA1, GRP, HDAC4, } \\
\text { HIST1H4C, INHBB, GRIK5, CNKSR2, } \\
\text { ITGA8, ASB4, GLRA1 }\end{array}$ \\
\hline & $\begin{array}{l}\text { regulation of } \\
\text { developmental }\end{array}$ & & & & & $\begin{array}{l}\text { CTH, IFNA2, CCL7, APOH, HIST1H4C, } \\
\text { HDAC4, GPR37L1, FOXC2, COL3A1, } \\
\text { CFDP1, CDH15, ID 3, CTGF, ASB4, }\end{array}$ \\
\hline GO:0050793 & process & $1.36 \mathrm{E}-05$ & 17 & $0.00 \%$ & 0 & DAB2, GAL, AGTR2 \\
\hline GO:0032879 & $\begin{array}{l}\text { regulation of } \\
\text { localization }\end{array}$ & 0.000479144 & 16 & $0.00 \%$ & 0 & $\begin{array}{l}\text { IFNA2, CCL7, KCNJ4, FOXC2, COL3A1, } \\
\text { DRD1, KNG1, DAB2, AGTR2, CACNG3, } \\
\text { APOH, HDAC4, GRIK5, INHBB, GAL, } \\
\text { IL13RA2 }\end{array}$ \\
\hline
\end{tabular}




\begin{tabular}{|c|c|c|c|c|c|c|}
\hline GO:0065009 & $\begin{array}{l}\text { regulation of } \\
\text { molecular } \\
\text { function }\end{array}$ & $5.94 \mathrm{E}-05$ & 20 & $0.00 \%$ & 0 & $\begin{array}{l}\text { NDP, CCL7, GCLM, DRD1, CTGF, } \\
\text { HSPB2, KNG1, DAB2, AGTR2, DIRAS3, } \\
\text { CACNG3, ARID5B, CTH, DLG2, GFRA1, } \\
\text { APOH, HDAC4, GRIN2B, ID3, GAL }\end{array}$ \\
\hline GO:2000026 & $\begin{array}{l}\text { regulation of } \\
\text { multicellular } \\
\text { organismal } \\
\text { development }\end{array}$ & 0.000776707 & 13 & $0.00 \%$ & 0 & $\begin{array}{l}\text { CTH, IFNA2, APOH, HIST1H4C, HDAC4, } \\
\text { GPR37L1, FOXC2, COL3A1, CTGF, } \\
\text { ASB4, DAB2, GAL, AGTR2 }\end{array}$ \\
\hline GO:0051239 & $\begin{array}{l}\text { regulation of } \\
\text { multicellular } \\
\text { organismal } \\
\text { process }\end{array}$ & $5.78 \mathrm{E}-08$ & 21 & $0.00 \%$ & 0 & $\begin{array}{l}\text { IFNA2, KCNJ4, GPR37L1, FOXC2, } \\
\text { COL3A1, DRD1, CTGF, KNG1, DAB2, } \\
\text { AGTR2, CACNG3, CTH, APOH, HDAC4, } \\
\text { HIST1H4C, IFIH1, ID3, INHBB, ASB4, } \\
\text { GAL, GLRA1 }\end{array}$ \\
\hline GO:0043067 & $\begin{array}{l}\text { regulation of } \\
\text { programmed } \\
\text { cell death }\end{array}$ & $3.41 \mathrm{E}-06$ & 15 & $0.00 \%$ & 0 & $\begin{array}{l}\text { CTH, APOH, LIFR, HDAC4, GCLM, } \\
\text { FOXC2, CFDP1, ID3, INHBB, GRIK5, } \\
\text { CTGF, KNG1, DAB2, GAL, AGTR2 }\end{array}$ \\
\hline GO:0048583 & $\begin{array}{l}\text { regulation of } \\
\text { response to } \\
\text { stimulus }\end{array}$ & $5.75 \mathrm{E}-06$ & 23 & $0.00 \%$ & 0 & $\begin{array}{l}\text { IFNA2, CCL7, GCLM, GPR37L1, FOXC2, } \\
\text { COL3A1, LGR5, ADAMTS3, DRD1, } \\
\text { CTGF, KNG1, DAB2, AGTR2, CACNG3, } \\
\text { CTH, APOH, HDAC4, IFIH1, INHBB, } \\
\text { COL17A1, CNKSR2, ITGA8, IL13RA2 }\end{array}$ \\
\hline GO:0023051 & $\begin{array}{l}\text { regulation of } \\
\text { signaling }\end{array}$ & 0.000137005 & 19 & $0.00 \%$ & 0 & $\begin{array}{l}\text { IFNA2, CCL7, GCLM, GPR37L1, } \\
\text { COL3A1, LGR5, ADAMTS3, DRD1, } \\
\text { CTGF, DAB2, AGTR2, CACNG3, CTH, } \\
\text { GRIK5, INHBB, CNKSR2, ITGA8, GAL, } \\
\text { GLRA1 }\end{array}$ \\
\hline GO:0044057 & $\begin{array}{l}\text { regulation of } \\
\text { system } \\
\text { process }\end{array}$ & $3.15 E-06$ & 10 & $0.00 \%$ & 0 & $\begin{array}{l}\text { KCNJ4, HDAC4, DRD1, INHBB, CTGF, } \\
\text { KNG1, GAL, AGTR2 CACNG3, GLRA1 }\end{array}$ \\
\hline GO:0035150 & $\begin{array}{l}\text { regulation of } \\
\text { tube size }\end{array}$ & 9.53E-05 & 6 & $0.00 \%$ & 0 & $\begin{array}{l}\text { DRD1, ACTA2, KNG1, GCLM, FOXC2, } \\
\text { AGTR2 }\end{array}$ \\
\hline GO:0072001 & $\begin{array}{l}\text { renal system } \\
\text { development }\end{array}$ & $5.98 \mathrm{E}-06$ & 8 & $0.00 \%$ & 0 & $\begin{array}{l}\text { ARID5B, ACTA2, HMGCS2, FOXC2, } \\
\text { LGR5, ID3, ITGA8, AGTR2 }\end{array}$ \\
\hline GO:0001101 & $\begin{array}{l}\text { response to } \\
\text { acid chemical }\end{array}$ & 0.00039036 & 7 & $0.00 \%$ & 0 & $\begin{array}{l}\text { ID3, DRD1, CTGF, HMGCS2, COL6A1, } \\
\text { GLRA1, COL3A1 }\end{array}$ \\
\hline GO:0097305 & $\begin{array}{l}\text { response to } \\
\text { alcohol }\end{array}$ & 0.00908155 & 5 & $0.02 \%$ & 0.02 & DRD1, CCL7, HMGCS2, GRIN2B, GLRA1 \\
\hline GO:0043200 & $\begin{array}{l}\text { response to } \\
\text { amino acid }\end{array}$ & $8.76 \mathrm{E}-06$ & 6 & $0.00 \%$ & 0 & $\begin{array}{l}\text { DRD1, CTGF, HMGCS2, COL6A1, } \\
\text { GLRA1, COL } 3 A 1\end{array}$ \\
\hline
\end{tabular}

\begin{tabular}{|c|c|c|c|c|c|c|}
\hline GO:0042221 & $\begin{array}{l}\text { response to } \\
\text { chemical }\end{array}$ & $7.76 \mathrm{E}-11$ & 30 & $0.00 \%$ & 0 & $\begin{array}{l}\text { IFNA2, CCL7, GCLM, GPR37L1, FOXC2, } \\
\text { COL3A1, ADAMTS3, DRD1, CTGF, } \\
\text { HSPB2, DAB2, HNF4G, BYSL, AGTR2, } \\
\text { CYP2C18, CTH, APOH, LIFR, HMGCS2, } \\
\text { HDAC4, GRIN2B, ID3, INHBB, GRIK5, } \\
\text { ITGA8, GAL, IL13RA2, IBSP, COL6A1, } \\
\text { GLRA1 }\end{array}$ \\
\hline GO:0009719 & $\begin{array}{l}\text { response to } \\
\text { endogenous } \\
\text { stimulus }\end{array}$ & $2.42 \mathrm{E}-05$ & 14 & $0.00 \%$ & 0 & $\begin{array}{l}\text { HMGCS2, HDAC4, FOXC2, COL3A1, } \\
\text { INHBB, DRD1, CTGF, ITGA8, DAB2, } \\
\text { HNF4G, GAL, AGTR2, COL6A1, GLRA1 }\end{array}$ \\
\hline GO:0045471 & $\begin{array}{l}\text { response to } \\
\text { ethanol }\end{array}$ & 0.001478928 & 5 & $0.00 \%$ & 0 & DRD1, CCL7, HMGCS2, GRIN2B, GLRA1 \\
\hline GO:0009605 & $\begin{array}{l}\text { response to } \\
\text { external } \\
\text { stimulus }\end{array}$ & 0.000577938 & 15 & $0.00 \%$ & 0 & $\begin{array}{l}\text { ACTA2, IFNA2, CCL } 7, \text { APOH, KCNJ4, } \\
\text { HMGCS2, HDAC4, IFIH1, COL } 3 A 1 \text {, } \\
\text { INHBB, DRD1, KNG1, BYSL, IL13RA2, } \\
\text { GLRA1 }\end{array}$ \\
\hline GO:0070848 & $\begin{array}{l}\text { response to } \\
\text { growth factor }\end{array}$ & 0.007266335 & 8 & $0.02 \%$ & 0.02 & $\begin{array}{l}\text { ADAMTS3, CTGF, ITGA8, DAB2, BYSL, } \\
\text { IBSP, AGTR2, COL } 3 \text { A1 }\end{array}$ \\
\hline GO:0009725 & $\begin{array}{l}\text { response to } \\
\text { hormone }\end{array}$ & 0.000668949 & 10 & $0.00 \%$ & 0 & $\begin{array}{l}\text { HMGCS2, HDAC4, FOXC2, INHBB, } \\
\text { DRD1, CTGF, DAB2, HNF } 4 \text { G, GAL, } \\
\text { AGTR2 }\end{array}$ \\
\hline GO:0033993 & $\begin{array}{l}\text { response to } \\
\text { lipid }\end{array}$ & 0.008318598 & 9 & $0.02 \%$ & 0.02 & $\begin{array}{l}\text { APOH, HMGCS2, ID3, DRD1, CTGF, } \\
\text { DAB2, BYSL, HNF4G, AGTR2 }\end{array}$ \\
\hline GO:1901698 & $\begin{array}{l}\text { response to } \\
\text { nitrogen } \\
\text { compound }\end{array}$ & 0.000228868 & 11 & $0.00 \%$ & 0 & $\begin{array}{l}\text { IFNA2, HMGCS2, FOXC2, COL3A1, } \\
\text { INHBB, DRD1, CTGF, GAL, AGTR2, } \\
\text { COL6A1, GLRA1 }\end{array}$ \\
\hline GO:0014070 & $\begin{array}{l}\text { response to } \\
\text { organic cyclic } \\
\text { compound }\end{array}$ & 0.001729965 & 10 & $0.00 \%$ & 0 & $\begin{array}{l}\text { IFNA2, LIFR, HMGCS2, ID3, DRD1, } \\
\text { CTGF, DAB2, BYSL, HNF4G, AGTR2 }\end{array}$ \\
\hline & & & & & & $\begin{array}{l}\text { IFNA2, CCL7, FOXC2, COL } 3 \text { A1, } \\
\text { ADAMTS3, DRD1, CTGF, HSPB2, DAB2, } \\
\text { HNF4G, BYSL, AGTR2, CTH, APOH, }\end{array}$ \\
\hline GO:0010033 & $\begin{array}{l}\text { response to } \\
\text { organic } \\
\text { substance }\end{array}$ & $3.57 \mathrm{E}-12$ & 27 & $0.00 \%$ & 0 & $\begin{array}{l}\text { LIFR, HDAC4, HMGCS2, GRIN2B, ID3, } \\
\text { INHBB, GRIK5, ITGA8, GAL, IL13RA2, } \\
\text { IBSP, COL6A1, GLRA1 }\end{array}$ \\
\hline GO:0010243 & $\begin{array}{l}\text { response to } \\
\text { organ nitrogen| } \\
\text { compound }\end{array}$ & 0.000644137 & 10 & $0.00 \%$ & 0 & $\begin{array}{l}\text { HMGCS2, FOXC2, COL3A1, INHBB, } \\
\text { DRD1, CTGF, GAL, AGTR2, COL6A1, } \\
\text { GLRA1 }\end{array}$ \\
\hline GO:1901700 & $\begin{array}{l}\text { response to } \\
\text { oxygen- }\end{array}$ & $2.29 \mathrm{E}-08$ & 17 & $0.00 \%$ & 0 & $\begin{array}{l}\text { CCL7, GPR37L1, FOXC2, COL3A1, } \\
\text { DRD1, CTGF, BYSL, AGTR2, APOH, }\end{array}$ \\
\hline
\end{tabular}




\begin{tabular}{|c|c|c|c|c|c|c|}
\hline & $\begin{array}{l}\text { containing } \\
\text { compound }\end{array}$ & & & & & $\begin{array}{l}\text { HMGCS2, GRIN2B, ID3, GRIK5, INHBB, } \\
\text { GAL, COL6A1, GLRA1 }\end{array}$ \\
\hline GO:1901652 & $\begin{array}{l}\text { response to } \\
\text { peptide }\end{array}$ & 0.003249007 & 7 & $0.02 \%$ & 0.02 & $\begin{array}{l}\text { INHBB, DRD1, CTGF, HMGCS2, GAL, } \\
\text { FOXC2, AGTR2 }\end{array}$ \\
\hline GO:0043434 & $\begin{array}{l}\text { response to } \\
\text { peptide } \\
\text { hormone }\end{array}$ & 0.00187346 & 7 & $0.00 \%$ & 0 & $\begin{array}{l}\text { INHBB, DRD1, CTGF, HMGCS2, GAL, } \\
\text { FOXC2, AGTR2 }\end{array}$ \\
\hline GO:0050896 & $\begin{array}{l}\text { response to } \\
\text { stimulus }\end{array}$ & $6.27 \mathrm{E}-14$ & 49 & $0.00 \%$ & 0 & $\begin{array}{l}\text { IFNA2, DCBLD2, NDP, GCLM, MPP3, } \\
\text { GPR135, COL3A1, LGR5, DRD1, CTGF, } \\
\text { HSPB2, KNG1, AGTR2, CACNG3, } \\
\text { CYP2C18, ACTA2, ARID5B, CTH, APOH, } \\
\text { LIFR, IFIH1, DZII1, GRIN2B, ID3, } \\
\text { COL17A1, GAL, IL13RA2, IBSP, } \\
\text { COL6A1, CCL7, KCNJ4, FOXC2, } \\
\text { GPR37L1, ADAMTS3, DAB2, HNF4G, } \\
\text { BYSL, DIRAS3, GFRA1, GRP, HMGCS2, } \\
\text { HDAC4, HIST1H4C, INHBB, GRIK5, } \\
\text { CNKSR2, ITGA8, ASB4, GLRA1 }\end{array}$ \\
\hline GO:0006950 & $\begin{array}{l}\text { response to } \\
\text { stress }\end{array}$ & 0.000366184 & 21 & $0.00 \%$ & 0 & $\begin{array}{l}\text { IFNA2, DCBLD2, CCL7, GCLM, } \\
\text { GPR37L1, FOXC2, COL3A1, DRD1, } \\
\text { CTGF, HSPB2, KNG1, AGTR2, CTH, } \\
\text { APOH, HDAC4, HIST1H4C, HMGCS2, } \\
\text { IFIH1, ID3, INHBB, GAL }\end{array}$ \\
\hline GO:0009611 & $\begin{array}{l}\text { response to } \\
\text { wounding }\end{array}$ & 0.004128371 & 8 & $0.02 \%$ & 0.02 & $\begin{array}{l}\text { ID3, IFNA2, DCBLD2, CTGF, APOH, } \\
\text { KNG1, FOXC2, COL3A1 }\end{array}$ \\
\hline GO:0007165 & $\begin{array}{l}\text { signal } \\
\text { transduction }\end{array}$ & $1.06 \mathrm{E}-08$ & 36 & $0.00 \%$ & 0 & $\begin{array}{l}\text { IFNA2, DCBLD2, NDP, GCLM, MPP3, } \\
\text { GPR135, COL3A1, LGR5, DRD1, CTGF, } \\
\text { AGTR2, CACNG3, ARID5B, CTH, LIFR, } \\
\text { IFIH1, DZIP1, GRIN2B, GAL, IL13RA2, } \\
\text { CCL7, FOXC2, GPR37L1, ADAMTS3, } \\
\text { DAB2, HNF4G, DIRAS3, GFRA1, GRP, } \\
\text { HDAC4, GRIK5, INHBB, CNKSR2, ASB4, } \\
\text { ITGA8, GLRA1 }\end{array}$ \\
\hline GO:0023052 & signaling & $2.47 \mathrm{E}-09$ & 38 & $0.00 \%$ & 0 & $\begin{array}{l}\text { IFNA2, DCBLD2, NDP, GCLM, MPP3, } \\
\text { GPR135, COL3A1, LGR5, DRD1, CTGF, } \\
\text { AGTR2, CACNG3, ARID5B, CTH, DLG2, } \\
\text { LIFR, IFIH1, DZIP1, GRIN2B, GAL, } \\
\text { IL13RA2, CCL7, KCNJ4, FOXC2, } \\
\text { GPR37L1, ADAMTS3, DAB2, HNF4G, }\end{array}$ \\
\hline
\end{tabular}

DIRAS3, GFRA1, GRP, HDAC4, GRIK5, INHBB, CNKSR2, ITGA8, ASB4, GLRA1 IFNA2, DCBLD2, NDP, GCLM, MPP3, GPR135, COL3A1, LGR5, DRD1, CTGF, AGTR2, CACNG3, ARID5B, CTH, DLG2 LIFR, IFIH1, DZIP1, GRIN2B, GAL IL13RA2, CCL7, KCNJ4, FOXC2, GPR37L1, ADAMTS3, DAB2, HNF4G, DIRAS3, GFRA1, GRP, HDAC4, GRIK5, INHBB, CNKSR2, ITGA8, ASB4, GLRA1 IFNA2, NDP, COL3A1, LGR5, DRD1 CTGF, KNG1, AGTR2, CACNG3, ACTA2 ARID5B, CTH, DLG2, APOH, LIFR, IFIH1 DZIP1, GRIN2B, ID3, GAL, IBSP,

singlemulticellular organism 3.98E-14

38

$0.00 \% \quad 0$ COL6A1, FUT9, KCNJ4, FOXC2, BYR 37L1, CFDP1, ADAMTS3, DAB2, HMGCS2, INHBB, ASB4, ITGA8, GLRA1 IFNA2, DCBLD2, NDP, GCLM, MPP3, COL3A1, LGR5, DRD1 CTGF KNG1, AGTR2, CYP2C18, DLG2, CTH, ACTA2, ARID5B, APOH, LIFR, DZIP1, GRIN2B, ARID5B, APOH, LIFR, DZIP1, GRIN2B,
ID3, COL17A1, GAL, IL13RA2, IBSP. ID3, COL17A1, GAL, IL13RA2, IBSP, COL6A1, FUT9, CCL7, KCNJ4, FOXC2, CH25H, DAB2, BYSL, DIRAS3, GFRA1, CDH12, HMGCS2, HIST1H4C, HDAC4, INHBB, GRIK5, ITGA8, ASB4, CKM, GLRA1

singleorganism
cellular GO:0044763 process 7.06E-11 49 $0.00 \% \quad 0$

single-
organism
developmental
Go:0044767
process
single-
organism
metabolic

GO:0044710 process
4.15E-10 33 $0.001255126 \quad 25$
$0.00 \% \quad 0$

$0.00 \%$ o

IFNA2, NDP, COL3A1, LGR5, DRD1, CTGF, AGTR2, ACTA2, ARID5B, CTH DLG2, APOH, LIFR, DZIP1, ID3, GAL, IBSP, COL6A1, FUT9, CCL7, FOXC2, GPR37L1, CDH15, CFDP1, DAB2, BYSL, GFRA1, HDAC4, HIST1H4C, HMGCS2, INHBB, ASB4, ITGA8

FUT9, CCL7, GCLM, APOF, MPP3, GPR37L1, COL3A1, ADAMTS3, DRD1 CTGF, CH25H, CYP2C18, GFRA1. ARID5B, CTH, DLG2, APOH, HMGCS2, 


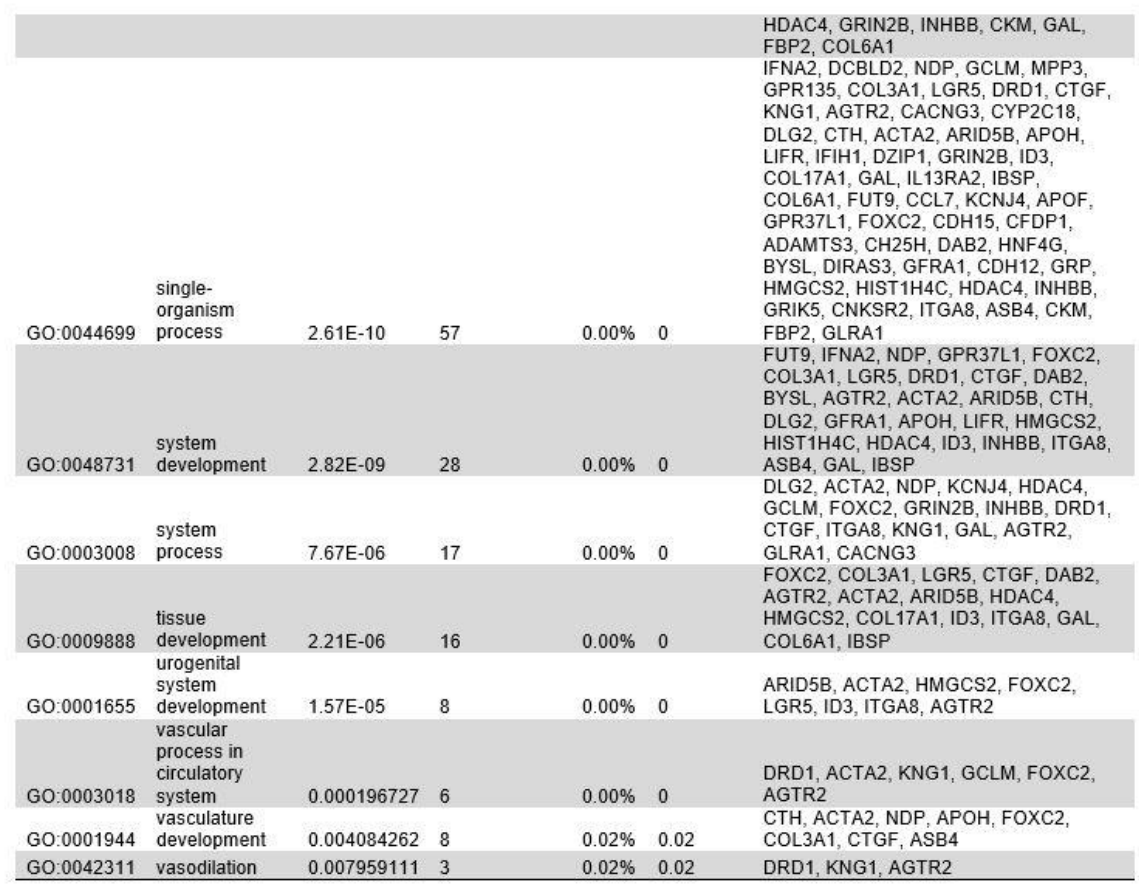

Table 4.8 Demonstration of biological processes that ID3 \& ID3 target genes are involved with in blood. 
ID3 and ID3 candidate target genes in tissue. In order to understand the roles of these genes in functional processes gene ontology methodology was used to demonstrate the processes in which ID3 \& ID3 candidate target genes in tissue were overrepresented. Candidate target genes in tissue were overrepresented in 89 biological processes.

\begin{tabular}{|c|c|c|c|c|c|c|}
\hline $\begin{array}{l}\text { Gene } \\
\text { Ontology ID }\end{array}$ & $\begin{array}{l}\text { Biological } \\
\text { Process }\end{array}$ & $\begin{array}{l}\text { Corrected } \\
\text { p-value }\end{array}$ & $\begin{array}{l}\text { Number } \\
\text { List } \\
\text { Annotation }\end{array}$ & $\begin{array}{l}\text { FDR } \\
\text { Rate }\end{array}$ & $\begin{array}{l}\text { Expected } \\
\text { False } \\
\text { Positive }\end{array}$ & Annotated Genes \\
\hline GO:0048856 & $\begin{array}{l}\text { anatomical } \\
\text { structure } \\
\text { development }\end{array}$ & $8.28 \mathrm{E}-05$ & 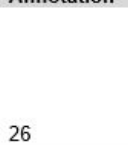 & $0.00 \%$ & 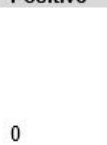 & $\begin{array}{l}\text { MTM1, FLOT2, NAGLU, CDKN2B, } \\
\text { NEDD8, MFGE8, FRAT2, GPR4, CDH15, } \\
\text { AGGF1, CTSZ, MAPK1, BYSL, EEF2, } \\
\text { LGALS1, AXIN1, CEBPG, CDK5, ID3, } \\
\text { FZD2, DCTN5, HSP90AB1, BCAR3, } \\
\text { CTNNBIP1, ATF6, EPHA1 }\end{array}$ \\
\hline GO:0009653 & $\begin{array}{l}\text { anatomical } \\
\text { structure } \\
\text { morphogenesis }\end{array}$ & 0.0006562 & 16 & $0.00 \%$ & 0 & $\begin{array}{l}\text { MTM1, NAGLU, NEDD8, MFGE8, GPR4, } \\
\text { AGGF1, CTSZ, MAPK1, BYSL, AXIN1, } \\
\text { CDK5, FZD2, ID3, BCAR3, CTNNBIP1, } \\
\text { EPHA1 }\end{array}$ \\
\hline GO:0048513 & $\begin{array}{l}\text { animal organ } \\
\text { development }\end{array}$ & 0.000127866 & 19 & $0.00 \%$ & 0 & $\begin{array}{l}\text { MTM1, NAGLU, CDKN2B, GPR4, CTSZ, } \\
\text { MAPK1, BYSL, EEF2, LGALS1, AXIN1, } \\
\text { CEBPG, CDK5, ID3, DCTN5, FZD2, } \\
\text { BCAR3, HSP90AB1, CTNNBIP1, ATF6 }\end{array}$ \\
\hline GO 1904886 & $\begin{array}{l}\text { beta-catenin } \\
\text { destruction } \\
\text { complex } \\
\text { disassembly }\end{array}$ & 0.004245634 & 3 & $0.00 \%$ & 0 & FZD2 AXIN1 FRAT2 \\
\hline GO:0065007 & $\begin{array}{l}\text { biological } \\
\text { regulation }\end{array}$ & 4.61E-07 & 52 & $0.00 \%$ & 0 & $\begin{array}{l}\text { DCBLD2, NEDD8, LY96, GPR4, COX8A, } \\
\text { CCL23, BCL7B, C4BPB, COMMD4, EEF2, } \\
\text { MIF, HIST1H1D, GABRD, CDK5, DDN, } \\
\text { ID3, CD2BP2, BCAR3, LMAN1, } \\
\text { CTNNBIP1, AHCTF1, GBF1, MTM1, } \\
\text { FLOT2, CDKN2B, MFGE8, FRAT2, } \\
\text { CDH15, AGGF1, MR1, KIFAP3, } \\
\text { HIST1H1B, ARFGEF2, CTSZ, MAPK1, } \\
\text { GRIN2D, GOT1, KPNA4, DAP, LGALS1, } \\
\text { GTF2F2, AXIN1, LSM3, CEBPG, FZD2, } \\
\text { HSP90AB1, FXR2, MAPRE1, ATF6, } \\
\text { EPHA1, FAM20B, EIF4EBP2 }\end{array}$ \\
\hline GO:0009056 & $\begin{array}{l}\text { catabolic } \\
\text { process }\end{array}$ & 0.003827336 & 16 & $0.00 \%$ & 0 & $\begin{array}{l}\text { MTM1, GOT1, NAGLU, DAP, HERC4, } \\
\text { NEDD8, AXIN1, LSM3, C18orf25, CDK5, } \\
\text { HSP90AB1, COX8A, FXR2, CTSZ, } \\
\text { C4BPB, H1F0 }\end{array}$ \\
\hline GO:0007154 & $\begin{array}{l}\text { cell } \\
\text { communication }\end{array}$ & 0.000898247 & 31 & $0.00 \%$ & 0 & $\begin{array}{l}\text { GBF1, MTM1, FLOT2, DCBLD2, CDKN2B, } \\
\text { NEDD8, LY96, FRAT2, GPR4, MR1, } \\
\text { KIFAP3, ARFGEF2, BCL7B, CCL23, }\end{array}$ \\
\hline
\end{tabular}




\begin{tabular}{|c|c|c|c|c|c|c|}
\hline & \multirow[b]{2}{*}{$\begin{array}{l}\text { cell } \\
\text { differentiation }\end{array}$} & \multirow[b]{2}{*}{0.002005838} & \multirow[b]{2}{*}{19} & \multirow[b]{2}{*}{$0.00 \%$} & \multirow[b]{2}{*}{0} & \multirow{3}{*}{$\begin{array}{l}\text { MAPK1, GRIN2D, GOT1, DAAP, LGALS1, } \\
\text { MIF, GTF2F2, AXIN1, CDK5, GABRD, } \\
\text { FZD2, HSP90AB1, BCAR3, CTNNBIP1, } \\
\text { ATF6, EPHA1, EIF4EBP2 } \\
\text { FLOT2, NAGLU, HERC4, CDKN2B, GPR4, } \\
\text { CDH15, AGGF1, BCL7B, MAPK1, BYSL, } \\
\text { EEF2, LGALS1, AXIN1, CEBPG, CDK5, } \\
\text { ID3, FZD2, CTNNBIP1, EPHA1 } \\
\text { EEF2, CDKN2B, MIF, MFGE8, FRAT2, } \\
\text { CDK5, AGGF1, KIFAP3, CCL23, MAPRE1, } \\
\text { MAPK1, BYSL, CTNNBIP1, EPHA1 }\end{array}$} \\
\hline \multirow[t]{2}{*}{ GO:0030154 } & & & & & & \\
\hline & cell proliferation & 0.001483763 & 14 & $0.00 \%$ & 0 & \\
\hline GO:0007166 & $\begin{array}{l}\text { cell surface } \\
\text { receptor } \\
\text { signaling } \\
\text { pathway }\end{array}$ & 0.001988295 & 18 & $0.00 \%$ & 0 & $\begin{array}{l}\text { CDKN2B, NEDD8, LY96, FRAT2, BCL7B, } \\
\text { CCL23, MAPK1, GRIN2D, GOT1, MIF, } \\
\text { AXIN1, GTF2F2, CDK5, FZD2, } \\
\text { HSP90AB1, CTNNBIP1, EPHA1, } \\
\text { EIF4EBP2 }\end{array}$ \\
\hline GO:0007267 & $\begin{array}{l}\text { cell-cell } \\
\text { signaling }\end{array}$ & 0.008900922 & 12 & $0.02 \%$ & 0.02 & $\begin{array}{l}\text { FLOT2, AXIN1, FRAT2, GABRD, CDK5, } \\
\text { FZD2, BCL7B, CCL23, MAPK1, } \\
\text { CTNNBIP1, GRIN2D, EIF4EBP2 }\end{array}$ \\
\hline GO:0044248 & $\begin{array}{l}\text { cellular } \\
\text { catabolic } \\
\text { process }\end{array}$ & 0.008928515 & 14 & $0.02 \%$ & 0.02 & $\begin{array}{l}\text { MTM1, GOT1, DAP, HERC4, NEDD8, } \\
\text { AXIN1, LSM3, C18orf25, CDK5, } \\
\text { HSP90AB1, COX8A, FXR2, CTSZ, H1F0 }\end{array}$ \\
\hline GO:0022607 & $\begin{array}{l}\text { cellular } \\
\text { component } \\
\text { assembly }\end{array}$ & $9.75 \mathrm{E}-05$ & 19 & $0.00 \%$ & 0 & $\begin{array}{l}\text { MTM1, FLOT2, NDUFA1, KIFAP3, } \\
\text { HIST1H1B, CTSZ, MIF, AXIN1, GTF2F2, } \\
\text { LSM3, CDK5, HIST1H1D, CD2BP2, } \\
\text { LMAN1, CTNNBIP1, AHCTF1, MAPRE1, } \\
\text { EPHA1, H1F0 }\end{array}$ \\
\hline GO:0044085 & $\begin{array}{l}\text { cellular } \\
\text { component } \\
\text { biogenesis }\end{array}$ & $1.55 \mathrm{E}-05$ & 21 & $0.00 \%$ & 0 & $\begin{array}{l}\text { MTM1, FLOT2, NDUFA1, IMP4, KIFAP3, } \\
\text { HIST1H1B, CTSZ, BYSL, MIF, AXIN1, } \\
\text { GTF2F2, LSM3, CDK5, HIST1H1D, } \\
\text { CD2BP2, LMAN1, MAPRE1, CTNNBIP1, } \\
\text { AHCTF1, EPHA1, H1F0 }\end{array}$ \\
\hline GO:0016043 & $\begin{array}{l}\text { cellular } \\
\text { component } \\
\text { organization }\end{array}$ & $4.30 \mathrm{E}-08$ & 35 & $0.00 \%$ & 0 & $\begin{array}{l}\text { DCBLD2, COX8A, C4BPB, MIF, MRPS12, } \\
\text { HIST1H1D, CDK5, CD2BP2, LMAN1, } \\
\text { CTNNBIP1, AHCTF1, H1F0, GBF1, MTM1, } \\
\text { FLOT2, NAGLU, CDKN2B, NDUFA1, } \\
\text { FRAT2, MFGE8, CDH15, KIFAP3, } \\
\text { HIST1H1B, ARFGEF2, CTSZ, MAPK1, } \\
\text { LGALS1, AXIN1, GTF2F2, LSM3, FZD2, } \\
\text { HSP90AB1, MAPRE1, FAM20B, EPHA1 }\end{array}$ \\
\hline
\end{tabular}

\begin{tabular}{|c|c|c|c|c|c|c|}
\hline GO:0071840 & $\begin{array}{l}\text { cellular } \\
\text { component } \\
\text { organization or } \\
\text { biogenesis }\end{array}$ & $3.68 \mathrm{E}-09$ & 37 & $0.00 \%$ & 0 & $\begin{array}{l}\text { DCBLD2, COX8A, C4BPB, MIF, MRPS12, } \\
\text { HIST1H1D, CDK5, CD2BP2, LMAN1, } \\
\text { AHCTF1, CTNNBIP1, H1F0, GBF1, MTM1, } \\
\text { FLOT2, NAGLU, CDKN2B, NDUFA1, } \\
\text { IMP4, FRAT2, MFGE8, CDH15, KIFAP3, } \\
\text { HIST1H1B, ARFGEF2, CTSZ, BYSL, } \\
\text { MAPK1, LGALS1, AXIN1, GTF2F2, LSM3, } \\
\text { FZD2, HSP90AB1, MAPRE1, FAM20B, } \\
\text { EPHA1 }\end{array}$ \\
\hline GO:0048869 & $\begin{array}{l}\text { cellular } \\
\text { developmental } \\
\text { process }\end{array}$ & 0.00022203 & 21 & $0.00 \%$ & 0 & $\begin{array}{l}\text { MTM1, FLOT2, NAGLU, HERC4, } \\
\text { CDKN2B, GPR4, CDH15, AGGF1, BCL7B, } \\
\text { MAPK1, BYSL, EEF2, LGALS1, MIF, } \\
\text { AXIN1, CEBPG, CDK5, ID3, FZD2, } \\
\text { CTNNBIP1, EPHA1 }\end{array}$ \\
\hline GO:0044260 & $\begin{array}{l}\text { cellular } \\
\text { macromolecule } \\
\text { metabolic } \\
\text { process }\end{array}$ & 0.000350622 & 42 & $0.00 \%$ & 0 & $\begin{array}{l}\text { NEDD8, C18orf25, CCL23, C4BPB, } \\
\text { COMMD4, EEF2, MIF, MRPS12, } \\
\text { HIST1H1D, CDK5, DDN, ID3, CD2BP2, } \\
\text { BCAR3, LMAN1, AHCTF1, CTNNBIP1, } \\
\text { H1F0, MTM1, CDKN2B, HERC4, IMP4, } \\
\text { DNAJC8, MFGE8, AGGF1, HIST1H1B, } \\
\text { ARFGEF2, CTSZ, MAPK1, BYSL, } \\
\text { GRIN2D, DAP, AXIN1, GTF2F2, LSM3, } \\
\text { CEBPG, FZD2, FXR2, HSP90AB1, ATF6, } \\
\text { EPHA1, EIF4EBP2 }\end{array}$ \\
\hline GO:0044237 & $\begin{array}{l}\text { cellular } \\
\text { metabolic } \\
\text { process }\end{array}$ & 0.000178547 & 48 & $0.00 \%$ & 0 & $\begin{array}{l}\text { NEDD8, C180r25, COX8A, CCL23, } \\
\text { C4BPB, CYC1, COMMD4, EEF2, MIF, } \\
\text { MRPS12, HIST1H1D, CDK5, DDN, ID3, } \\
\text { CD2BP2, BCAR3, LMAN1, CTNNBIP1, } \\
\text { AHCTF1, H1F0, GBF1, MTM1, HERC4, } \\
\text { CDKN2B, NDUFA1, IMP4, DNAJC8, } \\
\text { MFGE8, AGGF1, HIST1H1B, ARFGEF2, } \\
\text { CTSZ, MAPK1, BYSL, GRIN2D, GOT1, } \\
\text { DAP, AXIN1, GTF2F2, LSM3, CEBPG, } \\
\text { FZD2, HSP90AB1, FXR2, ATF6, EPHA1, } \\
\text { FAM20B, EIF4EBP2 }\end{array}$ \\
\hline GO:0009987 & cellular process & $1.22 \mathrm{E}-06$ & 63 & $0.00 \%$ & 0 & $\begin{array}{l}\text { DCBLD2, NEDD8, LY96, C18orf25, GPR4, } \\
\text { COX8A, CCL23, BCL7B, C4BPB, CYC1, } \\
\text { COMMD4, EEF2, MIF, MRPS12, } \\
\text { HIST1H1D, GABRD, CDK5, DDN, ID3, } \\
\text { CD2BP2, BCAR3, LMAN1, CTNNBIP1, }\end{array}$ \\
\hline
\end{tabular}




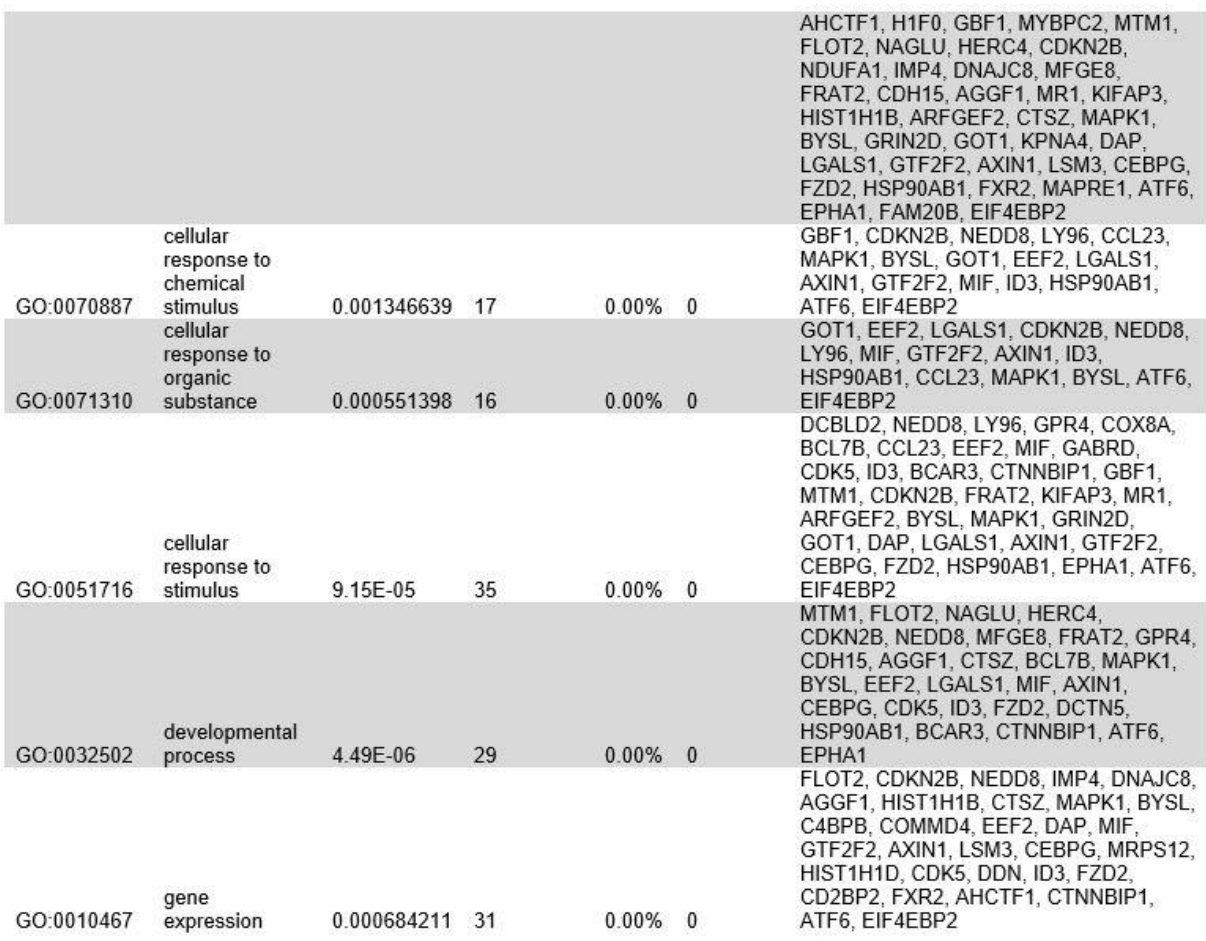

\begin{tabular}{|c|c|c|c|c|c|c|}
\hline GO:0002376 & $\begin{array}{l}\text { immune system } \\
\text { process }\end{array}$ & 0.000525349 & 18 & $0.00 \%$ & 0 & $\begin{array}{l}\text { GBF1, FLOT2, CDKN2B, LY96, MR1, } \\
\text { KIFAP3, COX8A, CCL23, MAPK1, C4BPB, } \\
\text { EEF2, LGALS1, MIF, CEBPG, DCTN5, } \\
\text { FXR2, HSP90AB1, CTNNBIP1 }\end{array}$ \\
\hline GO:0065003 & $\begin{array}{l}\text { macromolecular } \\
\text { complex } \\
\text { assembly }\end{array}$ & 0.000231204 & 15 & $0.00 \%$ & 0 & $\begin{array}{l}\text { NDUFA1, MIF, GTF2F2, AXIN1, LSM3, } \\
\text { HIST1H1D, CD2BP2, KIFAP } 3 \text {, LMAN1, } \\
\text { HIST1H1B, CTSZ, MAPRE1, AHCTF1, } \\
\text { CTNNBIP1, H1F0 }\end{array}$ \\
\hline GO:0043933 & $\begin{array}{l}\text { macromolecular } \\
\text { complex } \\
\text { subunit } \\
\text { organization }\end{array}$ & $5.09 \mathrm{E}-06$ & 18 & $0.00 \%$ & 0 & $\begin{array}{l}\text { NDUFA1, FRAT2, KIFAP3, HIST1H1B, } \\
\text { CTSZ, AXIN1, GTF2F2, MIF, LSM3 }, \\
\text { MRPS12, HIST1H1D, FZD2, CD2BP2, } \\
\text { LMAN1, CTNNBIP1, AHCTF1, MAPRE1, } \\
\text { H1F0 }\end{array}$ \\
\hline GO:0009057 & $\begin{array}{l}\text { macromolecule } \\
\text { catabolic } \\
\text { process }\end{array}$ & 0.000993401 & 12 & $0.00 \%$ & 0 & $\begin{array}{l}\text { MTM1, NAGLU, HERC4, NEDD8, AXIN1, } \\
\text { LSM3, C18orf25, CDK5, HSP90AB1, } \\
\text { CTSZ, C4BPB, H1F0 }\end{array}$ \\
\hline GO:0043170 & $\begin{array}{l}\text { macromolecule } \\
\text { metabolic } \\
\text { process }\end{array}$ & 0.000978265 & 44 & $0.00 \%$ & 0 & $\begin{array}{l}\text { NEDD8, C18orf25, CCL23, C4BPB, } \\
\text { COMMD4, EEF2, MIF, MRPS12, } \\
\text { HIST1H1D, CDK5, DDN, ID3, CD2BP2, } \\
\text { BCAR3, LMAN1, AHCTF1, CTNNBIP1, } \\
\text { H1F0, MTM1, FLOT2, NAGLU, CDKN2B, } \\
\text { HERC4, IMP4, DNAJC8, MFGE8, AGGF1, } \\
\text { HIST1H1B, ARFGEF2, CTSZ, MAPK1, } \\
\text { BYSL, GRIN2D, DAP, AXIN1, GTF2F2, } \\
\text { LSM3, CEBPG, FZD2, HSP90AB1, FXR2, } \\
\text { ATF6, EPHA1, EIF4EBP2 }\end{array}$ \\
\hline GO:0008152 & $\begin{array}{l}\text { metabolic } \\
\text { process }\end{array}$ & 0.001714225 & 51 & $0.00 \%$ & 0 & $\begin{array}{l}\text { NEDD8, C18orf25, COX8A, CCL23, } \\
\text { C4BPB, CYC1, COMMD4, EEF2, MIF, } \\
\text { MRPS12, HIST1H1D, CDK5, DDN, ID3, } \\
\text { CD2BP2, BCAR3, LMAN1, CTNNBIP1, } \\
\text { AHCTF1, H1F0, GBF1, MTM1, FLOT2, } \\
\text { NAGLU, HERC4, CDKN2B, NDUFA1, } \\
\text { IMP4, DNAJC8, MFGE8, AGGF1, } \\
\text { HIST1H1B, ARFGEF2, CTSZ, MAPK1, } \\
\text { BYSL, GRIN2D, GOT1, DAP, GTF2F2, } \\
\text { AXIN1, LSM3, CEBPG, FZD2, HSP90AB1, } \\
\text { FXR2, ATF6, EPHA1, FAM20B, } \\
\text { CYB561D2, EIF4EBP2 }\end{array}$ \\
\hline
\end{tabular}




\begin{tabular}{|c|c|c|c|c|c|c|}
\hline GO:0007275 & $\begin{array}{l}\text { multicellular } \\
\text { organism } \\
\text { development }\end{array}$ & 0.000988858 & 23 & $0.00 \%$ & 0 & $\begin{array}{l}\text { MTM1, NAGLU, CDKN2B, MFGE8, } \\
\text { FRAT2, GPR4, AGGF1, CTSZ, MAPK1, } \\
\text { BYSL, EEF2, LGALS1, AXIN1, CEBPG, } \\
\text { CDK5, ID3, DCTN5, FZD2, HSP90AB1, } \\
\text { BCAR3, CTNNBIP1, ATF6, EPHA1 }\end{array}$ \\
\hline GO:0032501 & $\begin{array}{l}\text { multicellular } \\
\text { organismal } \\
\text { process }\end{array}$ & $1.21 \mathrm{E}-06$ & 33 & $0.00 \%$ & 0 & $\begin{array}{l}\text { LY96, GPR4, C4BPB, EEF2, MIF, CDK5, } \\
\text { ID3, BCAR3, LMAN1, CTNNBIP1, MTM1, } \\
\text { MYBPC2, NAGLU, CDKN2B, HERC4, } \\
\text { FRAT2, MFGE8, AGGF1, MR1, ARFGEF2, } \\
\text { CTSZ, BYSL, MAPK1, GRIN2D, LGALS1, } \\
\text { AXIN1, CEBPG, DCTN5, FZD2, } \\
\text { HSP90AB1, EPHA1, ATF6, EIF4EBP2 }\end{array}$ \\
\hline GO:0051704 & $\begin{array}{l}\text { multi-organism } \\
\text { process }\end{array}$ & 0.003807121 & 15 & $0.00 \%$ & 0 & $\begin{array}{l}\text { GBF1, KPNA4, LGALS1, HERC4, LY96, } \\
\text { MIF, GTF2F2, MFGE8, MR1, COX8A, } \\
\text { FXR2, HSP90AB1, MAPK1, BYSL, } \\
\text { EIF4EBP2 }\end{array}$ \\
\hline GO:0061061 & $\begin{array}{l}\text { muscle } \\
\text { structure } \\
\text { development }\end{array}$ & 0.00028054 & 9 & $0.00 \%$ & 0 & $\begin{array}{l}\text { MTM1, FLOT2, EEF2, LGALS1, AXIN1, } \\
\text { CDK5, CDH15, ID3, FZD2 }\end{array}$ \\
\hline GO:0048519 & $\begin{array}{l}\text { negative } \\
\text { regulation of } \\
\text { biological } \\
\text { process }\end{array}$ & $2.06 \mathrm{E}-06$ & 27 & $0.00 \%$ & 0 & $\begin{array}{l}\text { MTM1, FLOT2, DCBLD2, CDKN2B, LY96, } \\
\text { GPR4, KIFAP3, HIST1H1B, CCL23, } \\
\text { MAPK1, C4BPB, DAP, LGALS1, MIF, } \\
\text { AXIN1, LSM3, CEBPG, CDK5, HIST1H1D, } \\
\text { ID3, CD2BP2, HSP90AB1, FXR2, } \\
\text { MAPRE1, CTNNBIP1, EPHA1, EIF4EBP2 }\end{array}$ \\
\hline GO:0031324 & $\begin{array}{l}\text { negative } \\
\text { regulation of } \\
\text { cellular } \\
\text { metabolic } \\
\text { process }\end{array}$ & 0.00086878 & 16 & $0.00 \%$ & 0 & $\begin{array}{l}\text { MTM1, CDKN2B, HIST1H1B, C4BPB, } \\
\text { DAP, AXIN1, MIF, CDK5, HIST1H1D, } \\
\text { CD2BP2, ID3, FXR2, HSP90AB1, } \\
\text { CTNNBIP1, EPHA1, EIF4EBP2 }\end{array}$ \\
\hline GO:0048523 & $\begin{array}{l}\text { negative } \\
\text { regulation of } \\
\text { cellular process }\end{array}$ & 0.000152704 & 23 & $0.00 \%$ & 0 & $\begin{array}{l}\text { MTM1, DCBLD2, CDKN2B, LY96, KIFAP3, } \\
\text { HIST1H1B, CCL23, MAPK1, C4BPB, DAP, } \\
\text { LGALS1, MIF, AXIN1, CDK5, HIST1H1D, } \\
\text { ID3, CD2BP2, FXR2, HSP90AB1, } \\
\text { MAPRE1, CTNNBIP1, EPHA1, EIF4EBP2 }\end{array}$ \\
\hline GO:0010629 & $\begin{array}{l}\text { negative } \\
\text { regulation of } \\
\text { gene } \\
\text { expression }\end{array}$ & 0.001748952 & 13 & $0.00 \%$ & 0 & $\begin{array}{l}\text { FLOT2, DAP, MIF, AXIN1, LSM3, } \\
\text { HIST1H1D, CDK5, ID3, FXR2, HIST1H1B, } \\
\text { C4BPB, CTNNBIP1, EIF4EBP2 }\end{array}$ \\
\hline
\end{tabular}

\begin{tabular}{|c|c|c|c|c|c|c|}
\hline GO:0010605 & $\begin{array}{l}\text { negative } \\
\text { regulation of } \\
\text { macromolecule } \\
\text { metabolic } \\
\text { process }\end{array}$ & 0.000279927 & 17 & $0.00 \%$ & 0 & $\begin{array}{l}\text { MTM1, FLOT2, CDKN2B, HIST1H1B, } \\
\text { C4BPB, DAP, AXIN1, MIF, LSM3, CDK5, } \\
\text { HIST1H1D, ID3, FXR2, HSP90AB1, } \\
\text { CTNNBIP1, EPHA1, EIF4EBP2 }\end{array}$ \\
\hline GO:0009892 & $\begin{array}{l}\text { negative } \\
\text { regulation of } \\
\text { metabolic } \\
\text { process }\end{array}$ & 0.000168458 & 18 & $0.00 \%$ & 0 & $\begin{array}{l}\text { MTM1, FLOT2, CDKN2B, HIST1H1B, } \\
\text { C4BPB, DAP, AXIN1, MIF, LSM3, CDK5, } \\
\text { HIST1H1D, ID3, CD2BP2, FXR2, } \\
\text { HSP90AB1, CTNNBIP1, EPHA1, } \\
\text { EIF4EBP2 }\end{array}$ \\
\hline GO:0051172 & $\begin{array}{l}\text { negative } \\
\text { regulation of } \\
\text { nitrogen } \\
\text { compound } \\
\text { metabolic } \\
\text { process }\end{array}$ & 0.000411432 & 16 & $0.00 \%$ & 0 & $\begin{array}{l}\text { MTM1, FLOT2, DAP, CDKN2B, MIF, } \\
\text { AXIN1, HIST1H1D, CDK5, ID3, } \\
\text { HSP90AB1, FXR2, HIST1H1B, C4BPB, } \\
\text { CTNNBIP1, EPHA1, EIF4EBP2 }\end{array}$ \\
\hline GO:0006807 & $\begin{array}{l}\text { nitrogen } \\
\text { compound } \\
\text { metabolic } \\
\text { process }\end{array}$ & 0.000315375 & 47 & $0.00 \%$ & 0 & $\begin{array}{l}\text { NEDD8, C18orf25, COX8A, CCL23, } \\
\text { C4BPB, CYC1, COMMD4, EEF2, MIF, } \\
\text { MRPS12, HIST1H1D, CDK5, DDN, ID3, } \\
\text { CD2BP2, BCAR3, LMAN1, AHCTF1, } \\
\text { CTNNBIP1, H1F0, MTM1, FLOT2, NAGLU, } \\
\text { CDKN2B, HERC4, NDUFA1, IMP4, } \\
\text { DNAJC8, MFGE8, AGGF1, HIST1H1B, } \\
\text { CTSZ, MAPK1, BYSL, GRIN2D, GOT1, } \\
\text { DAP, AXIN1, GTF2F2, LSM3, CEBPG, } \\
\text { FZD2, HSP90AB1, FXR2, ATF6, EPHA1, } \\
\text { EIF4EBP2 }\end{array}$ \\
\hline GO:0071704 & $\begin{array}{l}\text { organic } \\
\text { substance } \\
\text { metabolic } \\
\text { process }\end{array}$ & 0.002140448 & 48 & $0.00 \%$ & 0 & $\begin{array}{l}\text { NEDD8, C18orf25, COX8A, CCL23, } \\
\text { C4BPB, CYC1, COMMD4, EEF2, MIF, } \\
\text { MRPS12, HIST1H1D, CDK5, DDN, ID3, } \\
\text { CD2BP2, BCAR3, LMAN1, CTNNBIP1, } \\
\text { AHCTF1, H1F0, MTM1, FLOT2, NAGLU, } \\
\text { HERC4, CDKN2B, NDUFA1, IMP4, } \\
\text { DNAJC8, MFGE8, AGGF1, HIST1H1B, } \\
\text { ARFGEF2, CTSZ, MAPK1, BYSL, } \\
\text { GRIN2D, GOT1, DAP, AXIN1, GTF2F2, } \\
\text { LSM3, CEBPG, FZD2, HSP90AB1, FXR2, } \\
\text { ATF6, EPHA1, EIF4EBP2 }\end{array}$ \\
\hline GO:1901564 & $\begin{array}{l}\text { organonitrogen } \\
\text { compound }\end{array}$ & 0.007895034 & 33 & $0.02 \%$ & 0.02 & $\begin{array}{l}\text { NEDD8, C18orf25, COX8A, CCL23, } \\
\text { C4BPB, CYC1, EEF2, MIF, MRPS12, }\end{array}$ \\
\hline
\end{tabular}




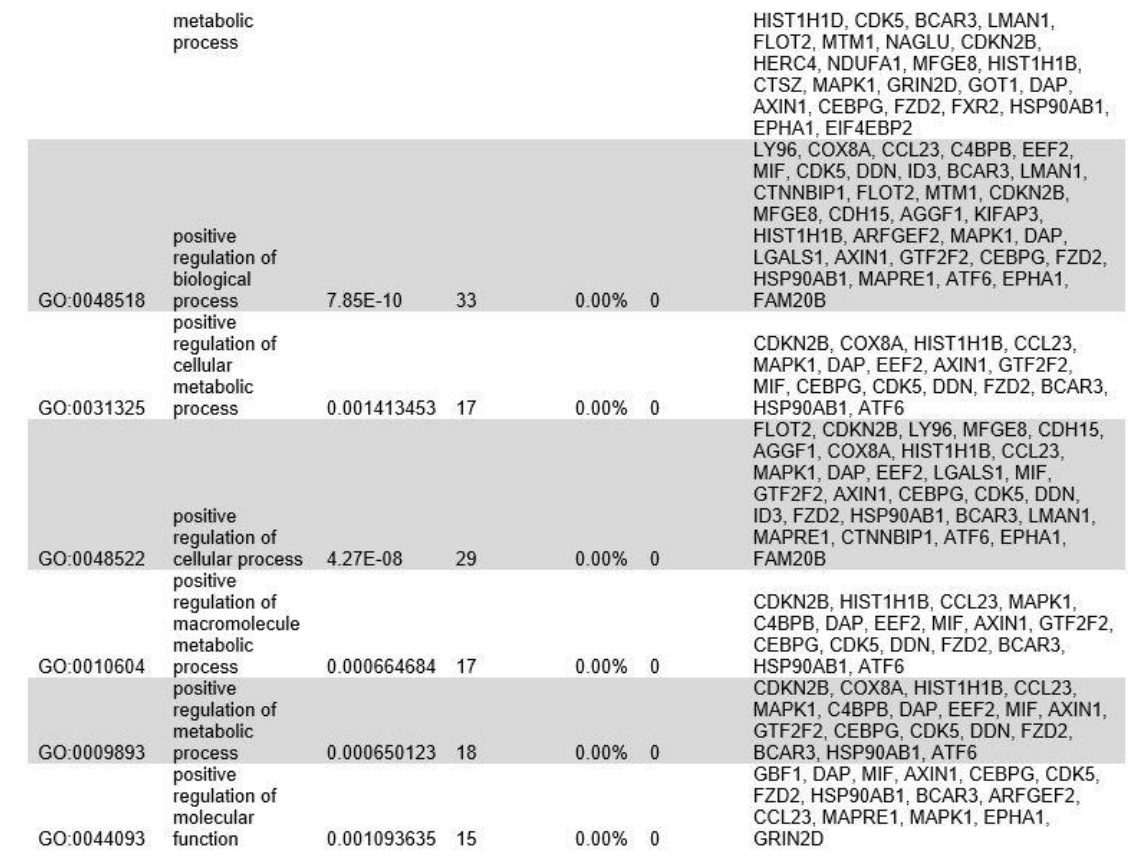

\begin{tabular}{|c|c|c|c|c|c|c|}
\hline GO:0051173 & $\begin{array}{l}\text { positive } \\
\text { regulation of } \\
\text { nitrogen } \\
\text { compound } \\
\text { metabolic } \\
\text { process }\end{array}$ & 0.000544576 & 17 & $0.00 \%$ & 0 & $\begin{array}{l}\text { CDKN2B, HIST1H1B, CCL23, MAPK1, } \\
\text { C4BPB, DAP, EEF2, MIF, AXIN1, GTF2F2, } \\
\text { CEBPG, CDK5, DDN, FZD2, BCAR3, } \\
\text { HSP90AB1, ATF6 }\end{array}$ \\
\hline GO:0010638 & $\begin{array}{l}\text { positive } \\
\text { regulation of } \\
\text { organelle } \\
\text { organization }\end{array}$ & 0.008993792 & 9 & $0.02 \%$ & 0.02 & $\begin{array}{l}\text { CDKN2B, CDK5, COX8A, HIST1H1B, } \\
\text { LMAN1, MAPK1, MAPRE1, EPHA1, } \\
\text { FAM20B }\end{array}$ \\
\hline GO:0051247 & $\begin{array}{l}\text { positive } \\
\text { regulation of } \\
\text { protein } \\
\text { metabolic } \\
\text { process }\end{array}$ & 0.002261232 & 12 & $0.00 \%$ & 0 & $\begin{array}{l}\text { EEF2, DAP, MIF, AXIN1, CEBPG, CDK5, } \\
\text { HSP90AB1, BCAR3, HIST1H1B, CCL23, } \\
\text { MAPK1, C4BPB }\end{array}$ \\
\hline & & & & & & $\begin{array}{l}\text { NEDD8, C18orf25, COX8A, CCL23, } \\
\text { C4BPB, CYC1, COMMD4, EEF2, MIF, } \\
\text { MRPS12, HIST1H1D, CDK5, DDN, ID3, } \\
\text { CD2BP2, BCAR3, LMAN1, AHCTF1, } \\
\text { CTNNBIP1, H1F0, MTM1, FLOT2, } \\
\text { CDKN2B, HERC4, NDUFA1, IMP4, } \\
\text { DNAJC8, MFGE8, AGGF1, HIST1H1B, } \\
\text { CTSZ, MAPK1, BYSL, GRIN2D, GOT1, }\end{array}$ \\
\hline GO:0044238 & $\begin{array}{l}\text { primary } \\
\text { metabolic } \\
\text { process }\end{array}$ & 0.006764705 & 46 & $0.02 \%$ & 0.02 & $\begin{array}{l}\text { DAP, AXIN1, GTF2 22, LSM3, CEBPG, } \\
\text { FZD2, HSP90AB1, FXR2, ATF6, EPHA1, } \\
\text { EIF4EBP2 }\end{array}$ \\
\hline GO:0071822 & $\begin{array}{l}\text { protein complex } \\
\text { subunit } \\
\text { organization }\end{array}$ & 0.002568001 & 13 & $0.00 \%$ & 0 & $\begin{array}{l}\text { NDUFA1, MIF, GTF2F2, AXIN1, FRAT2, } \\
\text { MRPS12, FZD2, KIFAP3, LMAN1, CTSZ, } \\
\text { MAPRE1, AHCTF1, CTNNBIP1 }\end{array}$ \\
\hline GO:0008104 & $\begin{array}{l}\text { protein } \\
\text { localization }\end{array}$ & 0.008115101 & 16 & $0.02 \%$ & 0.02 & $\begin{array}{l}\text { GBF1, MTM1, FLOT2, KPNA4, NEDD8, } \\
\text { MIF, AXIN1, CDK5, KIFAP3, HSP90AB1, } \\
\text { HIST1H1B, ARFGEF2, MAPRE1, MAPK1, } \\
\text { AHCTF1, FAM20B }\end{array}$ \\
\hline GO:0051098 & $\begin{array}{l}\text { regulation of } \\
\text { binding }\end{array}$ & 0.003677534 & 6 & $0.00 \%$ & 0 & $\begin{array}{l}\text { HSP90AB1, CCL23, MAPRE1, CTNNBIP1, } \\
\text { CEBPG, CDK5 }\end{array}$ \\
\hline GO:0050789 & $\begin{array}{l}\text { regulation of } \\
\text { biological } \\
\text { process }\end{array}$ & 3.13E-08 & 52 & $0.00 \%$ & 0 & $\begin{array}{l}\text { DCBLD2, NEDD8, LY96, GPR4, COX8A, } \\
\text { CCL23, BCL7B, C4BPB, COMMD4, EEF2, } \\
\text { MIF, HIST1H1D, GABRD, CDK5, DDN, } \\
\text { ID3, CD2BP2, BCAR3, LMAN1, } \\
\text { CTNNBIP1, AHCTF1, GBF1, MTM1, }\end{array}$ \\
\hline
\end{tabular}




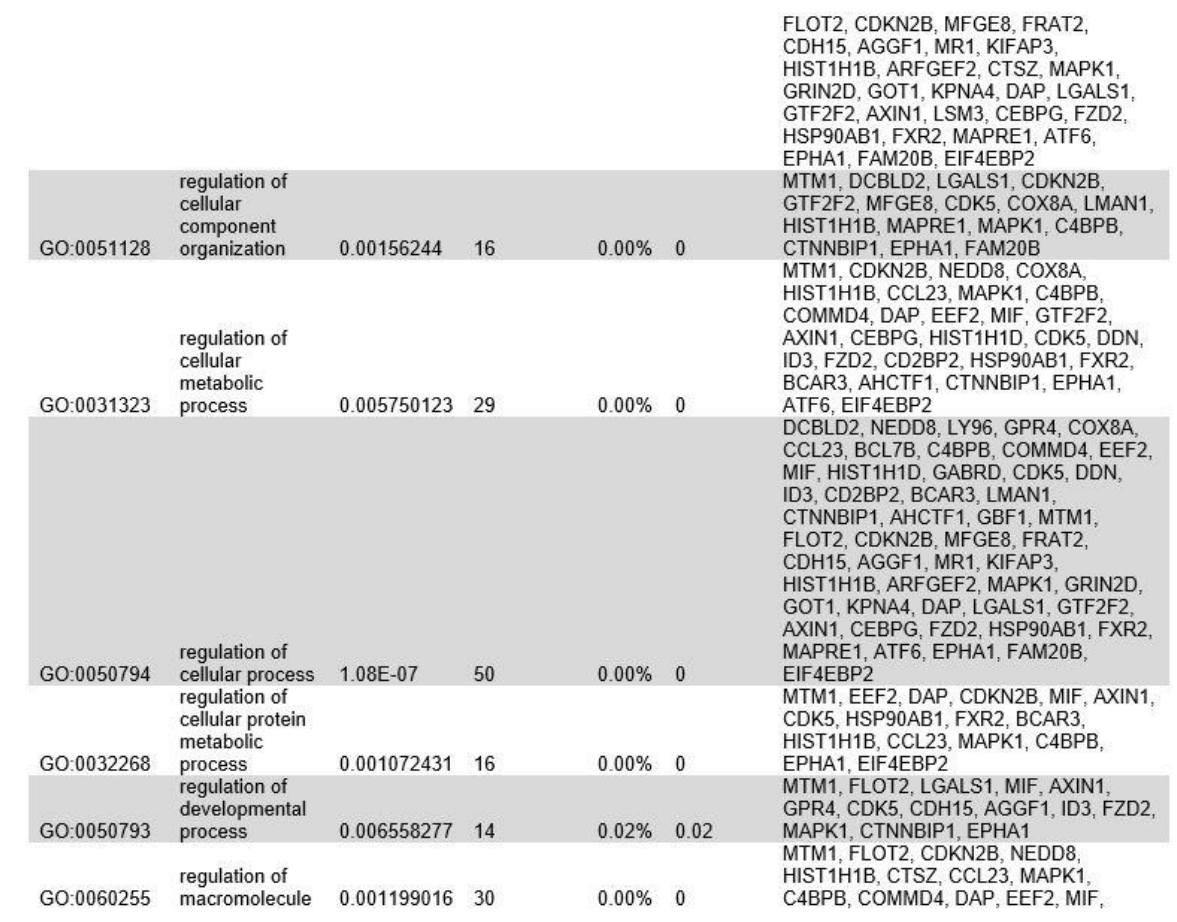

metabolic GTF2F2, AXIN1, LSM3, CEBPG,

process HIST1H1D, CDK5, DDN, ID3, FZD2,

HSP90AB1, FXR2, BCAR3, AHCTF1, CTNNBIP1, ATF6, EPHA1, EIF4EBP2 NEDD8, COX8A, CCL23, C4BPB, COMMD4, EEF2, MIF, HIST1H1D, CDK DDN, ID3, CD2BP2, BCAR3, AHCTF1 CTNAP, FLOT2, MTM1, CDKN2B, HIST1H1B, CTSZ, MAPK1, DAP, AXIN1

regulation of metabolic 0.00042805232 $0.00 \%$ regulation of molecular GO:0065009 function $0.000832051 \quad 19$ $0.00 \% \quad 0$

regulation of nitrogen compound metabolic

GO:0051171 process GTF2F2, CEBPG, LSM3, FZD2, FXR2 HSP90AB1, ATF6, EPHA1, EIF4EBP GBF1, CDKN2B, ARFGEF2, CCL23, MAPK1, GRIN2D, DAP, MIF, AXIN1, CEBPG, CDK5, ID3, CD2BP2, FZD2, BCAR3, HSP90AB1, MAPRE1, CTNNBIP1, EPHA1 MTM1, FLOT2, CDKN2B, NEDD8, HIST1H1B, CTSZ, CCL23, MAPK1 C4BPB, COMMD4, DAP, EEF2, MIF GTF2F2, AXIN1, CEBPG, HIST1H1D, CDK5 DDN ID3 FZD2 HSP90AB1 FXR2 BCAR3 AHCTF1 CTNNBIP1 ATF6, EPHA1, EIF4EBP2 MTM1, FLOT2, CDKN2B, NEDD8 MTM1, FLOT2, CDKN2B, NEDD8,
HIST1H1B, CTSZ, CCL23, MAPK1, C4BPB, COMMD4, DAP, EEF2, MIF, GTF2F2, AXIN1, CEBPG, HIST1H1D CDK5, DDN, ID3, FZD2, HSP90AB1, FXR2, BCAR3, AHCTF1, CTNNBIP1

regulation of primary

metabolic

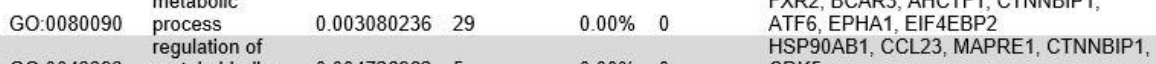
GO:0043393 protein binding $0.004726962 \quad 5 \quad 0.00 \% \quad 0 \quad 0 \quad$ CDK5 regulation of protein metabolic

GO:0051246 process 1.54E-05 19 $0.00 \% \quad 0$ MTM1, FLOT2, CDKN2B, HIST1H1B, CCL23, CTSZ, MAPK1, C4BPB, DAP EEF2, MIF, AXIN1, CEBPG, CDK5, BCAR3, FXR2, HSP90AB1, EPHA1, EIF4EBP2

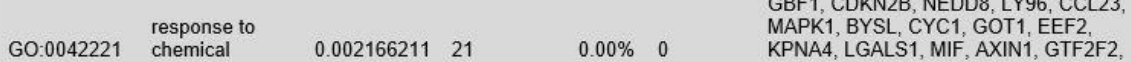




\begin{tabular}{|c|c|c|c|c|c|c|}
\hline & & & & & & $\begin{array}{l}\text { CDK5, ID3, BCAR3, HSP90AB1, ATF6, } \\
\text { EIF4EBP2 }\end{array}$ \\
\hline GO:0009605 & $\begin{array}{l}\text { response to } \\
\text { external } \\
\text { stimulus }\end{array}$ & 0.001245943 & 15 & $0.00 \%$ & 0 & $\begin{array}{l}\text { GBF1, EEF2, DAP, CDKN2B, LY96, MIF, } \\
\text { CDK5, MR1, FXR2, COX8A, CCL23, } \\
\text { MAPK1, BYSL, C4BPB, GRIN2D }\end{array}$ \\
\hline GO:0014070 & $\begin{array}{l}\text { response to } \\
\text { organic cyclic } \\
\text { compound }\end{array}$ & 0.002874616 & 10 & $0.00 \%$ & 0 & $\begin{array}{l}\text { GOT1, EEF2, LGALS1, NEDD8, AXIN1, } \\
\text { CDK5, ID3, HSP90AB1, BYSL, MAPK1 }\end{array}$ \\
\hline GO:0010033 & $\begin{array}{l}\text { response to } \\
\text { organic } \\
\text { substance }\end{array}$ & 0.000605808 & 18 & $0.00 \%$ & 0 & $\begin{array}{l}\text { CDKN2B, NEDD8, LY96, CCL23, MAPK1, } \\
\text { BYSL, CYC1, GOT1, EEF2, LGALS1, } \\
\text { AXIN1, GTF2F2, MIF, CDK5, ID3, } \\
\text { HSP90AB1, ATF6, EIF4EBP2 }\end{array}$ \\
\hline GO: 1901700 & $\begin{array}{l}\text { response to } \\
\text { oxygen- } \\
\text { containing } \\
\text { compound }\end{array}$ & 0.002276073 & 12 & $0.00 \%$ & 0 & $\begin{array}{l}\text { GOT1, KPNA4, EEF2, LGALS1, LY96, } \\
\text { MIF, CDK5, ID3, BYSL, MAPK1, CYC1, } \\
\text { EIF4EBP2 }\end{array}$ \\
\hline GO:0050896 & $\begin{array}{l}\text { response to } \\
\text { stimulus }\end{array}$ & $3.43 \mathrm{E}-06$ & 41 & $0.00 \%$ & 0 & $\begin{array}{l}\text { DCBLD2, NEDD8, LY96, GPR4, COX8A, } \\
\text { BCL7B, CCL23, C4BPB, CYC1, EEF2, } \\
\text { MIF, GABRD, CDK5, ID3, BCAR3, LMAN1, } \\
\text { CTNNBIP1, GBF1, MTM1, CDKN2B, } \\
\text { MFGE8, FRAT2, MR1, KIFAP3, ARFGEF2, } \\
\text { BYSL, MAPK1, GRIN2D, GOT1, DAP, } \\
\text { KPNA4, LGALS1, AXIN1, GTF2F2, } \\
\text { CEBPG, FZD2, FXR2, HSP90AB1, ATF6, } \\
\text { EPHA1, EIF4EBP2 }\end{array}$ \\
\hline GO:0006950 & $\begin{array}{l}\text { response to } \\
\text { stress }\end{array}$ & 0.000241022 & 22 & $0.00 \%$ & 0 & $\begin{array}{l}\text { DCBLD2, LY96, GPR4, MR1, COX8A, } \\
\text { CCL23, MAPK1, C4BPB, DAP, EEF2, } \\
\text { KPNA4, LGALS1, MIF, AXIN1, CEBPG, } \\
\text { CDK5, ID3, FXR2, HSP90AB1, LMAN1, } \\
\text { CTNNBIP1, ATF6 }\end{array}$ \\
\hline GO:0009611 & $\begin{array}{l}\text { response to } \\
\text { wounding }\end{array}$ & 0.006154923 & 8 & $0.03 \%$ & 0.02 & $\begin{array}{l}\text { ID3, DCBLD2, LMAN1, LGALS1, MAPK1, } \\
\text { C4BPB, GPR4, CDK5 }\end{array}$ \\
\hline GO:0007165 & $\begin{array}{l}\text { signal } \\
\text { transduction }\end{array}$ & 0.000690034 & 30 & $0.00 \%$ & 0 & $\begin{array}{l}\text { GBF1, MTM1, DCBLD2, CDKN2B, } \\
\text { NEDD8, LY96, FRAT2, GPR4, MR1, } \\
\text { KIFAP3, ARFGEF2, BCL7B, CCL23, } \\
\text { MAPK1, GRIN2D, GOT1, DAP, LGALS1, } \\
\text { MIF, GTF2F2, AXIN1, CDK5, GABRD, } \\
\text { FZD2, HSP90AB1, BCAR3, CTNNBIP1, } \\
\text { ATF6, EPHA1, EIF4EBP2 }\end{array}$ \\
\hline
\end{tabular}

\begin{tabular}{|c|c|c|c|c|c|c|}
\hline GO:0023052 & signaling & 0.000880782 & 31 & $0.00 \%$ & 0 & $\begin{array}{l}\text { GBF1, MTM1, FLOT2, DCBLD2, CDKN2B, } \\
\text { NEDD8, LY96, FRAT2, GPR4, MR1, } \\
\text { KIFAP3, ARFGEF2, BCL7B, CCL23, } \\
\text { MAPK1, GRIN2D, GOT1, DAP, LGALS1, } \\
\text { MIF, GTF2F2, AXIN1, CDK5, GABRD, } \\
\text { FZD2, HSP90AB1, BCAR3, CTNNBIP1, } \\
\text { ATF6, EPHA1, EIF4EBP2 }\end{array}$ \\
\hline GO:0044700 & $\begin{array}{l}\text { single organism } \\
\text { signaling }\end{array}$ & 0.000814049 & 31 & $0.00 \%$ & 0 & $\begin{array}{l}\text { GBF1, MTM1, FLOT2, DCBLD2, CDKN2B, } \\
\text { NEDD8, LY96, FRAT2, GPR4, MR1, } \\
\text { KIFAP3, ARFGEF2, BCL7B, CCL23, } \\
\text { MAPK1, GRIN2D, GOT1, DAP, LGALS1, } \\
\text { MIF, GTF2F2, AXIN1, CDK5, GABRD, } \\
\text { FZD2, HSP90AB1, BCAR3, CTNNBIP1, } \\
\text { ATF6, EPHA1, EIF4EBP2 }\end{array}$ \\
\hline GO:0044707 & $\begin{array}{l}\text { single- } \\
\text { multicellular } \\
\text { organism } \\
\text { process }\end{array}$ & $2.90 \mathrm{E}-07$ & 31 & $0.00 \%$ & 0 & $\begin{array}{l}\text { MTM1, NAGLU, CDKN2B, LY96, MFGE8, } \\
\text { FRAT2, GPR4, AGGF1, MR1, CTSZ, } \\
\text { ARFGEF2, MAPK1, BYSL, C4BPB, } \\
\text { GRIN2D, EEF2, LGALS1, MIF, AXIN1, } \\
\text { CEBPG, CDK5, ID3, FZD2, DCTN5, } \\
\text { HSP90AB1, BCAR3, LMAN1, CTNNBIP1, } \\
\text { ATF6, EPHA1, EIF4EBP2 }\end{array}$ \\
\hline GO:0044763 & $\begin{array}{l}\text { single-organism } \\
\text { cellular process }\end{array}$ & 4.72E-07 & 46 & $0.00 \%$ & 0 & $\begin{array}{l}\text { DCBLD2, LY96, GPR4, COX8A, BCL7B, } \\
\text { CCL23, CYC1, EEF2, MIF, MRPS12, } \\
\text { GABRD, CDK5, ID3, LMAN1, AHCTF1, } \\
\text { CTNNBIP1, H1F0, GBF1, MYBPC2, } \\
\text { MTM1, FLOT2, NAGLU, CDKN2B, } \\
\text { HERC4, NDUFA1, MFGE8, FRAT2, } \\
\text { CDH15, AGGF1, KIFAP3, HIST1H1B, } \\
\text { ARFGEF2, CTSZ, BYSL, MAPK1, } \\
\text { GRIN2D, GOT1, DAP, LGALS1, AXIN1, } \\
\text { CEBPG, FZD2, HSP90AB1, MAPRE1, } \\
\text { EPHA1, EIF4EBP2 }\end{array}$ \\
\hline GO:0044767 & $\begin{array}{l}\text { single-organism } \\
\text { developmental } \\
\text { process }\end{array}$ & 1.50E-05 & 28 & $0.00 \%$ & 0 & $\begin{array}{l}\text { MTM1, FLOT2, NAGLU, HERC4, } \\
\text { CDKN2B, MFGE8, FRAT2, GPR4, CDH15, } \\
\text { AGGF1, CTSZ, BCL7B, MAPK1, BYSL, } \\
\text { EEF2, LGALS1, MIF, AXIN1, CEBPG, } \\
\text { CDK5, ID3, FZD2, DCTN5, HSP90AB1, } \\
\text { BCAR3, CTNNBIP1, ATF6, EPHA1 }\end{array}$ \\
\hline GO:0044699 & $\begin{array}{l}\text { single-organism } \\
\text { process }\end{array}$ & $1.81 \mathrm{E}-06$ & 55 & $0.00 \%$ & 0 & $\begin{array}{l}\text { DCBLD2, NEDD8, LY96, GPR4, COX8A, } \\
\text { CCL23, BCL7B, C4BPB, CYC1, EEF2, }\end{array}$ \\
\hline
\end{tabular}




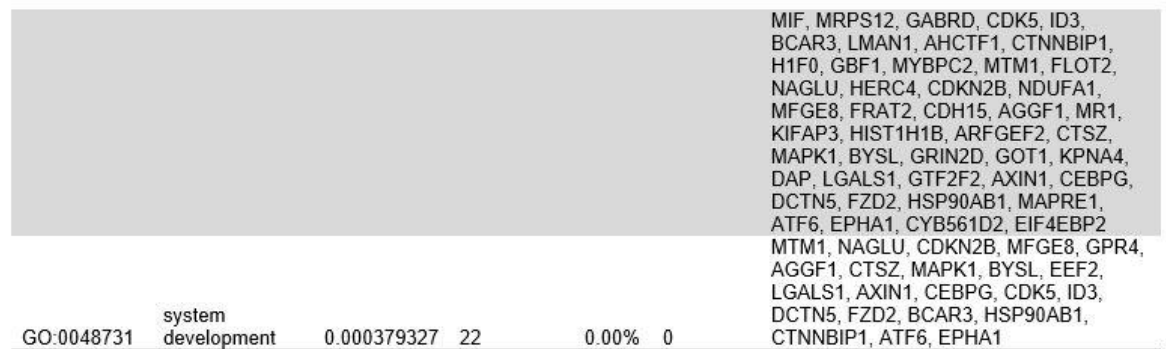

Table 4.9 Biological processes that ID3 \& ID3 candidate target genes in tissue.

\section{ID3 \& ID3 gene-associated signaling pathways}

ID3 and ID3 candidate target genes in blood. In order to understand the potential relationships among the genes in the most over-represented processes STRING, a database of predicted \& identified protein-protein interactions was used to show direct (physical) and indirect (functional) associations. ID3 \& ID3 candidate target genes in blood (134) was matched to the database and generated network maps for the genes involved in over-represented processes. We show that ID3 and ID3 candidate target genes in blood are involved in 5 pathways (Arrhythmogenic right ventricular-cardiomyopathy, Neuro-active ligand-receptor interaction, focal adhesion, ECM-receptor interaction, \& hypertrophic cardiomyopathy as shown in Table 4.10 Interestingly two of the pathways represented ID3 as matching proteins. Focal adhesion pathway includes proteins: ACTN1, COL1A2, COL3A1, COL6A1, CTNNB1, IBSP, ID3, ITGA8, and MYL2. ECM-receptor interaction includes proteins: COL1A2, COL3A1, COL6A1, IBSP, ID3, and ITGA8. Figure 4.7.1 and 4.7.2 demonstrate both networks. Furthermore we also represented the biological 
processes these genes (134) are signified as seen in Table 4.11. Overall 119 biological processes are over-represented via ID3 \& ID3 candidate genes in blood.

\begin{tabular}{|c|c|c|c|c|}
\hline Pathway ID & Pathway Description & $\begin{array}{l}\text { Gene } \\
\text { Count }\end{array}$ & $\begin{array}{l}\text { False } \\
\text { Discovery } \\
\text { Rate }\end{array}$ & Matching proteins in your network \\
\hline 5412 & $\begin{array}{l}\text { Arrhythmogenic right ventricular } \\
\text { cardiomyopathy (ARVC) }\end{array}$ & 6 & 0.00241 & \multirow{3}{*}{$\begin{array}{l}\text { ACTN1, CACNB4, CACNG3, CDH2, CTNNB1, ITGA8 } \\
\text { AGTR2, AVPR2, DRD1, GABRA2, GLRA1, GRIA2, } \\
\text { GRIK5, GRIN2B, HTR4 } \\
\text { ACTN1, COL1A2, COL3A1, COL6A1, CTNNB1, IBSP, ID3, } \\
\text { ITGA8, MYL2 }\end{array}$} \\
\hline 4080 & $\begin{array}{l}\text { Neuroactive ligand-receptor } \\
\text { interaction }\end{array}$ & 9 & 0.00686 & \\
\hline 4510 & Focal adhesion & 9 & 0.00686 & \\
\hline 4512 & $\begin{array}{l}\text { Extracellular matrix-receptor } \\
\text { interaction }\end{array}$ & 6 & 0.0138 & COL1A2, COL3A1, COL6A1, IBSP, ID3, ITGA8 \\
\hline 5410 & $\begin{array}{l}\text { Hypertrophic cardiomyopathy } \\
\text { (HCM) }\end{array}$ & 5 & 0.0138 & CACNB4, CACNG3, IL6, ITGA8, MYL2 \\
\hline
\end{tabular}

Table 4.10 Demonstrated pathways of ID3 and ID3 candidate targets genes in blood. 


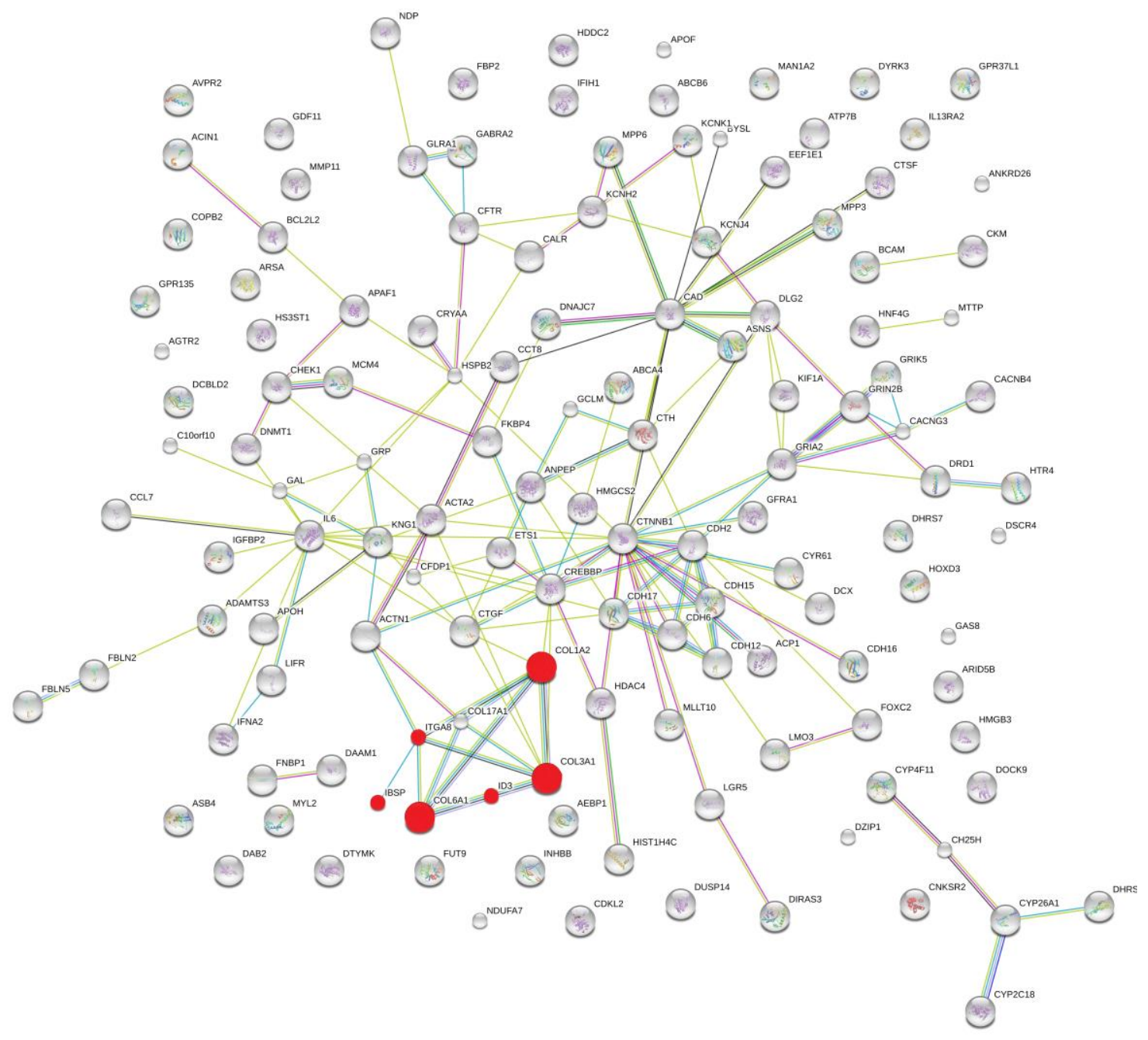

Figure 4.6.1 Network demonstrated from STRING database of ID3-involved pathway in Extra Cellular Matrix Receptor (ECM) interaction. Genes (6) highlighted in red are involved in the pathway: COL1A2, COL3A1, COL6A1, IBSP, ID3, and ITGAB 


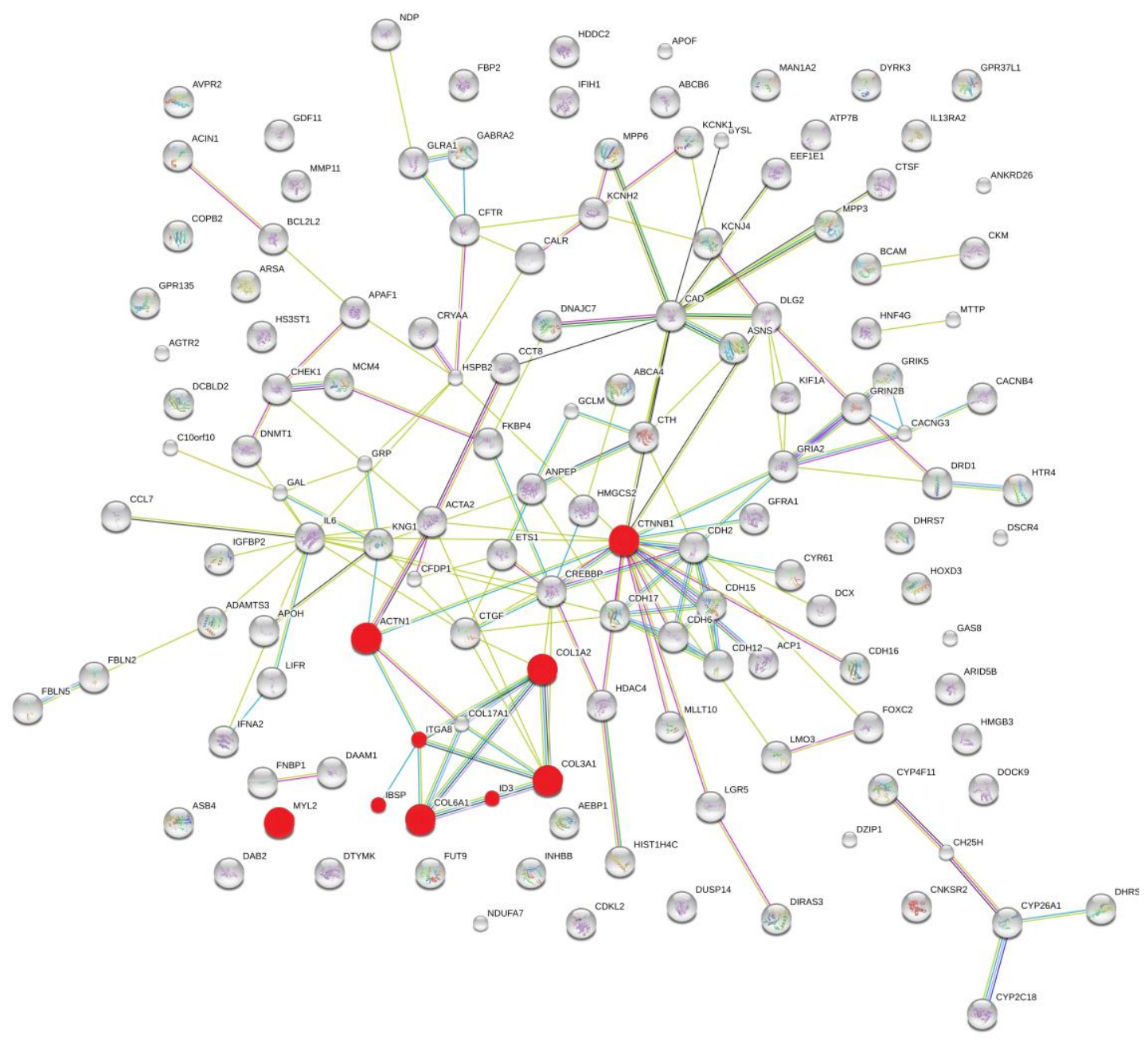

Figure 4.6.2 Network demonstrated from STRING database of ID3-involved pathway in focal adhesion. Genes (9) highlighted in red are involved in the pathway: ACTN1, COL6A1, COL6A2, COL3A1, CTNNB1, IBSP, ID3, ITGAB, and MYL2. 


\begin{tabular}{|c|c|c|c|c|}
\hline Pathway ID & Pathway Description & $\begin{array}{l}\text { Gene } \\
\text { Count }\end{array}$ & $\begin{array}{l}\text { False } \\
\text { Discovery } \\
\text { Rate }\end{array}$ & Matching Proteins in the Network \\
\hline GO.0034332 & $\begin{array}{l}\text { adherens junction } \\
\text { organization }\end{array}$ & 7 & 0.000433 & ACTN1,CDH12,CDH15,CDH17,CDH2,CDH6,CTNNB1 \\
\hline GO.0048856 & $\begin{array}{l}\text { anatomical structure } \\
\text { development }\end{array}$ & 45 & 0.00335 & $\begin{array}{l}\text { ABCB6,ACIN1,ACTA2,ACTN1,AEBP1,AGTR2,ANPEP,APOH,ASNS,ATP7B, } \\
\text { AVPR2,BCL2L2,BYSL,CAD,CALR,CDH15,CFTR,COL17A1, COL1A2, } \\
\text { COL6A1,CREBBP,CTNNB1,CYR61,DAB2,DHRS3,DLG2,DRD1,DTYMK, } \\
\text { DZIP1,ETS1,FOXC2,FUT9, GAL, GFRA1, GPR37L1,HMGCS2,HNF4G,IBSP,I } \\
\text { D3,IFNA2,IL6,LGR5LIFR,MAN1A2,MYL2 }\end{array}$ \\
\hline GO.0009653 & $\begin{array}{l}\text { anatomical structure } \\
\text { morphogenesis }\end{array}$ & 27 & 0.0147 & $\begin{array}{l}\text { ACTA2,ACTN1,AGTR2,ANPEP,APAF1,ARID5B,BYSL,CACNB4,CDH2,COL } \\
\text { 1A2COL6A1,CREBBP,CTGF,CTNNB1,CYR61,DHRS3,DZIP1,ETS1, GDF11, } \\
\text { GFRA1GRIN2B,ID3,IL6,LGR5,LIFR,MYL2,NDP }\end{array}$ \\
\hline GO.0008015 & blood circulation & 10 & 0.00335 & ACTA2,AGTR2,ANPEP,COL1A2,DRD1,FOXC2,GCLM,KCNH2,KNG1,MYL2 \\
\hline GO.0072358 & $\begin{array}{l}\text { cardiovascular system } \\
\text { development }\end{array}$ & 16 & 0.00533 & $\begin{array}{l}\text { ACTA2,AGTR2,ANPEP,CAD,CALR,CDH2,COL1A2,CTGF,CTNNB1,CYR61, } \\
\text { DHRS3,ETS1,FOXC2,ID3,MYL2,NDP }\end{array}$ \\
\hline G0.0007155 & cell adhesion & 17 & 0.0326 & $\begin{array}{l}\text { ACTN1,BCAM,BYSL,CDH12,CDH17,CFDP1, COL17A1,COL3A1,COL6A1,C } \\
\text { TNNB1, FBLN5, HOXD3,IBSP,ID3,IFNA2,IL6,ITGA8 }\end{array}$ \\
\hline GO.0007154 & cell communication & 53 & 0.00156 & 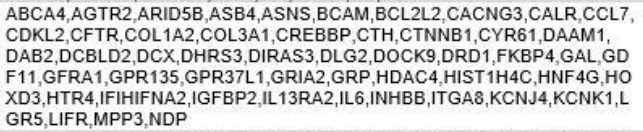 \\
\hline GO.0048468 & cell development & 22 & 0.0305 & $\begin{array}{l}\text { ACTA2,ACTN1,AGTR2,ARID5B,CDH2,CFTR,COL3A1,COL6A1,CREBBP,C } \\
\text { TNNB1,CYR61, } \\
\text { DRD1,DZIP1,FOXC2,GFRA1,GRIN2B,HDAC4,IL6,ITGA8,LGR5,LIFR,MYL2 }\end{array}$ \\
\hline G0.0030154 & cell differentiation & 34 & 0.0301 & $\begin{array}{l}\text { ACIN1,ACTA2,ACTN1,AGTR2,ANPEP,APAF1,ARID5B,BYSL,CALR,CDH15, } \\
\text { CFTR,COL3A1, } \\
\text { COL6A1,CREBBP,CTGF,CTNNB1,CYR61,DAB2,DRD1,DTYMK,DZIP1,ETS } \\
\text { 1,FKBP4,GFRA1, } \\
\text { GPR37L1,GRIN2B,HOXD3,IBSP,ID3,IFNA2,IL6,LGR5,LIFR,MYL2 }\end{array}$ \\
\hline GO.0034329 & cell junction assembly & 8 & 0.00283 & ACTN1,CDH12,CDH15,CDH17,CDH2,CDH6,COL17A1,CTNNB1 \\
\hline GO.0008283 & cell proliferation & 13 & 0.0329 & $\begin{array}{l}\text { BCL2L2,BYSL,CREBBP,CTGF, CTNNB1, CYR61,DAB2, DTYMK,FOXC2,IFN } \\
\text { A2,IL6,LGR5,NDP }\end{array}$ \\
\hline GO.0007267 & cell-cell signaling & 19 & 0.0015 & $\begin{array}{l}\text { AGTR2,CACNG3,CCL7,CTGF,CTNNB1, CYR61,DLG2,DRD1,GABRA2,GAL, } \\
\text { GLRA1,GRIA2,HTR4,IFNA2,IL6,KCNH2,KCNJ4,KCNK1,NDP }\end{array}$ \\
\hline GO.0007160 & cell-matrix adhesion & 10 & 0.000131 & $\begin{array}{l}\text { ACTN1,BCAM, COL17A1, COL3A1,CTGF, CTNNB1, FBLN5,HOXD3,ID3,ITGA } \\
8\end{array}$ \\
\hline Go.0016043 & $\begin{array}{l}\text { cellular component } \\
\text { organization }\end{array}$ & 50 & 0.00226 & $\begin{array}{l}\text { ABCA } 4, \text { ACIN1,ADAMTS3,APAF1,ARID5B,CACNB4,CALR,CCL } 7, \text { CCT } 8, C D H \\
12, \mathrm{CDH} 15 \text {, } \\
\text { CDH17,CDH6,CHEK1,COL17A1,COL3A1,COL6A1,COPB2,CREBBP,CRYA } \\
\text { A,CTGF,CTH, }\end{array}$ \\
\hline
\end{tabular}

\begin{tabular}{|c|c|c|c|c|}
\hline GO. 0071840 & $\begin{array}{l}\text { cellular component } \\
\text { organization or } \\
\text { biogenesis }\end{array}$ & 51 & 0.00205 & $\begin{array}{l}\text { CTNNB1,CYR61,DAAM1,DAB2,DLG2,DNMT1,DRD1,DZIP1,ETS1,FBLN2,F } \\
\text { BLN5, } \\
\text { FKBP4,FOXC2,GCLM,GFRA1,GRIK5,GRIN2B,HDAC4,HIST1H4C,HMGB3,I } \\
\text { BSP,IL6, } \\
\text { LIFR,MCM4,MPP6,MYL2,NDP,NDUFA7 } \\
\text { ABCA4,ACIN1,ADAMTS3,APAF1,ARID5B,BYSL,CACNB4,CALR,CCL7,CCT } \\
\text { 8,CDH12, } \\
\text { CDH15,CDH17,CDH6,CHEK1,COL17A1,COL3A1,COL6A1,COPB2,CREBB } \\
\text { P,CRYAA,CTGF,CTH, } \\
\text { CTNNB1,CYR61,DAAM1,DAB2,DLG2,DNMT1,DRD1,DZIP1,ETS1,FBLN2,F } \\
\text { BLN5,FKBP4, } \\
\text { FOXC2,GCLM,GFRA1,GRIK5,GRIN2B,HDAC4,HIST1H4C,HMGB3,IBSP,IL6 } \\
\text {,LIFR,MCM4, } \\
\text { MPP6,MYL2,NDP,NDUFA7 }\end{array}$ \\
\hline GO.0071230 & $\begin{array}{l}\text { cellular response to } \\
\text { amino acid stimulus }\end{array}$ & 5 & 0.00398 & COL1A2,COL3A1,COL6A1,DNMT1,HMGCS2 \\
\hline GO.0070887 & $\begin{array}{l}\text { cellular response to } \\
\text { chemical stimulus }\end{array}$ & 32 & 0.0015 & $\begin{array}{l}\text { AGTR2,APAF1,AVPR2, BYSL,CAD,CFTR, COL6A1,CREBBP,CTGF, CTH,CT } \\
\text { NNB1,CYP26A1,CYP2C18,CYP4F11,DNMT1,DRD1,DTYMK,ETS1,FOXC2, } \\
\text { GCLM,GFRA1,GRIK5,HDAC4, } \\
\text { HMGCS2,HNF4G,IBSP,IFNA2,IGFBP2,IL13RA2,IL6,KCNH2,LIFR }\end{array}$ \\
\hline GO.0071495 & $\begin{array}{l}\text { cellular response to } \\
\text { endogenous stimulus }\end{array}$ & 16 & 0.0448 & $\begin{array}{l}\text { AGTR2,ASNS,AVPR2, CAD,CFTR, COL6A1, CTGF, CTNNB1,DNMT1,DRD1,F } \\
\text { OXC2,HDAC4, } \\
\text { HMGCS } 2 \text {,HNF4G,IGFBP2,IL6 }\end{array}$ \\
\hline GO. 0071310 & $\begin{array}{l}\text { cellular response to } \\
\text { organic substance }\end{array}$ & 27 & 0.00335 & $\begin{array}{l}\text { AGTR2,APAF1,AVPR2,BYSL,CAD,CALR,CCL7,CFTR,COL6A1,CTGF,CTH, } \\
\text { CTNNB1,DNMT1,DRD1,DTYMK,FOXC2,GFRA1, GRIK5,HDAC4,HMGCS2,H } \\
\text { NF4G,IBSP,IFNA2,IGFBP2,IL13RA2,IL6,LIFR }\end{array}$ \\
\hline GO. 1901701 & $\begin{array}{l}\text { cellular response to } \\
\text { oxygen-containing } \\
\text { compound }\end{array}$ & 16 & 0.0057 & $\begin{array}{l}\text { AGTR2,BYSL,CCL7,CFTR,COL1A2,COL3A1,COL6A1,CTNNB1,DNMT1, } \\
\text { DRD1,ETS1,FOXC2,GRIK5, HMGCS2,IL6,INHBB }\end{array}$ \\
\hline GO. 0051716 & $\begin{array}{l}\text { cellular response to } \\
\text { stimulus }\end{array}$ & 63 & 0.000131 & 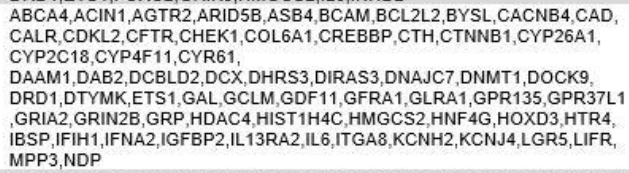 \\
\hline GO.0072359 & $\begin{array}{l}\text { circulatory system } \\
\text { development }\end{array}$ & 16 & 0.00533 & $\begin{array}{l}\text { ACTA2,AGTR2,ANPEP,CAD, CALR,CDH2,COL1A2,CTGF,CTNNB1, CYR61, } \\
\text { DHRS } 3 \text {,ETS1,FOXC2,ID } 3 \text {,MYL2,NDP }\end{array}$ \\
\hline GO.0030574 & $\begin{array}{l}\text { collagen catabolic } \\
\text { process }\end{array}$ & 6 & 0.00226 & ADAMTS3,COL17A1,COL1A2,COL3A1,COL6A1,MMP11 \\
\hline GO.0030199 & $\begin{array}{l}\text { collagen fibril } \\
\text { organization }\end{array}$ & 5 & 0.00197 & ADAMTS3,COL1A2,COL3A1,FOXC2,MMP11 \\
\hline
\end{tabular}


ABCB6,ACIN1,ACTA2,ACTN1, AEBP1,AGTR2,ANPEP,APOH,ASNS,ATP7B,

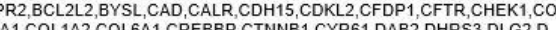
RD1,

\begin{tabular}{|c|c|c|c|c|}
\hline GO.0032502 & developmental process & 49 & 0.00335 & $\begin{array}{l}\text { DTYMK,DZIP1,FOXC2,FUT9, GAL, GFRA1,GPR37L1,HMGB3,HMGCS2, } \\
\text { HNF4G,IBSP,IFNA2,IGFBP2,IL6,LGR5,LIFR,MAN1A2,MMP11,MYL2 }\end{array}$ \\
\hline GO.0030198 & $\begin{array}{l}\text { extracellular matrix } \\
\text { organization }\end{array}$ & 14 & 0.000433 & $\begin{array}{l}\text { ACTN1,ADAMTS3,COL17A1, COL } 1 \text { A2, COL3A1,COL6A1,CTGF, CYR61,FBL } \\
\text { N2,FBLN5,FOXC2,IBSP,ID } 3 \text {,ITGA8 }\end{array}$ \\
\hline GO.0007214 & $\begin{array}{l}\text { gamma-aminobutyric } \\
\text { acid signaling pathway }\end{array}$ & 3 & 0.0458 & CACNB4,GABRA2,HTR4 \\
\hline GO. 0048732 & gland development & 10 & 0.0312 & ASNS,ATP7B,CACNB4,CAD,CTNNB1,ETS1,FKBP4,HMGCS2,HOXD3,IL6 \\
\hline GO.0072144 & $\begin{array}{l}\text { glomerular mesangial } \\
\text { cell development }\end{array}$ & 2 & 0.0329 & ACTA2,FOXC2 \\
\hline G0.0072008 & $\begin{array}{l}\text { glomerular mesangial } \\
\text { cell differentiation }\end{array}$ & 2 & 0.0443 & 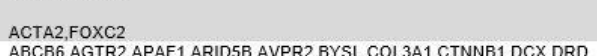 \\
\hline Go.0060322 & head development & 13 & 0.04 & $\begin{array}{l}\text { ABCB6,AGTR2,APAF1,ARID5B,AVPR2,BYSL,COL3A1,CTNNB1,DCX,DRD } \\
\text { 1,ETS1, } \\
\text { HMGCS2,ITGA8 }\end{array}$ \\
\hline GO. 0007507 & $\begin{array}{l}\text { heart development } \\
\text { hemophilic cell } \\
\text { adhesion via plasma } \\
\text { membrane adhesion }\end{array}$ & 10 & 0.0476 & AGTR2,CAD,CALR, COL3A1, CTNNB1, CYR61, DHRS3,FOXC2,ID 3,MYL2 \\
\hline G0.0007156 & molecules & 6 & 0.0388 & $\mathrm{CDH} 12, \mathrm{CDH} 15, \mathrm{CDH} 16, \mathrm{CDH} 17, \mathrm{CDH} 2, \mathrm{CDH} 6$ \\
\hline Go.0035235 & $\begin{array}{l}\text { ionotropic glutamate } \\
\text { receptor signaling } \\
\text { pathway }\end{array}$ & 3 & 0.0499 & GRIA2,GRIK5,GRIN2B \\
\hline GO.0001822 & kidney development & 8 & 0.0242 & ACTA2,AGTR2,ARID5B,CTNNB1,FOXC2,,GDF11,HMGCS2,ID3 \\
\hline G0.0040011 & locomotion & 18 & 0.0346 & $\begin{array}{l}\text { ANPEP,ARID5B,CACNB4,CCL7,CDH2,COL1A2,COL3A1,COL6A1,CTGF, } \\
\text { TNNB1,CYR61,DCX,DRD1,ETS1,GAS8,GFRA1,GRIN2B,IL6 }\end{array}$ \\
\hline GO.0001656 & $\begin{array}{l}\text { metanephros } \\
\text { development }\end{array}$ & 6 & 0.00352 & AGTR2,CTNNB1,FOXC2,GDF11,ID3,ITGA8 \\
\hline G0.0006928 & $\begin{array}{l}\text { multicellular organismal } \\
\text { development }\end{array}$ & 19 & 0.00328 & 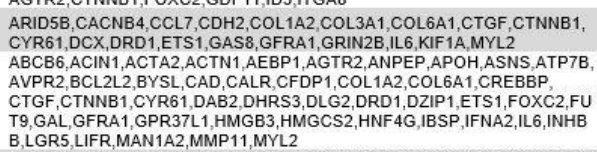 \\
\hline GO.0032501 & $\begin{array}{l}\text { multicellular organismal } \\
\text { process }\end{array}$ & 51 & 0.0428 & $\begin{array}{l}\text { ABCB6,ACIN1,ACTA2,ACTN1,ADAMTS3,AEBP } 1 \text {,AGTR2,ANPEP, APOH,AS } \\
\text { NS,ATP78,CAD, CALR,CFDP 1,CFTR,COL17A1,COL1A2,COL6A1,CREBBP, } \\
\text { CRYAA,CTGF,CTNNB1,CYP4F11,CYR61,DAB2, DOCK9,DRD1,DZIP1,ETS }\end{array}$ \\
\hline
\end{tabular}

\begin{tabular}{|c|c|c|c|c|}
\hline & & & & $\begin{array}{l}\text { 1,FOXC2, FUT9, GAL, GCLM, GFRA1, GPR 37L1, HDAC4,HMGB3, HMGCS2, H } \\
\text { NF4G,HTR4,IBSP,IFNA2,IGFBP2,IL6,KCNH2,KNG1,LGR5,LIFR,MAN1A2,M } \\
\text { MP11,MYL2 }\end{array}$ \\
\hline G0.0044703 & $\begin{array}{l}\text { multi-organism } \\
\text { reproductive process }\end{array}$ & 15 & 0.04 & $\begin{array}{l}\text { BCL2L2,BYSL,CAD,CALR,CCT8,CFTR,CTNNB1,DRD1,DZIP1,ETS1,FKBP4 } \\
\text { GLRA1, } \\
\text { IGFBP2,INHBB,LGR5 }\end{array}$ \\
\hline GO.0061061 & $\begin{array}{l}\text { muscle structure } \\
\text { development }\end{array}$ & 12 & 0.00533 & $\begin{array}{l}\text { AEBP1,AGTR2,ARID5B,CACNB4,CALR,CDH15,COL3A1,DTYMK,FOXC2,I } \\
\text { D3, } \\
\text { ITGA8,MYL2 }\end{array}$ \\
\hline GO.0048519 & $\begin{array}{l}\text { negative regulation of } \\
\text { biological process }\end{array}$ & 45 & 0.00527 & $\begin{array}{l}\text { ACIN1,ACTN1,AGTR2,ANKRD26,APOH,ARID5B,ASNS,AVPR2,BCL2L2,CA } \\
\text { LR,CFDP1,CHEK1,COL3A1,CREBBP,CRYA,CTH,CTNNB1,CYP26A1,DAB } \\
\text { 2,DCBLD2,DHRS3,DLG2,DRD1,DUSP14,EEF1E1,FOXC2,GAS8,GCLM,GD } \\
\text { F11,GLRA1,GRIK5,HDAC4,HIST1H4C, HMGB3,IFIH1,IFNA2,IL13RA2,IL6,IN } \\
\text { HBB,KCNH2,KNG1,LIFR,LMO3MMP11,MYL2 }\end{array}$ \\
\hline GO.0010648 & $\begin{array}{l}\text { negative regulation of } \\
\text { cell communication }\end{array}$ & 18 & 0.0326 & $\begin{array}{l}\text { AGTR2,ANKRD26,BCL2L2,CALR,CDH2,CTH,CTNNB1,CYP26A1,DAB2, } \\
\text { DHRS3,DRD1,DUSP14,GCLM,GLRA1,GPR37L1,IL6,INHBB,LMO3 }\end{array}$ \\
\hline GO.0010721 & $\begin{array}{l}\text { negative regulation of } \\
\text { cell development }\end{array}$ & 8 & 0.0301 & CALR,COL3A1,CTNNB1,FKBP4,FOXC2,GAL,GDF11,GPR37L1 \\
\hline Go.0045596 & $\begin{array}{l}\text { negative regulation of } \\
\text { cell differentiation }\end{array}$ & 18 & 0.000155 & 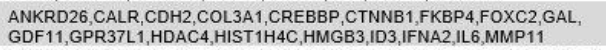 \\
\hline GO. 0048523 & $\begin{array}{l}\text { negative regulation of } \\
\text { cellular process }\end{array}$ & 45 & 0.0015 & $\begin{array}{l}\text { ACIN1,ACTN1,AGTR2,ANKRD26,APOH,ARID5B,ASNS, BCL2L2,CALR,CFD } \\
\text { P1,CHEK1,COL3A1,CREBBP,CRYAA,CTGF, CTH,CTNNB1,CYP26A1,DAB2 } \\
\text {,DCBLD2,DHRS3,DLG2,DNMT1,DRD1,DUSP14,EEF1E1,ETS1,FOXC2,GA } \\
\text { S8,GCLM, GDF11,GLRA1,HDAC4,HIST1H4C,HMGB3,IFNA2,IL13RA2,IL6,IN } \\
\text { HBB, KCNH2,KNG1,LIFR,LMO3,MMP11,MYL2 }\end{array}$ \\
\hline G0.0051093 & $\begin{array}{l}\text { negative regulation of } \\
\text { developmental process }\end{array}$ & 19 & 0.000629 & $\begin{array}{l}\text { ANKRD26,APOH,CALR,CDH2,COL3A1,CREBBP,CTNNB1,FKBP4,FOXC2, } \\
\text { GAL,GDF11, } \\
\text { GPR37L1,HDAC4,HIST1H4C,HMGB3,ID3,IFNA2,IL6,MMP11 }\end{array}$ \\
\hline GO.0051241 & $\begin{array}{l}\text { negative regulation of } \\
\text { multicellular organismal } \\
\text { process }\end{array}$ & 22 & 0.000131 & $\begin{array}{l}\text { AGTR2,ANKRD26,APOH,AVPR2, CALR,COL3A1,DRD1,FKBP4,FOXC2,GAL } \\
\text { 'GDF11,GLRA1,GPR37L1,HDAC4,HIST1H4C,HMGB3,ID3,IFIH1,IFNA2,IL6, } \\
\text { INHBB,KNG1 }\end{array}$ \\
\hline GO.0048585 & $\begin{array}{l}\text { negative regulation of } \\
\text { response to stimulus }\end{array}$ & 20 & 0.0172 & $\begin{array}{l}\text { AGTR2,ANKRD } 26, \text { APOH,BCL2L2,CALR,CDH2,COL3A1,CTH,CTNNB1,CYP } \\
26 \text { A1,DAB2,DHRS3,DRD1,DUSP14,ETS1, GCLM,IFNA2,IL13RA2,KNG1,LM } \\
\text { O3 }\end{array}$ \\
\hline GO.0023057 & $\begin{array}{l}\text { negative regulation of } \\
\text { signaling }\end{array}$ & 18 & 0.0305 & $\begin{array}{l}\text { AGTR2,ANKRD26,BCL2L2,CALR,CDH2,CTH,CTNNB1,CYP26A1,DAB2,DH } \\
\text { RS3,DRD1,DUSP14,GCLM,GLRA1,GPR } 37 L 1 \text {,IL6,INHBB,LMO3 }\end{array}$ \\
\hline GO.0007399 & $\begin{array}{l}\text { nervous system } \\
\text { development }\end{array}$ & 25 & 0.0333 & 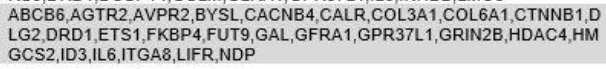 \\
\hline GO. 0007270 & $\begin{array}{l}\text { neuron-neuron synaptic } \\
\text { transmission }\end{array}$ & 5 & 0.00789 & CACNB4,DRD1,GLRA1,GRIA2,GRIK5 \\
\hline G0.0048513 & organ development & 42 & $1.86 \mathrm{E}-05$ & $\begin{array}{l}\text { ABCB6,ACIN1,ACTA2,ACTN1,AEBP1,AGTR2,APAF1,APOH,ASNS,ATP7B, } \\
\text { AVPR2, }\end{array}$ \\
\hline
\end{tabular}




\begin{tabular}{|c|c|c|c|c|}
\hline GO. 0009887 & organ morphogenesis & 16 & 0.0132 & $\begin{array}{l}\text { BCL2L2,BYSL,CACNB4,CAD,CALR,COL1A2,CTGF,CTNNB1,CYR61,DCX, } \\
\text { DHRS3,DRD1, } \\
\text { ETS1,FKBP4,FOXC2,GDF11, GRIN2B,HDAC4,HMGCS2,HNF4G,HOXD3,IB } \\
\text { SP,ID3,IFNA2,IL6, } \\
\text { INHBB,LGR5,LIFR,MAN1A2,MYL2,NDP } \\
\text { ACTA2,AGTR2,ARID5B,COL1A2,COL3A1,CTGF,CTNNB1,CYR61,DHRS3,F } \\
\text { OXC2,GDF11, } \\
\text { HOXD3,ID3,IL6,ITGA8,MYL2 }\end{array}$ \\
\hline GO. 0043065 & $\begin{array}{l}\text { positive regulation of } \\
\text { apoptotic process }\end{array}$ & 13 & 0.0069 & $\begin{array}{l}\text { ACIN1,AGTR2,CTGF, CTNNB1, CYR61,EEF1E1, GAL,GRIK5,HDAC4, ID3,IL6 } \\
\text {,INHBB,KNG1 }\end{array}$ \\
\hline GO. 0048518 & $\begin{array}{l}\text { positive regulation of } \\
\text { biological process }\end{array}$ & 54 & 0.00065 & $\begin{array}{l}\text { ACIN1,ACTA2,ADAMTS3,AGTR2,APOH,ARID5B,ASB4,ASNS,AVPR2,CAC } \\
\text { NB4,CALR,CCL7,CDH15,CDKL2,CFTR,CHEK1,COL3A1,CREBBP, CTGF, C } \\
\text { TH,CTNNB1,CYR61,DAB2,DNMT1,DOCK9,DRD1,EEF1E1,ETS1,FBLN2,FO } \\
\text { XC2,GCLM,GDF11,GLRA1,GRIK5, GRIN2B,HDAC4,HNF4G,HOXD3,HSPB2 } \\
\text {,HTR4,ID3, } \\
\text { IFIH1,IFNA2,IGFBP2,IL13RA2,IL6,ITGA8,KCNH2,KNG1,LGR5,LIFR,LMO3, } \\
\text { MLLT10,NDP }\end{array}$ \\
\hline GO.0009891 & $\begin{array}{l}\text { positive regulation of } \\
\text { biosynthetic process }\end{array}$ & 23 & 0.0357 & $\begin{array}{l}\text { AGTR2,ARID5B,AVPR2,CALR,CHEK1,CREBBP,CTGF,CTH,CTNNB1,CYR6 } \\
\text { 1,DAB2,DRD1, } \\
\text { ETS1,FOXC2,GAL,HDAC4,HNF4G,HTR4,IFNA2,IL6,ITGA8,MLLT10,NDP }\end{array}$ \\
\hline G0.0010647 & $\begin{array}{l}\text { positive regulation of } \\
\text { cell communication }\end{array}$ & 22 & 0.0242 & $\begin{array}{l}\text { ACIN1,ADAMTS3,AGTR2,APAF1, CDH2,CFTR, COL3A1,CTGF,CTH,CYR61, } \\
\text { DAB2,DRD1, } \\
\text { EEF1E1,GAL,GDF11,GPR37L1,GRIN2B,IFNA2,IL6,ITGA8,LGR5,LMO3 }\end{array}$ \\
\hline GO.0030335 & $\begin{array}{l}\text { positive regulation of } \\
\text { cell migration }\end{array}$ & 9 & 0.0357 & CALR,CCL7,CYR61,DAB2,DRD1,ETS1,FOXC2,HDAC4,IL6 \\
\hline GO.0048522 & $\begin{array}{l}\text { positive regulation of } \\
\text { cellular process }\end{array}$ & 46 & 0.00464 & 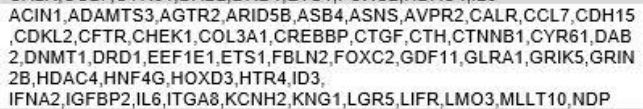 \\
\hline GO. 0010628 & $\begin{array}{l}\text { positive regulation of } \\
\text { gene expression }\end{array}$ & 24 & 0.00868 & $\begin{array}{l}\text { ACTA2,AGTR2,ARID5B,AVPR2, CALR, CHEK1, CREBBP, CTGF,CTH,CTNNB } \\
1, \text { CYR61,DAB2,DNMT1,ETS1,FOXC2,GAL,HDAC4,HNF4G,HOXD3,IFNA2,I } \\
\text { L6,ITGA8,MLLT10,NDP }\end{array}$ \\
\hline Go.0032846 & $\begin{array}{l}\text { positive regulation of } \\
\text { homeostatic process }\end{array}$ & 6 & 0.0436 & AGTR2,CFTR,CTNNB1,DRD1,ETS1,KNG1 \\
\hline GO. 0009893 & $\begin{array}{l}\text { positive regulation of } \\
\text { metabolic process }\end{array}$ & 36 & 0.0438 & 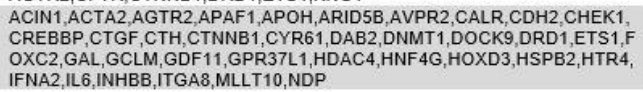 \\
\hline GO.0045935 & $\begin{array}{l}\text { positive regulation of } \\
\text { nucleobase-containing } \\
\text { compound metabolic } \\
\text { process }\end{array}$ & 22 & 0.04 & $\begin{array}{l}\text { AGTR2,ARID5B,AVPR2,CALR,CHEK1,CREBBP,CTH,CTNNB1,CYR61,DAB } \\
\text { 2,DRD1,ETS1,FOXC2,GAL,HDAC4,HNF4G,HTR4,IFNA2,IL6,ITGA8,MLLT1 } \\
0, \text { NDP }\end{array}$ \\
\hline
\end{tabular}

\begin{tabular}{|c|c|c|c|c|}
\hline GO.0048584 & $\begin{array}{l}\text { positive regulation of } \\
\text { response to stimulus }\end{array}$ & 27 & 0.00457 & $\begin{array}{l}\text { ACIN1,ADAMTS3,AGTR2,APAF1,APOH,CACNB4,CALR,CCL7,CDH2,CFTR } \\
\text { 'COL3A1,CREBBP,CTGF,CTH,CYR61,DAB2,DRD1,EEF1E1,FOXC2,GDF11 } \\
\text { 'GPR37L1,IFIH1,IFNA2,IL6,ITGA8,LGR5,LMO3 }\end{array}$ \\
\hline GO.0023056 & $\begin{array}{l}\text { positive regulation of } \\
\text { signaling }\end{array}$ & 21 & 0.0205 & $\begin{array}{l}\text { ADAMTS3,AGTR2,APAF1,CDH2,CFTR,COL3A1, CTGF, CTH,CYR61,DAB2, } \\
\text { DRD1,EEF1E1, GAL, GDF11,GPR37L1,GRIN2B,IFNA2,IL6,ITGA8,LGR5,LM } \\
\text { O3 }\end{array}$ \\
\hline GO. 0090100 & $\begin{array}{l}\text { positive regulation of } \\
\text { transmembrane } \\
\text { receptor protein } \\
\text { serine/threonine kinase } \\
\text { signaling pathway }\end{array}$ & 5 & 0.04 & CYR61.DAB2.GDF11.INHBB.ITGA8 \\
\hline Go.0042981 & $\begin{array}{l}\text { regulation of apoptotic } \\
\text { process }\end{array}$ & 27 & 0.000131 & $\begin{array}{l}\text { ACIN1,ACTN1,AGTR2,APOH,ASNS, BCL2L2, CALR, CFDP1,CRYAA,CTGF, } \\
\text { CTH,CTNNB1,CYR61,DAB2, EEF1E1,ETS1,FOXC2, GAL, GCLM,GDF11,GRI } \\
\text { K5,HDAC4,ID } 3 \text {,IFIH1, IL6, KNG1, LIFR }\end{array}$ \\
\hline GO. 0065008 & $\begin{array}{l}\text { regulation of biological } \\
\text { quality }\end{array}$ & 38 & 0.00145 & $\begin{array}{l}\text { ABCA4,ABCB6,ACIN1,ACTA2,ACTN1,AGTR2,ANKRD26,ANPEP,APOH,CA } \\
\text { D,CALR,CCL7, CDH2,CFDP1,CFTR,COL1A2,COL3A1,CREBBP,CTGF,CTN } \\
\text { NB1,CYP26A1,CYP4F11,DHRS3,DOCK9,DRD 1,FOXC2,GABRA2, GAL,GCL } \\
\text { M,GRIK5,GRIN2B,HIST1H4C, HTR4,IFNA2,IL6,KCNH2,KCNK1,KNG1 }\end{array}$ \\
\hline GO. 0050880 & $\begin{array}{l}\text { regulation of blood } \\
\text { vessel size }\end{array}$ & 6 & 0.00197 & $\begin{array}{l}\text { ACTA2,AGTR2,DRD1,FOXC2,GCLM,KNG1 } \\
\text { ACIN1,ADAMTS3,AGTR2,ANKRD26,APAF1,BCL2L2,CACNG3,CALR,CDH2 }\end{array}$ \\
\hline GO. 0010646 & $\begin{array}{l}\text { regulation of cell } \\
\text { communication }\end{array}$ & 34 & 0.00717 & $\begin{array}{l}\text { CFTR, } \\
\text { CNKSR2, COL3A1,CREBBP,CTGF,CTH,CYP26A1,CYR61,DAB2,DHRS3,D } \\
\text { RD1,DUSP14,EEF1E1, GAL,GCLM,GDF11,GLRA1, GRIK5, GRIN2B,IFNA2,I } \\
\text { GFBP2, } \\
\text { IL6,ITGA8,LGR5,LMO3 }\end{array}$ \\
\hline G0.0010941 & regulation of cell death & 26 & 0.000485 & $\begin{array}{l}\text { ACIN1,ACTN1,AGTR2,APOH,ASNS, BCL2L2, CALR,CFDP1,CRYAA,CTH,CT } \\
\text { NNB1,DAB2,EEF1E1,ETS1,FOXC2,GAL, GCLM,GDF11,GPR37L1, GRIK5, H } \\
\text { DAC4, } \\
\text { ID3,IFIH1,IL6,KNG1,LIFR }\end{array}$ \\
\hline GO. 0045595 & $\begin{array}{l}\text { regulation of cell } \\
\text { differentiation }\end{array}$ & 26 & 0.000485 & $\begin{array}{l}\text { ACIN1,ANKRD } 26, \text { ASB } 4, \text { CALR,CDH15,COL3A1,CREBBP,CTGF,CTNNB1,C } \\
\text { YR } 61 \text {,DAB2, } \\
\text { ETS1,FKBP4,FOXC2,GAL,GDF11,GPR37L1,HDAC4,HIST1H4C,HMGB3,H } \\
\text { OXD3,ID3, } \\
\text { IFNA2,IL6,LMO3,MMP11 }\end{array}$ \\
\hline Go.0030334 & $\begin{array}{l}\text { regulation of cell } \\
\text { migration }\end{array}$ & 12 & 0.0399 & $\begin{array}{l}\text { AGTR2,APOH,CALR, CCL7, COL3A1,CYR61,DAB2,DRD1, ETS1,FOXC2,HD } \\
\text { AC4,IL6 }\end{array}$ \\
\hline GO. 0051270 & $\begin{array}{l}\text { regulation of cellular } \\
\text { component movement }\end{array}$ & 14 & 0.0199 & $\begin{array}{l}\text { ACTN1,AGTR2,APOH,CALR,CCL7,COL3A1,CYR61,DAB2,DRD1,ETS1,FO } \\
\text { XC2,HDAC4, } \\
\text { IL6,KCNH2 }\end{array}$ \\
\hline
\end{tabular}




\begin{tabular}{|c|c|c|c|c|}
\hline GO.0050793 & $\begin{array}{l}\text { regulation of } \\
\text { developmental process }\end{array}$ & 29 & 0.00335 & $\begin{array}{l}\text { ACIN1,AGTR2,ANKRD26,APOH,ASB4,CALR,CCL7,CDH15,CFDP1,COL3A } \\
\text { 1,CREBBP, } \\
\text { CTGF,CTNNB1,CYR61,DAB2,FKBP4,FOXC2,GAL,GDF11,GPR37L1,HDAC } \\
\text { 4,HIST1H4C, } \\
\text { HMGB3,HOXD3,ID3,IFNA2,IL6,LMO3,MMP11 }\end{array}$ \\
\hline GO.0032879 & $\begin{array}{l}\text { regulation of } \\
\text { localization }\end{array}$ & 30 & 0.00517 & 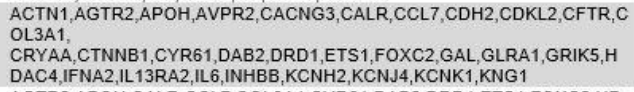 \\
\hline GO.0040012 & $\begin{array}{l}\text { regulation of } \\
\text { locomotion }\end{array}$ & 13 & 0.0397 & $\begin{array}{l}\text { AGTR2,APOH,CALR, CCL7, COL3A1,CYR61,DAB2,DRD1,ETS1,FOXC2,HD } \\
\text { AC4 } \\
\text {,IFNA2,IL6 }\end{array}$ \\
\hline GO.2000026 & $\begin{array}{l}\text { regulation of } \\
\text { multicellular organismal } \\
\text { development }\end{array}$ & 22 & 0.0172 & $\begin{array}{l}\text { ACIN1,AGTR2,APOH,ASB4,CALR,CDH2,COL3A1,CTGF,CTNNB1,CYR61, } \\
\text { DAB2,FKBP4, } \\
\text { FOXC2,GAL,GDF11,GPR37L1,HDAC4,HIST1H4C,HMGB3,HOXD3,IFNA2,I } \\
\text { L6 }\end{array}$ \\
\hline GO.0051239 & $\begin{array}{l}\text { regulation of } \\
\text { multicellular organismal } \\
\text { process }\end{array}$ & 32 & 0.00205 & $\begin{array}{l}\text { ACIN1,AGTR2,ANKRD26,APOH,ASB4,CALR,CDH2,COL3A1, CREBBP,CTG } \\
\text { F,CTNNB1, } \\
\text { CYR61,DAB2, DHRS3,DRD1,FKBP4,FOXC2, GAL,GDF11,GPR37L1,HDAC4, } \\
\text { HIST1H4C, HMGB3,HOXD3,ID3,IFIH1,IFNA2,IL6, INHBB,KCNH2,KNG1,MYL } \\
2\end{array}$ \\
\hline GO.0031399 & $\begin{array}{l}\text { regulation of protein } \\
\text { modification process } \\
\text { regulation of renal }\end{array}$ & 21 & 0.0476 & $\begin{array}{l}\text { AGTR2,ANKRD26,AVPR2,CDH2,CHEK1,CTGF,CTNNB1,CYR61,DAB2,DIR } \\
\text { AS3,DLG2, } \\
\text { DNMT1,DRD1,DUSP14,GDF11,GPR37L1,HDAC4,IFNA2,IL6,INHBB,LMO3 }\end{array}$ \\
\hline G0.0035813 & sodium excretion & 3 & 0.0426 & AGTR2,AVPR2,KNG1 \\
\hline GO.0048583 & $\begin{array}{l}\text { regulation of response } \\
\text { to stimulus }\end{array}$ & 44 & 0.000131 & $\begin{array}{l}\text { ACIN1,ADAMTS3,AGTR2,ANKRD26,APAF1,APOH,BCL2L2,CACNB4,CAC } \\
\text { NG3,CALR,CCL7,CDH2,CFTR,CHEK1,CNKSR2,COL3A1,CREBBP,CTGF, C } \\
\text { TH, } \\
\text { CYP26A1,CYR61,DAB2,DHRS3,DNA,JC7,DRD1,DUSP14,EEF1E1,ETS1, } \\
\text { FBLN5,FKBP4,FOXC2,GCLM,GDF11,GRIN2B,,HDAC4,IFIH1,IFNA2,IGFBP2 } \\
\text {,IL13RA2,IL6,ITGA8,KNG1,LGR5,LMO3 }\end{array}$ \\
\hline G0.0009966 & $\begin{array}{l}\text { regulation of signal } \\
\text { transduction }\end{array}$ & 28 & 0.0399 & $\begin{array}{l}\text { ADAMTS3,AGTR2,ANKRD26,APAF1,BCL2L2,CACNG3,CALR,CDH2,CNKS } \\
\text { R2,COL3A1,CREBBP,CTGF,CTH,CYP26A1,CYR61,DAB2,DHRS3,DUSP14, } \\
\text { EEF1E1,GCLM,GDF11,GRIN2B,IFNA2,IGFBP2,IL6,ITGA8,LGR5,LMO3 }\end{array}$ \\
\hline G0.0023051 & regulatio & 33 & 0.00666 & 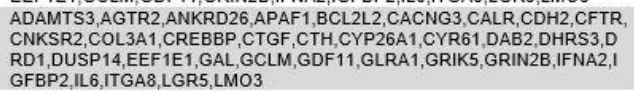 \\
\hline GO.0044057 & $\begin{array}{l}\text { regulation of } \\
\text { process }\end{array}$ & 10 & 0.0382 & AGTR2,CTGF,DRD1,GAL, HDAC4,IL6,INHBB,KCNH2,KNG1,MYL2 \\
\hline GO.0072001 & $\begin{array}{l}\text { renal system } \\
\text { development }\end{array}$ & 9 & 0.00695 & \\
\hline
\end{tabular}

\begin{tabular}{|c|c|c|c|c|}
\hline G0.0009628 & $\begin{array}{l}\text { response to abiotic } \\
\text { stimulus }\end{array}$ & 21 & 0.0015 & $\begin{array}{l}\text { ABCA4,APAF1,ASNS,CACNB4,CCL7,CHEK1,CREBBP,CTGF,DCX,DHRS3, } \\
\text { DNAJC7,DRD1,ETS1,FKBP4, GRIN2B, HDAC4, HMGCS2,IGFBP2,IL6,INHBB } \\
\text { KCNJ4 }\end{array}$ \\
\hline G0.0001101 & $\begin{array}{l}\text { response to acid } \\
\text { chemical }\end{array}$ & 10 & 0.00457 & $\begin{array}{l}\text { ASNS, COL1A2, COL3A1, COL6A1, CTGF,DNMT1,DRD1, HMGCS2,IGFBP2,IL } \\
6\end{array}$ \\
\hline GO.0097305 & response to alcohol & 12 & 0.000521 & $\begin{array}{l}\text { AGTR2,CAD,CALR,CCL7,CTGF,CTNNB1,DRD1,ETS1,GRIN2B,HMGCS2, } \\
\text { IGFBP2,IL6 }\end{array}$ \\
\hline GO.0043200 & response to amino acid & 9 & 0.000103 & ASNS,COL1A2,COL3A1,COL6A1,CTGF,DNMT1,DRD1,HMGCS2,IL6 \\
\hline GO.0031960 & $\begin{array}{l}\text { response to } \\
\text { corticosteroid }\end{array}$ & 6 & 0.0464 & 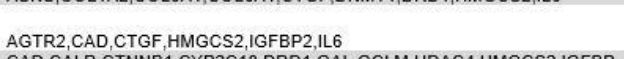 \\
\hline G0.0042493 & response to drug & 12 & 0.00335 & $\begin{array}{l}\text { CAD,CALR,CTNNB1, CYP2C18,DRD1,GAL, GCLM,HDAC4,HMGCS2,IGFBP } \\
2, \mathrm{IL} 6, \mathrm{KCNH} 2\end{array}$ \\
\hline G0.0009719 & $\begin{array}{l}\text { response to } \\
\text { endogenous stimulus }\end{array}$ & 20 & 0.0336 & $\begin{array}{l}\text { AGTR2,ASNS,AVPR2,CAD,CALR,CFTR,COL6A1,CTGF,CTNNB1,DNMT1,D } \\
\text { RD1,DTYMK,ETS1,FOXC2,GAL,HDAC4,HMGCS2,HNF4G,IGFBP2,IL6 }\end{array}$ \\
\hline G0.0032355 & response to estradiol & 6 & 0.023 & CALR,CTGF,CTNNB1,DRD1,ETS1,IGFBP2 \\
\hline G0.0043627 & response to estrogen & 8 & 0.00771 & CALR,CTGF,CTNNB1, DRD1,DTYMK,ETS1, GAL,IGFBP2 \\
\hline GO.0009725 & response to hormone & 17 & 0.00464 & $\begin{array}{l}\text { AGTR2,ASNS,AVPR2,CAD,CALR,CTGF,CTNNB1,DRD1,DTYMK,ETS1,FO } \\
\text { XC2,GAL,HDAC4,HMGCS2,HNF4G,IGFBP2,IL6 }\end{array}$ \\
\hline G0.0070555 & 1 & 5 & 0.0205 & REBBP,ETS1,HDAC4,IL6 \\
\hline GO.0033993 & response to lipid & 14 & 0.0379 & $\begin{array}{l}\text { AGTR2,BYSL,CAD,CALR,CTGF,CTNNB1,DRD1,DTYMK,ETS1, GAL,HMGC } \\
\text { S2,HNF } 4 \text { G,IGFBP2,IL6 }\end{array}$ \\
\hline GO.0009612 & $\begin{array}{l}\text { response to } \\
\text { mechanical stimulus }\end{array}$ & 10 & 0.000485 & ASNS,CHEK1,COL3A1,ETS1,GRIN2B,HDAC4,IGFBP2,IL6,INHBB,KCNJ4 \\
\hline GO.1901698 & $\begin{array}{l}\text { response to nitrogen } \\
\text { compound }\end{array}$ & 18 & 0.00199 & $\begin{array}{l}\text { AGTR2,ASNS,AVPR2,CAD,CFTR,COL1A2,COL3A1, COL6A1,CTGF, CTNNB } \\
\text { 1,DNMT1,DRD1,FOXC2,GAL,HMGCS2,IFNA2,IL6,INHBB }\end{array}$ \\
\hline Go.0014070 & $\begin{array}{l}\text { response to organic } \\
\text { cyclic compound }\end{array}$ & 18 & 0.000911 & $\begin{array}{l}\text { AGTR2,ASNS,BYSL,CAD,CALR,CFTR,CTGF,CTNNB1,DRD1,DTYMK,ETS1 } \\
\text {,GAL,HMGCS2, HNF } 4 \text { G, IFNA2,IGFBP2, IL6,LIFR }\end{array}$ \\
\hline Go.0010033 & $\begin{array}{l}\text { response to organic } \\
\text { substance }\end{array}$ & 30 & 0.0152 & $\begin{array}{l}\text { AGTR2,APAF1,BYSL,CAD,CCL7, CFTR,COL6A1,CREBBP,CTGF,CTH,CTN } \\
\text { NB1, DNMT1,DRD 1,DTYMK,ETS1,FOXC2,GAL, GFRA1, GRIIK5, GRIN2B,HD } \\
\text { AC4,HMGCS2,HNF 4G,HSPB2, IBSP,IFNA2,IGFBP2,IL13RA2,IL6,LIFR }\end{array}$ \\
\hline GO.0010243 & $\begin{array}{l}\text { response to organot } \\
\text { nitrogen compound }\end{array}$ & 17 & 0.00205 & $\begin{array}{l}\text { AGTR2,ASNS,AVPR2,CAD,CFTR,COL1A2,COL3A1, COL6A1,CTGF, CTNNB } \\
\text { 1,DNMT1,DRD1,FOXC2,GAL, HMGCS2,IL6,INHBB }\end{array}$ \\
\hline Go. 1901700 & $\begin{array}{l}\text { response to oxygen- } \\
\text { containing compound }\end{array}$ & 24 & 0.00065 & $\begin{array}{l}\text { AGTR2,ASNS,AVPR2, BYSL,CAD,CALR, CCL7, CFTR, COL1A2,COL3A1,CO } \\
\text { L6A1,CTGF, CTNNB1,DNMT1,DRD1, ETS1,FOXC2, GAL, GRIK5, GRIN2B, HM } \\
\text { GCS2,IGFBP2,IL6, INHBB }\end{array}$ \\
\hline GO.0048545 & $\begin{array}{l}\text { response to steroid } \\
\text { hormone }\end{array}$ & 13 & 0.000834 & $\begin{array}{l}\text { AGTR2,CAD,CALR,CTGF,CTNNB1,DRD1,DTYMK,ETS1,GAL,HMGCS2,HN } \\
\text { F4G,IGFBP2,IL6 }\end{array}$ \\
\hline G0.0050896 & response to stimulus & 60 & 0.0242 & $\begin{array}{l}\text { ABCA4,ACIN1,ACTA2,ACTN1,AGTR2,APOH,ARID5B,ASB4,ATP7B,BCAM, } \\
\text { BCL2L2,BYSL,CAD,CALR,CDKL2,CFTR,CHEK1,CRYAA,CTH,CTNNB1,CY }\end{array}$ \\
\hline
\end{tabular}




\begin{tabular}{|c|c|c|c|c|}
\hline & & & & 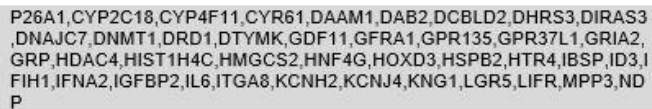 \\
\hline GO.0009611 & response to wounding & 14 & 0.0305 & $\begin{array}{l}\text { ACTN1,APOH,COL1A2,COL3A1,CTGF,CYP4F11,CYR61,DCBLD2,DOCK9, } \\
\text { ETS1,ID3,IFNA2,IL6,KNG1 }\end{array}$ \\
\hline G0.0051208 & $\begin{array}{l}\text { sequestering of calcium } \\
\text { ion }\end{array}$ & 2 & 0.0329 & 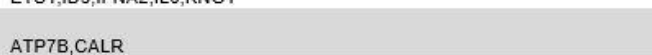 \\
\hline GO.0007165 & signal transduction & 54 & 0.000131 & $\begin{array}{l}\text { ABCA4,AGTR2,ARID5B,ASB4,ASNS,BCAM,BCL2L2,CACNB4,CALR,CCL7, } \\
\text { CDKL2,CFTR,COL1A2,COL3A1,CREBBP, CTH,CTNNB1,CYR61,DAAM1,DA } \\
\text { B2,DCBLD2,DCX,DHRS3,DIRAS3,DOCK9,DRD1,FKBP4,GAL,GDF11,GFR } \\
\text { A1,GLRA1,GPR135,GPR37L1, GRIA2,GRIK5,GRIN2B,GRP,HDAC4, HIST1H } \\
\text { 4C,HNF4G,HOXD3,HTR4,IFIH1,IFNA2,IGFBP2,IL13RA2,IL6,INHBB,ITGA8, } \\
\text { KCNH2,LGR5,LIFR,MPP3,NDP }\end{array}$ \\
\hline GO. 0044700 & $\begin{array}{l}\text { single organism } \\
\text { signaling }\end{array}$ & 54 & 0.000517 & 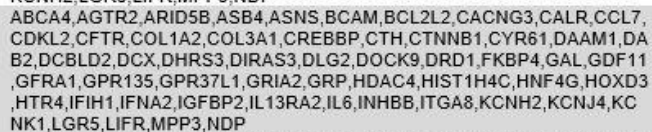 \\
\hline GO.0044707 & $\begin{array}{l}\text { single-multicellular } \\
\text { organism process }\end{array}$ & 53 & 0.00603 & $\begin{array}{l}\text { ABCB6,ACIN1,ACTA2,ACTN1,ADAMTS3,AEBP1,AGTR2,ANPEP,APOH,AS } \\
\text { NS,ATP7B,BCL2L2,BYSL,CAD,CALR,CFDP1,CFTR,COLL17A1,COL1A2,CO } \\
\text { L6A1,CREBBP,CRYAA,CTGF, CTNNB1,CYP4F11,CYR61,DAB2,DOCK9,DR } \\
\text { D1,DZIP1,ETS1,FOXC2,FUT9,GAL,GCLM,GFRA1,GPR37L1,HDAC4,HMGB } \\
\text { 3,HMGCS2,HNF4G, HTR4,IBSP,IFNA2,IL6,INHBB,KCNH2,KNG1,LGR5,LIF } \\
\text { R,MAN1A2,MMP11,MYL2 }\end{array}$ \\
\hline & & & & 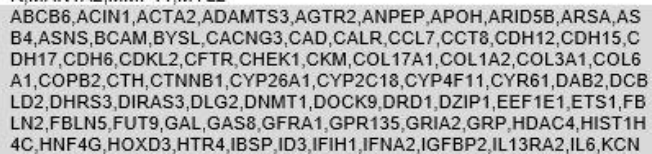 \\
\hline GO. 0044763 & $\begin{array}{l}\text { single-organism cellular } \\
\text { process }\end{array}$ & 81 & 0.0067 & $\begin{array}{l}\text { H2,KCNJ4,KCNK1, KIF1A, KNG1, LIFR, MAN1A2,MCM4,MPP } 3 \text {,MYL2, NDP, N } \\
\text { DUFA7 }\end{array}$ \\
\hline GO. 0044767 & $\begin{array}{l}\text { single-organism } \\
\text { developmental process }\end{array}$ & 48 & 0.0048 & $\begin{array}{l}\text { ABCB6,ACIN1,ACTA2,ACTN1,AEBP1,AGTR2,ANPEP,APOH,ASNS,ATP7B, } \\
\text { AVPR2,BCL2L2,BYSL,CAD,CALR,CDH15,CFDP1,CFTR,CHEK1,COL1A2,C } \\
\text { OL6A1,CREBBP,CTGF,CTNNB1,CYR61,DAB2,DHRS3,DLG2,DRD1,DTYM } \\
\text { K,DZIP1,FOXC2,FUT9,GAL,GFRA1,GPR37L1,HMGB3,HMGCS2,HNF4G,IB } \\
\text { SP,IFNA2,IGFBP2,IL6,LGR5,LIFR,MAN1A2,MMP11,MYL2 }\end{array}$ \\
\hline GO.0001501 & $\begin{array}{l}\text { skeletal system } \\
\text { development }\end{array}$ & 12 & 0.00529 & $\begin{array}{l}\text { AEBP1,ARID5B,COL1A2,COL3A1,CTGF,CTNNB1, CYR61,DHRS3,FOXC2, } \\
\text { GDF11,HDAC4,HOXD3 }\end{array}$ \\
\hline Go.0001964 & startle response & 3 & 0.0499 & DRD1,GLRA1,GRIN2B \\
\hline
\end{tabular}

\begin{tabular}{|c|c|c|c|c|}
\hline GO.0048731 & system development & 40 & 0.00529 & $\begin{array}{l}\text { ABCB6,ACIN1,ACTA2,ACTN1,AEBP1,AGTR2,ANPEP,APOH,ASNS,ATP7B, } \\
\text { AVPR2,BCL2L2,BYSL,CAD,CALR,COL1A2,COL6A1,CTGF,CTNNB1,CYR6 } \\
\text { 1,DHRS3,DLG2,DRD1,ETS1,FOXC2,FUT9,GAL,GFRA1,GPR37L1,HMGCS } \\
\text { 2,HNF4G,IBSP,ID3,IFNA2,IL6,INHBB,LGR5,LIFR,MAN1A2,MYL2, }\end{array}$ \\
\hline GO. 0001655 & $\begin{array}{l}\text { urogenital system } \\
\text { development }\end{array}$ & 10 & 0.00412 & $\begin{array}{l}\text { ACTA2,AGTR2,ARID5B,CTNNB1, FKBP4,FOXC2, GDF11, HMGCS2,ID3, LGR } \\
5\end{array}$ \\
\hline
\end{tabular}

Table 4.11 Biological processes represented through STRING database of ID3 \& ID3-candidate targets proteins in blood. Table represents 119 biological processes.

ID3 and ID3 candidate target genes in tissue. Furthermore we also used STRING to investigate the potential relationships among ID3 \& ID3 candidate target genes in tissue (217). These genes demonstrate to be involved in 20 pathways as shown in Table 4.12. Additionally two of the pathways represented have a role in vascular diseases. Oxidative phosphorylation pathway included proteins: ATP5D, ATP5H, ATP6V0B, ATP6V0D1, ATP6V1B2, COX5A, COX7C, COX8A, CYC1, ID3, NDUFA1, NDUFA7, NDUFS4, NDUFV1, and NDUFV2. Cell cycle pathway includes: ANAPC10, ATM, CDKN2B, E2F5, MCM3, and MCM4. 
Figures 4.8.1 and 4.8.2 represent both pathways. We also show the biological processes in which these genes (217) are over-represented in. A total of 116 processes are shown in Table 4.13.

\begin{tabular}{|c|c|c|c|c|}
\hline Pathway ID & Pathway Description & $\begin{array}{l}\text { Gene } \\
\text { Count }\end{array}$ & $\begin{array}{l}\text { False } \\
\text { Discovery Rate }\end{array}$ & $\begin{array}{l}\text { Matching Proteins in the Network } \\
\text { ACLY,ACOX1,AK2,ALDOC,ALPL,AOX1,APRT,ATP5D,ATP5H,ATP6V0B } \\
\text { ATP6V0D1,ATP6V1B2,BCAT2,CAD,COX5A,COX7C,COX8A,CYC1, } \\
\text { DEGS1,DHCR7,DHRS3,DNMT1,DPM2,EPRS,FLAD1,GALK2,GLB1,GOT1, } \\
\text { GPAA1,GPI,HIBCH,HMGCR,IDH2,IDH3B,IDH3G,IVD,MGAT1,MPI, } \\
\text { MTM1,MVK,NAGLU,NDST1,NDUFA1,NDUFA7,NDUFS4,NDUFV1, } \\
\text { NDUFV2 }\end{array}$ \\
\hline 5010 & Alzheimer's disease & 16 & $3.04 \mathrm{E}-09$ & $\begin{array}{l}\text { ATF } 6, A T P 5 D, A T P 5 H, C D K 5, C O X 5 A, C O X 7 C, C O X 8 A, C Y C 1, \text { GRIN2D, } \\
\text { MAPK1,NCSTN,NDUFA1,NDUFA7,NDUFS4,NDUFV1,NDUFV2 }\end{array}$ \\
\hline 190 & $\begin{array}{l}\text { Oxidative } \\
\text { phosphorylation }\end{array}$ & 14 & 7.49E-09 & $\begin{array}{l}\text { ATP5D,ATP5H,ATP6V0B,ATP6V0D1,ATP6V1B2,COX5A,COX7C, } \\
\text { COX8A,CYC1, NDUFA1,NDUFA7,NDUFS4,NDUFV1,NDUFV2 }\end{array}$ \\
\hline 5016 & Huntington's disease & 16 & 7.49E-09 & $\begin{array}{l}\text { AP2S1,ATP5D,ATP5H,BAX,CLTB, COX5A,COX7C, COX8A,CYC1, } \\
\text { DCTN2,GPX1,NDUFA1,NDUFA7,NDUFS4,NDUFV1,NDUFV2 }\end{array}$ \\
\hline 5012 & Parkinson's disease & 11 & $1.55 \mathrm{E}-05$ & $\begin{array}{l}\text { ATP5D,ATP5H,COX5A, COX7C, COX8A,CYC1,NDUFA1,NDUFA7 } \\
\text {,NDUFS4,NDUFV1,NDUFV2 }\end{array}$ \\
\hline 4142 & Lysosome & 10 & 2.82E-05 & $\begin{array}{l}\text { ATP6V0B,ATP6V0D1,CLN3,CLTB,CTSZ,DNASE2,GLB1,M6PR, } \\
\text { NAGLU,NAGPA }\end{array}$ \\
\hline 1210 & $\begin{array}{l}\text { 2-Oxocarboxylic acid } \\
\text { metabolism }\end{array}$ & 5 & 2.87E-05 & BCAT2,GOT1,IDH2,IDH3B,IDH3G \\
\hline 4932 & $\begin{array}{l}\text { Non-alcoholic fatty } \\
\text { liver disease (NAFLD) }\end{array}$ & 10 & 0.000135 & $\begin{array}{l}\text { BAX,COX5A,COX7C, COX8A, CYC1,NDUFA1,NDUFA7, NDUFS4, } \\
\text { NDUFV1,NDUFV2 }\end{array}$ \\
\hline 1200 & Carbon metabolism & 7 & 0.00301 & ALDOC,GOT1,GPI,HIBCH,IDH2,IDH3B,IDH3G \\
\hline 1230 & $\begin{array}{l}\text { Biosynthesis of amino } \\
\text { acids }\end{array}$ & 6 & 0.00301 & ALDOC,BCAT2,GOT1,IDH2,IDH3B,IDH3G \\
\hline 20 & $\begin{array}{l}\text { Citrate cycle (TCA } \\
\text { cycle) }\end{array}$ & 4 & 0.00529 & $\mathrm{ACLY}, \mathrm{IDH} 2, \mathrm{IDH} 3 \mathrm{~B}, \mathrm{IDH} 3 \mathrm{G}$ \\
\hline 4721 & Synaptic vesicle cycle & 5 & 0.0102 & AP2S1,ATP6V0B,ATP6V0D1,ATP6V1B2,CLTB \\
\hline 5152 & Tuberculosis & 8 & 0.0102 & ATP6V0B,ATP6V0D1,BAX,CEBPG,IFNGR2,ITGAM,MAPK1,MAPK13 \\
\hline 5133 & Pertussis & 5 & 0.0167 & C4BPB,ITGAM,LY96,MAPK1,MAPK13 \\
\hline 280 & $\begin{array}{l}\text { Valine, leucine and } \\
\text { isoleucine degradation }\end{array}$ & 4 & 0.0226 & AOX1,BCAT2,HIBCH,IVD \\
\hline 4146 & Peroxisome & 5 & 0.0254 & $\mathrm{ACOX} 1, \mathrm{DDO}, \mathrm{IDH} 2, \mathrm{MPV} 17, \mathrm{MVK}$ \\
\hline 4110 & Cell cycle & 6 & 0.0304 & ANAPC10,ATM,CDKN2B,E2F5, MCM3,MCM4 \\
\hline 5014 & $\begin{array}{l}\text { Amyotrophic lateral } \\
\text { sclerosis (ALS) }\end{array}$ & 4 & 0.0304 & NCK1, ATM, AOX1, C4BPB \\
\hline 5130 & $\begin{array}{l}\text { Pathogenic } \\
\text { Escherichia coli } \\
\text { infection }\end{array}$ & 4 & 0.0333 & ARPC1A,HCLS1,LY96,NCK1 \\
\hline 5131 & Shigellosis & 4 & 0.0442 & ARPC1A,HCLS1,MAPK1,MAPK 13 \\
\hline
\end{tabular}

Table 4.12 Demonstrated pathways of ID3 \& ID3 candidate target proteins in tissue. 


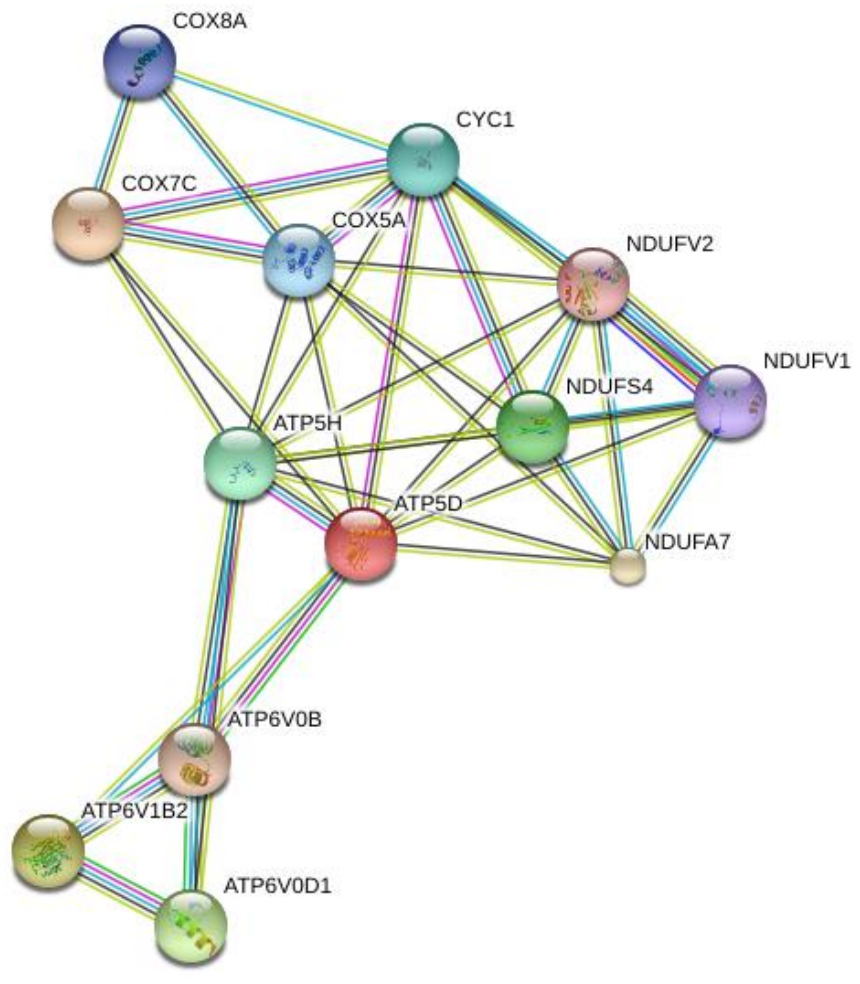

Figure 4.7.1 Network demonstrated from STRING database of ID3 candidate targets involved in the oxidative phosphorylation pathway. Proteins involved in the pathway: ATP5D, ATP5H, ATP6V0B, ATP6V0D1, ATP6V1B2, COX5A, COX7C, COX8A, CYC1, NDUFA1, NDUFA7, NDUFS4, NDUFV1, and NDUFV2.

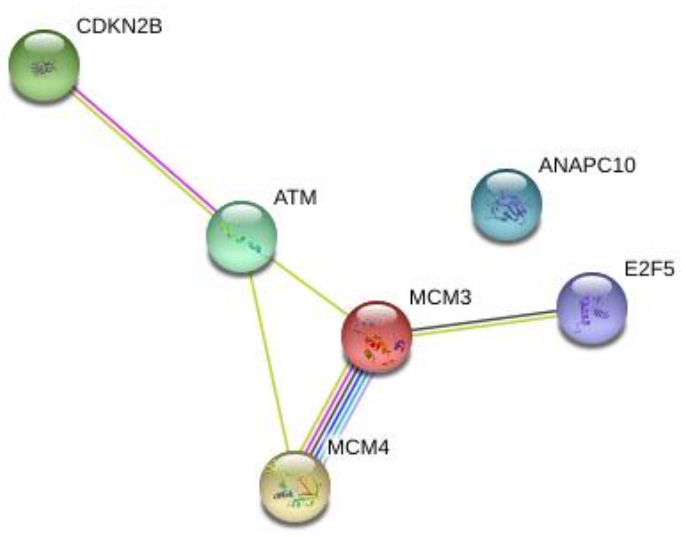

Figure 4.7.2 Network demonstrated from STRING database of ID3 candidate targets involved in the cell cycle pathway. Proteins include: ANAPC10, ATM, CDKN2B, E2F5, MCM3, and MCM4. 


\begin{tabular}{|c|c|c|c|c|}
\hline $\begin{array}{l}\text { Pathway } \\
\text { ID }\end{array}$ & $\begin{array}{l}\text { Pathway } \\
\text { Description }\end{array}$ & $\begin{array}{l}\text { Gene } \\
\text { Count }\end{array}$ & $\begin{array}{l}\text { False } \\
\text { Discovery } \\
\text { Rate }\end{array}$ & Matching Proteins in the Network \\
\hline $\begin{array}{l}\text { GO. } 00486 \\
46\end{array}$ & $\begin{array}{l}\text { anatomical } \\
\text { structure formation } \\
\text { involved in } \\
\text { morphogenesis }\end{array}$ & 22 & 0.0351 & $\begin{array}{l}\text { ACTR2,AGGF1,APOD,ATM,ATP6V0D1,AXIN1,BAX,BYSL,CCDC6, } \\
\text { CDK5,CSF3R,EPHA1,ERCC2,FZD2,GPI,GPX1,HESX1,HTATIP2,ITGB5, } \\
\text { KRT19,MAPK1,MFGE8 }\end{array}$ \\
\hline $\begin{array}{l}\text { GO. } 00096 \\
53\end{array}$ & $\begin{array}{l}\text { anatomical } \\
\text { structure } \\
\text { morphogenesis }\end{array}$ & 38 & 0.0152 & 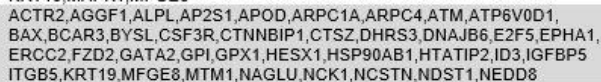 \\
\hline $\begin{array}{l}\mathrm{GO} .00480 \\
02\end{array}$ & $\begin{array}{l}\text { antigen processing } \\
\text { and presentation } \\
\text { of peptide antigen }\end{array}$ & 8 & 0.0458 & ACTR1A,AP2S1,BCAP31,DCTN2,DCTN5,ITGB5,KIFAP3,MR1 \\
\hline $\begin{array}{ll}\text { GO. } \\
34\end{array}$ & $\begin{array}{l}\text { ATP metabolic } \\
\text { process }\end{array}$ & 12 & $7.94 \mathrm{E}-05$ & $\begin{array}{l}\text { AK2,ALDOC,ATP5D,ATP5H,ATP6V1B2,ENO1, GPI,NDUFA1,NDUFA7, } \\
\text { NDUFS4,NDUFV1,NDUFV2 }\end{array}$ \\
\hline & & & & \\
\hline $\begin{array}{l}\text { GO. } 19011 \\
37\end{array}$ & $\begin{array}{l}\text { biosynthetic } \\
\text { process }\end{array}$ & 18 & 0.00821 & $\begin{array}{l}\text { AK2,APRT,ARF4,ATP5D,ATP5H,COG7,CSPG5,DPM2,GLB1,GPAA1, } \\
\text { GPC5,LMAN1,MGAT1,MPDU1,MPI,MPPE1,NAGPA,NDST1 }\end{array}$ \\
\hline $\begin{array}{l}\text { GO. } 19011 \\
35\end{array}$ & $\begin{array}{l}\text { carbohydrate } \\
\text { derivative } \\
\text { metabolic process }\end{array}$ & 32 & 7.17E-06 & $\begin{array}{l}\text { ACLY,AK2,ALDOC,APRT,ARF4,ASGR2,ATP5D,ATP5H,ATP6V1B2, } \\
\text { BAX,CLN3,COG7,CSPG5,DPM2,ENO1,GLB1, GPAA1,GPC5, GPD1L, } \\
\text { HMGCR,LMAN1,MPDU1,MPI,MPPE1,NAGLU,NAGPA,NDST1,NDUFA1, } \\
\text { NDUFA7,NDUFS4,NDUFV1,NDUFV2 }\end{array}$ \\
\hline $\begin{array}{l}\text { GO. } 00059 \\
75\end{array}$ & $\begin{array}{l}\text { carbohydrate } \\
\text { metabolic process }\end{array}$ & 23 & 0.000955 & $\begin{array}{l}\text { ACLY,ALDOC,APOD,ARF 4,COG7,CSPG5,DPM2,ENO1,GLB1,GOT1, } \\
\text { GPC5,GPD1L,GPI,HAGH,IDH2,IDH3G,IGFBP5,LMAN1,MGAT1, } \\
\text { MPDU1,MPI,NAGLU,NAGPA }\end{array}$ \\
\hline $\begin{array}{l}\text { GO. } 00071 \\
66\end{array}$ & $\begin{array}{l}\text { cell surface } \\
\text { receptor signaling } \\
\text { pathway }\end{array}$ & 38 & 0.0121 & 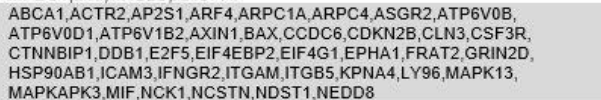 \\
\hline $\begin{array}{l}\text { GO. } 00160 \\
43\end{array}$ & $\begin{array}{l}\text { cellular component } \\
\text { organization }\end{array}$ & 73 & 0.00129 & 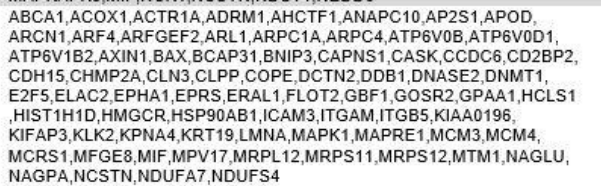 \\
\hline
\end{tabular}

\begin{tabular}{|c|c|c|c|c|}
\hline $\begin{array}{l}\text { GO. } 00425 \\
92\end{array}$ & $\begin{array}{l}\text { homeostatic } \\
\text { process }\end{array}$ & 27 & 0.0251 & $\begin{array}{l}\text { ABCA1,ABCB6,ACOX1,ASGR2,ATM,ATOX1,ATP6V0B,ATP6V0D1,ATP6V1B2,BC } \\
\text { AP31,CCL23,CEBPG, CLN3,DDB1,DNASE2,ERCC2,GATA2,GOT1,GPR39,GPX1, } \\
\text { HCLS1,IGFBP5,IL2RA,LGALS1,MPV17,MTM1,NCSTN }\end{array}$ \\
\hline $\begin{array}{l}\text { GO. } 19026 \\
00\end{array}$ & $\begin{array}{l}\text { hydrogen ion } \\
\text { transmembrane } \\
\text { transport }\end{array}$ & 6 & & \\
\hline & & $b$ & 0.0376 & $\begin{array}{l}\text { ATP5D,ATP6V0B,ATP6V0D1,COX5A,COX7C,COX8A } \\
\text { ACTR1A ACTR2,AP2S1,ARPC1A ARPC4 BAXBCAP31,BNIP3 C4BPB, CCDC6. }\end{array}$ \\
\hline $\begin{array}{l}\text { GO. } 00023 \\
76\end{array}$ & $\begin{array}{l}\text { immune system } \\
\text { process }\end{array}$ & 37 & 0.0124 & 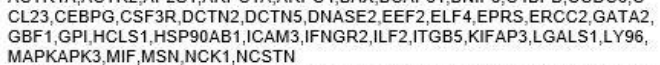 \\
\hline $\begin{array}{l}\text { GO. } 00469 \\
07\end{array}$ & $\begin{array}{l}\text { intracellular } \\
\text { transport }\end{array}$ & 35 & 4.27E-05 & 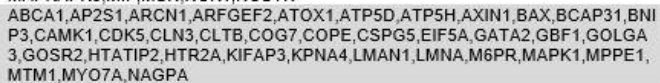 \\
\hline $\begin{array}{l}\text { GO. } 00061 \\
02\end{array}$ & $\begin{array}{l}\text { isocitratel } \\
\text { metabolic process }\end{array}$ & 3 & 0.00292 & IDH2,IDH3B,IDH3G \\
\hline $\begin{array}{l}\text { GO. } 00650 \\
03\end{array}$ & $\begin{array}{l}\text { macromolecular } \\
\text { complex assembly }\end{array}$ & 24 & 0.0474 & $\begin{array}{l}\text { ABCA1,ADRM1,AHCTF1,AP2S1,ARPC4,AXIN1,BAX,CD2BP2,CHMP2A,CLPP,EP } \\
\text { RS,ERAL1,GPAA1,H1F0, HCLS1,HIST1H1B,HIST1H1D,HMGCR,KIAA0196,KIFAP } \\
3, \text { KPNA4,MIF,NCK1,NDUFS } 4\end{array}$ \\
\hline $\begin{array}{l}\text { GO. } 00330 \\
36\end{array}$ & $\begin{array}{l}\text { macromolecule } \\
\text { localization }\end{array}$ & 37 & 0.0177 & 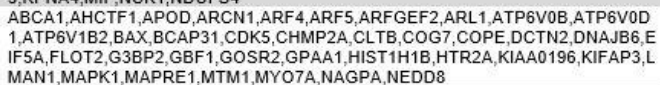 \\
\hline $\begin{array}{l}\text { GO. } 00081 \\
52\end{array}$ & metabolic process & 113 & 0.0474 & 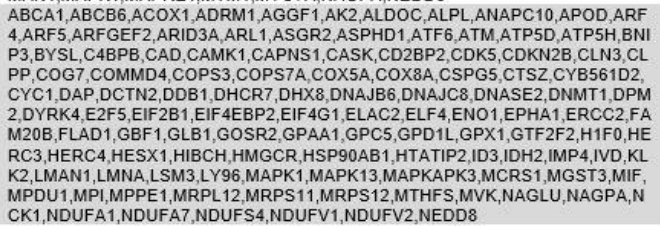 \\
\hline $\begin{array}{l}\text { GO. } 00427 \\
75\end{array}$ & $\begin{array}{l}\text { mitochondrial ATP } \\
\text { synthesis coupled } \\
\text { electron transport }\end{array}$ & 5 & 0.0474 & NDUFA1,NDUFA7,NDUFS4,NDUFV1,NDUFV2 \\
\hline $\begin{array}{l}\text { GO. } 00061 \\
20\end{array}$ & $\begin{array}{l}\text { mitochondrial } \\
\text { electron transport, } \\
\text { NADH to } \\
\text { ubiquinone }\end{array}$ & 5 & 0.0187 & NDUFA1, NDUFA7,NDUFS4,NDUFV1,NDUFV2 \\
\hline GO. 00517 & $\begin{array}{l}\text { multi-organism } \\
\text { process }\end{array}$ & 38 & 0.0351 & $\begin{array}{l}\text { ABCA1,ACOX1,ALPL,AP2S1,ATM,ATP6VVB,ATP6V0D1,ATP6V1B2,BAX,BCAP31, } \\
\text { BNIP3,CAD,CCNI,CHMP2A,DDB1,DDO,EIF 4EEB2,EIF4G1,ENO1,ERCC2,FAM } 50\end{array}$ \\
\hline
\end{tabular}




\begin{tabular}{|c|c|c|c|c|}
\hline & & & & 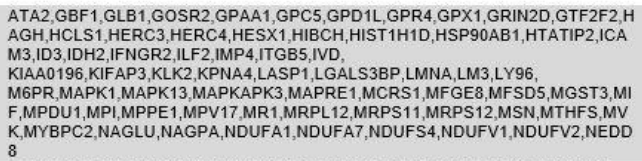 \\
\hline $\begin{array}{l}\text { GO. } 00346 \\
13\end{array}$ & $\begin{array}{l}\text { cellular protein } \\
\text { localization }\end{array}$ & 24 & 0.0349 & $\begin{array}{l}\text { AP2S1,ARCN1,ARF4,ARL1,BAX,BCAP31,CDK5,CLTB,COG7,DCTN2,DNAJB6, } \\
\text { EIF5A,FLOT2,G3BP2,GBF1,GOSR2,GPAA1,HIST1H1B,HTR2A,KPNA4, } \\
\text { MAPK1,MAPRE1MYOOANAGPA }\end{array}$ \\
\hline $\begin{array}{l}\text { GO. } 00442 \\
67\end{array}$ & $\begin{array}{l}\text { cellular protein } \\
\text { metabolic process }\end{array}$ & 54 & 0.0121 & 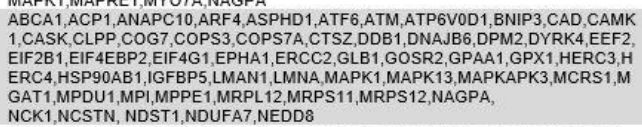 \\
\hline $\begin{array}{l}\text { GO. } 00453 \\
33\end{array}$ & cellular respiration & 15 & 9.67E-07 & $\begin{array}{l}\text { ATP5D,ATP5H,BAX,COX5A,COX7C,COX8A,CYC1,IDH2,IDH3B,IDH3G,NDUFA1, } \\
\text { NDUFA7,NDUFS4,NDUFV1,NDUFV2 }\end{array}$ \\
\hline $\begin{array}{l}\text { GO. } 00708 \\
87\end{array}$ & $\begin{array}{l}\text { cellular response } \\
\text { to chemical } \\
\text { stimulus }\end{array}$ & 44 & 0.00145 & 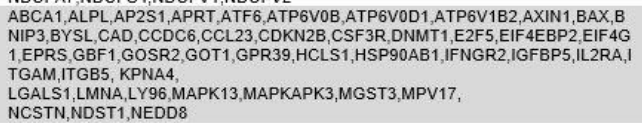 \\
\hline $\begin{array}{l}\text { GO. } 00713 \\
10\end{array}$ & $\begin{array}{l}\text { cellular response } \\
\text { to organic } \\
\text { substance }\end{array}$ & 37 & 0.0038 & $\begin{array}{l}\text { ABCA1,ALPL,AP2S1,APRT,ATF6,ATP6V0B,ATP6V0D1,ATP6V1B2,AXIN1,BAX,BY } \\
\text { SL, } \\
\text { CAD,CCDC6,CDKN2B,CSF3R,DNMT1,E2F5,EIF4EBP2,EIF4G1,EPRS, GOSR2, G } \\
\text { OT1,HCLS1,HSP90AB1,IFNGR2,IGFBP5,IL2RA,ITGB5,KPNA4,LGALS1, } \\
\text { LMNA,LY96,MAPK13,MAPKAPK3,NCSTN.NDST1,NEDD8 }\end{array}$ \\
\hline $\begin{array}{l}\text { GO. } 00061 \\
01\end{array}$ & $\begin{array}{l}\text { citrate metabolic } \\
\text { process }\end{array}$ & 4 & 0.039 & ACLY,IDH2,IDH3B,IDH3G \\
\hline GO.00067 & $\begin{array}{l}\text { coenzyme } \\
\text { metabolic process }\end{array}$ & 10 & 0.0214 & ALDOC,ENO1,FLAD1,GPD1L,GPI,HMGCR,IDH3B,IDH3G,MTHFS,MVK \\
\hline & $\begin{array}{l}\text { cofactor metabolic } \\
\text { process }\end{array}$ & 11 & 0.024 & ABCB6,ALDOC,EN01,FLAD1,GPD1L,GPI,HMGCR,IDH3B,IDH3G,MTHFS,MVK \\
\hline $\begin{array}{l}\text { GO. } 00482 \\
05\end{array}$ & $\begin{array}{l}\text { COPI coating of } \\
\text { Golgi vesicle }\end{array}$ & 3 & 0.0365 & 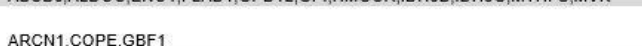 \\
\hline $\begin{array}{l}\text { GO.00359 } \\
64\end{array}$ & $\begin{array}{l}\text { COPI-coated } \\
\text { vesicle budding }\end{array}$ & 3 & 0.0365 & ARCN1,COPE,GBF1 \\
\hline $\begin{array}{l}\text { GO. } 00164 \\
82\end{array}$ & $\begin{array}{l}\text { cytoplasmic } \\
\text { transport }\end{array}$ & 19 & 0.0151 & $\begin{array}{l}\text { ARFGEF2,AXIN1,BCAP31,CAMK1, CDK5,COPE,EIF5A, GBF1,GOSR2,HTATIP2,H } \\
\text { TR2A,KPNA4,LMAN1,LMNA,M6PR,MAPK1,MPPE1,MTM1,NAGPA }\end{array}$ \\
\hline
\end{tabular}

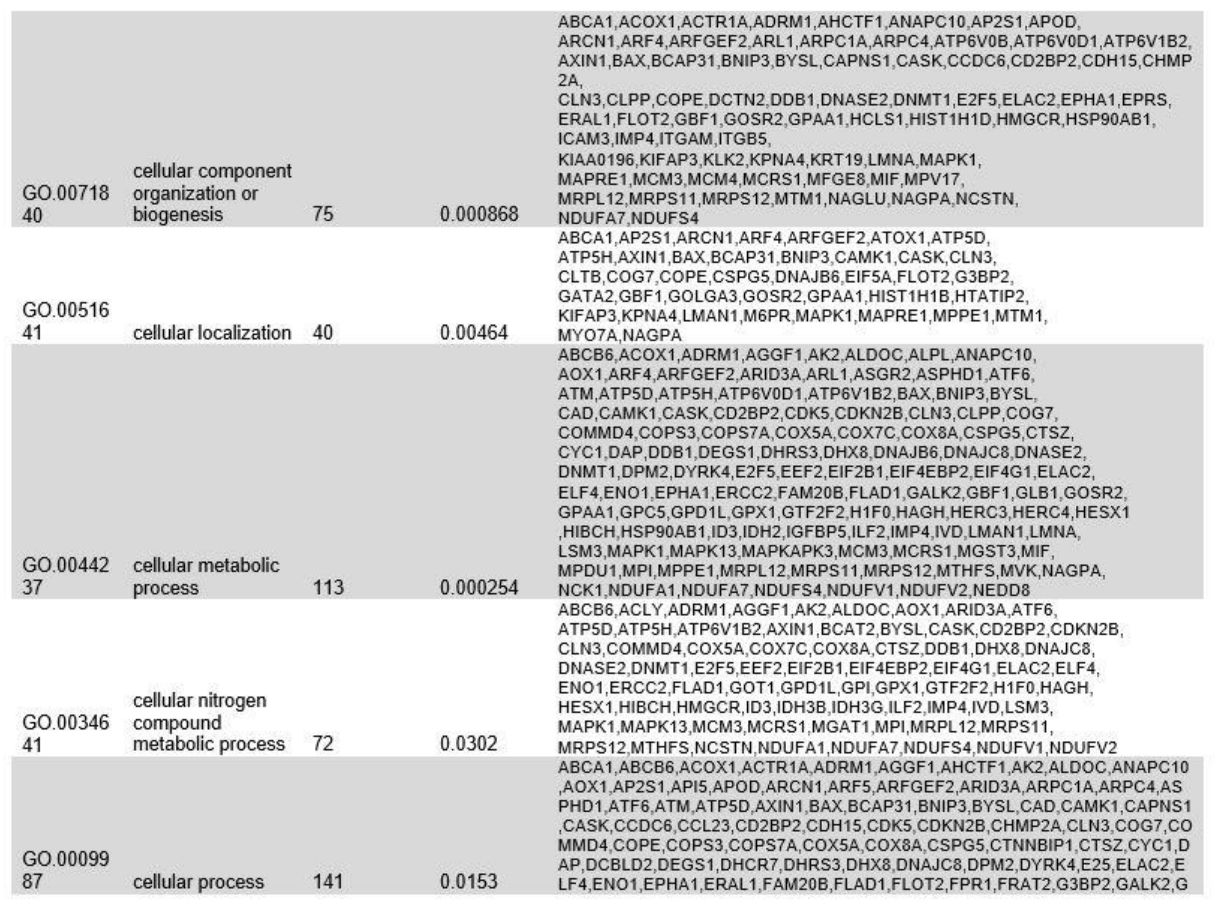




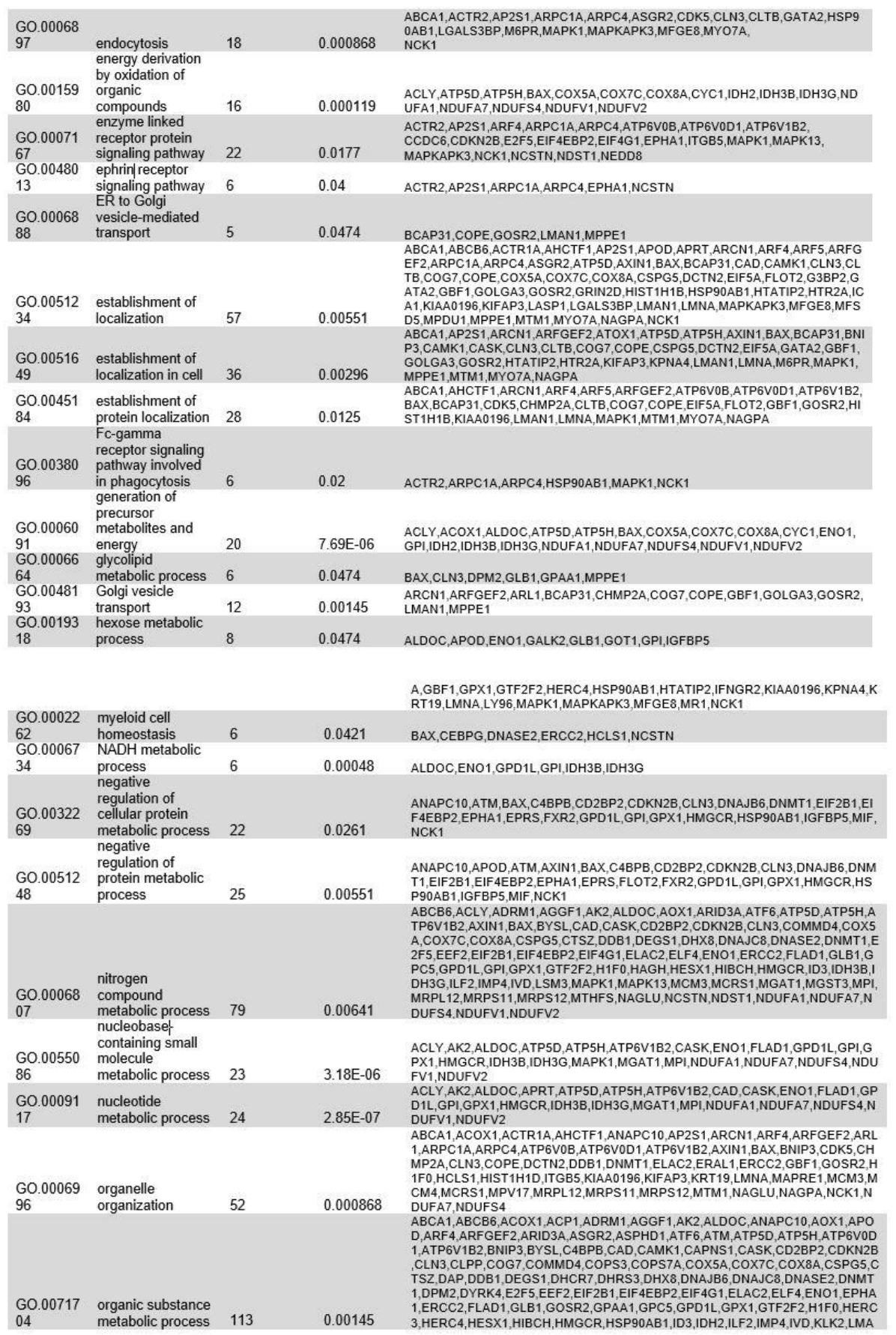




\begin{tabular}{|c|c|c|c|c|}
\hline & & & & $\begin{array}{l}\text { N1,LMNA,LSM3,LY96,MAPK1,MAPK13,MAPKAPK3,MCM3,MCRS1,MGST3,MIF,M } \\
\text { PDU1,MP1,MPPE1,MRPL 12,MRPS11,MRPS12,MTHFS,MVK,NAGLU,NAGPA,NCK } \\
\text { 1,NDUFA1,NDUFA7,NDUFS4,NDUFV1,NDUFV2,NEDD8 }\end{array}$ \\
\hline $\begin{array}{l}\text { GO. } 19015 \\
64\end{array}$ & $\begin{array}{l}\text { Organo-nitrogen } \\
\text { compound } \\
\text { metabolic process }\end{array}$ & 45 & $2.85 \mathrm{E}-07$ & $\begin{array}{l}\text { ABCB6,ACLY,AK2,ALDOC,AOX1,ATP5D,ATP5H,ATP6V1B2,BAX,CAD,CLN3, } \\
\text { CSPG5,CTSZ,DEGS1,EEF2,EIF2B1, EIF4EBP2,EIF4G1,ENO1,FLAD1,GLB1, } \\
\text { GPC5,GPD1L,GPI,GPX1,HAGH,HIBCH,HMGCR,IDH3B,IDH3G,IVD,MAPK1, } \\
\text { MGST3,MRPL12,MRPS11,MRPS12,MTHFS,NAGLU,NCSTN,NDST1,NDUFA1,ND } \\
\text { UFA7,NDUFS4,NDUFV1,NDUFV2, }\end{array}$ \\
\hline $\begin{array}{l}\text { GO. } 00904 \\
07\end{array}$ & $\begin{array}{l}\text { organophosphate } \\
\text { biosynthetic } \\
\text { process }\end{array}$ & 14 & 0.0262 & $\begin{array}{l}\text { AK2,APRT,ATM,ATP5D,ATP5H,CAD,DPM2,FLAD1, GPAA1, GPD1L,MPI,MPPE1,M } \\
\text { TM1,MVK }\end{array}$ \\
\hline $\begin{array}{l}\text { GO. } 00196 \\
37\end{array}$ & $\begin{array}{l}\text { organophosphate } \\
\text { metabolic process }\end{array}$ & 30 & 7.88E-07 & $\begin{array}{l}\text { ACLY,AK2,ALDOC,APRT,ATM,ATP5D,ATP5H,ATP6V1B2,CAD,CASK,CLN3,DPM } \\
\text { 2,ENO1,FLAD1,GPAA1,GPD1L,GPX1,HMGCR,IDH3B,IDH3G,MGAT1,MPI,MPPE1 } \\
\text {,MTM1,MVK,NDUFA1,NDUFA7,NDUFS4,NDUFV1,NDUFV2, }\end{array}$ \\
\hline $\begin{array}{l}\text { GO. } 00551 \\
14\end{array}$ & $\begin{array}{l}\text { oxidation- } \\
\text { reduction process }\end{array}$ & 31 & $1.56 \mathrm{E}-05$ & $\begin{array}{l}\text { ACLY,ACOX1,ALDOC,ASPHD 1,ATP5D,ATP5H,BAX,COX5A,COX8A,CYB561D2,C } \\
\text { YC1,DDO,DEGS1,DHCR7,DHRS3,ENO1,GPD 1L,GPI,GPX1,HMGCR,HTATIP2,ID } \\
\text { H2,IDH3B,IDH3G,IVD,MGST3,NDUFA1,NDUFA7,NDUFS4,NDUFV1,NDUFV2, }\end{array}$ \\
\hline $\begin{array}{l}\text { GO. } 00061 \\
19\end{array}$ & $\begin{array}{l}\text { oxidative } \\
\text { phosphorylation }\end{array}$ & 6 & 0.0145 & ATP5D,NDUFA1,NDUFA7,NDUFS4,NDUFV1,NDUFV2 \\
\hline $\begin{array}{l}\text { GO. } 00067 \\
33\end{array}$ & $\begin{array}{l}\text { oxidoreduction } \\
\text { coenzyme } \\
\text { metabolic process }\end{array}$ & 7 & 0.0115 & ALDOC.ENO1.GPD1L.GPI.HMGCR.IDH3B.IDH3G \\
\hline $\begin{array}{l}\text { GO. } 00069 \\
09\end{array}$ & phagocytosis & 10 & 0.00198 & $\begin{array}{l}\text { ABCA1,ACTR2,ARPC1A,ARPC 4,GATA2, HSP90AB1, MAPK1,MFGE8,MYO7A } \\
\text {,NCK1 }\end{array}$ \\
\hline $\begin{array}{l}\text { GO.00067 } \\
96\end{array}$ & $\begin{array}{l}\text { phosphate- } \\
\text { containing } \\
\text { compound } \\
\text { metabolic process }\end{array}$ & 43 & 2.46E-05 & $\begin{array}{l}\text { ACLY,AK2,ALDOC,ALPL,APRT,ATM,ATP5D,ATP5H,ATP6V1B2,AXIN1,CAD, } \\
\text { CAMK1,CASK,CDK5,CLN3,DPM2,DYRK4,ENO1,EPHA1,ERCC2,FAM20B,FLAD1, } \\
\text { GALK2,GPAA1,GPD1L, GPX1,HMGCR,IDH3B,IDH3G,MAPK1,MAPK13,MAPKAPK } \\
3 \text {,MGAT1,MPI,MPPE1,MVK,NCK1,NDST1,NDUFA1,NDUFA7,NDUFS4, } \\
\text { NDUFV1,NDUFV2 }\end{array}$ \\
\hline $\begin{array}{l}\text { GO. } 00067 \\
93\end{array}$ & $\begin{array}{l}\text { phosphorus } \\
\text { metabolic process }\end{array}$ & 42 & 7.04E-05 & 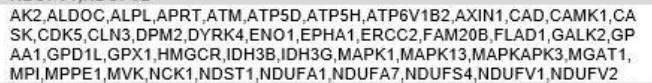 \\
\hline $\begin{array}{l}\text { GO. } 00163 \\
10\end{array}$ & phosphorylation & 26 & 0.00426 & 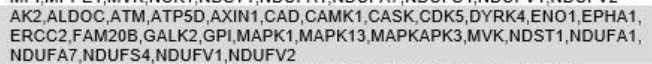 \\
\hline $\begin{array}{l}\text { GO.00485 } \\
18\end{array}$ & $\begin{array}{l}\text { positive regulation } \\
\text { of biological } \\
\text { process }\end{array}$ & 72 & 0.0117 & 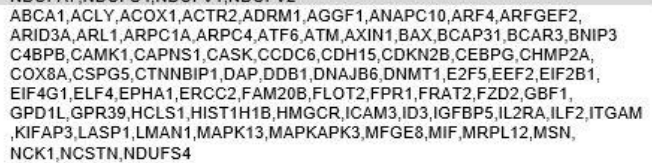 \\
\hline
\end{tabular}

\begin{tabular}{|c|c|c|c|c|}
\hline $\begin{array}{l}\text { GO. } 00485 \\
22\end{array}$ & $\begin{array}{l}\text { positive regulation } \\
\text { of cellular process }\end{array}$ & 62 & 0.0394 & 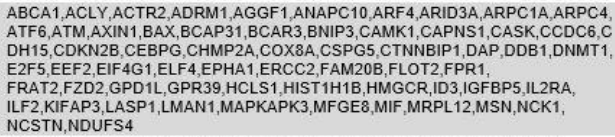 \\
\hline $\begin{array}{l}\text { GO. } 00442 \\
38\end{array}$ & $\begin{array}{l}\text { primary metabolic } \\
\text { process }\end{array}$ & 111 & 0.00145 & 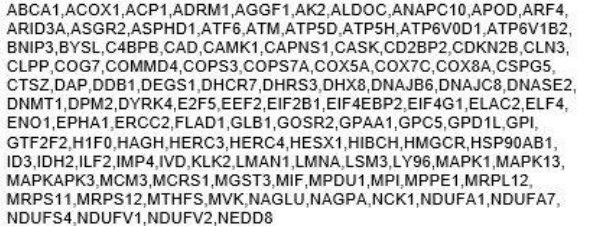 \\
\hline $\begin{array}{l}\text { GO.00064 } \\
61\end{array}$ & $\begin{array}{l}\text { protein complex } \\
\text { assembly }\end{array}$ & 21 & 0.0487 & $\begin{array}{l}\text { ADRM1, AHCTF1, AP2S1, ARPC4,AXIN1, BAX,CHMP2A,CLPP, EPRS, GPAA1, H1F0, } \\
\text { HCLS1, HIST11H1B, HIST1H1D, HMGCR, KIAA0196,KIFAP3,KPNA4,MIF, } \\
\text { NCK1,NDUFS } 4\end{array}$ \\
\hline $\begin{array}{l}\text { GO. } 00702 \\
71\end{array}$ & $\begin{array}{l}\text { protein complex } \\
\text { biogenesis }\end{array}$ & 21 & 0.0487 & $\begin{array}{l}\text { ADRM1,AHCTF1,AP2S1,ARPC4,AXIN1,BAX,CHMP2A,CLPP,EPRS, GPAA1,H1F0, } \\
\text { HCLS1,HIST1H1B,HIST1H1D, HMGCR,KIAA0196,KIFAP3,KPNA4,MIF, } \\
\text { NCK1,NDUFS4 }\end{array}$ \\
\hline $\begin{array}{l}\text { GO. } 00718 \\
22\end{array}$ & $\begin{array}{l}\text { protein complex } \\
\text { subunit } \\
\text { organization }\end{array}$ & 29 & 0.0186 & 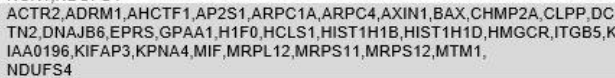 \\
\hline $\begin{array}{l}\text { GO. } 00081 \\
04\end{array}$ & protein localization & 36 & 0.00145 & 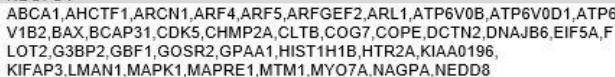 \\
\hline GO.00709 & $\begin{array}{l}\text { protein localization } \\
\text { to endoplasmic } \\
\text { reticulum exit site }\end{array}$ & 2 & 0.0377 & 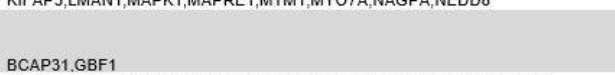 \\
\hline $\begin{array}{l}\text { GO. } 00333 \\
65\end{array}$ & $\begin{array}{l}\text { protein localization } \\
\text { to organelle }\end{array}$ & 16 & 0.0151 & $\begin{array}{l}\text { ARF4,ARL1,BAX,BCAP31,COG7,DCTN2,DNAJB6,GBF1,GOSR2,GPAA1, } \\
\text { HIST1H1B,HTR2A,KPNA4,MAPK1,MAPRE1,NAGPA }\end{array}$ \\
\hline $\begin{array}{l}\text { GO.00195 } \\
38\end{array}$ & $\begin{array}{l}\text { protein metabolic } \\
\text { process }\end{array}$ & 60 & 0.0164 & 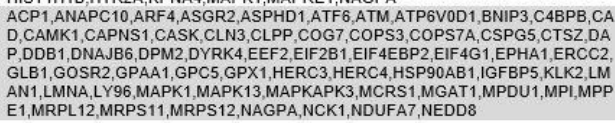 \\
\hline
\end{tabular}




\begin{tabular}{|c|c|c|c|c|}
\hline GO.00150 & protein transport & 25 & 0.04 & $\begin{array}{l}\text { ABCA1,AHCTF1,ARCN1,ARF4,ARF5,ARFGEF2,ATP6V0B,ATP6V0D1,ATP6V1B2, } \\
\text { BCAP31,CDK5,CHMP2A,CLTB,COG7,COPE,EIF5A, GBF1,GOSR2,KIAA0196,LMA } \\
\text { N1,LMNA,MAPK1,MTM1,MYO7A,NAGPA }\end{array}$ \\
\hline $\begin{array}{l}\text { GO. } 00061 \\
63\end{array}$ & $\begin{array}{l}\text { purine nucleotide } \\
\text { metabolic process } \\
\text { purine }\end{array}$ & 16 & 8.13E-05 & $\begin{array}{l}\text { ACLY,AK2,ALDOC,APRT,ATP5D,ATP5H,ATP6V1B2,ENO1,GPI,GPX1, HMGCR,N } \\
\text { DUFA1,NDUFA7,NDUFS4,NDUFV1,NDUFV2 }\end{array}$ \\
\hline $\begin{array}{l}\text { GO. } 00461 \\
28\end{array}$ & $\begin{array}{l}\text { ribonucleoside } \\
\text { metabolic process }\end{array}$ & 15 & $6.29 \mathrm{E}-05$ & $\begin{array}{l}\text { ACLY,AK2,ALDOC,APRT,ATP5D,ATP5H,ATP6V1B2,ENO1,GPI,HMGCR,NDUFA1, } \\
\text { NDUFA7,NDUFS4,NDUFV1,NDUFV2 }\end{array}$ \\
\hline $\begin{array}{l}\text { GO. } 00091 \\
67\end{array}$ & $\begin{array}{l}\text { purine } \\
\text { ribonucleoside } \\
\text { monophosphate } \\
\text { metabolic process }\end{array}$ & 13 & $5.57 \mathrm{E}-05$ & $\begin{array}{l}\text { AK2,ALDOC,APRT,ATP5D,ATP5H,ATP6V1B2,ENO1, GPI,NDUFA1,NDUFA7,NDU } \\
\text { FS4,NDUFV1,NDUFV2 }\end{array}$ \\
\hline $\begin{array}{l}\text { GO. } 00091 \\
50\end{array}$ & $\begin{array}{l}\text { ribonucleotide } \\
\text { metabolic process }\end{array}$ & 15 & 0.00017 & $\begin{array}{l}\text { ACLY,AK2,ALDOC,APRT,ATP5D,ATP5H,ATP6V1B2,ENO1,GPI,HMGCR,NDUFA1, } \\
\text { NDUFA7,NDUFS4,NDUFV1,NDUFV2 }\end{array}$ \\
\hline $\begin{array}{l}\text { GO. } 00725 \\
21\end{array}$ & $\begin{array}{l}\text { purine-containing } \\
\text { compound } \\
\text { metabolic process }\end{array}$ & 15 & 0.00113 & $\begin{array}{l}\text { ACLY,AK2,ALDOC,ATP5D,ATP5H,ATP6V1B2,ENO1,GPI,GPX1,HMGCR,NDUFA1, } \\
\text { NDUFA7,NDUFS4,NDUFV1,NDUFV2 }\end{array}$ \\
\hline $\begin{array}{l}\text { GO. } 00725 \\
24\end{array}$ & $\begin{array}{l}\text { pyridine-containing } \\
\text { compound } \\
\text { metabolic process }\end{array}$ & 7 & 0.00671 & ALDOC,AOX1,ENO1,GPD1L,GPI,IDH3B,IDH3G \\
\hline $\begin{array}{l}\text { GO. } 00650 \\
08\end{array}$ & $\begin{array}{l}\text { regulation of } \\
\text { biological quality }\end{array}$ & 55 & 0.000335 & 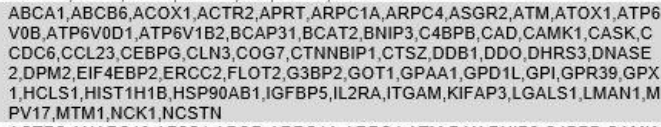 \\
\hline $\begin{array}{l}\text { GO. } 00511 \\
28\end{array}$ & $\begin{array}{l}\text { regulation of } \\
\text { cellular component } \\
\text { organization }\end{array}$ & 37 & 0.0376 & $\begin{array}{l}\text { ACTR2,ANAPC10,AP2S1,APOD,ARPC1A,ARPC4,ATM,BAX,BNIP3,C4BPB,CAMK } \\
1 \text {,CCDC6,CHMP2A,COX8A,CSPG5,CTNNBIP1,DCBLD2,DNAJB6,DNMT1,EIF5A, } \\
\text { ENO1,EPHA1,FAM20B,GPX1,GTF2F2,HCLS1,HIST1H1B,IGFBP5,LGALS1,LMAN } \\
\text { 1,LMNA,MAPK1,MAPRE1,MFGE8,MSN,MTM1,NCK1 }\end{array}$ \\
\hline $\begin{array}{l}\text { GO. } 00026 \\
82\end{array}$ & $\begin{array}{l}\text { regulation of } \\
\text { immune system } \\
\text { process }\end{array}$ & 28 & 0.0186 & $\begin{array}{l}\text { ACTR2,AP2S1,APOD,ARPC1A,ARPC4,ATM,BAX,C4BPB, COX8A,CSF3R,CSPG5, } \\
\text { CTNNBIP1,FLOT2,FXR2, GATA2,GPX1, HCLS1, HSP90AB1,ICAM3,IFNGR2,IL2RA, } \\
\text { ITGAM,LGALS1,LY96,MAPKAPK } 3, M I F, M S N, N C K 1\end{array}$ \\
\hline $\begin{array}{l}\text { GO. } 00330 \\
43\end{array}$ & $\begin{array}{l}\text { regulation of } \\
\text { organelle } \\
\text { organization }\end{array}$ & 25 & 0.0125 & $\begin{array}{l}\text { ACTR2,ANAPC } 10, \text { ARPC } 1 \text { A,ARPC } 4, \text { ATM, BAX,BNIP3, CDK5,CHMP2A, COX8A,CSP } \\
\text { G5,DNMT1,EPHA1,FAM20B,GATA2, GPX1,HCLS1, HIST1H1B,LMAN1, } \\
\text { LMNA,MAPK1,MAPRE1,MSN,MTM1,NCK1 }\end{array}$ \\
\hline $\begin{array}{l}\text { GO. } 00331 \\
35\end{array}$ & $\begin{array}{l}\text { regulation of } \\
\text { peptidyl|serine } \\
\text { phosphorylation }\end{array}$ & 8 & 0.00551 & AXIN1,BAX,BCAR3,CAMK1,GPD1L,HCLS1,MIF.NCK1 \\
\hline
\end{tabular}

\begin{tabular}{|c|c|c|c|c|}
\hline $\begin{array}{l}\text { G0.00512 } \\
46\end{array}$ & $\begin{array}{l}\text { regulation of } \\
\text { protein metabolic } \\
\text { process }\end{array}$ & 40 & 0.0458 & $\begin{array}{l}\text { ADRM1,ANAPC10,APOD,ATM,AXIN1,BCAP } 31 \text {,BCAR3,C4BPB, CAMK1,CCDC6,C } \\
\text { D2BP2,CDKN2B,CEBPG, CLN3,CTSZ,DAP,DNAJB6,DNMT1,EEF2,EIF4EBP2,EIF4 } \\
\text { G1,EPHA1,EPRS,FLOT2,FPR1,FXR2,GATA2,GPD1L,GPI,GPX1,HCLS1,HIST1H1 } \\
\text { B,HMGCR,IGFBP5,LY96,MAPKAPK3,MIF,MSN,NCK1,NDUFS4 }\end{array}$ \\
\hline $\begin{array}{l}\text { G0.00801 } \\
34\end{array}$ & $\begin{array}{l}\text { regulation of } \\
\text { response to stress }\end{array}$ & 28 & 0.0318 & 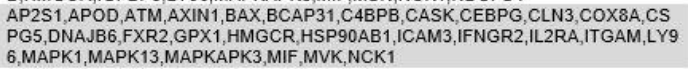 \\
\hline $\begin{array}{l}\text { Go.00229 } \\
04\end{array}$ & $\begin{array}{l}\text { respiratory } \\
\text { electron transport } \\
\text { chain }\end{array}$ & 11 & $5.92 \mathrm{E}-05$ & 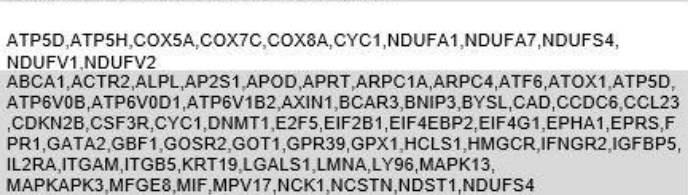 \\
\hline $\begin{array}{l}\text { GO.00097 } \\
19\end{array}$ & $\begin{array}{l}\text { response to } \\
\text { endogenous } \\
\text { stimulus }\end{array}$ & 28 & 0.00665 & 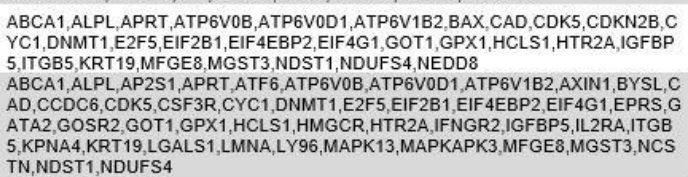 \\
\hline $\begin{array}{l}\text { GO. } 00102 \\
43\end{array}$ & $\begin{array}{l}\text { response to } \\
\text { organonitrogen } \\
\text { compound }\end{array}$ & 19 & 0.0349 & $\begin{array}{l}\text { APRT,ATP6V0B,ATP6V0D1,ATP6V1B2,BAX,CAD,CDK5,CYC1,DNMT1,EIF2B1,EI } \\
\text { F4EBP2,EIF4G1,GOT1,GPX1,HTR2A,IGFBP5,MAPK1,MGST3,NDUFS4 }\end{array}$ \\
\hline $\begin{array}{l}\text { GO. } 19017 \\
00\end{array}$ & $\begin{array}{l}\text { response to } \\
\text { oxygen-containing } \\
\text { compound }\end{array}$ & 30 & 0.00308 & $\begin{array}{l}\text { ABCA1,ALPL,APOD,APRT,ATOX1,ATP6V0B,ATP6V0D1,ATP6V1B2, BAX,BNIP3,B } \\
\text { YSL,CAD, CCDC6, CDK5,CYC1, DNMT1, EIF2B1,EIF 4EBP2, EIF 4G1, GOT1, GPX1, H } \\
\text { MGCR, HTR2A,IGFBP5,KPNA4,LGALS1,LY96,MAPKAPK3,MPV17, } \\
\text { NDUFS } 4\end{array}$ \\
\hline $\begin{array}{l}\text { GO.00068 } \\
90\end{array}$ & $\begin{array}{l}\text { retrograde vesicle- } \\
\text { mediated } \\
\text { transport, Golgi to } \\
\text { ER }\end{array}$ & 4 & 0.0365 & ARCN1, COG $7, C O P E, G B F 1$ \\
\hline $\begin{array}{l}\text { GO. } 00091 \\
19\end{array}$ & $\begin{array}{l}\text { ribonucleoside } \\
\text { metabolic process } \\
\text { ribonucleoside }\end{array}$ & 16 & 4.86E-05 & $\begin{array}{l}\text { ACLY,AK2,ALDOC,APRT,ATP5D,ATP5H,ATP6V1B2,CAD, ENO1,GPI,HMGCR,ND } \\
\text { UFA1,NDUFA7,NDUFS4,NDUFV1,NDUFV2 }\end{array}$ \\
\hline $\begin{array}{l}\text { GO. } 00091 \\
61\end{array}$ & $\begin{array}{l}\text { monophosphate } \\
\text { metabolic process }\end{array}$ & 14 & $2.46 \mathrm{E}-05$ & $\begin{array}{l}\text { AK2,ALDOC,APRT,ATP5D,ATP5H,ATP6V1B2,CAD,ENO1,GPI,NDUFA1,NDUFA7, } \\
\text { NDUFS4,NDUFV1,NDUFV2 }\end{array}$ \\
\hline
\end{tabular}




\begin{tabular}{|c|c|c|c|c|}
\hline $\begin{array}{l}\text { GO. } 00091 \\
99\end{array}$ & $\begin{array}{l}\text { ribonucleoside } \\
\text { triphosphate } \\
\text { metabolic process }\end{array}$ & 13 & 5.57E-05 & $\begin{array}{l}\text { AK2,ALDOC,ATP5D,ATP5H,ATP6V1B2,CAD,ENO1,GPI,NDUFA1,NDUFA7, NDUF } \\
\text { S4,NDUFV1,NDUFV2 }\end{array}$ \\
\hline $\begin{array}{l}\text { GO. } 00092 \\
59\end{array}$ & $\begin{array}{l}\text { ribonucleotide } \\
\text { metabolic process }\end{array}$ & 16 & $7.94 \mathrm{E}-05$ & $\begin{array}{l}\text { ACLY,AK2,ALDOC,APRT,ATP5D,ATP5H,ATP6V1B2,CAD,ENO1,GPI,HMGCR,ND } \\
\text { UFA1,NDUFA7,NDUFS4,NDUFV1,NDUFV2 }\end{array}$ \\
\hline G0.00071 & signal transduction & 66 & 0.0269 & $\begin{array}{l}\text { ABCA1,ACTR2,AHCTF1,AP2S1,ARF4,ARF5,ARFGEF2,ARL1,ARPC1A,ARPC4,AS } \\
\text { GR2,ATF6,ATM,ATP6V0B,ATP6V0D1,ATP6V1B2,AXIN1,BAX,BCAP31,BNIP3,CA } \\
\text { MK1,CCL23,CDKN2B,CLN3,COPS3,CTNNBIP1,DAP,DCBLD2,DDB1,DHRS3,E2F } \\
5 \text {,EIF4G1,EPHA1,FPR1,FRAT2,G3BP2,,GABRD,GOSR2,GPC5,GPR39,GPR4,GPX } \\
\text { 1,GRIN2D,HCLS1,HSP90AB1,ICAM3,IFNGR2,ITGAM,ITGB5,KIFAP 3,KLK2,KPNA } \\
\text { 4,LGALS1,LGALS3BP,LY96,M6PR,MAPK13,MAPKAPK3,MAPRE1,MGST3,MR1,N } \\
\text { CK1,NCSTN,NDST1,NDUFS4,NEDD8 }\end{array}$ \\
\hline $\begin{array}{l}\text { GO. } 00447 \\
08\end{array}$ & $\begin{array}{l}\text { single-organism } \\
\text { behavior }\end{array}$ & 13 & 0.0256 & $\begin{array}{l}\text { APRT,ARCN1,CDK5, CLN3,DDO,EIF4EBP2,EIF4G1, GPI, GPR39, GRIN2D, HMGCR, } \\
\text { HTR2A,NAGLU }\end{array}$ \\
\hline $\begin{array}{l}\text { GO.00447 } \\
11\end{array}$ & $\begin{array}{l}\text { single-organism } \\
\text { biosynthetic } \\
\text { process }\end{array}$ & 31 & 0.0012 & $\begin{array}{l}\text { AK2,ALDOC,APRT,ATM,ATP5D,ATP5H,BCAT2,CSPG5,DDB1,DEGS1,DHCR7,DP } \\
\text { M2,EEF2,EIF5A,ENO1,FLAD1,GPAA1,GPC5,GPD1L,HMGCR,MGST3,MIF,MPDU } \\
\text { 1,MPI,MPPE1,MRPL12,MRPS11,MRPS12,MTM1,MVK,NDUFA7 }\end{array}$ \\
\hline $\begin{array}{l}\text { GO. } 00447 \\
23\end{array}$ & $\begin{array}{l}\text { single-organism } \\
\text { carbohydrate } \\
\text { metabolic process }\end{array}$ & 17 & 0.0153 & $\begin{array}{l}\text { ALDOC,APOD,ARF4,COG7,DPM2,ENO1,GALK2,GOT1,GPI,IDH2,IGFBP5,LMAN1 } \\
\text {,MGAT1,MPDU1,MPI,NAGPA,NDST1 }\end{array}$ \\
\hline $\begin{array}{l}\text { GO. } 00447 \\
63\end{array}$ & $\begin{array}{l}\text { single-organism } \\
\text { cellular process }\end{array}$ & 128 & 0.00039 & 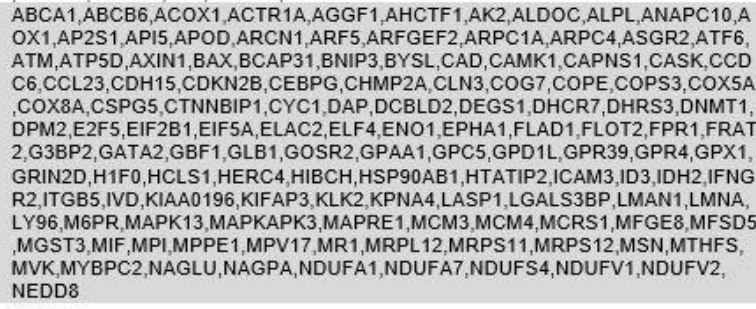 \\
\hline $\begin{array}{l}\text { GO. } 19025 \\
82\end{array}$ & $\begin{array}{l}\text { single-organism } \\
\text { intracellular } \\
\text { transport }\end{array}$ & 27 & 0.00394 & $\begin{array}{l}\text { ABCA1,ARCN1,ARFGEF2,ATOX1,ATP5D,ATP5H,BAX,BCAP31,BNIP3,CLN3,CO } \\
\text { G7,COPE,EIF5A,GATA2,GBF1, GOLGA3,GOSR2,HTR2A,KIFAP3, KPNA4,LMAN1, } \\
\text { LMNA,M6PR,MAPK1,MPPE1,MTM1,NAGPA }\end{array}$ \\
\hline $\begin{array}{l}\text { GO. } 00447 \\
10\end{array}$ & $\begin{array}{l}\text { single-organism } \\
\text { metabolic process }\end{array}$ & 68 & 0.000702 & 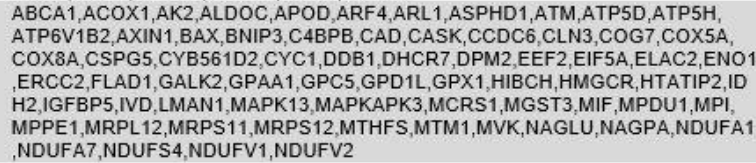 \\
\hline
\end{tabular}

\begin{tabular}{|c|c|c|c|c|}
\hline $\begin{array}{l}\text { GO. } 00442 \\
81\end{array}$ & $\begin{array}{l}\text { small molecule } \\
\text { metabolic process }\end{array}$ & 46 & $7.94 \mathrm{E}-05$ & $\begin{array}{l}\text { ABCA1,ACOX1,AK2,ALDOC,AOX1,ATP5D,ATP5H,ATP6V1B2,CAD,CASK, } \\
\text { CLN3,COX5A, COX7C, COX8A, CSPG5,CYC1,DEGS1,DHCR7,DHRS3,DPM2, } \\
\text { ENO1,ERCC2,FLAD1,GLB1,GPC5,GPD1L,GPX1,HIBCH,HMGCR,IDH2,IVD, } \\
\text { MAPK1,MGAT1,MGST3,MIF,MPI,MTHFS,MTM1,MVK,NAGLU,NDST1,NDUFA1, } \\
\text { NDUFA7,NDUFS4,NDUFV1,NDUFV2 }\end{array}$ \\
\hline $\begin{array}{l}\text { GO. } 00444 \\
03\end{array}$ & $\begin{array}{l}\text { symbiosis, } \\
\text { encompassing } \\
\text { mutualism through } \\
\text { parasitism }\end{array}$ & 19 & 0.0376 & $\begin{array}{l}\text { AP2S1,ATP6V0B,ATP6V0D1,ATP6V1B2,BAX,BNIP3, CHMP2A,DDB1, EIF4G1, } \\
\text { ERCC2, GBF1, GPX1,GTF2F2,HSP90AB1, HTATIP2,KPNA4,KRT19,MAPK1, } \\
\text { MFGE8 }\end{array}$ \\
\hline $\begin{array}{l}\text { GO. } 00071 \\
69\end{array}$ & $\begin{array}{l}\text { transmembrane } \\
\text { receptor protein } \\
\text { tyrosine kinase } \\
\text { signaling pathway }\end{array}$ & 18 & 0.0262 & $\begin{array}{l}\text { ACTR2,AP2S1,ARF4,ARPC1A,ARPC4,ATP6V0B,ATP6V0D1,ATP6V1B2,CCDC6,E } \\
\text { IF4EBP2,EIF4G1,EPHA1,MAPK1,MAPK13,MAPKAPK3,NCK1,NCSTN,NDST1 }\end{array}$ \\
\hline $\begin{array}{l}\text { GO. } 00068 \\
10\end{array}$ & transport & 55 & 0.00821 & $\begin{array}{l}\text { ABCA1,ABCB6,ACTR1A,AHCTF1,AP2S1,APOD,APRT,ARCN1,ARF4,ARF5, } \\
\text { ARFGEF2,ARPC1A,ARPC4,ASGR2,ATP5D,AXIN1,BAX,BCAP31,CAD,CAMK1, } \\
\text { CLN3,CLTB,COG7,COPE, COX5A, COX7C,COX8A,CSPG5,DCTN2,EIF5A, } \\
\text { G3BP2, GATA2,GBF1,GOLGA3,GOSR2, GRIN2D, HSP90AB1,HTATIP2,HTR2A, } \\
\text { ICA1,KIAA0196,KIFAP3,LASP1,LGALS3BP,LMAN1,LMNA,MAPKAPK3, } \\
\text { MFGE8,MFSD5,MPDU1,MPPE1,MTM1,MYO7A,NAGPA,NCK1 }\end{array}$ \\
\hline $\begin{array}{l}\text { GO. } 00070 \\
34\end{array}$ & vacuolar transport & 6 & 0.0238 & \\
\hline $\begin{array}{l}\text { GO. } 00161 \\
92\end{array}$ & $\begin{array}{l}\text { vesicle-mediated } \\
\text { transport }\end{array}$ & 31 & 0.000102 & $\begin{array}{l}\text { ABCA1,ACTR1A,ACTR2,AP2S1, ARCN1,ARF 4,ARF5,ARFGEF2,ARPC1A,ARPC4, } \\
\text { ASGR2,BCAP31,CHMP2A,CLN3,CLTB,COG7,COPE, GATA2,GBF1,GOLGA3, GOS } \\
\text { R2,HSP90AB1,LGALS3BP,LMAN1,M6PR,MAPK1,MAPKAPK3,MFGE8,MPPE1,MY } \\
\text { O7A,NCK1 }\end{array}$ \\
\hline
\end{tabular}

Table 4.13 Biological processes of ID3 and ID3 candidate target genes in tissue. Gene ontology (GO) shown via STRING database demonstrate 116 biological processes. 
ID3 \& ID3 candidate target genes \& EDC-associated genes. Comparative Toxicogenomic Database examination yielded various results. When comparing ID3 candidate target genes in blood (134) with PCB associated genes (648) results demonstrated 12 genes which include: AEBP1, APOH, CHEK1, DNMT1, DTYMK, FKBP4, GFRA1, HIST1H4C, ID3, IL6, LIFR, and MTTP (Figure 4.9.1 \& Table 4.15.1). Furthermore, when comparing ID3 candidate target genes in tissue (217) with PCB associated genes (648) results showed 13 genes including: ACOX1, ACTR2, ALDOC, CDK2AP2, CSF3R, CTSZ, DNMT1, GPI, HSP90AB1, ID3, ILF2, ITGB5, LY96 (Figure 4.9.2 \& Table 4.15.2). Additionally, we also investigated two specific PCB congeners (PCB153 and PCB180) and examined their associated genes with ID3/ID3 candidate target genes. ID3 candidate target genes in blood (134) and PCB153-associated genes (2016) resulted in 19 genes including: CCL7, CTNNB1, DCX, DLG2, DTYMK, DUSP14, FNBP1, GRIN2B, HMGB3, HNF4G, HS3ST1, HTR4, IFIH1, IGFBP2, IL6, LIFR, MCM4, MMP11, and NDUFA7 (Figure 4.9.4 \& Table 4.15.4). ID3 candidate target genes in tissue (217) and PCB153associated genes (2016) resulted in 24 genes: ABCA1, AOX1, APOD, ASGR2, ATM, BAX, COG7, EEF2, ELF4, GOT1, GPC5, GPX1, HIST1H1B, HMGCR, HTATIP2, IDH2, IL2RA, MAPK1, MCM3, MCM4, MGST3, MTM1, MVK, NDUFA7 (Figure 4.9.5 \& Table 4.15.5). When comparing ID3 candidate target genes in blood (134) with PCB180-assciated genes (1876) results yielded 20 genes including: ACTN1, ARID5B, CACNG3, CCL7, CHEK1, DCX, DLG2, DUSP14, FBLN5, FNBP1, GRIN2B, HDAC4, HMGB3, HNF4G, HS3ST1, HTR4, IFIH1, IL6, MCM4, and NDUFA7 (Figure 4.9.7 \& Table 4.15.7). ID3 candidate target genes in 
tissue (217) vs. PCB180-associated gens (1876) resulted in 18 genes: APOD, ATM, BAX, COG7, ELF4, GPC5, HIBCH, HSP90AB1, HTR2A, IL2RA, LGALS1, LGALS3BP, MAPK1, MCM3, MCM4, MGST3, MTM1, and NDUFA7 (Figure 4.9.8 \& Table 4.15.8). Lastly we also demonstrated BPA-associated genes (19169) with ID3 candidate targets in both blood and tissue respectively. These results indicated 126 genes in blood and 202 genes in tissue further demonstrated in Figures 4.10.1 \& 4.10.2 and Tables 4.16.1 \& 4.16.2.

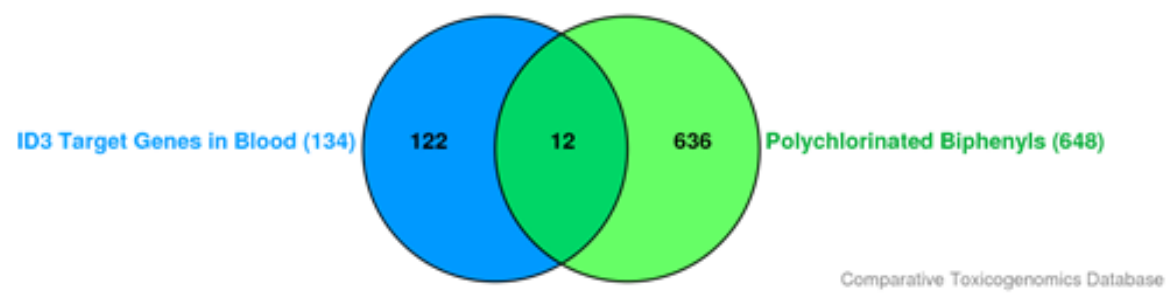

Figure 4.8.1 Venn diagram illustrating ID3 candidate target genes in blood with PCBs. ID3 candidate target genes (134), PCB associated genes (648), and overlapping genes (12).

\begin{tabular}{|c|}
\hline Associated ID3 Target Genes in blood with PCBs \\
\hline AEBP1 \\
\hline APOH \\
CHEK1 \\
DNMT1 \\
DTYMK \\
FKBP4 \\
GFRA1 \\
HIST1H4C \\
ID3 \\
IL6 \\
LIFR \\
MTTP \\
\hline
\end{tabular}

Table 4.14.1 ID3 candidate target genes in blood associated with polychlorinated biphenyls (PCBs). 


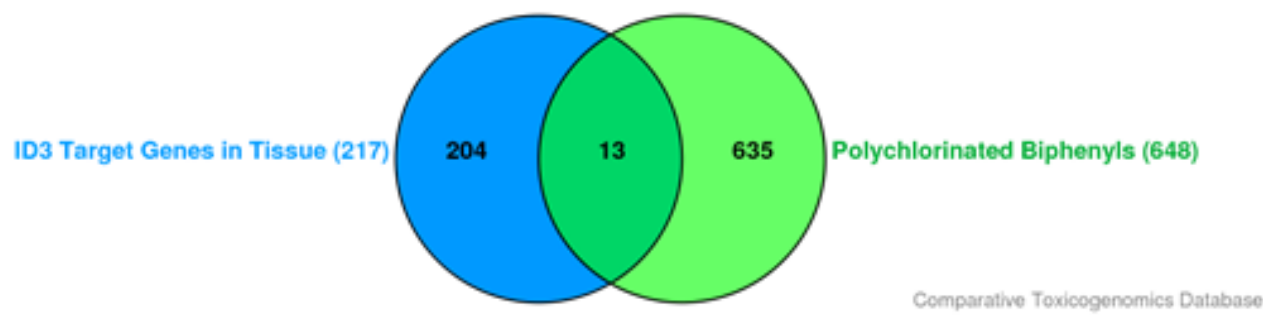

Figure 4.8.2 Venn diagram illustrating ID3 candidate target genes in tissue with PCBs. ID3 candidate target genes (217), PCB associated genes (648), and overlapping genes (13)

\begin{tabular}{|c|}
\hline Associated ID3 Target Genes in tissue with PCBs \\
\hline ACOX1 \\
\hline ACTR2 \\
\hline ALDOC \\
\hline CDK2AP2 \\
\hline CSF3R \\
CTSZ \\
\hline DNMT1 \\
\hline GPI \\
\hline HSP90AB1 \\
\hline ID3 \\
ILF2 \\
\hline ITGB5 \\
\hline LY96 \\
\hline
\end{tabular}

Table 4.14.2 ID3 candidate target genes in tissue associated with polychlorinated biphenyls (PCBs). 
Overlapping ID3 Target Genes in Blood \& Tissue (11)

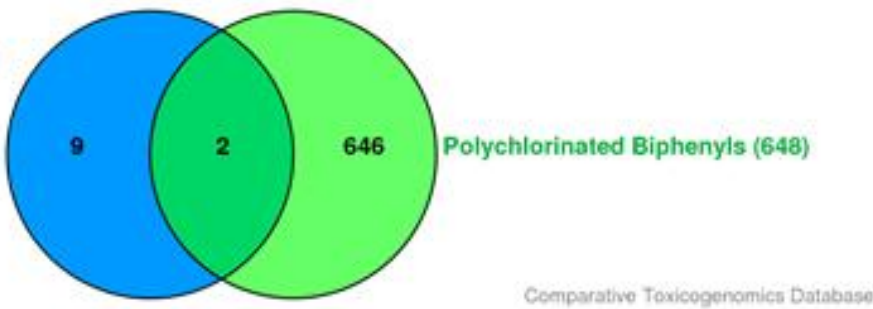

Figure 4.8.3 Venn diagram summarizing overlapping ID3 candidate target genes in blood-tissue with PCBs. ID3 candidate target genes (11), PCB associated genes (648), and overlapping genes (2)

\begin{tabular}{c}
\hline Overlapping ID3 Candidate Target Genes \\
Genes in blood-tissue with PCBs \\
DNMT1 \\
ID3 \\
\hline
\end{tabular}

Table 4.14.3 Overlapping ID3 candidate target genes in blood-tissue associated with polychlorinated biphenyls (PCBs).

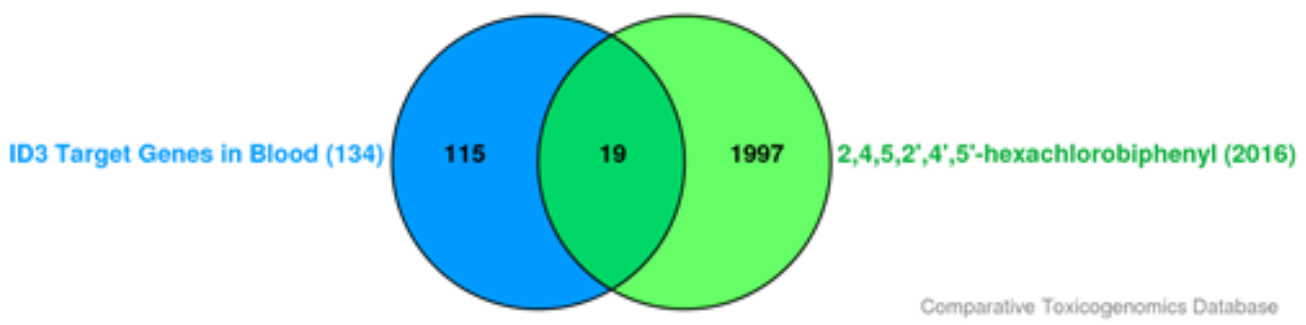

Figure 4.8.4 Venn diagram summarizing ID3 candidate target genes in blood with PCB153. ID3 candidate target genes (134), PCB153 associated genes (2016), and overlapping genes (19) 


\begin{tabular}{|c|}
\hline Associated ID3 Candidate Target Genes in blood with PCB153 \\
\hline CCL7 \\
\hline CTNNB1 \\
\hline DCX \\
\hline DLG2 \\
\hline DTYMK \\
\hline DUSP14 \\
\hline FNBP1 \\
GRIN2B \\
HMGB3 \\
HNF4G \\
HS3ST1 \\
HTR4 \\
\hline IFIH1 \\
\hline IGFBP2 \\
\hline IL6 \\
\hline LIFR \\
\hline MCM4 \\
\hline MMP11 \\
\hline NDUFA7 \\
\hline
\end{tabular}

Figure 4.14.4 ID3 candidate target genes in blood associated with polychlorinated biphenyl 153 (PCB153).

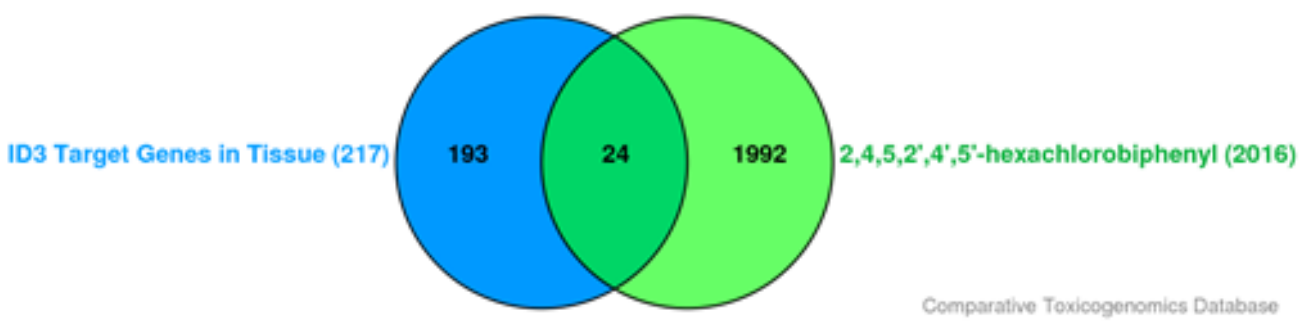

Figure 4.8.5 Venn diagram summarizing ID3 candidate target genes in tissue with PCB153. ID3 candidate target genes (217), PCB153 associated genes (2016), and overlapping genes (24). 


\begin{tabular}{|c|}
\hline Associated ID3 Candidate Target Genes in tissue with PCB153 \\
\hline ABCA1 \\
\hline AOX1 \\
\hline APOD \\
\hline ASGR2 \\
\hline ATM \\
\hline BAX \\
\hline COG7 \\
\hline EEF2 \\
\hline ELF4 \\
\hline GOT1 \\
GPC5 \\
\hline GPX1 \\
\hline HIST1H1B \\
\hline HMGCR \\
\hline HTATIP2 \\
IDH2 \\
\hline L2RA \\
\hline MAPK1 \\
\hline MCM3 \\
\hline MCM4 \\
\hline MGST3 \\
\hline MTM1 \\
\hline MVK \\
\hline NDUFA7 \\
\hline
\end{tabular}

Figure 4.14.5 ID3 target genes in tissue associated with polychlorinated biphenyl 153 (PCB153).

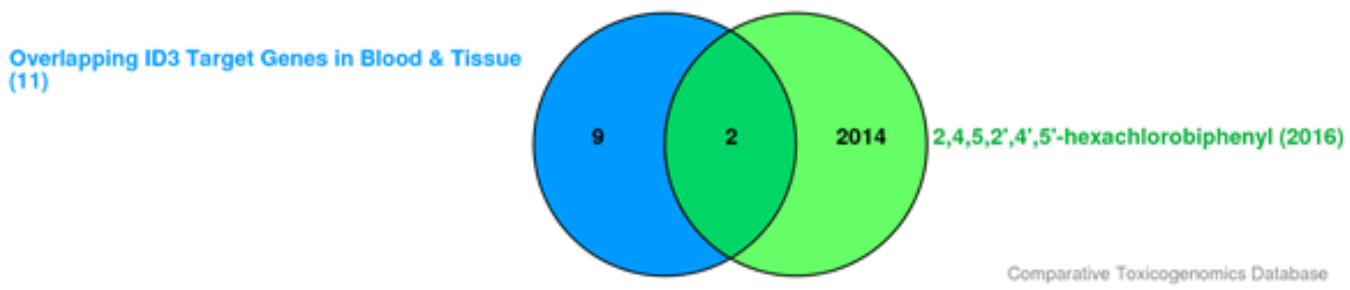

Figure 4.8.6 Venn diagram summarizing ID3 candidate target genes in blood-tissue. ID3 candidate target genes (11), PCB153 associated genes (2016), and overlapping genes (2). 


\begin{tabular}{c}
\hline Overlapping ID3 Candidate Target Genes \\
in blood-tissue with PCB153 \\
MCM4 \\
NDUFA7 \\
\hline
\end{tabular}

Figure 4.14.6 ID3 target genes in blood-tissue associated with polychlorinated biphenyl 153 (PCB153).

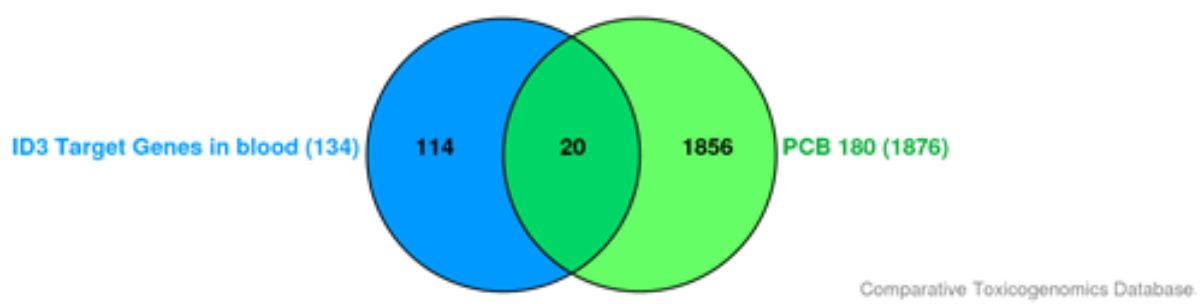

Figure 4.8.7 Venn diagram summarizing ID3 target genes in blood with PCB180. ID3 candidate target genes (134), PCB180 associated genes (1876), and overlapping genes (20).

\begin{tabular}{|c|}
\hline Associated ID3 Candidate Target Genes in blood with PCB180 \\
\hline ACTN1 \\
\hline ARID5B \\
\hline CACNG3 \\
CCL7 \\
\hline CHEK1 \\
\hline DCX \\
\hline DLG2 \\
\hline DUSP14 \\
\hline FBLN5 \\
\hline FNBP1 \\
GRIN2B \\
\hline HDAC4 \\
HMGB3 \\
HNF4G \\
\hline HS3ST1 \\
HTR4 \\
\hline IFIH1 \\
\hline IL6 \\
\hline MCM4 \\
\hline NDUFA7 \\
\hline
\end{tabular}

Figure 4.14.7 ID3 candidate target genes in blood associated with polychlorinated biphenyl 180 (PCB180). 


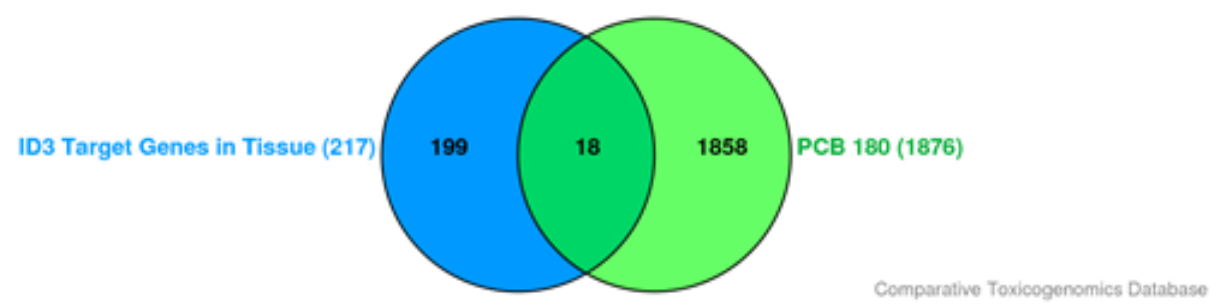

Figure 4.8.8 Venn diagram summarizing ID3 candidate target genes in tissue with PCB180. ID3 candidate target genes (217), PCB180 associated genes (1876), and overlapping genes (18).

\begin{tabular}{|c|}
\hline Associated ID3 Candidate Target Genes in tissue with PCB180 \\
\hline APOD \\
\hline ATM \\
\hline BAX \\
COG7 \\
ELF4 \\
GPC5 \\
HIBCH \\
\hline HSP90AB1 \\
\hline HTR2A \\
\hline IL2RA \\
\hline LGALS1 \\
\hline LGALSBP \\
\hline MAPK1 \\
MCM3 \\
MCM4 \\
\hline MGST3 \\
\hline MTM1 \\
\hline NDUFA7 \\
\hline
\end{tabular}

Figure 4.14.8 ID3 candidate target genes in tissue associated with polychlorinated biphenyl 180 (PCB180).

Overlapping ID3 Target Genes in blood \& tissue (11)

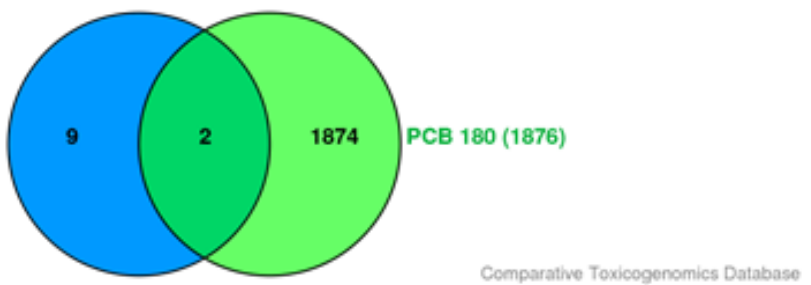

Figure 4.8.9 Venn diagram summarizing overlapping ID3 candidate target genes in blood-tissue with PCB180. ID3 candidate target genes (11), PCB180 associated genes (1876), and overlapping genes (2). 


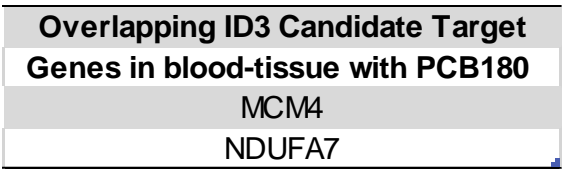

Table 4.14.9 ID3 candidate target genes in blood-tissue associated with polychlorinated biphenyl 180 (PCB180).

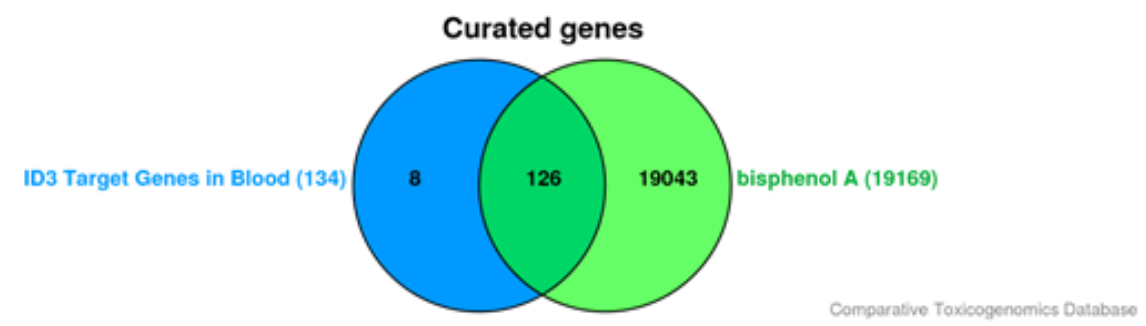

Figure 4.9.1. Venn diagram summarizing ID3 candidate target genes in blood with BPA. ID3 candidate target genes (134), Bisphenol A associated genes (19169), and overlapping genes (126). 


\begin{tabular}{|c|c|c|}
\hline ABCA4 & COL1A2 & GLRA1 \\
\hline ABCB6 & COL3A1 & GPR135 \\
\hline ACIN1 & COL6A1 & GPR37L1 \\
\hline ACP1 & COPB2 & GRIA2 \\
\hline ACTA2 & CREBBP & GRIK5 \\
\hline ACTN1 & CRYAA & GRIN2B \\
\hline ADAMTS3 & CTGF & GRP \\
\hline AEBP1 & CTH & HDAC4 \\
\hline AGTR2 & CTNNB1 & HDDC2 \\
\hline ANKRD26 & CTSF & HMGB3 \\
\hline ANPEP & CYP26A1 & HMGCS2 \\
\hline APAF1 & CYP4F11 & HNF4G \\
\hline APOF & CYR61 & HOXD3 \\
\hline $\mathrm{APOH}$ & DAAM1 & HS3ST1 \\
\hline ARID5B & DAB2 & HSPB2 \\
\hline ARSA & DCX & HTR4 \\
\hline ASB4 & DHRS3 & IBSP \\
\hline ASNS & DHRS7 & ID3 \\
\hline ATP7B & DIRAS3 & $\mathbb{I F} \| \mathrm{H} 1$ \\
\hline AVPR2 & DLG2 & IGFBP2 \\
\hline BCAM & DNAJC7 & IL13RA2 \\
\hline BCL2L2 & DNMT1 & IL6 \\
\hline BYSL & DOCK9 & INHBB \\
\hline C10ORF10 & DRD1 & ITGA8 \\
\hline CACNB4 & DTYMK & $\mathrm{KCNH} 2$ \\
\hline CACNG3 & DUSP14 & KCNJ4 \\
\hline CAD & DYRK3 & KCNK1 \\
\hline CALR & DZIP1 & KIF1A \\
\hline CCL7 & EEF1E1 & KNG1 \\
\hline ССТ8 & ETS1 & LGR5 \\
\hline $\mathrm{CDH} 15$ & FBLN2 & LIFR \\
\hline $\mathrm{CDH} 16$ & FBLN5 & LMO3 \\
\hline $\mathrm{CDH} 17$ & FBP2 & MAN1A2 \\
\hline $\mathrm{CDH} 2$ & FKBP4 & MCM4 \\
\hline $\mathrm{CDH} 6$ & FNBP1 & MLLT10 \\
\hline CFDP1 & FUT9 & MMP11 \\
\hline CFTR & GABRA2 & MPP3 \\
\hline $\mathrm{CH} 25 \mathrm{H}$ & GAL & MPP6 \\
\hline CHEK1 & GAS8 & MTTP \\
\hline CKM & GCLM & MYL2 \\
\hline CNKSR2 & GDF11 & NDP \\
\hline COL17A1 & GFRA1 & NDUFA7 \\
\hline
\end{tabular}

Table 4.15.1 ID3 candidate target genes in blood associated with BPA.

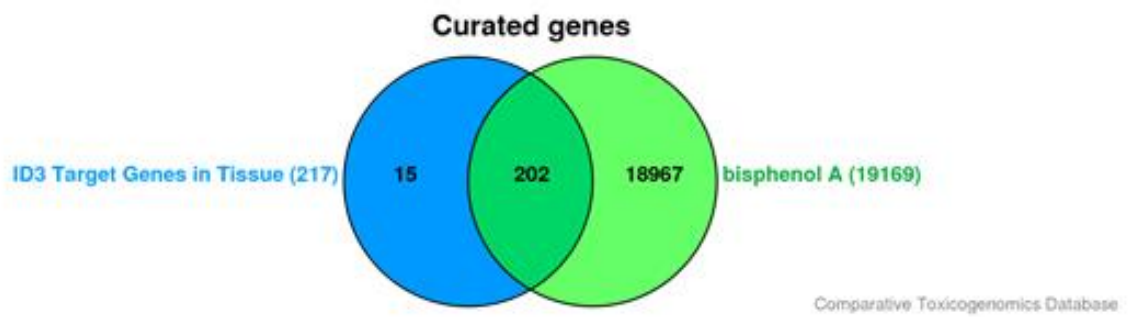

Figure 4.9.2. Venn diagram summarizing ID3 candidate target genes in tissue with BPA. ID3 candidate target genes (217), Bisphenol A associated genes (19169), and overlapping genes (202) 


\begin{tabular}{|c|c|c|c|c|c|}
\hline ABCA1 & BAX & DCTN2 & GLB1 & LASP1 & NDUFV1 \\
\hline ABCB6 & BCAP31 & DCTN5 & GOLGA3 & LGALS1 & NDUFV2 \\
\hline ACLY & BCAR3 & DDB1 & GOSR2 & LGALS3BP & NEDD8 \\
\hline ACOX1 & BCAT2 & DDN & GOT1 & LMAN1 & \\
\hline ACP1 & BCL7B & DDO & GPAA1 & LMNA & \\
\hline ACTR1A & BNIP3 & DEGS1 & GPC5 & LRRC42 & \\
\hline ACTR2 & BYSL & DHCR7 & GPD1L & LSM3 & \\
\hline ADRM1 & C4BPB & DHRS3 & GPI & LY96 & \\
\hline AGGF1 & CAD & DHX16 & GPR39 & M6PR & \\
\hline AHCTF1 & CAMK1 & $\mathrm{DHX8}$ & GPR4 & MAPK1 & \\
\hline AK2 & CASK & DNAJB6 & GPX1 & МАРК13 & \\
\hline ALDH3B1 & CCDC6 & DNAJC8 & GRIN2D & MAPKAPK3 & \\
\hline ALDOC & $\mathrm{CCNI}$ & DNASE2 & H1F0 & MAPRE1 & \\
\hline ALPL & $\mathrm{CD} 2 \mathrm{BP} 2$ & DNMT1 & HAGH & MCM3 & \\
\hline ANAPC10 & CD99 & DPM2 & HCLS1 & MCM4 & \\
\hline AOX1 & $\mathrm{CDH} 15$ & DYRK4 & HERC4 & MCRS1 & \\
\hline AP2S1 & CDK2AP2 & E2F5 & HESX1 & MFGE8 & \\
\hline API5 & CDK5 & EEF2 & $\mathrm{HIBCH}$ & MFSD5 & \\
\hline APOD & CDKN2B & EIF2B1 & HIST1H1B & MGAT1 & \\
\hline APRT & CEBPG & EIF4EBP2 & HIST1H1D & MGST3 & \\
\hline ARCN1 & CHMP2A & EIF4G1 & HMGCR & MIF & \\
\hline ARF4 & CLN3 & EIF5A & HSP90AB1 & MPDU1 & \\
\hline ARF5 & CLPP & ELAC2 & HTATIP2 & MPI & \\
\hline ARFGEF2 & CLTB & ENO1 & HTR2A & MPPE1 & \\
\hline ARID3A & COG7 & EPHA1 & ICA1 & MR1 & \\
\hline ARL1 & COMMD4 & EPRS & ID3 & MRPL12 & \\
\hline ARPC1A & COPE & ERAL1 & IDH2 & MRPS12 & \\
\hline ARPC4 & COPS3 & ERCC2 & IDH3B & MSN & \\
\hline ASGR2 & COPS7A & FAM2OB & IDH3G & MTHFS & \\
\hline ASPHD1 & COX5A & FAM50A & IFNGR2 & MTM1 & \\
\hline ATF6 & cox7C & FLAD1 & IGFBP5 & MYBPC2 & \\
\hline ATM & COX8A & FLOT2 & IL2RA & MYO7A & \\
\hline ATOX1 & CSF3R & FRAT2 & ILF2 & NAGLU & \\
\hline ATP5D & CSPG5 & FXR2 & IMP4 & NAGPA & \\
\hline ATP5H & CTNNBIP1 & FZD2 & ITGAM & NCK1 & \\
\hline ATP6V0B & CTSZ & G3BP2 & ITGB5 & NCSTN & \\
\hline ATP6V0D1 & CYB561D2 & GABRD & IVD & NDST1 & \\
\hline ATP6V1B2 & CYC1 & GALK2 & KIFAP3 & NDUFA1 & \\
\hline AXIN1 & CYHR1 & GATA2 & KPNA4 & NDUFA7 & \\
\hline $\mathrm{BAX}$ & DAP & GBF1 & KRT19 & NDUFS4 & \\
\hline
\end{tabular}

Table 4.15.2 ID3 candidate target genes in tissue associated with BPA.

\section{Discussion}

To our knowledge this is a novelty study approach investigating ID3 and ID3 candidate target genes in vascular-intimal lesions. Our analysis intergrading both statistical \& bioinformatics methods attempts to identify ID3 and ID3 candidate target genes alongside key gene networks that differentiate vascular disease subjects from non-disease subjects. We have used these approaches to elucidate a core set of genes in both blood \& tissue that represent ID3 and potential targets. Interestingly 11 of these genes are mutually expressed in the two locations of 
vascular diseases: blood \& tissue. These genes whose involvement in various biological processes such as extracellular matrix, focal adhesion, \& cell growth may help explain how ID3 signaling drives vascular dysfunction in the pathogenesis of these vascular diseases, in which vascular-intimal lesions manifest from. All mutually represented ID3 candidate target genes in both blood \& tissue demonstrate known roles in vascular diseases forming a tight cluster that is largely centered on the regulation of these biological processes.

The identification of ID3 \& ID3 candidate target genes helped truncate our vast quantity of mutually expressed genes (3665) across all the data. In our analysis we identified ID3 and ID3 candidate target genes in blood (134) and tissue (217) studies. In blood, 5 pathways were overrepresented by these genes. Interestingly, 2 pathways contribute to vascular perturbation in the lesion: extracellular matrix-receptor interaction \& focal adhesion. The extracellular matrix (ECM); which is a dynamic composite of various proteins that form structures connecting cells, provides an architectural framework within the network. Blood vessels are inflated by blood pressure and thus require ECM mechanisms with enough tensile strength and elasticity to resist rupture (Ponticos \& Smith. 2014). Furthermore focal adhesion, a type of adhesive contact between the cell and extracellular matrix is essential for proliferation, cell migrations, and embryonic development (Eleniste \& Bruzzaniti. 2012). Together both regulate \& control cellular function through biochemical and mechanical signaling. Cells respond to the ECM by alternating their environment which becomes dysregulated in vascular diseases such as atherosclerosis, restenosis, and hypertension (Ponticos \& Smith. 
2013). Both components are important for maintaining vascular integrity and prevention of unfavorable vascular remodeling (Raines. 2000). Overrepresented genes in both pathways include COL1A2, COL3A1, COL6A1, IBSP, ID3, \& ITGA8. Type I collagens COL1A1 and COL1A2 are part of the fibullar a-cellular component of basement membranes and connective tissue (Yurchenco, 2011). Most recently it was shown that the expression of pro-inflammatory genes such as TNF- $\alpha$ and MCP-1 was significantly up-regulated as well as the expression of the proremodeling genes collagen type I, fibronectin and the metalloproteinase MMP-2 and TIMP-1 (Zelko et al., 2016). Interestingly ID3 snp rs11574 was demonstrated to up-regulate MMP3 \& down-regulate COL6A3 leading to the stimulation of atherogensis, which includes biological processes such as apoptosis, cell movement, cellular proliferation, immune trafficking, \& adhesion (Doran et al., 2010). Integrin binding sialoprotein protein (IBSP) is a major structural protein of the bone matrix. The expression of IBSP also significantly increased on collagen type I ( 7 fold), vitrovectin ( 5 fold), and laminin during a study where the role of ECM proteins in regulating the proliferation and osteogenic differentiation of bone marrow derived human mesenchymal stem cells (hMSCs) was examined (Matthews et al., 2012). In tissue, 20 pathways were overrepresented by ID3 candidate target genes. Two pathways were identified as a contributing factor to vascular dysfunction: oxidative phosphorylation \& cell cycle pathway. Oxidative phosphorylation, which is the metabolic pathway in which cells use enzymes to oxidize nutrients is essential in the pathogenesis of vascular disease. Overproduction of reactive oxygen species (ROS) under various pathophysiologic 
conditions can trigger certain pathways that may lead to vascular inflammation causing vessel \& plaque rupture (Madamanchi et al. 2005; Gao et al. 2008). Vascular smooth muscle cell proliferation is a key component in the healing process of vascular dysfunction. This process is facilitated by multiple growth factors and cytokines which share a common pathway in inducing cell proliferation: the cell cycle (Braun-Dullaeus et al. 1998; Charron et al. 2006). Key molecular events in atherogenesis such as phospholipids, endothelial cell activation, oxidative modification of lipoproteins, and macrophage activation/infiltration are facilitated by vascular oxidative stress and inhibited by endothelial nitric oxide (Förstermann et al., 2017). Furthermore angiogenesis in the 3D collagen gel was demonstrated recently to be regulated by the JAK/STAT3 pathway which involves alterations in vessel diameter, vessel length, and sprout number. The essential mechanism was that the JAK/STAT3 signaling pathway regulated angiogenesis by perturbations in numbers of angiogenesis-associated growth factors and by direct regulation of cell cycle (Xue et al., 2016). Furthermore the top 10 most significant ID3 candidate target genes in both blood and tissue were demonstrated. In blood these genes include: COL1A2, COL6A1, CYP2C18, DIRAS3, DLG2, DZIP1, GCLM, GDF11, GRP, and KNG1. In tissue these genes include: ACLY, ACP1, ARPC4, ATP5D, CAMK1, CDKN2B, COPE, CYC1, EIF4EBP2, and MCRS1.

Additionally, genes including: ABCB6, ACP1, BYSL, CAD, CDH15, DCBLD2, DHRS3, DNMT1, ID3, MCM4, \& NDUFA7 are represented both in blood \& tissue data. In order to initially establish if these genes had an interaction within their network, a globally optimal Bayesian network structure without any structural 
limitations (Silander \& Myllymak) provided us with a fully connected structure. In order to further validate the model, the mutually common genes were implemented into a Bayesian network that allowed us to determine the probability distribution of gene expression (low, normal, \& high), location of disease (tissue and blood), and vascular state (disease and no disease). Represented by our initial model it was predicted that ID3 was predominately expressed as high (high: 79\%, normal: $4 \%$, \& low: $17 \%$ ). Also the vascular state was in close proximity of one another (disease state: $56 \%$, control state: $44 \%$ ). We demonstrated in the model when ID3 was expressed at various levels at $100 \%$ (high, normal, \& low). Interestingly when ID3 is highly expressed the genes in the model also became highly expressed predominantly occurring in blood with an evenly distributed vascular state (disease: $51 \%$, control state: $49 \%$ ). When ID3 expression is normal, the network is modeled more in tissue and the vascular state is principally geared toward vascular disease (disease: 65\%, control: 35\%). Low expression of ID3 represents activity principally in tissue toward vascular disease (disease: 66\%, control: $34 \%$ ). These changes in the model may elucidate to ID3 regulation that exists in this network. Furthermore we extended our analysis of ID3 candidate target genes in both blood \& tissue and investigated which genes are additionally estrogenic/endocrine disrupting chemical associated. Results demonstrated that gene DNMT1 is associated with ID3 candidate genes in both blood \& tissue and PCBs; and genes MCM4 \& NDUFA7 are associated with ID3 candidate target genes in both blood \& tissue and PCB153 \& PCB180. 
Interestingly each of these genes have been known to be involved in various vascular diseases through the literature. ABCB6 has been shown to have a new role in preventing atherosclerosis growth by inhibiting platelet production, reactivity, and chemokine ( $\mathrm{C}-\mathrm{C}$ motif) ligand-5 deposition in atherosclerotic lesions (Murphy et al., 2014). ACP1 is identified to be associated with atherosclerosis and autoimmune diseases in Caucasians. It was shown that rs79716074 genotype of GA polymorphism in ACP1 is associated with decreased risk of coronary arterial disease in Chinese northeast population especially in females (Li et al., 2015). CAD (carbamoyl-phosphate synthetase 2, aspartate transcarbamylase, and dihydroorotase) has been demonstrated as an unacknowledged mechanism that regulates NOTCH/VEGF signaling during angiogenesis (Caxam et al., 2015). DCBLD2 which is also known as ESDN has been established as a potential diagnostic and therapeutic target for graft atherosclerosis, which still remains a cause of progressive, chronic failure in cardiac allograft (Sadeghi et al., 2007). MCM4, part of a family of pre-replication complexes show that MCM2, MCM4, and MCM7 mRNA levels are increased in VSMCs during G1 phase, as indicated by increased Cyclin D1 levels (Guo et al., 2013). Furthermore this family of proteins is mutually modified by ID3 influence (MCM2, MCM3 and MCM10), such that genes down-regulated in PMEL-1 RAG1-/-ID3-/- T cells were induced by overexpression of ID3 (Ji et al., 2011). Also, DNMT1, a differentially expressed gene that is associated with VSMC-associated diseases which is regulated by 17 miRNAs, where these miRNAs are possible targets for developing anti-R based miRNA therapy, was recently established (Chen et al., 2017). DHRS3, was 
recently reported to be associated with rheumatoid arthritis (RA), a complex and prevalent complex inflammatory disease primarily affecting the joint (Wang et al., 2017). The vascular disease in RA encompasses a large spectrum ranging from rheumatoid vasculitis to atherosclerotic lesions (Tanasescua et al., 2009). NDUFA7, a subunit of the complex-I in the mitochondrial respiratory chain was also demonstrated to be associated with rheumatoid arthritis (RA). Association of NDUFA7 and RA suggest reactive oxygen species (ROS) in the pathogenesis of the disease (Mitsunaga et al., 2015). Additionally we have previously shown that ID3 is an important determinant of ROS-induced proliferation of estrogen exposed endothelial cells \& the overall results suggest ID3 may serve as a beneficial target for estrogen-dependent vascular-proliferative diseases (Felty \& Porther, 2008). We also demonstrated ID3 overexpressing cells which supported the formation of a 3-D microvascular lesion co-cultured with smooth muscle cells (Das JK et al., 2015) and overexpression of ID3 increased neovascularization, cell migration, and spheroid growth of human cerebral microvascular endothelial cells, hCMEC/D3 (Das \& Felty, 2015). We postulate that ID3 does have an essential role in regulation of these genes that take part in perturbations of vascular-intimal lesions.

\section{Conclusion}

In summary, our analysis strongly indicates that ID3 does have a molecular mechanism that affect changes in extracellular matrix, cell adhesion, \& cell growth which predisposes the blood vessel to vascular dysfunction. Common genes identified in blood and tissue samples show a strong suggestion for their several roles in vascular diseases. Therapeutic interventions which aim to target these 
particular processes may indicate great effectiveness in the treatment and prevention of vascular disease.

\section{References:}

1. Ji Y, Pos Z, Rao M, Klebanoff CA, Yu Z, Sukumar M, Reger RN, Palmer DC, Borman ZA, Muranski P, Wang E, Schrump DS, Marincola FM, Restifo NP, Gattinoni L. Repression of the DNA-binding inhibitor Id3 by Blimp-1 limits the formation of memory CD8+ T cells. Nature Immunology. 2011; 12, 1230-1237.

2. Doran AC, Lehtinen AB, Meller N, Lipinski, R MJ. Slayton P, Oldham SN, Skaflen MD, Yeboah J, Rich SS, Bowden DW, McNamara CA. Id3 Is a Novel Atheroprotective Factor Containing a Functionally Significant Single-Nucleotide Polymorphism Associated With Intima-Media Thickness in Humans. Circulation Research. 2010; 106: 1303-1311.

3. Carroll M, Luu T, Robaire B. Null Mutation of the Transcription Factor Inhibitor of DNA Binding 3 (Id3) Affects Spermatozoal Motility Parameters and Epididymal Gene Expression in Mice. Biology of Reproduction. 2011; 84(4): 765-774.

4. Szklarczyk D, Franceschini A, Wyder S, Forslund K, Heller D, Huerta-Cepas J, Simonovic M, Roth A, Santos A, Tsafou KP, Kuhn M, Bork P, Jensen LJ, von Mering C. STRING v10: protein-protein interaction networks, integrated over the tree of life. Nucleic Acids Research. 2015; 43:D447-52

5. GeNle \& SMILE. Graphical Network Interface GeNle \& SMILE. 1998; (http://dslpitt.org/genie/index.php/about).

6. Yoo C, Cooper GF. An evaluation of a system that recommends microarray experiments to perform to discover gene-regulation pathways. Artificial Intelligence in Medicine. 2004; 31 (2):169-182.

7. Heberle H, Meirelles GV, da Silva FR, Telles GP, Minghim R. InteractiVenn: a web-based tool for the analysis of sets through Venn diagrams. BMC Bioinformatics. 2015; 16:169.

8. Das JK, Voelkel, NF, Felty Q. ID3 Contributes to the Acquisition of Molecular Stem Cell-Like Signature in Microvascular Endothelial Cells: Its implication for understanding microvascular diseases. Microvascular Research. 2015; 98: 126138.

9. Felty Q, Porther N. Estrogen-induced redox sensitive Id3 signaling controls the growth of vascular cells. Atherosclerosis. 2008; 198(1): 12-21. 
10. Sakurai D, Tsuchiya N, Yamaguchi A, Okaji Y, Tsuno NH, Kobata T, Takahashi $\mathrm{K}$, Tokunaga K. Crucial role of inhibitor of DNA binding/differentiation in the vascular endothelial growth factor-induced activation and angiogenic processes of human endothelial cells. Journal of Immunology. 2004; 173(9): 5801-5809.

11. Cutchins A, Harmon DB, Kirby JL, Doran AC, Oldham SN, Skaflen M, Klibanov AL, Meller N, Keller SR, Garmey J, McNamara CA. Inhibitor of differentiation-3 mediates high fat diet-induced visceral fat expansion. Arteriosclerosis, Thrombosis, and Vascular Biology. 2012; 32(2): 317-24.

12. Eelen G, de Zeeuw $P$, Simons M, Carmeliet P. Endothelial Cell Metabolism in Normal and Diseased Vasculature. Circulation Research. 2015; 116:1231-1244.

13. Taylor AM, Hanchett R, Natarajan R, Hedrick CC, Forrest S, Nadler JL, McNamara CA. The effects of leukocyte-type 12/15-lipoxgenase on Id3-mediated vascular smooth muscle cell growth. Arteriosclerosis, Thrombosis, and Vascular Biology. 2005; 25 (10): 2069-74.

14. Silander T, Myllymaki P. A simple approach for finding the globally optimal Bayesian network structure. arXiv:1206.6875 [cs.Al].

15. Heckerman D. A Tutorial on Learning with Bayesian Networks. 1999; Spring Netherlands. pp. 301-354.

16. Friedman N, Koller D. Being Bayesian about Network Structure. A Bayesian Approach to Structure Discovery in Bayesian Networks. Machine Learning. 2003; 50, 95-125.

17. Yurchenco PD. Basement membranes: cell scaffoldings and signaling platforms. Cold Spring Harbor Perspectives in Biology. 2011; 3:a004911.

18. Zelko IN, Zhu J, Ritzenthaler JD, Roman J. Pulmonary hypertension and vascular remodeling in mice exposed to crystalline Silica. Respiratory Research. 2016. 17:160.

19. Li T., Xu X., Li J., Xing S., Zhang L., Li W., Ma J. and Fu X. Association of ACP1 gene polymorphisms and coronary artery disease in northeast Chinese population. Journal of Genetics. 2015. 94, 125-128.

20. Coxam B, Neyt C, Grassini DR, Le Guen L, Smith KA, Schulte-Merker S, Hogan BM. Carbamoyl-phosphate synthetase 2, aspartate transcarbamylase, and dihydroorotase (cad) Regulates Notch Signaling and Vascular Development in Zebrafish. Developmental Dynamics, 2015. 244:1-9.

21. Chen ST, Huang CH, Kok VC, Huang CF, Ciou JS, Tsai JJ, Kurubanjerdjit N, $\mathrm{Ng} \mathrm{KL}$. Drug repurposing and therapeutic anti-microRNA predictions for inhibition 
of oxidized low-density lipoprotein-induced vascular smooth muscle cellassociated diseases. Journal of Bioinformatics and Computational Biology, Vol. 15, No. 1 (2017) 1650043.

22. Tanasescua C, Jurcutb C, Jurcutc R, Ginghinac C. Vascular disease in rheumatoid arthritis: From subclinical lesions to cardiovascular risk. European Journal of Internal Medicine. 2009; 20; 348-354.

23. Sadeghi MM, Esmailzadeh L, Zhang J, Guo X, Asadi A, Krassilnikova S, Fassaeia HR, Luo G, Al-Lamkie RS, Takahashif T, Tellides G, Bender JR, Rodriguez ER. ESDN Is a Marker of Vascular Remodeling and Regulator of Cell Proliferation in Graft Arteriosclerosis. American Journal of Transplantation. 2007. 7: 2098-2105.

24. Mathews S, Bhonde R, Gupta PK, Totey S. Extracellular matrix protein mediated regulation of the osteoblast differentiation of bone marrow derived human mesenchymal stem cells. Differentiation. 2012. 84; 185-192.

25. Lapel M, Weston P, Strassheim D, Karoor V, Burns N, Lyubchenko T, Paucek $P$, Stenmark KR, Gerasimovskaya EV. Glycolysis and oxidative phosphorylation are essential for purinergic receptor-mediated angiogenic responses in vasa vasorum endothelial cells. American Journal of Physiology - Cell Physiology. 2017; 312: C56-C70.

26. Ulrich Förstermann, Ning Xia, Huige Li. Roles of Vascular Oxidative Stress and Nitric Oxide in the Pathogenesis of Atherosclerosis. Circulation Research. 2017; 120:713-735.

27. Guo Y, Fan Y, Zhang J, Chang L, Lin JD, Chen YE. Peroxisome proliferatoractivated receptor $y$ coactivator $1 \beta$ (PGC-1 $\beta$ ) protein attenuates vascular lesion formation by inhibition of chromatin loading of minichromosome maintenance complex in smooth muscle cells. Journal of Biological Chemistry. 2013; 288(7):4625-36.

28. Mitsunaga S, Hosomichi K, Okudaira Y, Nakaoka H, Suzuki Y, Kuwana M, Sato S, Kaneko Y, Homma Y, Oka A, Shiina T, Inoko H, Inoue I. Aggregation of rare/low-frequency variants of the mitochondria respiratory chain-related proteins in rheumatoid arthritis patients. Journal of Human Genetics. 2015; 60, 449-454.

29. Das JK, Felty Q. PCB153-Induced Overexpression of ID3 Contributes to the Development of Microvascular Lesions. PloS ONE 9 (8):e10159.

30. Fishman AP , Fishman MC, Freeman BA, Gimbrone MA, Rabinovitch M , Robinson D, Gail DB. Mechanisms of Proliferative and Obliterative Vascular Diseases Insights from the Pulmonary and Systemic Circulations. American 
Journal of Respiratory and Critical Care Medicine. 1998. https://doi.org/10.1164/ajrccm.158.2.9803084.

31. Davis AP, Grondin CJ, Johnson RJ, Sciaky D, King BL, McMorran R, Wiegers J, Wiegers TC, Mattingly CJ. The Comparative Toxicogenomics Database: update 2017. Nucleic Acids Research. 2016 Sep 19.

32. Raines EW. The extracellular matrix can regulated vascular cell migration, proliferation, and survival: relationships to vascular disease. International Journal of Experimental Pathology. 2000; 81 (3): 173 - 182.

33. Eleniste PP, Bruzzaniti A. Focal Adhesion Kinases in Adhesion Structures and Disease. Journal of Signal Transduction. 2012; Volume 2012, Article ID 296450, 12 pages.

34. Ponticos M, Smith BD. Extracellular matrix synthesis in vascular disease: hypertension and atherosclerosis. Journal of Biomedical Research. 2014; 28 (1): 25-29.

35. Madamanchi NR, Vendrov A, Runge MS. Oxidative Stress and Vascular Disease. Arteriosclerosis, Thrombosis, and Vascular Biology. 2005; 25: 29-38.

36. Gao L, Laude K, Cai H. Mitochondrial Pathophysiology, Reactive Oxygen Species, and Cardiovascular Diseases. The Veterinary Clinics of North America. Small Animal Practice. 2008; 38 (1): 137 - vi.

37. Charron T. Nili N. Strauss BH. The Cell Cycle: A Critical Therapeutic Target to Prevent Vascular Proliferative Disease. The Canadian Journal of Cardiology. 2006; 22: 41B-55B

38. Braun-Dullaeus RC, Mann MJ, Dzau VJ. Cell Cycle Progression: New Therapeutic Target for Vascular Proliferative Disease. Circulation. 1998; 98: 8289.

39. Yoo C, Cooper GF, Schmidt M. A control study to evaluate a computer-based microarray experiment design recommendation system for gene-regulation pathways discovery. Journal of Biomedical Informatics. 2006; 39, 126-146. 


\section{CHAPTER VI}

\section{OVERALL CONCLUSIONS}

The main objective of the findings in this dissertation was to assess the role of Inhibitor of DNA-binding/differentiaon-3 (ID3) in vascular diseases with respect to its regulation of vascular-intimal lesion formation and explanation of how ID3 predisposes the vessel to vascular dysfunction \& endocrine disrupting pollutants. Our approach to bridging gaps between ID3, endocrine disrupting chemicals \& vascular disease warrants unique work.

The initial goal addressed in manuscript 1 was utilized as a literature review to highlight the current understanding of how ID3 may contribute to multifaceted chronic diseases via metabolic perturbations such as cancer, neurological disorders, vascular, autoimmune, and bone diseases. Furthermore the existing literature suggests chronic exposure to endocrine disrupting chemicals (EDCs) within the human body are connected with metabolic disorders, and how the influence of these chemicals affect ID3. Also ID3 has the ability to inhibit or stimulate gene expression resultant in cellular hyper-proliferation or stemness markers. Additionally ID3 has been shown to be in involved in metabolic syndrome (MetS) and EDCs mainly focusing on the three conceivable etiological factors such as insulin resistance, obesity and adipose tissue disruption, and a group of independent factors. We also address ID3 and its involvement in molecular mechanisms \& signaling pathways that lead to these various disease outcomes. 
The second aim addressed in manuscript 2 explored the association of exposure to an endocrine disrupting chemical (PCBs) and participants diagnosed with peripheral arterial disease as well as participants defined with atherosclerosis. We analyzed a population 40 years and older with available PCB data from 1999 - 2004. Exposure assessment was based on lipid adjusted concentrations of 6 individual PCB congeners $(074,099,118,138,153$, and 180), the sum of dioxinlike PCBs $(074+118)$, and the sum of non-dioxin-like PCBs $(099+138+153+180)$ in conjunction with examination data obtained from NHANES. We calculated GMs (geometric means) to compare concentrations of PCBs in participants with PAD definition, atherosclerosis, and normal participants. GMs of the 6 individual PCB congeners were established to be higher among participants with PAD diagnosis as well as atherosclerosis when compared to the rest of the study population. The overall GM levels of PCBs increased significantly in PAD participants as age group progressed except PCB099, which demonstrated a non-consistent trend (10.04 $\mathrm{ng} / \mathrm{g}$ vs. $8.82 \mathrm{ng} / \mathrm{g}$ vs. $18.99 \mathrm{ng} / \mathrm{g})$. Furthermore consistent trends were shown in the first and second age group ( $\geq 40-59) \&(60-74)$ years old respectively, however in the final age group $\geq 75$ only 2 PCB congeners showed higher concentration levels in the diseased status compared to the normal and 4 congeners $(099,138,153$, and 180) shown to have higher PCB GMs in normal participants. We also demonstrated adjusted models for PAD confounders; gender and PAD confounders; age, race, BMI, and PAD confounders; and gender, age, race, $\mathrm{BMI}$, and PAD confounders. All models showed significant association with individual PCB congeners and increased risk of PAD when LOD $\geq 50$. 
Furthermore, adjusted models for both dioxin-like and non-dioxin-like PCBs also demonstrated significant association with higher exposure and increased risk of PAD.

We further extended the second aim in manuscript 3 by exploring the association between additional types of endocrine disrupting chemicals (phthalates, BPA) with PAD. GM levels demonstrated higher levels of phthalate metabolites: MnBP and MBzP in participants diagnosed with PAD and AS when compared to the rest of the population. Furthermore GM levels of BPA was shown to be higher in participants diagnosed with $P A D$ and $A S$ when compared to normal participants. Adjusted models for PAD confounders; gender and PAD confounders; age, race, BMI and PAD confounders; and gender, age, race, BMI, and PAD confounders demonstrated significant association with PAD and higher exposure of phthalate metabolites ( $\geq$ LOD) as well as BPA ( $\geq$ LOD). PAD confounder adjusted models showed significant association with phthalate metabolites: MnBP (OR: 1.33; 95\% Cl: 1.00 - 2.34) and MBzP (OR: 1.16; 95\% Cl: 1.08 - 5.07). Additionally PAD confounder adjusted model also demonstrated significant association with BPA (OR: $1.22 ; 95 \% \mathrm{Cl}: 1.02-5.07)$. Adjusted model for gender and PAD confounders showed significant association with phthalate metabolites: MnBP (OR: 1.83; 95\% Cl: $1.00-2.34$ ), MCHP (OR: 1.54 95\% Cl: $1.00-2.10$ ), MEP (OR: $1.01 ; 95 \% \mathrm{Cl}: 0.44-1.09$ ), and MBzP (OR: $1.76 ; 95 \% \mathrm{Cl}$ : $1.58-2.91$ ) as well as BPA (OR: 2.89; $1.50-10.19)$. Age, race, BMl, and PAD confounders adjusted model demonstrated significant association with phthalate metabolites: MnBP (OR: 1.33; 95\% Cl: 0.89 - 2.95), MCHP (OR: 1.39; 95\% Cl: 
1.00 -1.65), MiBP (OR: 1.48; 95\% Cl: $1.12-1.87$ ) alongside BPA (OR: $2.17 ; 95 \%$ $\mathrm{Cl}: 1.65$ - 7.15). The final model with gender, age, race, BMI, and the PAD confounders demonstrate MCHP (OR: 1.34; 95\% Cl: 1.22 - 1.59), MiBP (OR: 1.41; 95\% Cl: 0.99 - 1.83), MBzP (OR: 1.73; 95\% Cl: 0.92 - 3.18) alongside BPA (OR: 3.02; $95 \% \mathrm{Cl}: 0.14-12.15)$ showed significant association with higher exposure.

The aim addressed in manuscript 4 investigated the role of ID3 and ID3 candidate target genes in vascular diseases in respect to elucidating the specific focus of how ID3 plays a role in vascular-intimal lesion formation. ID3 has been previously shown to be important to the embryonic vasculogenesis and endothelial cell activation. Additionally it has been shown in various vascular disease mechanisms such as neo-intimal formation, VSMC growth, visceral adipose VEGFA expression, \& increased endothelial cell neovascularization. We compiled microarray expression data using NCBI GEO on vascular diseases. Using computational analysis such as pearson correlation \& independent t-test we identified ID3 candidate targets in blood and tissue respectively. We identified 217candidate target genes in blood and 134-candidate target genes in tissue. Gene ontology methodology further supported us to explore the role of the identified ID3 candidate target genes in blood and tissue samples (217 and 134 respectively). Overlapping genes in both blood and tissue were furthermore identified and include: ABCB6, ACP1, BYSL, CAD, CDH15, DCBLD2, DHRS3, DNMT1, ID3, MCM4, and NDUFA7. Utilizing Bayesian network structure without any structural limitations provided us with a fully connected structure validating an interactive model. Furthermore we implemented those same genes using Genie to allow us 
to determine probability distribution of gene expression within the network. Our initial model predicted ID3 to be predominately expressed high (79\%) with the vascular state of the disease being in close proximity of one another (disease state: $56 \%$, control state: $44 \%)$. Interestingly these mutually represented genes in both blood and tissue have been demonstrated in various vascular diseases throughout the literature such as atherosclerosis and vascular pathology of rheumatoid arthritis.

In conclusion, the major findings from the research conducted in this dissertation indicate a number of results. We investigated the role of endocrine disrupting chemicals (PCBs, phthalates, and BPA) and their association with vascular disease (PAD). Our findings show higher PCB, specific phthalate metabolites, and BPA concentrations in participants diagnosed with PAD as well as those with atherosclerosis when compared to the normal population. Furthermore, adjusted models demonstrated significant association with higher exposure to these endocrine disrupting chemicals and increased risk of PAD. ID3 may play a role in regulating certain genes in vascular diseases that take part in different biological processes that are significant drivers in the growth of vascularintimal lesions such as cell adhesion, extracellular matrix, \& cell growth. These genes include: ABCB6, ACP1, BYSL, CAD, CDH15, DCBLD2, DHRS3, DNMT1, ID3, MCM4, and NDUFA7. Overall, the exposure to EDCs particularly to vascular disease may contribute to the underlying understanding of how the mechanism of ID3 regulates certain genes that are essential components of the growth of vascular-intimal lesions. 


\section{Limitations}

There were a number of limitations to our study. For our NHANES study since it was a cross sectional design it does not allow for casual interpretations due to self-reported data. Self - reported data increases the likelihood of misclassification bias of cases and controls contributing to the risk of incorrectly or undiagnosed reported PAD and/or AS cases. Furthermore, missing data also limits the overall finding of our study. Additionally, observed associations could be potentially confounded due to lack of information. For our GEO study not all dataset characteristics were represented which could lead to bias with various variables.

\section{Future Studies}

Although our findings should be viewed upon with thoughtfulness, they indicate that research involving the complex combination of environmental \& molecular determinants should warrant further consideration. Additional research needs to be completed in order to account for the vast intricacy of how these types of determinants can change the development of not only vascular diseases but chronic diseases such as cancer and neurological disorders. The combined effects of EDCs and their influence on the molecular mechanisms that affect disease outcomes should be evaluated at a more complete perspective. Widespread exposure to EDCs and overall concern for growth in vascular disease risk, especially with sensitive molecular \& genetic mechanisms permits a strong need for further research. 
VITA

VINCENT E. AVECILLA

Date of Birth: December 5, 1987

Hometown: Tappan, New York

2015 - Present Doctor of Philosophy (PhD) Candidate

Dept. of Environmental Health Sciences

Robert Stempel College of Public Health \& Social Work

Florida International University

Miami, Florida

2016 - Present

Medical Science Liaison

Banco De Éxito Ventures

Miami, Florida

2016

Assistant Office Manger

Tutor Doctor

Miami, Florida

$2014-2017$

Academic Tutor (Science, Math, Reading Comprehension)

Club-Z In - Home Tutoring Services of Doral

Miami, Florida

$2013-2016$

Academic Tutor (Science \& Math)

Tutor Doctor

Miami, Florida

2014

Graduate Research Assistant

Chaplin School of Hospitality \& Tourism Management

Florida International University

Miami, Florida

2012 - $2013 \quad$ Academic Tutor (Science \& Math)

Homework Done Right -Tutoring Services, LLC 
Miami, Florida

2011 - 2012 Graduate Research Assistant

Dept. of Environmental \& Occupational Health

Robert Stempel College of Public Health \& Social Work

Florida International University

Miami, Florida

2011 - 2012 Master of Public Health (MPH)

Dept. of Environmental \& Occupational Health

Robert Stempel College of Public Health \& Social Work

Florida International University

Miami, Florida

$2006-2010 \quad$ Bachelor of Arts (BA): Psychology

College of Arts \& Sciences

University of Rhode Island

Kingston, RI

Publications \& Presentations:

Avecilla V, Doke M, Felty Q. Contribution of Inhibitor of DNA Binding/Differentiation-3 and Endocrine Disrupting Chemicals to Pathophysiological Aspects of Chronic Disease. BioMed Research International. 2017; vol. 2017, Article ID 6307109, 22 pages (Published; Subject Area: Toxicology).

Doke M, Avecilla V, Felty Q. Inhibitor of differentiation-3 (ID3) and estrogenic endocrine disruptors: Implications for Susceptibility to obesity and metabolic disorders. BioMed Research International. (Accepted \& In Press; Subject Area: Endocrinology)

Avecilla A, Avecilla V. Developmental Effects of Endocrine Disrupting Chemicals (EDCs) and Onset of Neuropsychiatric Disorders: Translation from Environmental Health Sciences to Clinical Psychology Practice. Frontiers in Psychology: Clinical Health \& Psychology Practice. (In-Preparation)

Doke M, Assaggaf $H$, Avecilla V, Das J, Felty Q. Vascular cell dysfunction from exposure to polychlorinated biphenyls contributes to lung toxicity. Society of Toxicology (SOT), San Antonio, 2018. (Accepted - Abstract/Poster Presentation) 